\title{
ACCELERATED LEACH TEST(S) PROGRAM ANNUAL REPORT
}

Contributors

R. Doty and J. Heiser, III

September 1986

NUCLEAR WASTE RESEARCH GROUP DEPARTMENT OF NUCLEAR ENERGY BROOKHAVEN NATIOHAL LABORATORY ASSOCIATED UNIVERSITIES, INC. UPTON, LONG ISLAND, NEW YORK 11973

Prepared for the

NATIONAL LOW-LEVEL WASTE MANAGEMENT PROGRAM UNDER CONTRACT NO. DE-ACO2-76CHO0016 WITH THE UNITED STATES DEPARTMENT OF ENERGY

$$
\text { 空. }
$$

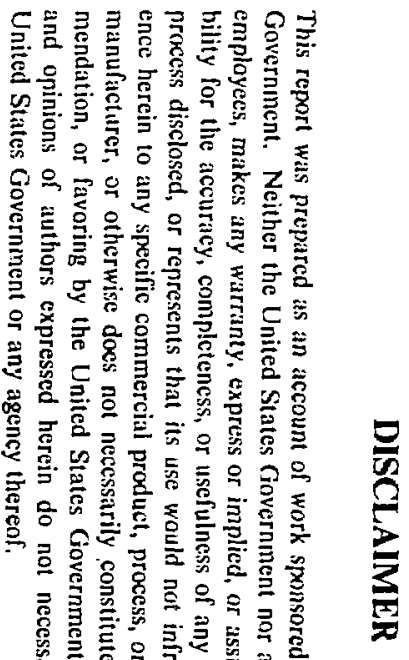




\section{DISCLAIMER}

This report was prepared as an account of work sponsored by an agency of the United States Government. Neither the United States Government nor any agency thereof, nor any of their employees, nor any of their contractors, subcontractors, or their employees. makes any warranty, express or implied, or assumes an y legal liability or responsibility for the accuracy, completeness, or usefulness of any information, apparatus. product, or process disclosed, or represents that its use would not infringe privately owned rights. Reference herein to any specific commercial product, process. or service by trade name, trademark, manufacturer, or otherwise, does not necessarily constitute or imply its endorsement, recommendation, or favoring by the United States Government or any agency, contractor or subcontractor thereof. The views and opinions of authors expressed herein do not necessarily state or reflect those of the United States Government or any agency, contractor or subcontractor thereof.

Printed in the United States of America Available from

National Technical Information Service

U.S. Department of Commerce

5285 Port Royal Road

Springfield, VA 22161

NTIS price codes

Prialed Copy: A09: Microfiche Copy: A01 
1. INTRODUCTION..................................... 1

2. SUMMARY OF THE DEVELOPMENT OF A COMPUTERIZED DATA BASE FOR LOW-LEVEL WASTE LEACHING DATA..........................

3. SAMPLE FABRICATION AND EXPERIMENTAL METHODOLOGY............... 6

3.1 Fabrication of Test Specimens....................... 6

3.1 .1 Matrix Materials.............................. 6

3.1.1.1 Hydraulic Cement.......................... 6

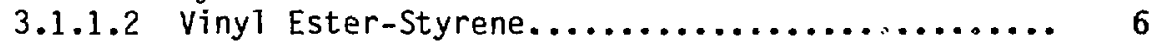

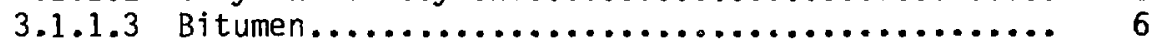

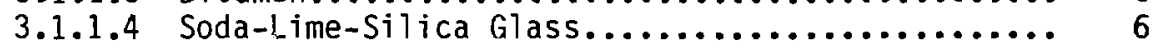

3.1 .2 Waste Materials............................. 6

3.1 .2 .1 Sodium Sulfate........................... 6

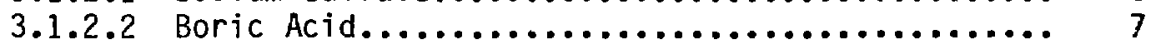

3.1.2.3 Incinerator Ash......................... 7

3.1.3 Selection of Matrix and Waste Material Combinations...... 7

3.1.3.1 Portland I Cement and Sodium Sulfate............ 7

3.1.3.2 Portland I Cement and Incinerator Ash........... 7

3.1.3.3 Vinyl Ester-Styrene, Sodium Sulfate and

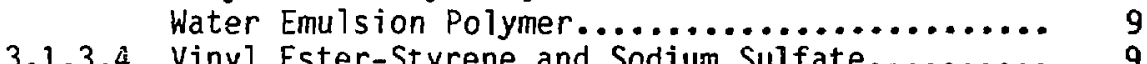

3.1.3.5 Bitumen and Sodium Tetraborate................ 9

3.1.3.6 Soda-Lime Glass and Incinerator Ash............ 9

3.1 .4 Sample Prepàration........................... 15

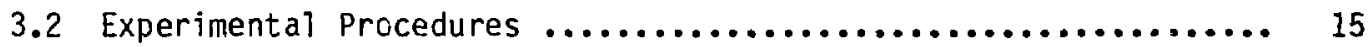

3.2 .1 Leaching Tests.................................. 15

3.2.1.1 ANS 16.1 Modified Leach Test............... 15

3.2.1.2 MCC3 Agit ated Powder Leach Test................ 15

3.2.1.3 MCC4S Flow Test.......................... 16

3.3 Analytical Methods................................. 16

3.3.1 Radiochemical Analysis............................... 16

3.3 .2 Elemental Leachate Analysis........................ 16

3.3 .3 Alkalinity.................................... 16

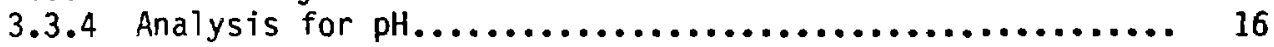

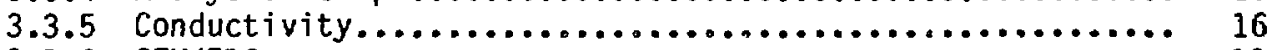

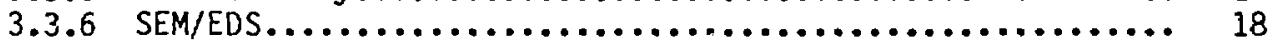


4. LEACHING BEHAVIOR OF SOLIDIFICATION AGENTS .................. 19

4.1 Sample Description............................... 19

4.2 Results of the Baseline Experiments..................... 19

4.2 .1 Portland Cement............................... 19

4.2 .2 Vinyl Ester-Styrene/Water Emulsion.................. 22

4.2 .3 Bitumen...................................... 22

4.2 .4 Vinyl Ester-Styrene/Dry Waste..................... 30

4.3 Leaching of Solidification Agent Components................ 30

4.3 .1 ANS 16.1 Leachate Anaiysis...................... 30

4.3 .2 Solubility Considerations....................... 30

4.3 .3 Statistical Correlations........................ 37

4.4 Solid Phase Analysis of Solidification Agent Matrices......... 40

4.4 .1 Portland Cement............................... 50

4.4.2 Vinyl Ester-Styrene/Water Emulsion.................. 50

4.4.3 Bitumen and Vinyl Ester-Styrene/Dry Wastes............. 40

5. LEACHING BEHAVIOR OF WASTE FORMS INCORPORATING SIMULATED WASTE...... 56

5.1 Portland Cement $+\mathrm{Na}_{2} \mathrm{SO}_{4}$ Salt....................... 56

5.1 .1 Leaching Results, Cemerit $+\mathrm{Na}_{2} \mathrm{SO}_{4} \mathrm{Sa} 1 \mathrm{~S} \ldots \ldots \ldots \ldots \ldots \ldots \ldots \ldots 57$

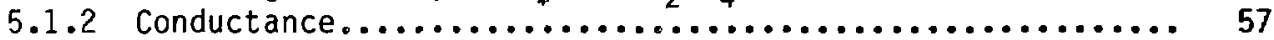

5.1 .3 Solid Phase Analysis............................ 57

5.1 .4 Conclusions.................................... 64

5.2 Portland Cement $+15 \%$ Incinerator Ash.................. 72

5.2 .1 Leaching Results.............................. 72

5.2 .2 Conductance................................ 72

5.2 .3 Conclusions................................ 72

5.3 Bitumen + Borate Salt............................ 76

5.3 .1 Leaching Results............................. 76

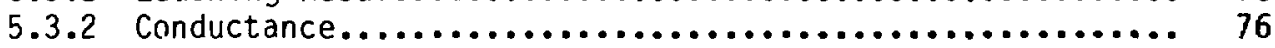

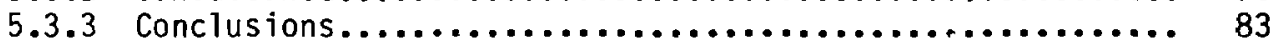

5.4 Vinyl Ester-Styrene/Emu?sion With Sulfate Salt Solution........ 83

5.4 .1 Leaching Results............................. 83

5.4 .2 Conductance.................................... 83

5.4 .3 Conclusions...................................... 83

5.5 Viny1 Ester-Styrene + Dry Sulfate Salts.................. 88

5.5 .1 Leaching Results.............................. 88

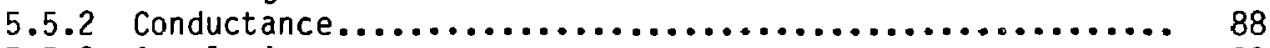

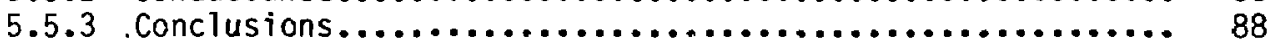


TABLE OF CONTENTS (cont.)

Page

5.6 Soda-Lime Glass + Incinerator Ash..................... 91

5.6 .1 Leaching Results............................. 91

5.6 .2 Conclusions................................ 91

6. GROUND WATER EFFECTS ON LEACHING (THE EFFECT OF DISPOSAL 92

ENVIRONMENT ON THE LEACHING BEHAVIOR OF WASTE FORMS) ............. 92

6.1 Simulated Groundwater Leaching of Radionuclides ............. 92

6.1 .1 Selection of Representative Groundwater.............. 92

6.1 .2 Major Ion Constituents of Groundwater............... 92

6.1 .3 Degradation Processes at a Waste Landfi11............. 94

6.1 .4 pH-Eh Characteristics of Fresh Waters................ 95

6.1 .5 Organic Matter: Occurrence and Identity.............. 96

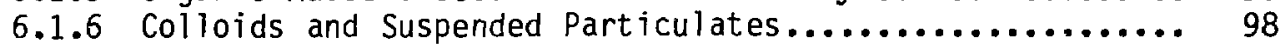

6.1.7 Comparative Summary of Oxic Aroundwater Versus Anoxic

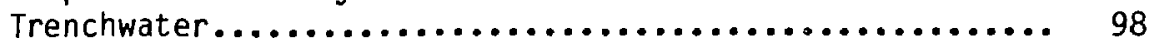

6.2 Experimental Description............................. 99

6.2 .1 Leach Test Procedure........................... 99

6.2.2 Preparation of a Simulated Groundwater................ 99

6.3 Simulated Groundwater Leaching - Radionuclide Results......... 99

6.3 .1 Portland I Cement $/ 5 \% \mathrm{Na}_{2} \mathrm{SO}_{4} \ldots \ldots \ldots \ldots \ldots \ldots \ldots \ldots \ldots \ldots \ldots \ldots \ldots \ldots$

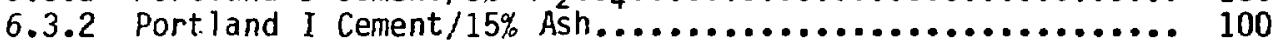

6.3 .3 Vinyl Ester-Styrene/15\% $\mathrm{Na}_{2} \mathrm{SO}_{4} /$ Water Emulsion........... 100

6.3 .4 Vinyl Ester-Styrene/40\% $\mathrm{Na}_{2} \mathrm{SO}_{4} \ldots \ldots \ldots \ldots \ldots \ldots \ldots \ldots \ldots \ldots \ldots \ldots$

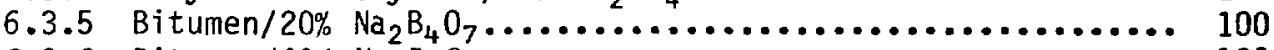

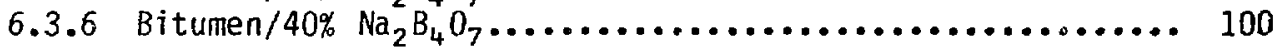

7. EVALUATION OF LEACH RATE CONTROLLING FACTORS................... 104

7.1 Temperature Effects on Leaching........................ 104

7.1.1 Experiment Description........................... 104

7.1.2 Temperature Effects - Radionuclide Leaching Resuits...... 104

7.1 .2 .1 Portland I Cement $/ 5 \% \mathrm{Na}_{2} \mathrm{SO}_{4} \ldots \ldots \ldots \ldots \ldots \ldots \ldots \ldots . . \ldots 104$

7.1.2.2 Portland I Cement/15\% Incinerator Ash........... 105

7.1.2.3 Vinyl Ester-Styrene/15\% $\mathrm{Na}_{2} \mathrm{SO}_{4} /$ Water Emulsion... 105

7.1.2.4 Vinyl Ester-Styrene/40\% $\mathrm{Na}_{2} \mathrm{SO}_{4} \ldots \ldots \ldots \ldots \ldots \ldots \ldots . . \ldots 105$

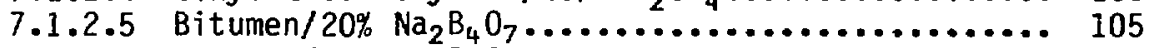

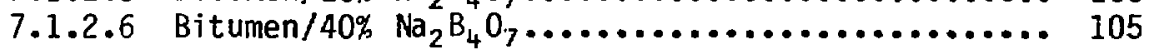

7.2 Scoping Study of the Effect of the Ratio of Waste Form

Surface Area to Leachant yolume............................. 109

7.2.1 Experiment Description............................. 109

7.2.2 Leachant Volume Effects - Radionuclide Leaching

Scoping Test Results.............................. 109 
7.2.2.1 Portland I Cement $/ 5 \% \mathrm{Na}_{2} \mathrm{SO}_{4} \ldots \ldots \ldots \ldots . \ldots . \ldots 109$

7.2.2.2 Vinyl Ester-Styrene/40\% $\mathrm{Na}_{2} \mathrm{SO}_{4} \ldots \ldots \ldots \ldots \ldots . \ldots 109$

7.3 Scoping Study of the Effects of pH on Radionuclide Leaching..... 109

7.3.1 Experiment Description........................... 112

7.3.1.1 Leach Test Procedure...................... 112

7.3 .1 .2 Leachants............................. 112

7.3.2 pH Effects - Scoping Study of Radionuclide Leaching...... 112

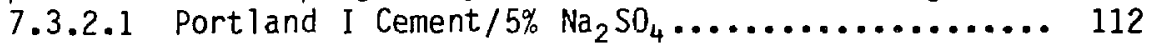

7.3.2.2 Portland I Cement/15\% Incinerator Ash........... 114

7.3.2.3 Vinyl Ester-Styrene/15\% $\mathrm{Na}_{2} \mathrm{SO}_{4} /$ Water Emulsion... 114

7.3.2.4 Vinyl Ester-Styrene/40\% $\mathrm{Na}_{2} \mathrm{SO}_{4} \ldots \ldots \ldots \ldots \ldots \ldots . . \ldots 114$

7.3.2.5 Bitumen $/ 20 \% \quad \mathrm{Na}_{2} \mathrm{~B}_{4} \mathrm{O}_{7} \ldots \ldots \ldots \ldots \ldots \ldots \ldots \ldots \ldots \ldots \ldots \ldots \ldots \ldots$

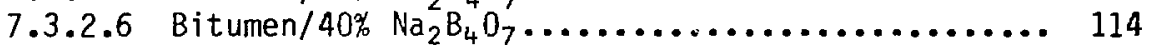

7.4 Leachant Flow Effects............................... 114

7.4.1 Experiment Description............................ 118

7.4.2 Flow Effects - Radionuclide Leaching Results............ 119

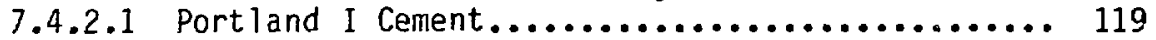

7.4.2.2 Vinyl Ester-Styrene Water Emulsion............ 119

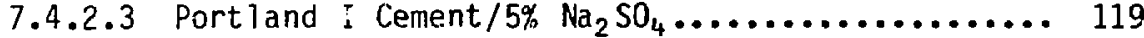

7.4.2.4 Portland I Cement/15\% Incinerator Ash.......... 119

7.4.2.5 Vinyl Ester-Styrene/15\% $\mathrm{Na}_{2} \mathrm{SO}_{4} /$ Water Emulsion... 119

7.4.2.6 Vinyl Ester-Styrene/40\% $\mathrm{Na}_{2} \mathrm{SO}_{4} \ldots \ldots \ldots \ldots \ldots \ldots . \ldots 124$

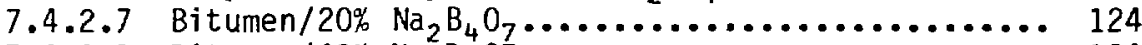

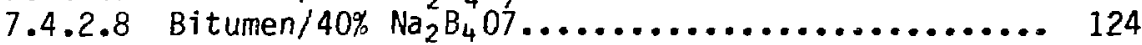

7.5 Sample Configuration Effects.......................... 124

7.5 .1 Experiment Description............................ 124

7.5.2 Waste Form Volume-to-Surface Area - Effects on

Radionuclide Leaching.............................. 124

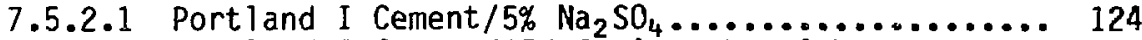

7.5.2.2 Portland 1 Cement/15\% Incinerator Ash.......... 127

7.5.2.3 Vinyl Ester-Styrene/15\% $\mathrm{Na}_{2} \mathrm{SO}_{4} /$ Water Emulsion... 127

7.5.2.4 Vinyl Ester-Styrene/40\% $\mathrm{Na}_{2} \mathrm{SO}_{4} \ldots \ldots \ldots \ldots \ldots \ldots . \ldots 127$

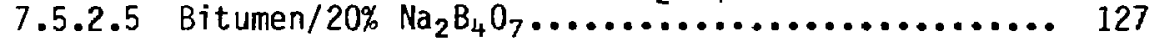

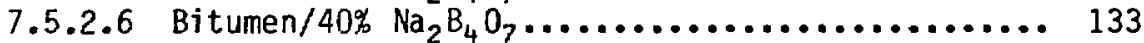

8. MODEL VALIDATION..................................... 135

8.1 Physicochemical Models of Leaching Behavior of Low-Level

Waste Forms ........................................ 136

8.1.1 Cement Waste Forms ............................ 136

8.1.1.1 Changes in Cemented Waste Forms Upon Leaching.... 138

8.1.2 Bitumen Waste Forms................................ 139

8.1.3 Vinyl Ester-Styrene (VES) Waste Forms................ 140 
TABLE OF CONTENTS (cont.)

Page

8.1.3.1 VES Emulsion with Aqueous Wastes............. 140

8.1.3.2 VES Incorporating Dry Wastes............... 140

8.2 Factors that Affect Model Validation................... 142

8.2.1 Initial Surface Wash in Leach Testing................ 143

8.2.2 Solid Phase Analysis............................. 144

8.2.3 Waste Loading Effects on Leaching Behavior............. 144

8.2.4 Solubility Effects on Leaching Behavior............... 150

8.2.5 Ion Exchange Effects on Leaching Behavior............. 151

8.2.6 Wet-Dry Cycling of Leaching Conditions............... 151

8.2.7 Container Effects on Waste Form Leachability........... 152

9. SUMMARY AND CONCLUSIONS............................... 153

9.1 Acceleration Factors............................... 154

REFERENCES.......................................... 157 


\section{LIST OF FIGURES}

Figure No.

Page

3.1 Compositional phase diagram for the solidification of aqueous waste containing $50 \mathrm{wt} \%$ or less $\mathrm{Na}_{2} \mathrm{SO}_{4}$ with portland type I

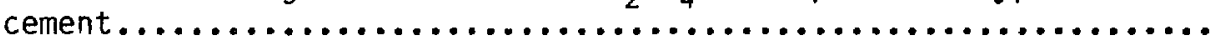

3.2 Ternary compositional phase diagram for the solidification of incinerator ash in portland type I cement.

3.3 Sodium ion concentrations released from vinyl ester-styrene/sodium sulfate waste forms after 3 day immersion in deionized water at

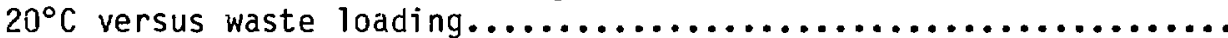

4.1 Cumulative fraction releases from portland cement for $\mathrm{Sr}-85$ and

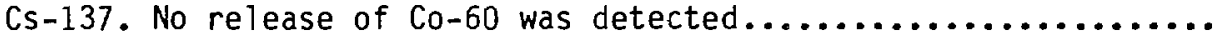

4.2 Cumulative fraction releases for Cs-137 from portland cement. Final release was 0.817 of total activity in the waste form.......

4.3 Rate of Cs -137 release from portland cement. Note the change of

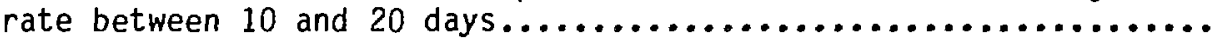

4.4 Cumulative fraction release for portland cement samples. Data only goes out to 144 days because of radioactive decay of the isot ope.

4.5 Release rates of $\mathrm{Sr}-85$ from portland cement

4.6 Cumulative fraction releases of $\mathrm{Cs}-137, \mathrm{Sr}-85$, Co-60 from a vinyl

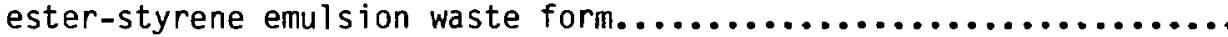

4.7 Cumulative fraction releases of Cs-137 from triplicate VES emulsion waste forms. Note the scale used on the $y$-axis makes a

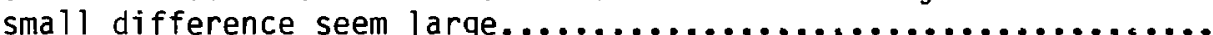

4.8 Release rates for Cs-137 from triplicate VES emulsion waste forms. The scatter at the lower right of the plot indicates larger counting errors due to low release rates.

4.9 Cumulative fraction releases for $\mathrm{Sr}-85$ from VES emulsion waste forms. These data extend only to 144 days because radioactive decay reduced the count rate to detection limit activities.........

4.10 Release rates for Sr-85 for triplicate VES emulsion samples.......

4.11 Cumulative fraction releases for Co-60 from triplicate vinyl ester-styrene emulsion samples. 


\section{LIST OF FIGURES (cont.)}

Figure No.

Page

4.12 Release rates of Co-60 from triplicate vinyl ester-styrene samples. Scatter at the bottom right is due to relatively large

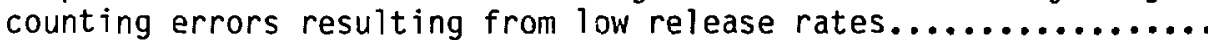

4.13 Cumulative fraction releases for $\mathrm{Cs}-137$, Co-60 and $\mathrm{Sr}-85$ from bitumen. The isotopes from this material leach at different

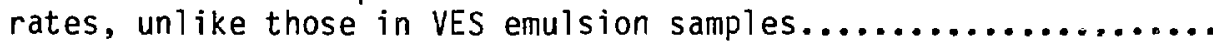

4.14 Cumulative fraction releases of $\mathrm{Cs}-137$ from triplicate bitumen waste forms. Note the scale of the $y$-axis indicating that

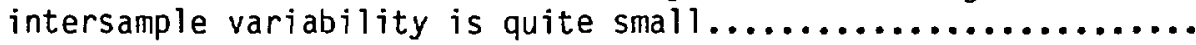

4.15 Release rates of $\mathrm{Cs}-137$ from triplicate bitumen samples......... 31

4.16 Cumulative fraction releases of $\mathrm{Sr}-85$ for triplicate bitumen

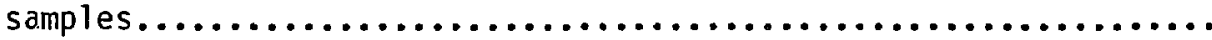

4.17 Release rates of $\mathrm{Sr}-85$ for triplicate bitumen samples.......... 32

4.18 Cumulative fraction releases of Co-60 from triplicate bitumen waste forms. Note the scale of the $y$-axis....................

4.19 Release rates of Co-60 from triplicate bitumen samples. The scatter at the bottom right is due to large counting errors

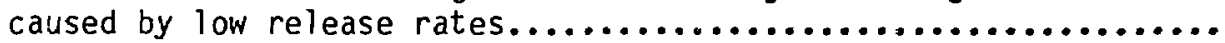

4.20 Cumulative fraction releases of $\mathrm{Cs}-137$ from cement, VES emulsion and bitumen samples. While VES and bitumen have similar low fraction releases that of cement is $82 \%$ of the total original activity...............................

4.21 Plot of conductance ( $\mathrm{mmhos} / \mathrm{cm}$ ) versus alkalinity (as $\mathrm{mgCaCO}_{3} / \mathrm{L}$ ) for portland cement leachates............................

4.22 Surface of unleached portland cement at a magnificstion of 400 times...............................................

4.23 Surface of unleached portland cement at a magnification of 1900 times. Note the great porosity and granular texture of the material.

4.24 Spectrum of unleached cement surface. Note the presence of potassium $(K)$ and the relative peak heights of calcium ( $\mathrm{Ca}$ ) and silicon (Si)...........................................

4.25 Part of a sectioned waste form after leaching for 471 days. Note the reaction rim around the top and sides which were exposed to water. 


\section{LIST OF FIGURES (cont.)}

Figure No.

Page

4.26 Outer surface of a cement sample leached for 471 days. Compare this to Figure 4.21. The texture is much smoother and grain is finer.............................................

4.27 Oblique angle of the leached surface at a magnification of 1300 times. The porosity is much lower than prior to leaching.

4.28 Spectrum of the surface of a cement sample leached for 471 days. Compare this to Figure 4.23. The potassium (K) peak is gone and the calcium (Ca) peak is reduced............................

4.29 Spectrum of the center of the leached cement sample. It more closely resembles the spectrum of the unleached cement in Figure 4.23 than it resembles the outer edge of the leached sample. Note that potassium is still present.

4.30 A cavity in the center of the leached cement sample. Crystals inside are thought to be portlandite $\left.\left(\mathrm{Ca}^{(} \mathrm{OH}_{2}\right)\right)$ a highly soluble mineral.

4.31 Spectrum of a small area on one of the crystals shown in Figure 4.29. Only calcium is present.

4.32 Surface of a vinyl ester-styrene emulsion at a magnification of 400 times. Most pores appear to be between 5 and $10 \mu \mathrm{m}$ in di ameter................................................

4.33 The surface of a vinyl ester-styrene emulsion sample at 1800 fold magnification. Much smaller pores are visible with diameters less

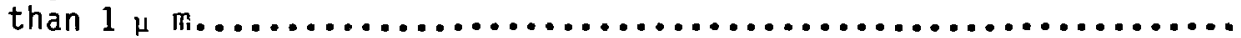

4.34 Interior of a vinyl ester-styrene emulsion. There is considerable saw debris, but the pores are in the same size range

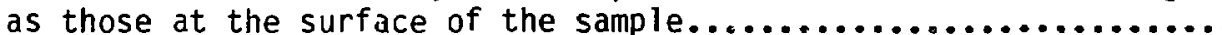

5.1 Cumulative fraction release of $\mathrm{Cs}-137$ from cement samples containing $5 \%$ sodium sulfate and from baseline sample.

5.2 Release rates of $\mathrm{Cs}-137$ from cement samples containing $5 \%$ sodium sulfate and from a baseline sample...........................

5.3 Incremental fraction releases of Cs-137 from cement samples containing $5 \%$ sodium sulfate. Note that the IFR is related to sampling interval.

5.4 Cumulative fraction release of $\mathrm{Sr}-85$ from cement samples containing $5 \%$ sodium sulfate and from baseline samples. 
Figure No.

Page

5.5 Release rates of Sr-85 from cement samples containing $5 \%$ sodium sulfate and from a single baseline sample. The rate of the last three sampling intervals appear to have increased over the baseline........................................

5.6 Outer surface of an unleached cement samp?e containing 5\% sodium sulfate at a magnification of 400 times. This surface is indistinguishable from the unleached baseline cement surface

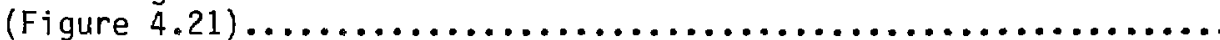

5.7 Outer surface of an unleached cement sample containing $5 \%$ sodium sulfate at a magnification of 4700 times......................

5.8 EDAX spectrum of the outer surface of an unleached cement sample containing $5 \%$ sodium sulfate. Note that a small sodium peak is present as wel! as a potassium peak. The sulfur is enriched

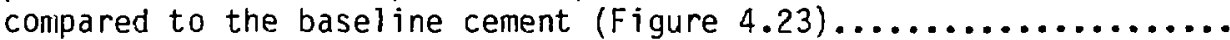

5.9 Outer surface of a cement sample containing $5 \%$ sodium sulfate after static leaching for 55 days at $50^{\circ} \mathrm{C}$. There is profuse crystal growth covering the entire outer surface of the sample. Magnification is 400 times................................

5.10 Outer surface of a cement sample containirg $5 \%$ sodium sulfate after static leaching for 55 days at $50^{\circ} \mathrm{C}$. Magnification is 1900 times.

5.11 Interior of a cement sample containing $5 \%$ sodium sulfate after static leaching for 55 days at $50^{\circ} \mathrm{C}$. This is a cut sample from $2 \mathrm{~mm}$ inside the outer edge. Note the many cracks................

5.12 A bubble that after leaching was full of crystals. This was typical of any voids in the sample.

5.13 A ciose-up view of the bladelike crystals filling a pore in the leached sample. Their morphology suggest that the mineral is

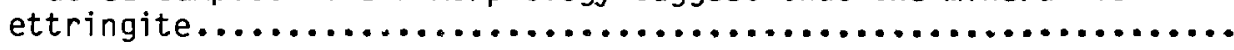

5.14 EDAX spectrum of one of the crystals from Figure 5.13. This spectrum is significantly different from that of the unleached cement containing sodium sulfate shown in Figure 5.8. Sulfur and aluminum are enriched and silicon is depleted beyond normal cement composition....................................... 


\section{LIST OF FIGURES (cont.)}

Figure No.

5.15 Cumulative fraction release of Cs-137 from triplicate cement waste forms containing 15\% incinerator ash compared to CFR of a baseline sampie.......................................

5.16 Release rates of Cs-137 from triplicate cement waste forms containing $15 \%$ incinerator ash compared to the release rate of Cs-137 from a baseline sample............................

5.17 Cumulative fraction release of $\mathrm{Sr}-85$ from triplicate cement waste forms containing 15\% incinerator ash compared to $\mathrm{Sr}-85$ CFR of a baseline sample........................................

5.18 Release rates of $\mathrm{Sr}-85$ from triplicate cement waste forms containing $15 \%$ incinerator ash compared to the $\mathrm{Sr}-85$ release rate

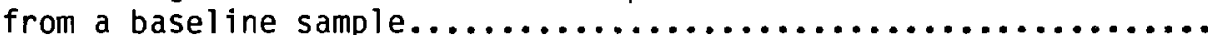

5.19 Cumulative fraction release of $\mathrm{Cs}-137, \mathrm{Co}-57$ and $\mathrm{Sr}-85$ from a single bitumen waste form containing $40 \%$ sodium tetraborate.......

5.20 Cumulative fraction release of $\mathrm{Cs}-137$ from triplicate bitumen samples containing $40 \%$ and $20 \%$ sodium tetraborate compared to CFR of Cs-137from a baseline sample.

5.21 Release rates of Cs-137 from single bitumen samples containing $20 \%$ and $40 \%$ sodium tetraborate compared to a baseline sample.......

5.22 Cumulative fraction release of Cs -137 from triplicate samples of bitumen containing $10 \%$ and $40 \%$ sodium tetraborate and for a baseline sample. The $\log / \mathrm{log}$ scales show the differences in leaching dramatically.

5.23 Cumulative fraction release of $\mathrm{Sr}-85$ from samples containing $20 \%$ and $40 \%$ sodium tetraborate and from a baseline sample........... 80

5.24 Cumulative fraction release of $\mathrm{Sr}-85$ from samples containing $20 \%$ and $40 \%$ sodium tetraborate and from a baseline sample.

5.25 Release rates of Sr-85 from bitumen samples containing $20 \%$ and $40 \%$ sodium tetraborate and from a baseline sample...............

5.26 Cumulative fraction releases of Co-57 from bitumen samples containing $20 \%$ and $40 \%$ sodium tetraborate and Co-60 from a baseline sample..........................................

5.27 Release rates of Co-57 from bitumen samples containing $20 \%$ and $40 \%$ sodium tetraborate and Co-60 from a baseline sample........... 
Figure No.

5.28 Cs $-137, \mathrm{Co}_{0}-57$ and $\mathrm{Sr}-85$ from a single VES emulsion sample containing sodium sulfate salts. Cesium releases are slightly faster than the other isotopes..............................

5.29 Cumulative fraction release of Cs-137 from triplicate VES emulsion samples containing $50 \mathrm{wt} \%$ of a $15 \%$ sodium sulfate solution compared to a VES baseline...........................

5.30 Release rates of Cs-137 from a single VES emulsion sample compared to release of VES baseline sample.................. 86

5.31 Cumulative fraction release of $\mathrm{Sr}-85$ from triplicate VES emulsion samples compared to CFR from a baseline sample...

5.32 Release rates of $\mathrm{Sr}-85$ from triplicate VES emulsion samples and from a baseline sample....................................

$5.33 \mathrm{Cs}-137, \mathrm{Co}-60$ and $\mathrm{Sr}-85$ cumulative fraction releases from a VES dry sample containing $40 \%$ sodium sulfate salt................... 90

5.34 Cumulative fraction releases of Cs-137 from triplicate VES dry sample containing $40 \%$ sodium sulfate salts compared to an estimated baseline derived from detection limits.................. 9

5.35 Releases rates of Cs-137 from triplicate VES dry sảmples compared to an estimated baseline............................ 91

6.1 Approximate position of some natural environments in terms of Eh and pH, (Garrels, 1960 and Bass Becking, et al., 1960).......... 98

6.2 Cs-137 cumulative fraction release (CFR) versus time for triplicate portland type I cement incorporating $5 \%$ by weight of $\mathrm{Na}_{2} \mathrm{SO}_{4}$ leached with a simulated groundwater compared to results for deionized water leaching............................... 102

6.3 CS-137 cumulative fraction released (CFR) versus time from triplicate portland type I cement incorporating $15 \%$ by weight incinerator ash leached with a simulated groundwater compared to results for deionized water leaching......................... 102

6.4 Cs-137 cumulative fraction released (CFR) versus time from triplicate vinyl ester-styrene waste forms incorporating $40 \%$ $\mathrm{Na}_{2} \mathrm{SO}_{4}$ leached with a simulated groundwater compared to results for deionized water leaching. 
LIST OF FIGURES (cont.)

Figure No.

Page

6.5 Cs-137 cumulative fraction released (CFR) versus time from triplicate vinyl ester-styrene waste forms incorporating $40 \%$ by weight $\mathrm{Na}_{2} \mathrm{SO}_{4}$ leached a simulated groundwater compared

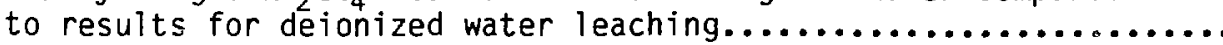

6.6 Cs-137 cumulative fraction released (FR) versus time for triplicate bitumen waste forms incorporating $20 \%$ by weight sodium tetraborate $\left(\mathrm{Na}_{2} \mathrm{~B}_{4} 0,7\right)$ leached with a simulated groundwater and compared to results for deionized water leaching..................

6.7 Cs-137 cumulative fraction released (CFR) versus time for iriplicate bit:men waste forms incorporating $40 \%$ by weight sodium tetraborate $\left(\mathrm{Na}_{2} \mathrm{~B}_{4} \mathrm{O}_{3}\right)$ leached with a simulated groundwater and

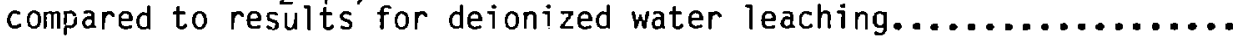

7.1 Cumulative fraction released (CFR) of Cs-137 versus time from portland type I cement waste forms, incorporating. $5 \%$ by weight

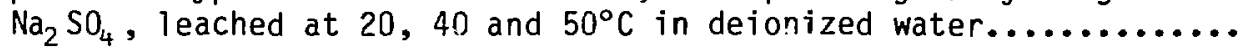

7.2 Cs-137 cumulative fraction released (CFR) yersus time from portland type I cement waste forms, incorporating $15 \%$ by weight incinerator ash, leached at 20,40 and $50^{\circ} \mathrm{C}$ in deionized water.....

7 . 3 Cs -137 cumulative fraction released (CFR) versus time from vinyl ester-styrene water emulsion waste forms, incorporating $15 \%$ py weight $\mathrm{Na}_{2} \mathrm{SO}_{4}$, leached at 20,40 and $50^{\circ} \mathrm{C}$ in deionized water......

7.4 Cs-137 cumulative fraction released (CFR) versus time from vinyl ester-styrene waste forms, incorporating $40 \%$ by weight sodium sulfate, leached at 20,40 and $50^{\circ} \mathrm{C}$ in deionized water............

7.5 Cs-137 cumulative fraction released (CFR) versus time from bitumen waste forms, incorporating $20 \%$ by weight sodium tetraborate $\left(\mathrm{Na}_{2} \mathrm{~B}_{4} \mathrm{O}_{7}\right)$, leached at 20,40 and $50^{\circ} \mathrm{C}$ in deionized water................................................

7.6 Cs-137 cumulative fraction released (CFR) versus time from bitumen waste forms, incorporating $40 \%$ by weight sodium tetraborate $\left(\mathrm{Na}_{2} \mathrm{~B}_{4} \mathrm{O}_{7}\right)$, leached at 20,40 and $50^{\circ} \mathrm{C}$ in deionized water..................................................

7.7a Cumulative fraction release (CFR) of Cs-137 versus time for portland I cement waste forms containing $5 \%$ by weight $\mathrm{Na}_{2} \mathrm{SO}_{4}$ leached with increasing leachant volumes $(1.3,2.6$ and $3.9 \mathrm{~L})$ of deionized water 
Figure No.

7.7b Cumulative fraction release (CFR) of $\mathrm{Sr}-85$ versus time for portland I cement waste forms containing $5 \%$ by weight $\mathrm{Na}_{2} \mathrm{SO}_{4}$ leached with increasing leachant volumes $(1.3,2.6$ and $3.9 \mathrm{~L})$ of

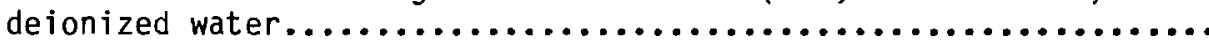

7.8a Cumulative fraction releases (CFR) versus time of Cs-137 from vinyl ester-styrene waste forms containing $40 \%$ by weight $\mathrm{Na}_{2} \mathrm{SO}_{4}$ leached with increasing leachant volumes $(1.3,2.6$ and $3.9 \mathrm{~L})$ of deionized water.

7.8b Incremental fraction releases (RATE $(f / s)$ ) versus time of Cs-137 from vinyl ester-styrene waste forms containing $40 \%$ by weight $\mathrm{Na}_{2} \mathrm{SO}_{4}$ leached with increasing leachant volumes $(1.3,2.6$

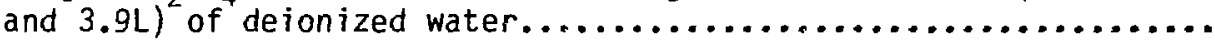

7.9 Cumulative fraction release (CFR) of $\mathrm{Cs}-137$ versus time for Portland type I cement containing $5 \%$ by weight $\mathrm{Na}_{2} \mathrm{SO}_{4}$ leached with so?utions of increasing initial pH $(3,4,5,6$ and 8$)$

7.10 Cumulative fraction release (CFR) of Cs-137 versus time for Portland type I cement cuntaining 15\% incinerator ash leached with solutions of increasing initial $\mathrm{pH}(4,6$ and 8$)$.

7.11 Cumulative fraction release (CFR) versus time from vinyl ester-styrene water emulsion waste forms containing $15 \% \mathrm{Na}_{2} \mathrm{SO}_{4}$ leached with solution of increasing $\mathrm{pH}(4,6$ and 8$) \ldots \ldots \ldots \ldots \ldots \ldots 116$

7.12 Cumulative fraction release (CFR) versus time from vinyl ester-styrene waste forms containing $40 \% \mathrm{Na}_{2} \mathrm{SO}_{4}$ leached with solutions of increasing $\mathrm{pH}(3,4,5,6$ and 8$)$.

7.13 Cumulative fraction release (CFR) of Cs-137 versus time from bitumen waste forms containing $20 \%$ by weight sodium tetraborate $\left(\mathrm{Na}_{2} \mathrm{~B}_{4} \mathrm{O}_{7}\right)$ leached with solutions of increasing initial $\mathrm{pH}(4,6$ and 8

7.14 Cumulative fraction release (CFR) of $\mathrm{Cs}-137$ versus time from bitumen waste forms containing $40 \%$ by weight sodium tetraborate $\left(\mathrm{Na}_{2} \mathrm{~B}_{4} \mathrm{O}_{7}\right)$ leached with solutions of increasing initial $\mathrm{pH}(4,6$

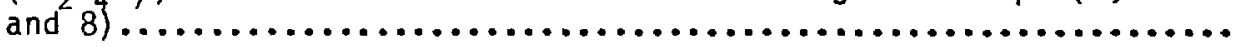

7.15a Incremental fractional release rate (Rate (f/s)) for Cs-137 from portland type I cement waste forms comparing the MCC-4S flow test, using a modified rate equation to the modified ANS 16.1 semidynamic leach test 


\section{LIST OF FIGURES (cont.)}

Figure No.

7.15b Incremental fractional release rates (Rate (f/s)) for Cs-137 versus time from portland type I cement waste forms comparing results for the MCC-4S flow test to the modified ANS 16.1

semidynamic leach test................................

7.16a Incremental fractional release rates (Rate $(f / s)$ ) for Cs-137 versus time from vinyl ester-styrene water emulsion waste forms comparing results for the MCC- $4 S$ flow test, using a modified rate equation, to the modified ANS 16.1 semidynamic leach test......... 122

7.16b Incremental fractional release rates (Rate ( $f / s)$ ) for Cs-137 versus time from vinyi ester-styrene water emulsion waste forms comparing results for the MCC-4S flow test to the modified

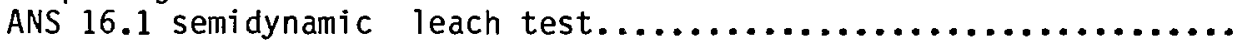

7.17 Incremental fractional release rates (Rate $(f / s)$ ) for Cs-137 versus time from portland type I cement containing $5 \%$ by weight $\mathrm{Na}_{2} \mathrm{SO}_{4}$. Results for the MCC-4S flow test, using a modified rate equation, were compared to t:e modified ANS 16.1 semidynamic

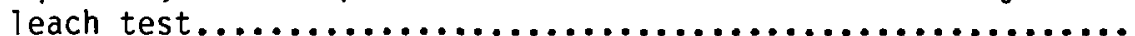

7.18 Incremental fractional release rates (Rate (f/s)) for $\mathrm{Cs}-137$ versus time from portland ivoe I cement waste forms containing $15 \%$ by weight incinerator asii. Results for the MCC-4S flow test, using a modified rate equation, were compared to the modified

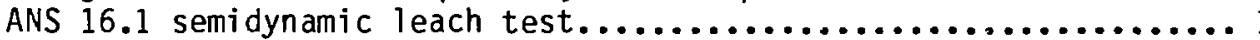

7.19 Incremental fractional release rates (Rate (f/s)) for $\mathrm{Cs}-137$ versus time from vinyl ester-styrene water emulsion waste forms containing $15 \% \mathrm{Na}_{2} \mathrm{SO}_{4}$. Results for the MCC-4S flow test, using a modified rate equation, were compared to the modified ANS 16.1

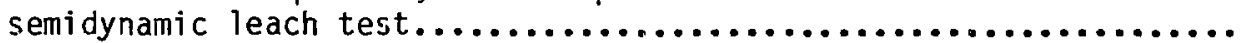

7.20 Incremental fiactional release rates (Rate $(f / s)$ ) for $\mathrm{Cs}-137$ versus time from vinyl ester-styrene waste forms containing $40 \% \mathrm{Na}_{2} \mathrm{SO}_{4}$. Results for the MCC-4S flow test, using a modified rate equation, were compared to the modified ANS 16.1 semidynamic leach test.

7.21 Incremental fractional release rates (Rate (f/s)) for Cs-137 versus time from bitumen waste forms containing $20 \%$ by weight sodium tetraborate $\left(\mathrm{Na}_{2} \mathrm{~B}_{4} \mathrm{O}_{7}\right)$. Results for the MCC-4S flow test, using a modified rate equation, were compared to the modified ANS 16.1 semidynamic leach test. 


\section{LIST OF FIGURES (cont.)}

Figure No.

Page

7.22 Incremental fractional release rates (Rate $(f / s)$ ) for $C s-137$ versus time from bitumen waste forms containing $40 \%$ by weight sodium tetraborate $\left(\mathrm{Na}_{2} \mathrm{~B}_{4} \mathrm{O}_{7}\right)$. Results for the MCC-4S flow test, using a modified rate equation, were compared to the modified ANS 16.1 semidynamic leach test.

7.23 Cumulative fraction release (CFR) of $\mathrm{Cs}-137$ versus time from triplicate small $c_{j} l$ inders $(V / S=0.42)$ compared to triplicate larger cylinders $(V / S=0.91)$ from portland type I cement waste forms containing $5 \%$ by weight $\mathrm{Na}_{2} \mathrm{SO}_{4} \ldots \ldots \ldots \ldots \ldots \ldots \ldots \ldots \ldots \ldots$

7.24 Cumulative fraction release (CFR) of CS-137 versus time from triplicate disc $(V / S=0.62)$ compared to triplicate larger cylinders $(V / S=0.91)$ from portland type I cement waste forms containing $5 \%$ by weight $\mathrm{Na}_{2} \mathrm{SO}_{4} \ldots \ldots \ldots \ldots \ldots \ldots \ldots \ldots \ldots \ldots \ldots \ldots \ldots \ldots$

7.25 Cumulative fraction release (CFR) of Cs-137 versus time from portland type I cement waste forms containing $5 \%$ by weight $\mathrm{Na}_{2} \mathrm{SO}_{4}$. Results for triplicate replicates of small cylinders $(V / S=0.42)$, a disc $(V / S=0.62)$ and a larger cylinder $(V / S=0.91)$ were compared

7.26 Cumulative fraction release (CFR) of CS-137 versus time for a triplicates of a small cylinder ( $V / S=0.42)$ compared to triplicate large cylinders $(V / S=0.91)$ from port 7 and type I cement waste forms containing $15 \%$ by weight incinerator ash....... 130

7.27 Cumulative fraction release (CFR) of Cs-137 versus time for triplicates of a disc $(\mathrm{V} / \mathrm{S}=0.62)$ compared to triplicates large cylinders $(\mathrm{V} / \mathrm{S}=0.91)$ from portland type I cement waste forms containing $15 \%$ by weight incinerator ash.

7.28 Cumulative fraction release (CFR) of CS-137 versus time from triplicate small cylinders $(V / S=0.42)$ compared to triplicate larger cylinders ( $V / S=0.91$ ) from vinyl ester-styrene water emulsion waste forms containing $15 \%$ by weight $\mathrm{Na}_{2} \mathrm{SO}_{4}$

7.29 Cumulative fraction release (CFR) of Cs-137 versus time from triplicate discs ( $V / S=0.62)$ compared to triplicate larger cylinders $(V / S=0.91)$ from vinyl ester-styrene water emulsion waste forms containing $15 \%$ by weight $\mathrm{Na}_{2} \mathrm{SO}_{4} \ldots \ldots \ldots \ldots \ldots \ldots \ldots$

7.30 Cumulative fraction release (CFR) of CS-137 from triplicate small cylinders ( $V / S=0.42)$ compared to triplicate larger cylinders ( $V / S=0.91$ ) from vinyl ester-styrene waste forms containing $40 \%$ by weight $\mathrm{Na}_{2} \mathrm{SO}_{4}$. 
Figure No.

7.31 Cumulative fraction release (CFR) of Cs-137 from triplicate $\operatorname{discs}(V / S=0.62)$ compared to triplicate larger cylinders $(V / S=0.91)$ from vinyl ester-styrene warte forms containing $40 \%$ by weight $\mathrm{Na}_{2} \mathrm{SO}_{4}$

7.32 Cumulative fraction release (CFR) of Cs-137 versus time for triplicate small cylinders $(V / S=0.42)$ compared to triplicate larger cylinders $(\mathrm{V} / \mathrm{S}=0.91)$ from bitumen waste forms containing $20 \%$ by weight sodium tetraborate $\left(\mathrm{Na}_{2} \mathrm{~B}_{4} \mathrm{O}_{7}\right)$

7.33 Cumulative fraction release (CFR) of $\mathrm{Cs}-137$ versus time from triplicate discs $(V / S=0.60)$ compared to triplicate larger cylinders ( $\mathrm{V} / \mathrm{S}=0.91$ ) from bitumen waste forms containing $20 \%$ by weight sodium tetraborate $\left(\mathrm{Na}_{2} \mathrm{~B}_{4} \mathrm{O}_{7}\right)$...

7.34 Cumulative fraction release (CFR) of Cs-137 versis time for triplicate small cylinders $(V / S=0.42)$ compared to triplicate larger cylinders ( $/ S=0.91)$ from bitumen waste forms containing $40 \%$ by weight sodium tetraborate $\left(\mathrm{Na}_{2} \mathrm{~B}_{4} \mathrm{O}_{7}\right)$.

7.35 Cumulative fraction release (CFR) of Cs-137 versus time for triplicate discs $(V / S=0.60)$ compared to triplicate larger cylinders ( $V / S=0.91$ ) from bitumen waste forms containing $40 \%$ by weight sodium tetraborate $\left(\mathrm{Na}_{2} \mathrm{~B}_{4} \mathrm{O}_{7}\right)$

8.1 Schematic model of expected leaching behavior of bitumen waste forms insorporating soluble waste and/or waste which swells upon hydration. The dashed vertical line separates Region $A$, in which no swelling has occurred, and Region $B$, in which there has been enough water uptake to cause swelling. The leach rate increases

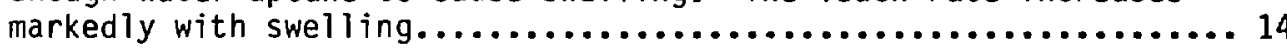

8.2 Linear plot of the data in Table 8.1. The line is the leastsquares fit to the $10 \mathrm{wt} \%$ and $30 \mathrm{wt} \%$ data.

8.3 Semi-long plot of the data in Table 8.1. The line is the least-squares fit to all of the data. 
Table No.

$2.1 \quad$ Leaching Scenarios............................... 3

2.2 The Five Parameters and Their Subdivision by Which Data are Divided into Groups................................. 5

3.1 Waste Form Composition Solidification Matrices Only.......... 11

3.2 Waste Form Composition Solidification Matrix Plus Simulated Waste.......................................... 12

3.3 Analysis of Leachates for Baseline Experiments.............. 17

4.1 Waste Form Characteristics......................... 20

4.2 Baseline Leaching Experiments Elemental Analysis of Portland Cement Leahate..................................... 35

4.3 Baseline Leaching Experiments Conductance ( $\mu$ mhos $/ \mathrm{cm}$ ) Analysis of Leachates....................................... 36

4.4 Baseline Leaching Experiments MCC-3 Agitated Powder Test for Saturation Limits................................... 38

4.5 Percentage of Elements Leached After One Year From Portland Cement...........................................

4.6 Baseline Leaching Experiments Correlation Matrix ( $R$ ) of Elementai Releases From Portland Cement leached at $20^{\circ} \mathrm{C} . . . . . .$.

5.1 Conductance (umhos/cm) of Leachates from Cement Samples Containing $5 \%$ Sodium Sulfate.

5.2 Conductance ( $\mu$ mhos $/ \mathrm{cm}$ ) of Leachates from Portland Cement

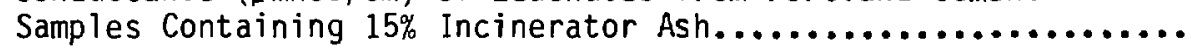

5.3 Conductance ( $\mu$ mhos/cm) of Leachates from Bitumen Samples Containing $20 \%$ and $40 \%$ Sodium Tetraborate...................

5.4 Conductance ( $\mu$ mhos/cm) of Leachates from Vinyl Ester-Styrene Emulsion Samples Containing Sodium Sulfate....................

5.5 Conductance ( $\mu$ mhos $/ \mathrm{cm}$ ) of Leachates from VES Samples Containing $40 \%$ Sodium Sulfate.

6.1 Representative Concentrations (ppm) of Chloride, Sulfate and Bicarbonate Plus Carbonate Anions in Natural Waters............. 


\section{LIST OF TABLES (cont.)}

Table No.

6.2 Concentrations of the Major Cations and Anions in Groundwater

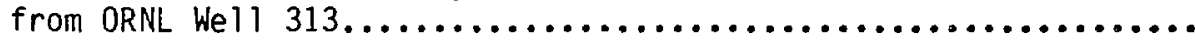

6.3 Typical Dissolved Organic Carbon (DOC) Concentrations in Naturat Waters...................................... 99

6.4 Inorganic Salts Used to Prepared $200 \mathrm{~L}$ of Simulated Groundwater.. 100

8.1 Cumulative Fraction Released After Five Days Leaching Time From Leaching Polyethylene Waste Forms Containing $10 \mathrm{wt} \%$, $30 \mathrm{n}: \%$ and 50 wt\% Sodium Sulfate Salt.

8.2 Equivalent Volume \% Values for the Weight $\%$ Data Listed in

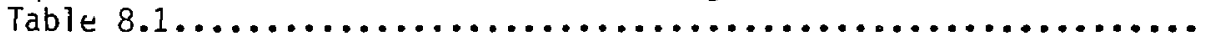

9.1 Summary of Relative change for Potential Acceleration Factors for Leaching of $\mathrm{Cs}-137$ from Low-Level Waste Forms................. 


\section{ABSTRACT}

This report summarizes the work performed for the Accelerated Leach Test(s) Program at Brookhaveri National Laboratory in Fiscal Year 1986 under the sponsorship of the U.S. Department of Energy's Low-Leval Waste Management Program (LLWMP).

Programmatic activities were concentrated in the foliowing areas:

(i) A computerized data base of LLW leaching data has been developed.

(ii) Long-term tests on portland cement, bitumen and vinyl ester-styrene (VES) polymer waste forms containing simulated wastes are underway which are designed to identify and evaluate factors that accelerate leaching without changing the mechanisms. 
An objective of the U.S. Department of Energy's Low-Level Waste Management Program is to provide support for the disposal of low-level waste in a manner which reduces risks "to the public health and safety over both the short and long term. One long-term concern is the release of radionuclides by leaching of solidified LLW after disposal in the shallow land burial. To provide a technical basis for understanding leaching behavior and, hence, to allow more realistic prediction of leachability, Brookhaven National Laboratory has initiated investigation(s) to predict long-term leaching behavior of low-level radioactive waste (LLW) forms in their disposal environments.

The objective of this program is to develop an accelerated leach test(s) that can be used to predict the long-term leaching behavior of solidified lowlevel waste forms. This is to be accomplished through an understanding of the prevailing leaching mechanisms and the factors which control leaching behavior. Leaching mechanisms for selected solidification agent/waste types are being determined through a literature survey, by experiment and by data analysis utilizing curve fitting to mathematical models. A comprehensive evaluation of the rate controlling factors associated with specific leachant and waste form compositions will establish the basis for the development and validation of an accelerated leach test(s) under a variety of environments. References 1-4 1ist the reports which have resulted from work in this program since its inception in FY 1985 and from the Leaching Mechanisms Program, which was a limited effort in FY 1984.

The scope of this investigation over the past year has encompassed work in the following areas:

(i) Development of a computerized data base of LLW leaching data and mathematical models.

(ii) Experimental investigations including long-term leach tests on portland cement, bitumen and vinyl ester-styrene (VES) polymer waste forms designed to identify and evaluate factors that accelerate leaching without changing mechanisms. 


\section{INTRODUCTION}

One of the most important potential initiating events for the return of radioactivity from solidified wastes to man is exposure to water. For this reason, the chemical stability of a waste form is invariably determined by conducting a leach test which involves the direct or indirect measurement of the release of radionuclides to aqueous media. In the absence of national and international agreement on leach test methodology, it is often difficult, if not impossible to compare the results obtained by different groups of workers even for similar waste forms. Although the release of radioactivity from a solidified waste to an aqueous environment is acknowledged to be due to one or more mechanisms such as diffusion, dissolution, corrosion and ion-exchange, most leaching studies have been limited to the early stages of the leaching process, and are insufficient to characterize long-term leachability over hundreds of years. However, the response of an effectively solidified waste to the leaching process is so slow that an extremely long period of time is required to complete one test which will characterize the long-term leachability of a waste form. Therefore, an accelerated test is needed to adequately assess the long-term leaching behavior of solidified radioactive wastes in their disposal environment. This involves an understanding of prevailing leaching mechanisms and factors that affect leaching of waste forms in disposal. 


\section{SUMMARY OF THE DEVELOPMENT OF A COMPUTERIZED DATA BASE FOR LOW-LEVEL WASTE LEACHING DATA}

A computerized data base (db) of low-level waste (LLW) leaching data has been developed as part of an effort to develop an accelerated leach test(s) that can be used to predict leachabilities of LLW forms over long times, i.e., hundreds of years [4]. The data compiled in the db include data from the Accelerated Leach Test(s) Program plus selected data from the literature. Since the accelerated leach test $(s)$ is (are) to be developed based on knowledge of leaching mechanisms and factors that affect leaching, the data compiled in the db have been selected to elucidate leaching mecharisms and factors that affect leaching and are not meant to be a comprehensive compilation of leaching data. The db report presents the organization of, and the data compilation aspect of the $\mathrm{db}$. Programmatic results obtained to date from analysis of the data are presented in Chapter 8 of this report.

Leaching data are, unfortunately, not unambiguous in information content as are, for example, majling addresses, for which there can be no confusion about eitier the information content or interpretation. Leaching data are of little use without additional information on the sample, leachant and leaching conditions, which immediately raises the question of how detailed the description of these parameters need be to unambiguously define the information content of the data. Rather than attempt to formally address this quastion, which would probably be futile anyway, the philosophical bent followed in developing the $\mathrm{db}$ is summarized in Section 2.1. The functional organization is summarized in Section 2.2 and a discussion of the availability and expandability of the $d b$ is presented in Section 2.3.

\subsection{Philosophical Context Under Which The Data Base Was Developed}

The data base was developed to assist in model validation and statistical analysis and to assist in evaluating factors that accelerate leaching. The db is used to curve fit data to leaching models as part of the model validation effort. Statistical analyses provide information on the inherent variability of leach testing and whether the factors investigated to accelerate leaching change the leaching mechanism(s).

Since these data are meant to be interpreted by various types of analysis, we first define what we mean by a leaching experiment in ways that are consistent with what is found in the literature. A survey of leaching experiments indicated that there are basically four bounding scenarios for leach testing, as listed in Table 2.1. Most of the literature on LLW leaching has assumed that the boundary conditions of scenario (1) hold for purposes of analysis.

Scenario (1) has generally been considered to be the worst case for LLW leaching. Scenario (2) has been shown to be the worst case for leaching alkaline glasses. However, LLW is not presently solidified using glass although the use of glass for $L L W$ incineration/solidification has been investigated [5]. 
Aithough the effects on leaching in scenarios (3) and (4) may be important under actual leaching conditions in disposal environments, cognizance of their importance appears to be relatively recent $[6,7]$. As a result, all of the data in the $\mathrm{db}$ is from leach testing which approximates scenarios (1) or (2).

\title{
TABLE 2.1
}

\section{Leaching Scenarios}

\author{
(1) Leaching a bare waste form in a leachant which remains infinitely \\ dilute with respect to the species of interest. \\ (2) Leaching in a static and relatively small volume of leachant. \\ (3) Varying leaching conditions by wet/dry cycling. \\ (4) Leaching the complete waste package, i.e., the waste form in its \\ container.
}

Leaching data obtained from the ANS 16.1 [8] and IAEA [9] standard leach tests are typically analysed based on the assumed boundary conditions in scenario (1). Since the measured leach rate may be affected by the buildup of leached material in each leachant replacement interval in these tests, the possible effect of such departure from the ideal boundary conditions on the measured leachability should be recognized and either shown to be insignificant or corrected for, if possible. In general, leachability is expected to decrease as the concentration of leached material in the leachant increases. Meaningful modeling of leaching data cannot be done without knowledge of the boundary conditions under which the data were obtained.

\subsection{Data Base Organization}

The $d b$ is organized around the computer programs, a file program and a program for data plotting and analysis. The file program is used to enter data into the $d b$, to update files by adding data and to print data files out in hardcopy. The plotting program calls data files for plotting on selected axes and for performing least-squares analysis over any chosen range of the data.

To be meaningful and usable, leaching data require additional information on waste form and leachant compositions and test conditions which provide the context for analysis and interpretation of the data. Within the data base, this contextual information and the data are contained in three "information sheets," as listed below. 
(i) A one-page abstract summarizing experimental information and conclusions from the reference from which the data were taken.

(ii) A summary sheet of specific information on waste form and leachant composition and pertinent experimental parameters.

(iii) Data sheets of cumulative fraction released (CFR) versus time (Days) for each radionuclide and/or other species measured in the experiment.

The abstract applies to all data files (TESTIDS) from the listed reference. The experimental summary sheet applies to individual or replicate leaching experiments. Data sheets list the data for each leaching experiment individually.

Within the data base the data have been cross-referenced according to five parameters as listed in Table 2.2. The subdivisions under each of these parameters, as listed in Table 2.2, provide efficient access to specific data types within the data base.

\subsection{Availability And Expandability}

The db consists of: (i) this report, which provides a written description of the organization and contents of the $d b$ as of the publication date, and, (ii) a $51 / 4$ inch, $360 \mathrm{~kb}$ floppy disc which contains the data, crossreferencing tables and programs for data manipulation and analysis. The programs are coded in IBM Basica and are not proprietary (i.e., need not be purchased). Further, the programs are not compiled. Therefore, the user can edit the programs, which allows both the analytical procedures and the data structure itself to be changed. Since the user has complete editing capability and the programs are, in fact, still undergoing revision as additional analytical capabilities are needed, the db cannot be considered to be a "standard" $\mathrm{db}$. Although standardization of this db into a commercial data base management system may ultimately be desirable, this is not in the scope of this program. 
The Five Primary Parameters and Their Subdivisions by which Data are Divided into Groups

(i) Solidification Agent

- portland cement

- masonry cement

- other cement (e.g. pozzolan cement)

- bitumen

- vinyl ester - styrene emulsion (DOW process)

- vinyl ester - styrene dry (i.e., dry wastes)

(ii) Waste Types

- sulfate wastes (e.g. BWR evaporator bottoms)

- boric acid wastes (e.g. PWR evaporator bottoms)

- nitrate wastes (e.g. reprocessing wastes)

- incinerator ash

- ion exchange resins

- tracers only (i.e., no bulk waste)

(iii) Element Leached

- radionuclides (Cs, Sr and Co are the radionuclides of most concern in LLW)

- other elements (e.g. other elements of interest from the solidification agent matrix or the bulk waste, such as $\mathrm{Ca}, \mathrm{Fe}$, sulfate and organic carbon)

(iv) Leachant Type

- DIW (i.e., deionized water, which is the usual leachant in standard leach tests)

- ground water (may be typical of a specific site)

- sea water

- brine (i.e., a saturated or highly concentrated solution of a salt or mixture of salts)

(v) Size and Shape

- cylinders with height-to-diameter ratios from approximately 1:1 to $2: 1$ are the most common

- cubes and/or spheres are less common but may be useful for modeling purposes

- powders of approximately uniform size (sieved powders) have proved useful for HLW glass studies and may be usefui for some types of $L L W$

- the effects of size differences, as between laboratory size test samples and full scale waste forms, have not been fully accounted for in modeling efforts. 


\section{SAMPLE FABRICATION AND EXPERIMENTAL METHODOLOGY}

This section describes the preparation of waste forms, the leach test methods and methods of analysis used in the experimental studies for this program. Samples prepared using only matrix materials were also described in an earlier report [3].

\subsection{Fabrication of Test Specimens}

3.1.1 Matrix Materials. The solidification agents selected for this study include portland cement, bitumen, a polymer (vinyl ester-styrene) and glass (soda-lime silica). These materials are representative of those currently in use or being considered for use by defense and/or comnercial LLW generators. They also represent a cross-section of materials properties which may influence leaching behavior.

3.1.1.1 Hydraulic Cement. Hydrauiic cement has been used for many years for the solidification of wet wastes. Water in the waste reacts with the cement to form hydrated silicate and other compounds, which interact to form a porous monolithic solid.

3.1.1.2 Vinyl Ester-Styrene. Vinyl ester-styrene is a thermosetting resin marketed by the Dow Chemical co. for use in solidification of radioactive wastes. The resin is mixed directly with either wet solid wastes or dry wastes and subsequently polymerized at room temperature using a promotercatalyst system. Wet wastes and resin are enulsified using high-shear mixing prior to initiating the polymerization reaction. The polymerization reaction is exothermic and a monolithic solid is formed within 30-60 minutes.

3.1.1.3 Bitumen. Bitumen (asphalt) systems are being used in the United States for radioactive waste soijdification.

Bitumen is a mixture of high molecular weight hydrocarbons obtained as a residue in petroleum or coal tar refining. It is a thermoplastic material which becomes liquid at approximately $120^{\circ} \mathrm{C}$. Waste is homogeneously mixed with the molten bitumen which solidifies upon cooling.

\subsubsection{Soda-Lime Silica Glass. The glass selected for this study} was developed at the Monsanto-Mound Facility in a process that simultaneously incinerates low-level waste and incorporates the ash in glass. The waste form is a non-porous material consisting of two solid phases; the glass matrix in which part of the waste components are dissolved, and the ash residue. The glass phase is comprised primarily of $\mathrm{SiO}_{2}$ with smaller amounts of oxides of $\mathrm{Na}, \mathrm{Ca}$ and $\mathrm{Mg}$.

3.1.2 Waste Materials. The simulated wastes selected for incorporation into waste forms are representative of those being generated by defense and/or commercial $\mathrm{LLW}$ generators. The waste materials include soluble salts and an insoluble waste product, a typical incinerator ash. The salts are sodium sulfate and sodium tetraborate, a boric acid derivative. 
3.1.2.1 Sodium Sulfate. Sodium sulfate, which is a product of ion exchange resins regeneration at $B W R$ power stations, is usualiy concentrated to an approximately 22 weight percent solution at $25^{\circ} \mathrm{C}$. Evaporation of this solution to dryness results in sodium sulfate decahydrate (Glauber's salt). Glauber's salt dehydrates to anhydrous sodium sulfate at $32^{\circ} \mathrm{C}$.

3.1.2.2 Boric Acid. PWR evaporator concentrates contain about 12 weight percent boric acid. To incorporate boric acid into bitumen, the boric acid must be converted to a sodium borate by neutralization with sodium hydroxide. Anhydrous sodium tetraborate was used as the waste simulant.

3.1.3.3 Incinerator Ash. Incinerator ash was obtained from the Tennessee Valley Authority waste incinerator. The major components of incinerator ash are typically uncombusted carbon, aluminum oxide $\left(\mathrm{Al}_{2} \mathrm{O}_{3}\right)$, ferric oxide $\left(\mathrm{Fe}_{2} \mathrm{O}_{3}\right)$ and silicon dioxide $\left(\mathrm{SiO}_{2}\right)$. The ash was sieved to pass a 2.38 $\mathrm{mm}$ sieve size to produce a uniform powder free of large clinkers and metal objects.

3.1.3 Selection of Matrix and Waste Material Combinations. Preliminary studies were made to select combinations of matrix solidification agents and waste materials which are chemically compatible. Waste form formulations were optimized to assure the waste forms maintained their physical integrity on immersion in water during the leaching experiments.

3.1.3.1 Portland I Cement and Sodium Sulfate. The compositional phase diagram for the solidification of aqueous sodium sulfate with portland type I cement was reported [10] in Figure 3.1

The solubility of sodium sulfate is 22 weight percent at $25^{\circ} \mathrm{C}$ which is typical concentration of BWR evaporator concentrates from resin regeneration. Up to approximately 45 weight percent sodium sulfate can be solidified with cement. However, waste forms in excess of 8 weight percent sodium sulfate were found to be unstable on immersion in deionized water. A waste form formulation of 5 weight percent sodium sulfate, 30 weight percent water and 65 weight percent cement was selected for testing. The waste to binder ratio of evaporator concentrate to cement corresponds to 0.54 .

3.1.3.2 Portland I Cement and Incinerator Ash. The solidification of incinerator ash with portland type I cement was reported by Neilson and Colombo, 1982 [11] and Buschbom, and others, 1984 [12]. The compositional phase diagram for the solidification of incinerator ash in cement is shown in Figure 3.2. Up to 50 weight percent incinerator ash can be solidified by portland I cement without free standing water being present. However, specimens swell with the development of large voids on curing. A waste form formulation of 15 weight percent ash, 25 weight percent water and 60 weight percent cement was selected for leach testing because waste forms with a low degree of voids due to swelling were produced. The formulation is consistent with those used by Colombo and Neilson, 1979 [10], USERDA, 1976 [13] and Buschbom, 1984 [12]. 


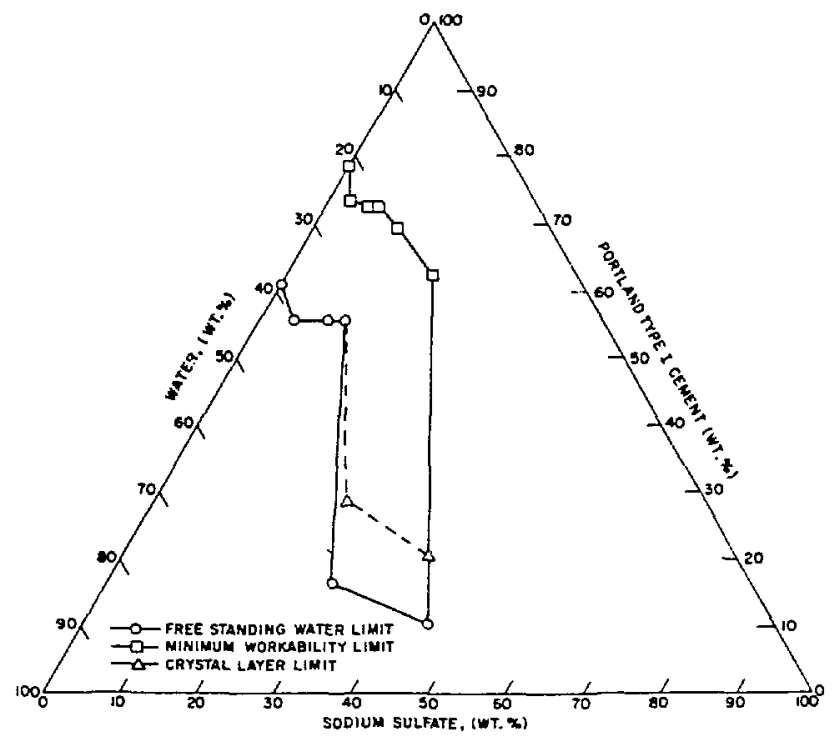

Figure 3.1 Compositional phase diagram for the solidification of aqueous waste containing $50 \mathrm{wt} \%$ or less $\mathrm{Na}_{2} \mathrm{SO}_{4}$ with portland type $\mathrm{I}$ cement.

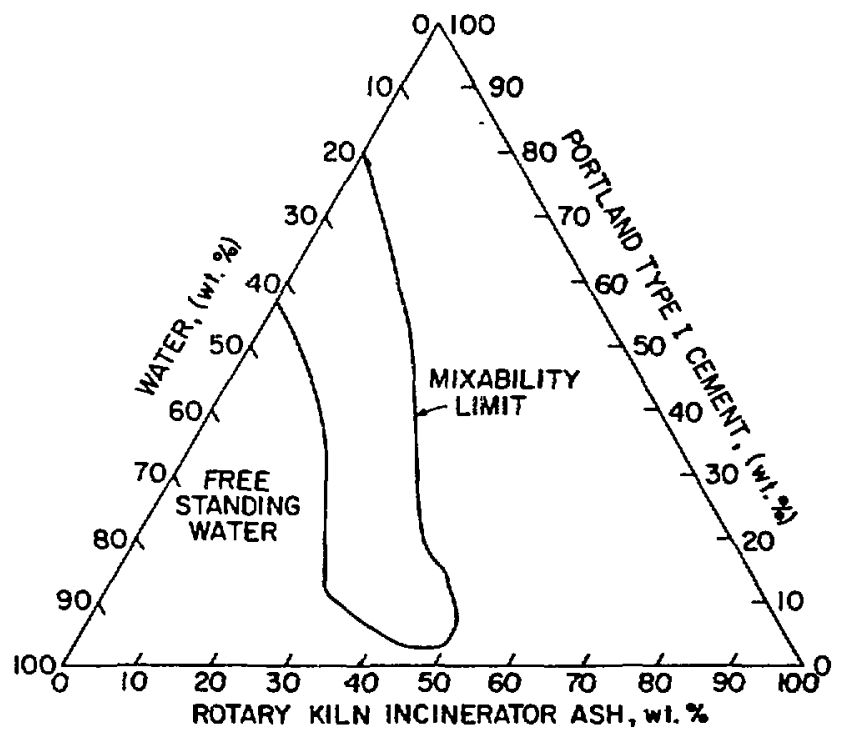

Figure 3.2 Ternary compositional phase diagram for the solidification of incinerator ash in portland type I cement. 


\subsubsection{Vinyl Ester-Styrene, Sodium Sulfate and Water Emulsion}

Polymer. The amount of sodium sulfate that can be solidified by the vinyl ester-styrene polymer emulsion system is 1 imited by the 22 weight percent solubility at $25^{\circ} \mathrm{C}$ of sodium sulfate in water. A mixture of 15 weight percent sodium sulfate, 45 weight percent water and 37 vinyl esterstyrene monomer produced a satisfactorily polymerized waste form with hard surfaces that was water immersion stable.

\subsubsection{Vinyl Ester-Styrene and Sodium Sulfate. Mixture of up to} 60 weight percent sodium sulfate with vinyl ester-styrene monomer polymerized satisfactorily to produce waste forms with hard surfaces. The waste forms were water immersion stable. The leaching of sodium sulfate from solidified waste forms was used to select a composition which maximized the amount of incorporated waste while minimizing the leaching of the waste. Waste forms of 2.0 inch diameter by 2.5 inch height were immersed in $1.3 \mathrm{~L}$ of water for 3 days. The concentration of sodium ions leached from the waste forms of increasing waste loadings is shown in Figure 3.3. The amount of sodium ion leached at waste loading above 40 weight percent rapidly increased. Below 40 weight percent the amount of leached sodium probably represents the washing of the waste form surfaces. The 40 weight percent sodium sulfate waste loading with 60 weight percent vinyl ester-styrene was selected for further study.

3.1.3.5 Bitumen/Sodium Tetraborate. Boric acid waste generated at a typical PWR Plant contains approximately 12 weight percent boric acid in aqueous solution. Solidification of the waste with bitumen requires the removal of water by evaporation. Because boric acid dehydrates at $160^{\circ} \mathrm{C}$, the loss of water would cause foaming of the bitumen mixture.

A satisfactory solidification process is to neutralize the boric acid solution with sodium hydroxide. Sodium tetraborate is the predominating product when the waste stream is neutralized to $\mathrm{pH} \mathrm{9.3} \mathrm{[14].} \mathrm{Evaporation} \mathrm{of}$ the solution to dryness results in the hydrated crystalline substance sodium tetraborate decahydrate (borax). The borax must be further dried at $200^{\circ} \mathrm{C}$ to produce the anhydrous borate.

A uniform solid waste form can be produced by mixing the anhydrous sodium tetraborate with molten bitumen. Two waste loadings were selected, $20 \%$ and $40 \%$ by weight sodium tetraborate in bitumen. The $20 \%$ loading is stable on long-term immersion. The $40 \%$ loading, slowly swells and cracks on immersion, but provided an opportunity to study important waste effects predicted by percolation theory on leaching.

\subsubsection{Soda-Lime Glass and Incinerator Ash. The glass waste form} material was developed at the Monsanto-Mound Facility in a process that simultaneously incinerates low-level waste and incorporates the ash in the glass. The glass is a non-porous material consisting of two solid phases; the glass matrix in which part of the waste component are dissolved, and suspended particulates of ash residue. 


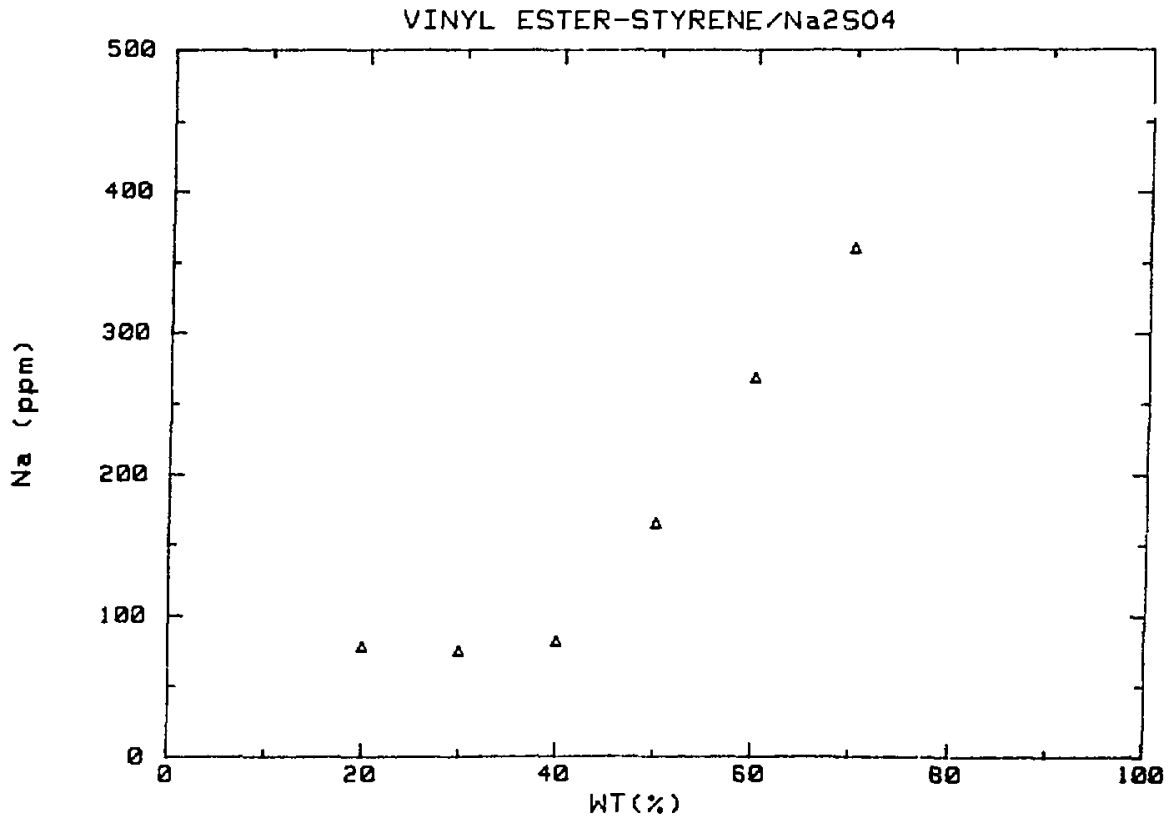

Figure 3.3 Sodium ion concentrations released from vinyl ester-styrene/ sodium sulfate waste forms after 3 day immersion in deionized water at $20^{\circ} \mathrm{C}$ versus waste loading. 


\section{Table 3.1}

Waste Form Composition

Solidification Matrices Only

\begin{tabular}{|c|c|c|}
\hline \multicolumn{3}{|c|}{ Portland Type I Cement } \\
\hline Component & Weight $\%$ & Activity(u Ci) \\
\hline $\begin{array}{l}\text { Cement Powder } \\
\text { Water } \\
\text { Co-60 } \\
\text { Cs }-137 \\
\text { Sr-85 }\end{array}$ & $\begin{array}{r}70 \\
30 \\
- \\
- \\
-\end{array}$ & $\begin{array}{r}- \\
- \\
16.3 \\
9.9 \\
23.6\end{array}$ \\
\hline \multicolumn{3}{|c|}{ Pioneer 321 Bitumen } \\
\hline Component & Weight \% & Activity (u Ci) \\
\hline $\begin{array}{l}\text { Bitumen } \\
\text { Co-60 } \\
\text { Cs }-137 \\
\text { Sr }-85\end{array}$ & $\begin{array}{c}100 \\
- \\
- \\
-\end{array}$ & $\begin{array}{r}- \\
13.8 \\
8.4 \\
20.0\end{array}$ \\
\hline
\end{tabular}

Vinyl Ester-Styrene Emulsion

Component

Weight \%

Activity (u Ci)

Vinyl Ester

49.2

Styrene Monomer

Water

Catalyst

Promoter

Co-60

Cs -137

$\mathrm{Sr}-85$

49.5

1.26

0.05

$-$

$-$

15.4

9.3

$\begin{array}{ll}- & 22.3\end{array}$

\section{Vinyl Ester-Styrene}

Component

Vinyl Ester

Styrene Monomer

Water

Catalyst

Promoter

Co-60

Cs -137

$\mathrm{Sr}-85$
Weight \%

97.9

0.7

1.3

0.05

$-$

$-$

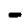

Activity $(\mu \quad C i)$

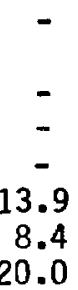


Table 3.2

Waste Form Composition

Solidification Matrix Plus Simulated Waste

Portland Type I Cement/Sodium Sulfate

Component

Cement Powder

Sodium Sulfate

(anhydrous)

Water

Co-57

Cs -137

$\mathrm{Sr}-85$

$\mathrm{Sr}-90$
Weight \%

65

5

30

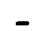

$-$

$-$

$-$

Activity ( $\mathrm{HCi})$

Portland I Cement/Incinerator Ash

Component

Cement Powder

Incinerator Ash

Water

Co-57

Cs -137

S r -85

$\mathrm{Sr}-90$
Weight \%

60

15

25

$-$

-

$-$
Activity (u Ci)

6.3

6.3

12.5

0.3

\section{Vinyl Ester-Styrene/Sodium Sulfate}

\section{Component}

Vinyl EsterStyrene Monomer Sodium Sulfate (anhydrous)

Water

Catalyst

Promoter

Co-57

Cs -137

$\mathrm{Sr}-85$

$\mathrm{Sr}-90$
Weight \%

54.7

39.3

1.8

1.5

0.06

-

-

$-$

-
Activity $(\mu \quad C i)$

100

100

200

5.0
- 
Table 3,2 (continued)

Waste Form Composition

Solidification Matrix Plus Simulated Waste

Vinyt Ester-Styrene Emulsion/Sodium Sulfate

Component

Vinyi Ester-

Styrene Monomer

Sodium Sulfate

(anhydrous)

Water

Catalyst

Promoter

Co-57

Cs -137

$\mathrm{Sr}-85$

$\mathrm{Sr}-90$
Weight \%

39.0

15.0

45.0

1.0

0.04

$-$

$-$

-

$-$
Activity ( $\mu$ Ci)
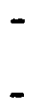

-

-

100

100

100

0

Bitumen/Sodium Tetraborate

Component

Bitumen

Sodium Tetraborate

(anhydrous)

Co-57

CS -137

$\mathrm{Sr}-85$

$\mathrm{Sr}-90$
Weight $\%$

80.0

20.0

$-$

-

$-$ $\underline{\text { Activity }(\mu \mathrm{Ci})}$

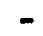

$-$

100

100

200

5

Bitumen/Sodium Tetraborate

Component

Bitumen

Sodium Tetraborate (anhydrous)

Co-57

Cs -137

$\mathrm{Sr}-85$

$\mathrm{Sr}-90$
Weight \%

60.0

40.0
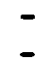

$-$

$-$
Activity $(\mu \mathrm{C} i)$

91

91

4.6 
Table 3.2 (continued)

Waste Form Composition

- Solidification Matrix Plus Simulated Waste

\begin{tabular}{lcc}
\multicolumn{2}{c}{ Portland Type I Cement/Sodium Sulfate } \\
Component & Weight $\%$ & Activity( $\mathrm{C}$ Ci) \\
\cline { 2 - 2 } Soda-Lime Glass & a & - \\
Incinerator Ash & a & - \\
Co-60 & - & $0.01-0.05$ \\
Cs -137 & - & $0.01-0.05$ \\
Mn-54 & - & $0.01-0.04$
\end{tabular}

a. The waste form composition will be determined. 
3.1.4 Sample Preparation. The samples prepared for conducting leaching experiments were cylindrical with approximate dimensions of $4.8 \mathrm{~cm}$ diameter and $6.4 \mathrm{~cm}$ length. Based on past experience this sample size is convenient for laboratory studies. Additional samples were prepared for sample configuration studies. These included small cylinders, approximately $2.5 \mathrm{~cm}$ diameter by $2.5 \mathrm{~cm}$ height and a disc, approximately $6.0 \mathrm{~cm}$ diameter by $1.2 \mathrm{~cm}$ height.

The samples prepared for leach testing had radioactive tracers incorporated into the waste. The radioisotopes were Co-57, Cs-137, Sr-85 and Sr-90. Because of the short half-1ife of $\mathrm{Sr}-85$ (65 days), the isotope $\mathrm{Sr}-90$ was added to determine $\mathrm{Sr}$ leaching after long-term leaching. Sr-85 can be conveniently determined by gamma-ray spectroscopy. Sr-90 determinations requires a chemical separation and beta-ray counting.

The low energy gamma ray emitted by $\mathrm{C}_{0}-57 \quad\left(T_{1 / 2}=270\right.$ days $)$ is better suited to the automated $\mathrm{NaI}$ counting system and works well with the Geli counting system. Formulations used to fabricate test specimens are given in Table 3.1 for solidification matrix only and Table 3.2 for solidification matrix plus simulated waste.

The soda-lime silica glass samples, which were produced at the Mound facility, were cylinders approximately $2.5 \mathrm{~cm}$ diameter and $2.5 \mathrm{~cm}$ in height. The glass specimens contain the radioisotope Cs-137, Mn-54 and Co-60.

\subsection{Experiment Description}

3.2.1 Leaching Tests. In the baseline study three leach tests were used to determine the leachability of various radionuclides and solidification agent constituents.

3.2.1.1 ANS 16.1 Leaching Test. The ANS 16.1 Leach Tests is a semi-dynamic leaching test in which the Teachate is replaced periodically after intervals of static leaching [8]. In this procedure, specimens are placed into the leachant solution in such a way that all external surface area is directly exposed. Specimens are tested in individual containers containing sufficient leachant to provide a leachant/specimen external geometric surface area ratio of $10 \mathrm{~cm}$ unless otherwise specified. Specimen formulations are usually tested in duplicate or triplicate to determine the extent of specimen variation in leaching. Leach test data are expressed as incremental fraction release, as cumulative fraction release or as a release rate to facilitate alternative methods of data treatment.

The leachant is typically distilled water with a conductance of $<5$ $\mu$ mhos $/ \mathrm{cm}$. The sampling interval has been modified to give more frequent intervals and to extend the duration of the test beyond the 90 day standard.

\subsubsection{MCC-3s Leaching Test. The MCC-3s Agitated Powder Leach}

Test Method is a static leach test developed for determining the solubility limits and the dissolution rates of materials used for the encapsulation of high-level wastes [15]. 
This method has been adapted for use with low-level waste materials to determine solubilities of sample components in the leachate. Leachate elemental concentration must be monitored with respect to chemical saturation to eliminate retardation of leach rates or mechanistic variations due to saturation conditions.

3.2.1.3 MCC-4s Leaching Test. The MCC-4s Low Flow Rate Leach Test Method is a single-pass flow through test which eliminates sampling interval effects and large leachate concentration changes, proyiding better control over the boundary conditions of leachant composition [16].

This leaching test was also developed for evaluation of high-level waste forms. Because of the nature of the materials used for this study, some modifications were made in the test procedure by increasing the flow-rates.

\subsection{Analytical Methods}

Leachates were analyzed for a variety of materials depending on the composition of the solidification agent. Initially "spot checks" were made for all elements of interest in the leachates. Spot checks were used to determine what elements of interest were present in significant quantities from the various waste forms. From this information it was determined which leachates should receive complete analys is for each of the elements in question. Cement leachates were subjected to the most analysis since reactions within the matrix cause significant differences in leaching among different elements. Table 3.3 shows which analyses were performed on leachates from the various soldification agents. Specific analytical methods are given below.

3.3.1 Radiochemical Analysis. The radiochemical component of the leach-

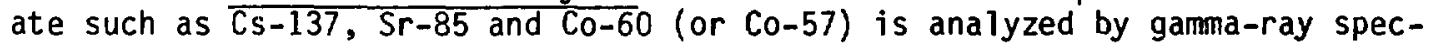
troscopy using an intrinsic Germanium detector or a sodium iodide detector in accordance with the methods described in ASTM D3648-78 [17] and ASTM D3649-78 $[18]$.

3.3.2 Elemental Leachate Analysis. Analysis of leachates for non-radioactive elements will be conducted with standard methods such as ASTM E663 [19] and those in, Analytical Methods for Atomic Absorption Spectrophotometry, revised January 1982, Perkin-Elmer Corporation, Norwalk, C.T [20].

3.3.3 Alkalinity. Will be measured by titration to the phenolphtalein and methyl orange end points according to Method Number 403 from Standard Methods for the Examination of Water and Waste Water, 15th edition, 1980 [21].

3.3.4 Analysis for $\mathrm{pH}$. Will be performed using ASTM D1293 [22] with a platinum combination probe.

3.3.5 Conductivity. Wi11 be measured by ASTM D1125 [2]. Waste forms will be analyzed before and after leaching by Scanning/Electron Microscopy (SEM) to obserye change in physical morphology and by Energy Dispersive Spectroscopy (EDS) to determine elemental ratios in profile and on waste form surfaces. 
Table 3.3

Analysis of Leachates for Baseline Experiments

\begin{tabular}{lccc} 
Analysis & Cement & Bitumen & VES \\
\cline { 2 - 3 } & & & \\
$\mathrm{Na}$ & $\mathrm{x}$ & 0 & 0 \\
$\mathrm{~K}$ & $\mathrm{x}$ & 0 & 0 \\
$\mathrm{Ca}$ & $\mathrm{x}$ & 0 & 0 \\
$\mathrm{Sr}$ & $\mathrm{x}$ & 0 & 0 \\
$\mathrm{Mn}$ & 0 & 0 & 0 \\
$\mathrm{Fe}$ & 0 & 0 & 0 \\
$\mathrm{Co}$ & $\mathrm{x}$ & 0 & 0 \\
$\mathrm{Si}$ & $\mathrm{x}$ & 0 & 0 \\
$\mathrm{Ai}$ & $\mathrm{x}$ & 0 & 0 \\
$\mathrm{Sr}-85$ & $\mathrm{x}$ & $\mathrm{x}$ & $\mathrm{x}$ \\
Co-60 & $\mathrm{x}$ & $\mathrm{x}$ & $\mathrm{x}$ \\
Cs-137 & $\mathrm{x}$ & $\mathrm{x}$ & $\mathrm{x}$ \\
pH & $\mathrm{x}$ & $\mathrm{x}$ & $\mathrm{x}$ \\
Alkalinity & $\mathrm{x}$ & 0 & 0 \\
Conductivity & $\mathrm{x}$ & $\mathrm{x}$ & $\mathrm{x}$ \\
Total Organic & - & 0 & 0 \\
Carbon & & &
\end{tabular}

$x=$ routinely analyzed

$0=$ spot check

$-=$ not analyzed

1 = includes both emulsion and dry waste forms 
3.3.6 SEM/EDS. Methods used will be those discussed by Goldstein and Yakowitz in Practical Scanning Electron Microscopy, Electron and Ion

Microprobe Analysis, (1975) [24]. 


\section{LEACHING BEHAVIOR OF SOLIDIFICATION AGENTS}

Leaching experiments were started during fiscal year 1984, as part of the Leaching Mechanisms Program, and were continued until January of $1986[1,3]$ for a total of 510 days leaching time. The purposes of the baseline leaching tests were:

- to provide long-term data for statistical and modeling purposes

- to provide leaching data and solid phase data against which acceleration factors could be evaluated and acceleration rates could be calibrated

- to provide leaching data and solid phase data against which waste effects could be evaluated

- to provide an understanding of prevailing leaching mechanisms.

\subsection{Sample Description}

Samples for this experiment were made as described in an earlier report [3] and in Section 3. They consisted of the solidification agent (portland type I cement, bitumen, vinyl ester-styrene emulsion and vinyl ester-styrene solid) and aqueous radioactive tracers. Samples were produced and tested in triplicate. Formulations are given in Section 3. Characteristics of the individual samples that were tested are given in Table 4.1 .

The relatively simple system of solidification agent/tracer allowed leaching properties of the individual materials to be investigated without alteration by the presence of wastes. Later work, as discussed in subsequent sections, focused on leaching behavior of various solidification agent/waste combinations.

\subsection{Results of the Baseline Experiments}

Results of the baseline experiments are described below for the various solidification agents. For each, data are presented as plots of Cumulative Fraction Released (CFR) versus time in days and as Incremental Fraction Release divided by time in seconds to give a leach rate as Fraction/Second (F/Sec).

4.2.1 Portland Cement. Cumulative Fraction released of $\mathrm{Cs}-137$ and $\mathrm{Sr}-85$ are shown in Figure 4.1 for the duration of the experiment (510 days). No Co-60 was observed in the leachate. This was expected since cobalt forms compounds of very low solubilities at $\mathrm{pH}=11$ or greater. The cumulative fraction released of $\mathrm{Cs}-137$ after 510 days averaged 0.817 , where 1.00 is one hundred percent release. The release of $\mathrm{Sr}-85$ could only be followed for approximately 144 days because the short half-life (64 days) of that isotope. Its low release rate resulted in leachate activities that were below detection

limits. At 144 days the average CFR for $\mathrm{Sr}-85$ was 0.046 . 
Waste Form Characteristics

\begin{tabular}{|c|c|c|c|c|c|}
\hline $\begin{array}{l}\text { Sample } \\
\text { Number }\end{array}$ & $\begin{array}{l}\text { Weight } \\
(\mathrm{g})\end{array}$ & $\begin{array}{l}\text { Height } \\
(\mathrm{cm})\end{array}$ & $\begin{array}{l}\text { Diameter } \\
\quad(\mathrm{cm})\end{array}$ & $\begin{array}{l}\text { Surface } \\
\text { Area }\left(\mathrm{cm}^{2}\right)\end{array}$ & $\begin{array}{r}\text { Volume } \\
\left(\mathrm{cm}^{3}\right)\end{array}$ \\
\hline$P C-A^{1}$ & 199.46 & 6.3 & 4.8 & 131.2 & 103.9 \\
\hline$P C-B$ & 198.62 & 6.3 & 4.8 & 131.2 & 103.9 \\
\hline$P C-B$ & 198.59 & 6.3 & 4.8 & 132.7 & 105.8 \\
\hline PC-Blank & 198.84 & 6.3 & 4.8 & 131.2 & 103.9 \\
\hline BIT-A ${ }^{2}$ & 111.00 & 6.4 & 4.7 & 129.2 & 102.7 \\
\hline BIT-B & 107.24 & 6.4 & 4.7 & 129.2 & 102.7 \\
\hline BIT-C & 108.66 & 6.4 & 4.7 & 129.2 & 102.7 \\
\hline BIT-BT ank & 110.15 & 6.4 & 4.7 & 1.29 .2 & 102.7 \\
\hline VESE- $A^{3}$ & 98.06 & 6.0 & 4.8 & 126.7 & 98.2 \\
\hline VESE-B & 102.70 & 6.0 & 4.8 & 126.7 & 98.2 \\
\hline VESE-C & 99.05 & 6.0 & 4.8 & 126.7 & 98.2 \\
\hline VESE-Bl ank & 108.48 & 6.1 & 4.8 & 128.2 & 100.1 \\
\hline VESD- $A^{4}$ & 111.84 & 6.3 & 4.8 & 131.2 & 103.9 \\
\hline VESD-B & 109.84 & 6.3 & 4.8 & 131.2 & 103.9 \\
\hline VESD-C & 110.83 & 6.3 & 4.8 & 131.2 & 103.9 \\
\hline VESD-Bl ank & 111.20 & 6.3 & 4.8 & 131.2 & 103.9 \\
\hline
\end{tabular}

1. Portland Cement

2. Bitumen

3. Vinyl Ester-Styrene Emulsion

4. Vinyl Ester-Styrene Dry 


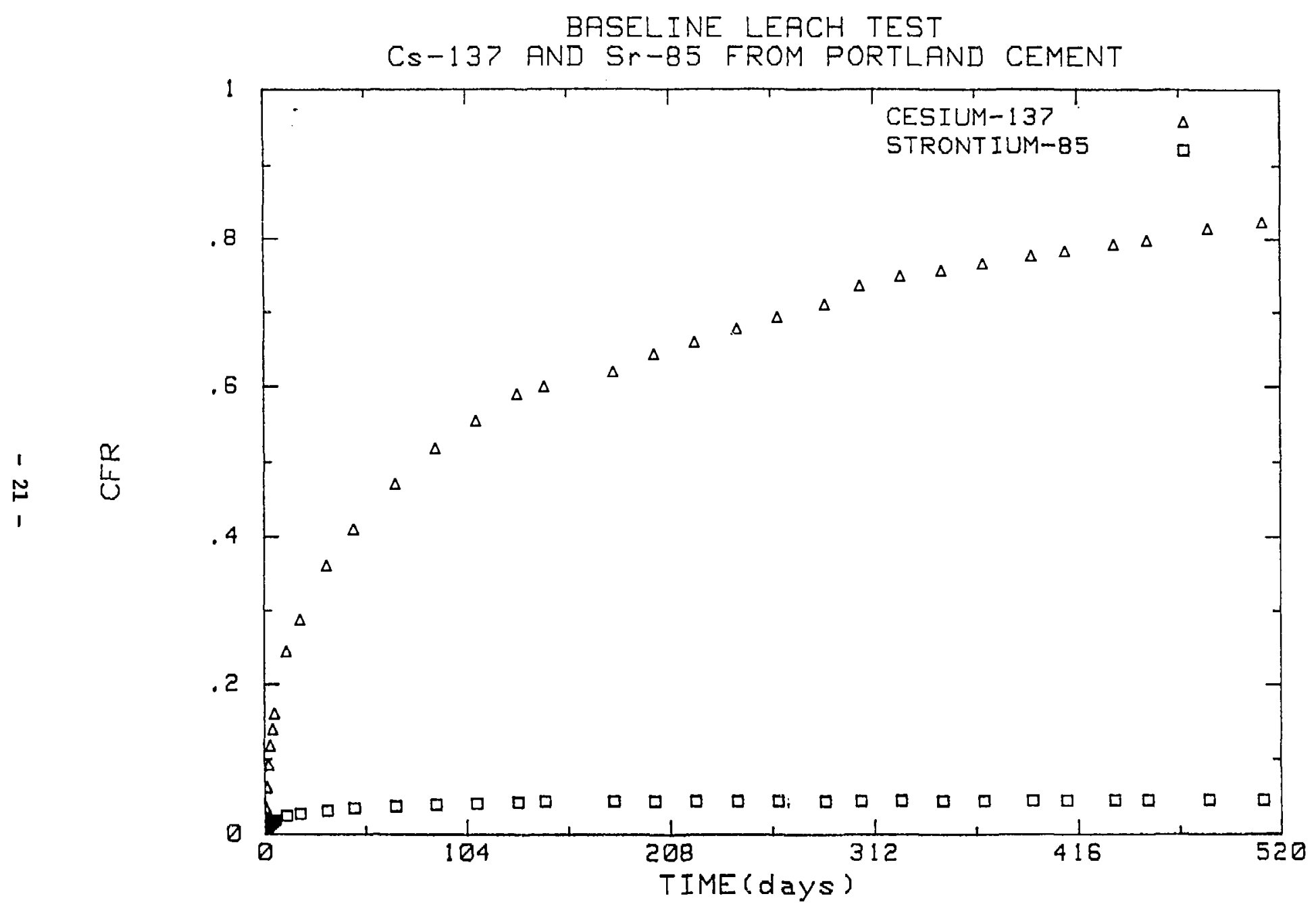

Figure 4.1 Cumulative fraction releases from portland cement for $\mathrm{Sr}-85$ and Cs-137. No release of Co-60 was detected. 
Cumulative fraction released and release rates for $\mathrm{Cs}-137$ from triplicate samples of cement are shown in Figures 4.2 and 4.3 , respectively. Similar results are shown for $\mathrm{Sr}-85$ (only for 144 days due to radioactive decay) in Figures 4.4 and 4.5 .

There is little scatter in the data for tracers leaching from cement although as the release rates decrease with time, and the count rate drops, the error becomes larger. This is seen in Figures 4.3 and 4.5 as increased scatter in the lower right-hand section of the plots. It also seems clear that the release rates change abruptly when samplings change from daily to longer intervals.

The standard deviation of the triplicate samples for the final sampling interval is $0.15 \%$ for $\mathrm{Cs}-137$ and $0.05 \%$ for $\mathrm{Sr}-85$; expressed as a percentage of the original activity in the waste form. The standard deviation for Sr-85 was calculated at 144 days.

\subsubsection{Vinyl Ester-Styrene/Water Emulsion. Cumulative fraction} released for all radionuclides from a VES emulsion sample are shown in Figure 4.6. Unlike cement there is little difference in leaching among the isotopes, indicating that none of the tracers reacted chemically with the solidification agent. Figure 4.7 shows cumulative fraction released from triplicate samples for Cs-137 while Figure 4.8 shows release rates for that isotope. Figures 4.9 and 4.10 are similar pair of plots for $\mathrm{Sr}-85$ and Figures 4.11 and 4.12 are plots for $\mathrm{Co}-60$.

Cumulative fraction released were similar for all isotopes. Sample $C$ had a slightly greater release rate than other samples although the final CFR was greater by only 0.0018 of the original activity in the sample. Variations in releases particularly when the release rates were low, were related to counting errors as well as small variations in the ieach rate itself. One standard deviation of the $\mathrm{Cs}-137$ releases at the last sampling interval was $\mathbf{0 . 0 0 3 \%}$ of the original activity in the waste form. At 130 days the standard deviation for the three $\mathrm{Sr}-85$ curves was $0.004 \%$.

The steplike appearances of the cumulative fraction release plots may be related to the way that the VES emulsion leaches. Apparently, small cells that contain the tracers in the emulsion become accessible to leaching suddenlyly and a microburst of material is released. The fraction of activity released allows the calculation of the volume of liquid released since the tracer was well mixed in the $49.5 \mathrm{ml}$ of water contained in the sample, giving a release of about $0.017 \mathrm{ml}$. This corresponds to a spherical cell with a radius of about $0.16 \mathrm{~cm}$ which is much larger than the observed pores in this material. The implication is that, not a single cell, but an interconnected network of cells suddenly opened to leaching.

4.2.3 Bitumen. Cumulative fraction releases of Cs-137, Sr-85 and Co-60 are shown in Figure 4.13 for a single bitumen sample. Releases are much less than those of cement and are about half that of the VES emulsion. Unlike VES, different radionuclides leach at different rates, with Cs-137 being the fastest and Co-60 the slowest. These differences appear to be only slightly greater than the inter-sample variability. Again, Sr-85 was tracked only for 144 days before radioactive decay rendered it undetectable in the leachates. 


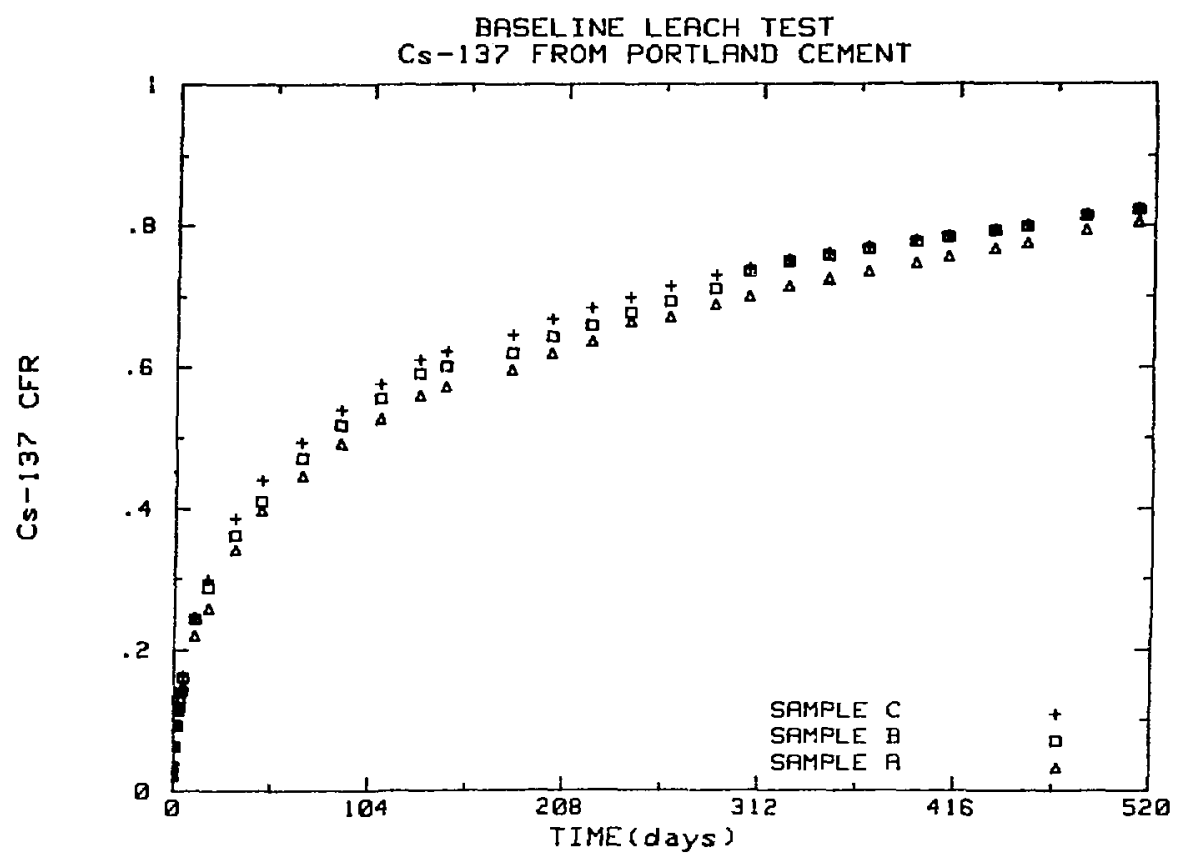

Figure 4.2 Cumulative fraction releases for Cs-137 from portland cement. Final release was 0.817 of total activity in the waste form.

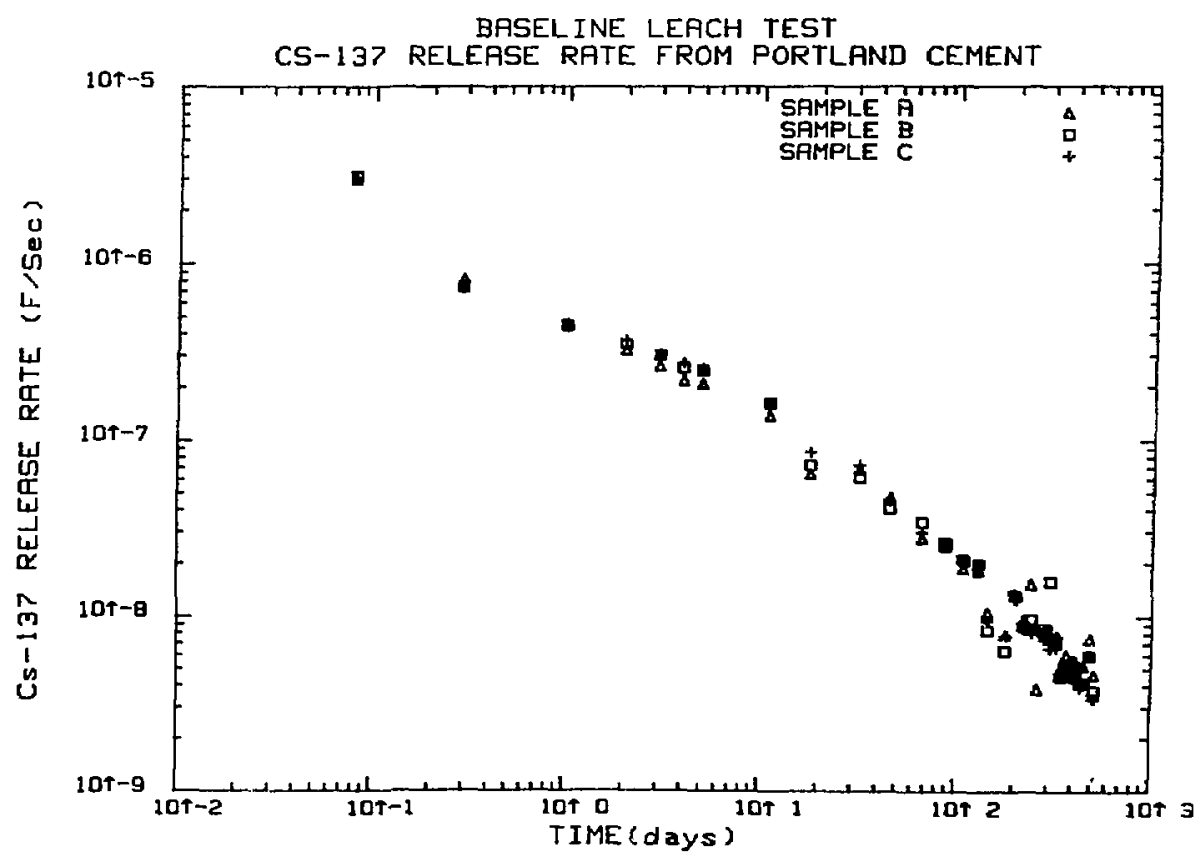

Figure 4.3 Rate of $\mathrm{Cs}-137$ release from port land cement. Note the change of rate between 10 and 20 days. 


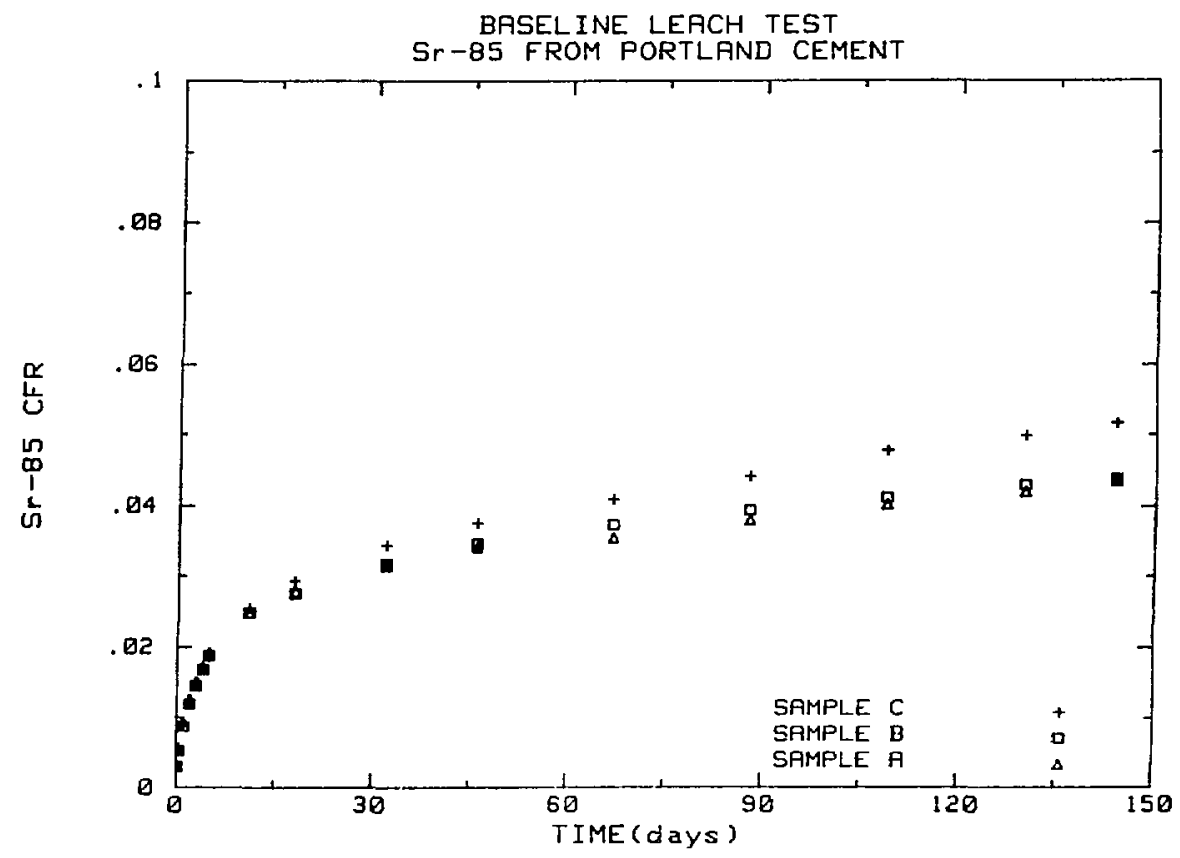

Figure 4.4 Cumulative fraction release for portland cement samples. Data only goes out to 144 days because of radioactive decay of the isotope.

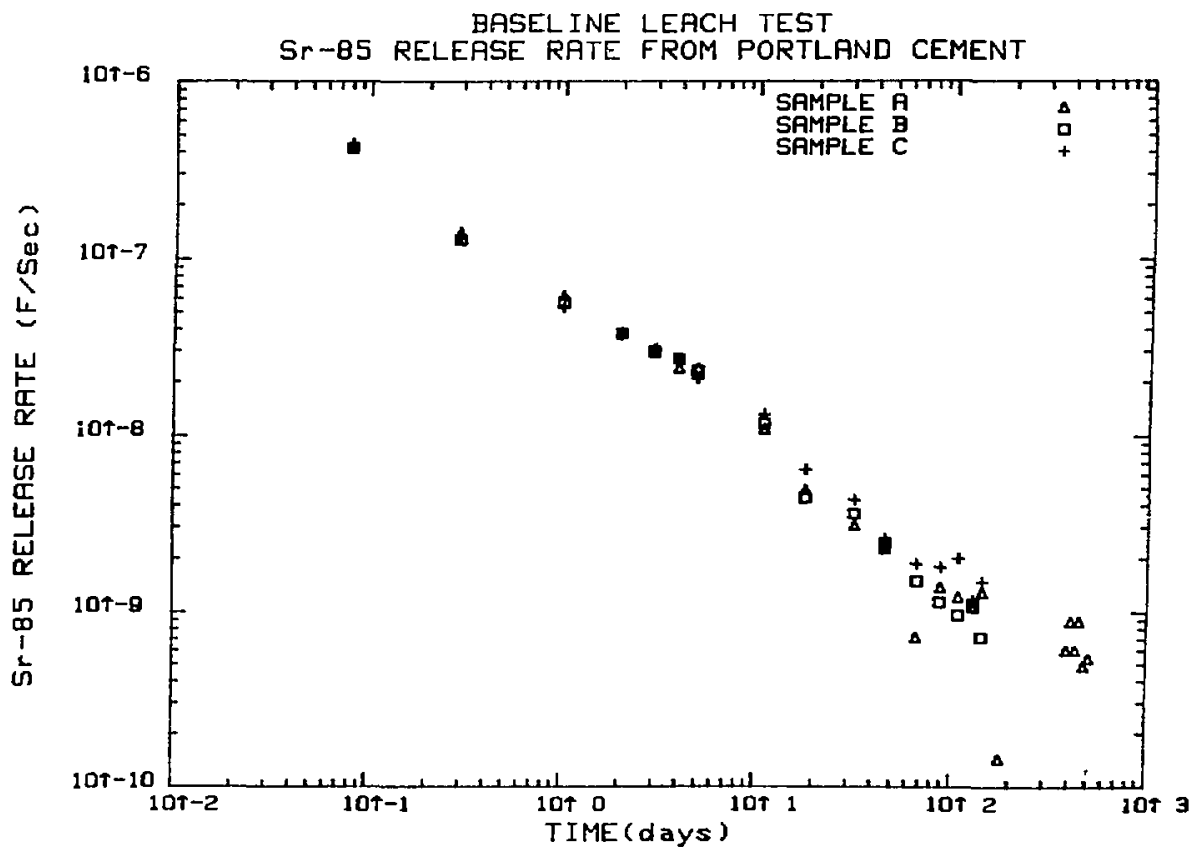

Figure 4.5 Release rates of $\mathrm{Sr}-85$ from portiand cement. 


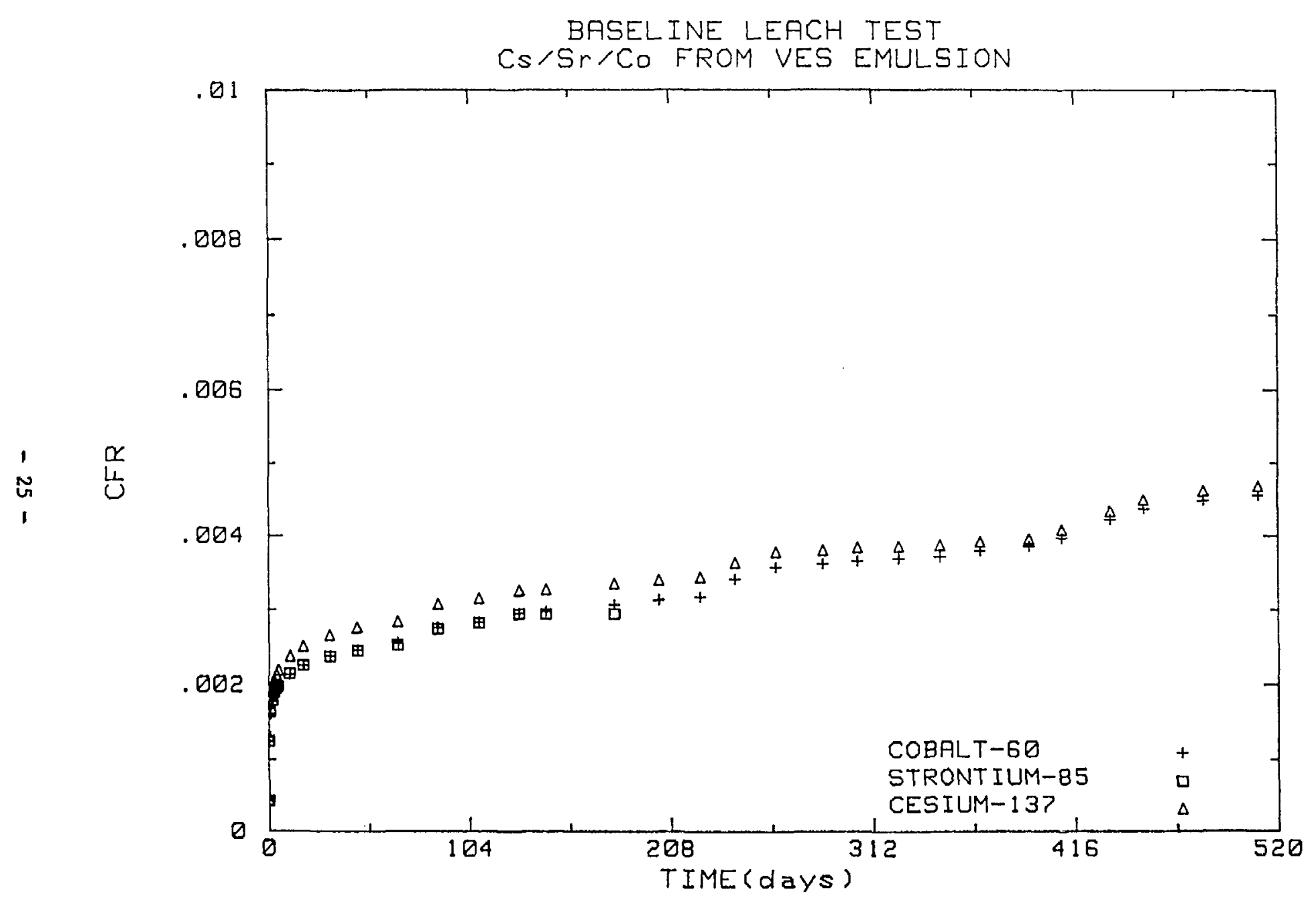

Figure 4.6 Cumulative fraction releases of $\mathrm{Cs}-137, \mathrm{Sr}-85, \mathrm{Co}-60$ from a vinyl ester-styrene emulsion waste form. 


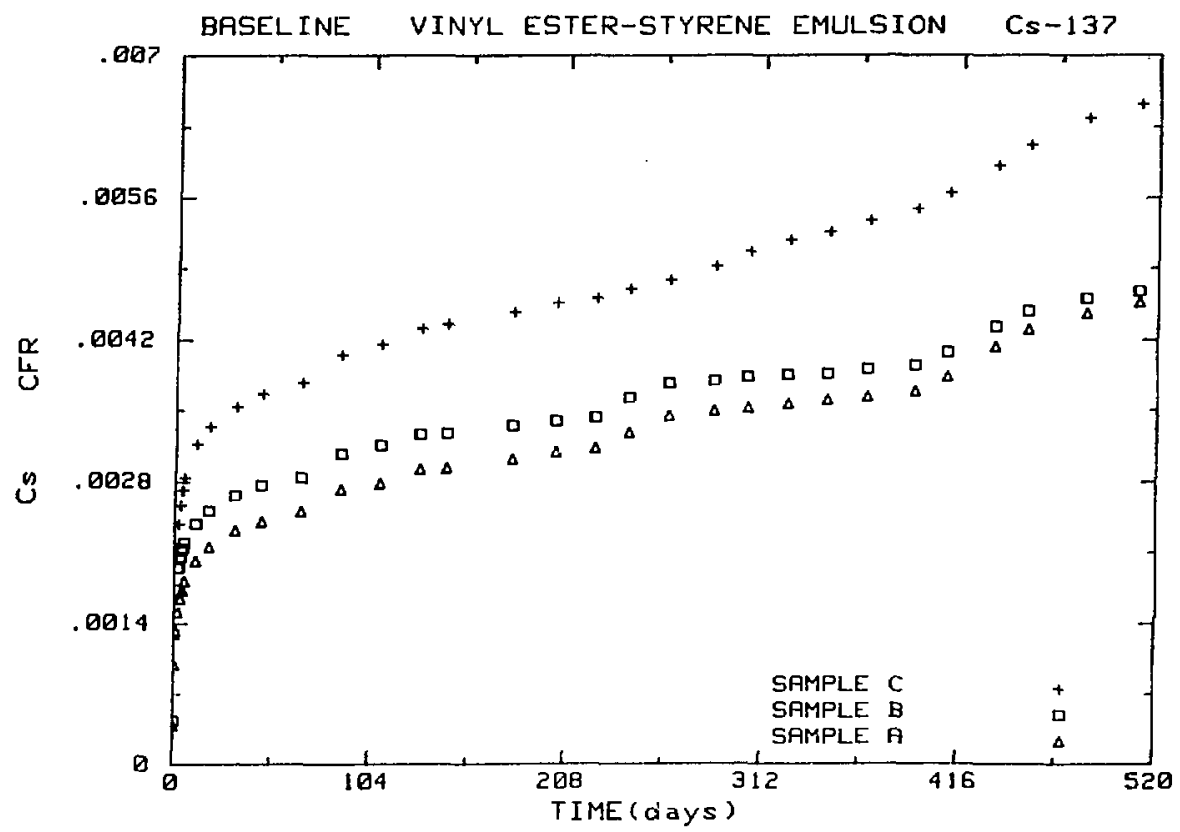

Figure 4.7 Cumulative fraction releases of Cs-137 from triplicate VES emulsion waste forms. Note the scale used on the $y$-axis makes a small difference seem large.

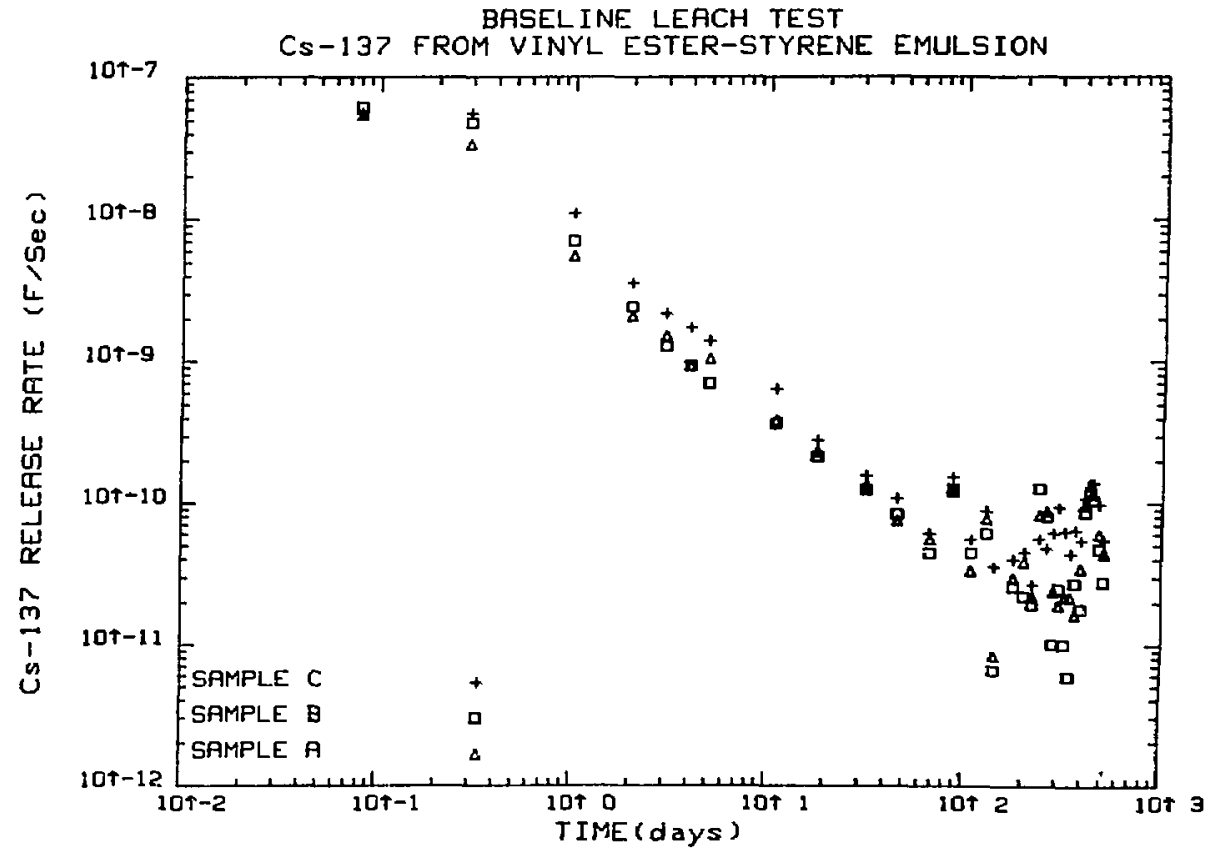

Figure 4.8 Release rates for Cs-137 from triplicate VES emulsion waste forms. The scatter at the lower right of the plot indicates larger counting errors due to low release rates. 


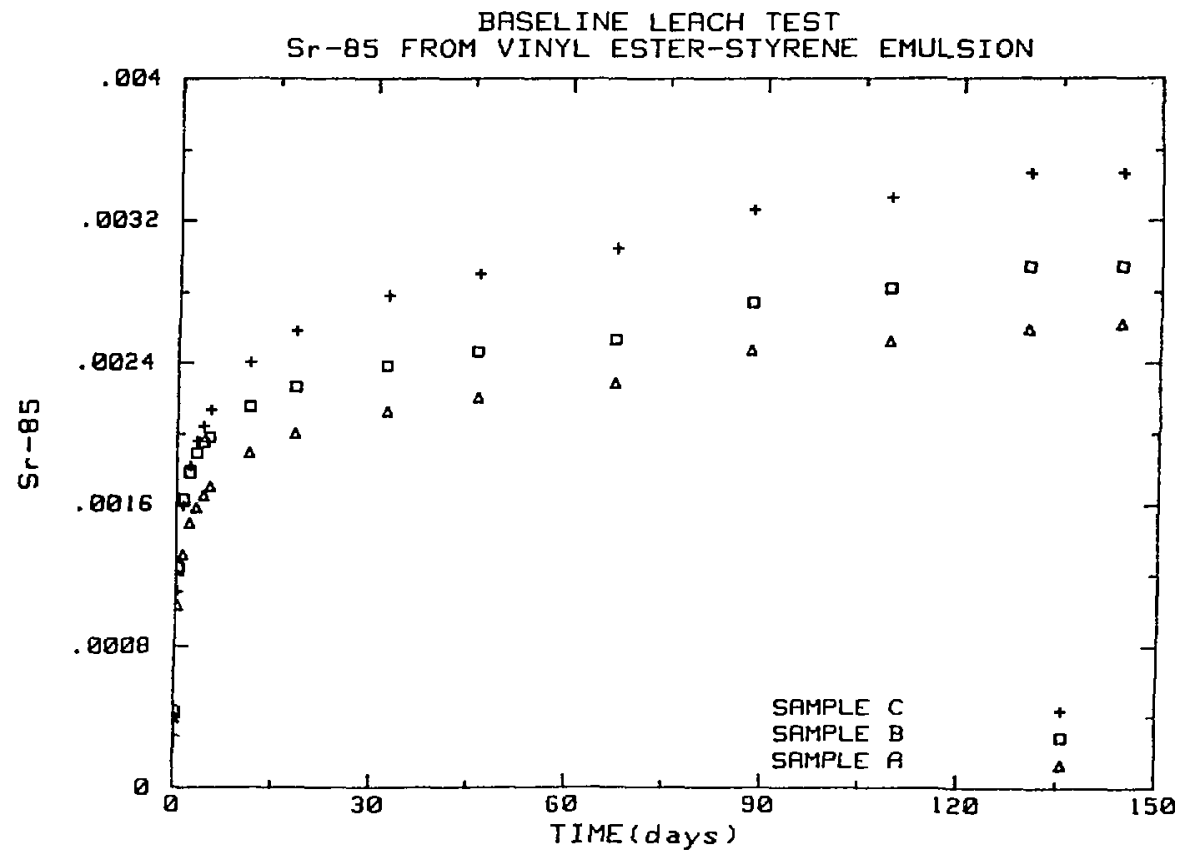

Figure 4.9 Cumulative fraction releases for Sr-85 from VES emulsion waste forms. These data extend only to 144 days because radioactive decay reduced the count rate to detection limit activities.

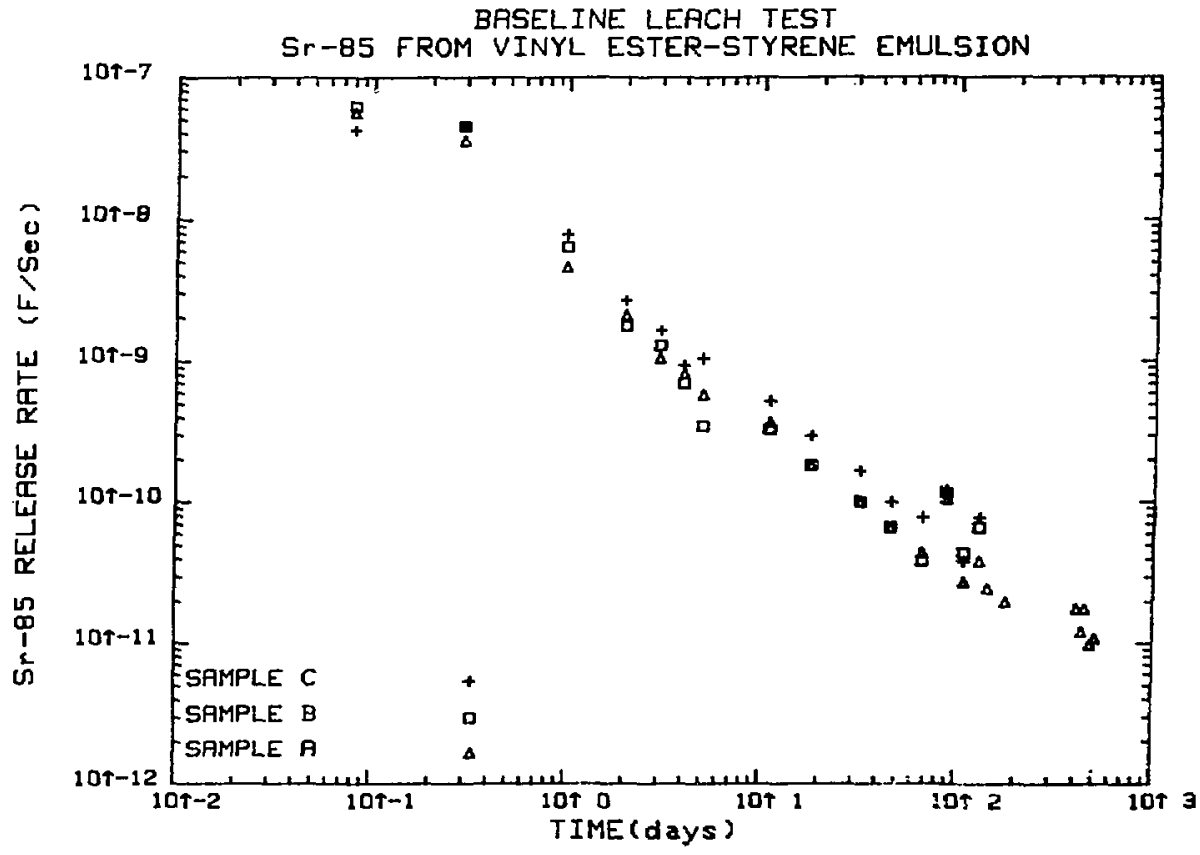

Figure 4.10 Release rates for Sr-85 for triplicate VES emulsion samples. 


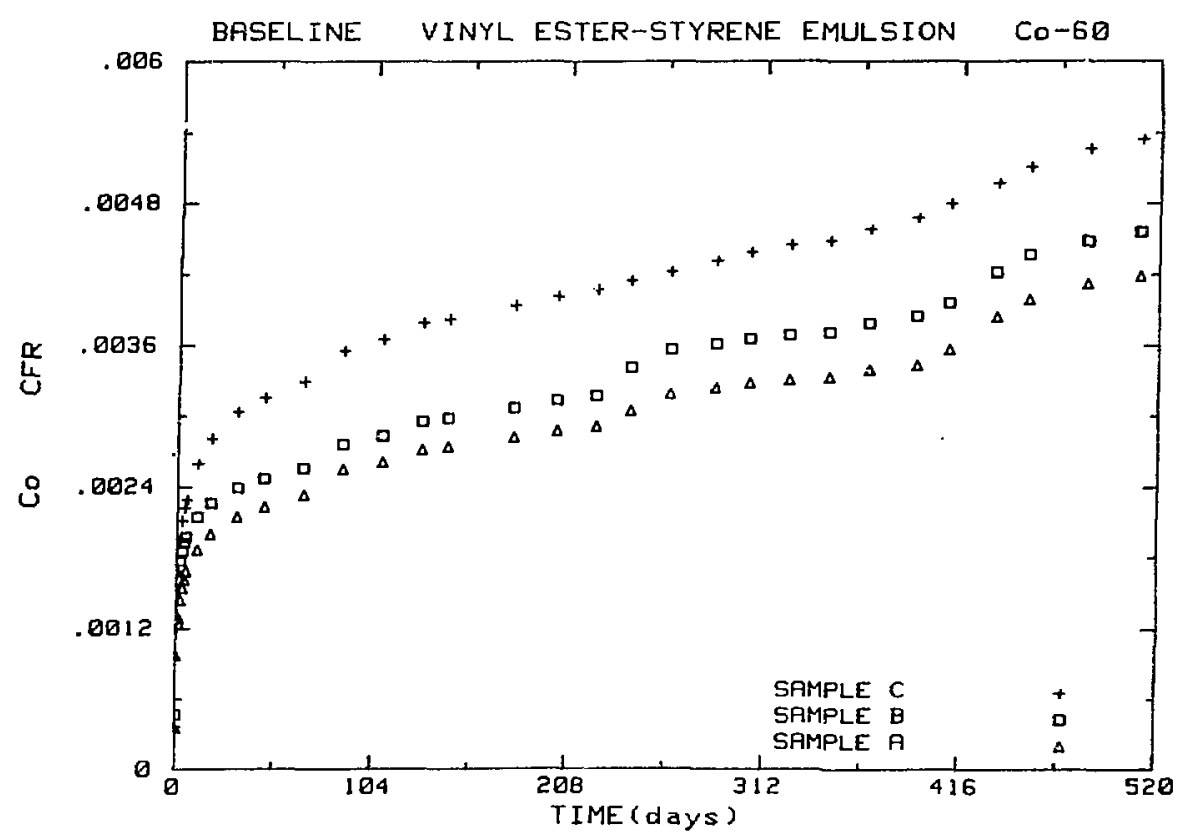

Figure 4.11 Cumulative fraction releases for Co-60 from triplicate vinyl ester-styrene emulsion samples.

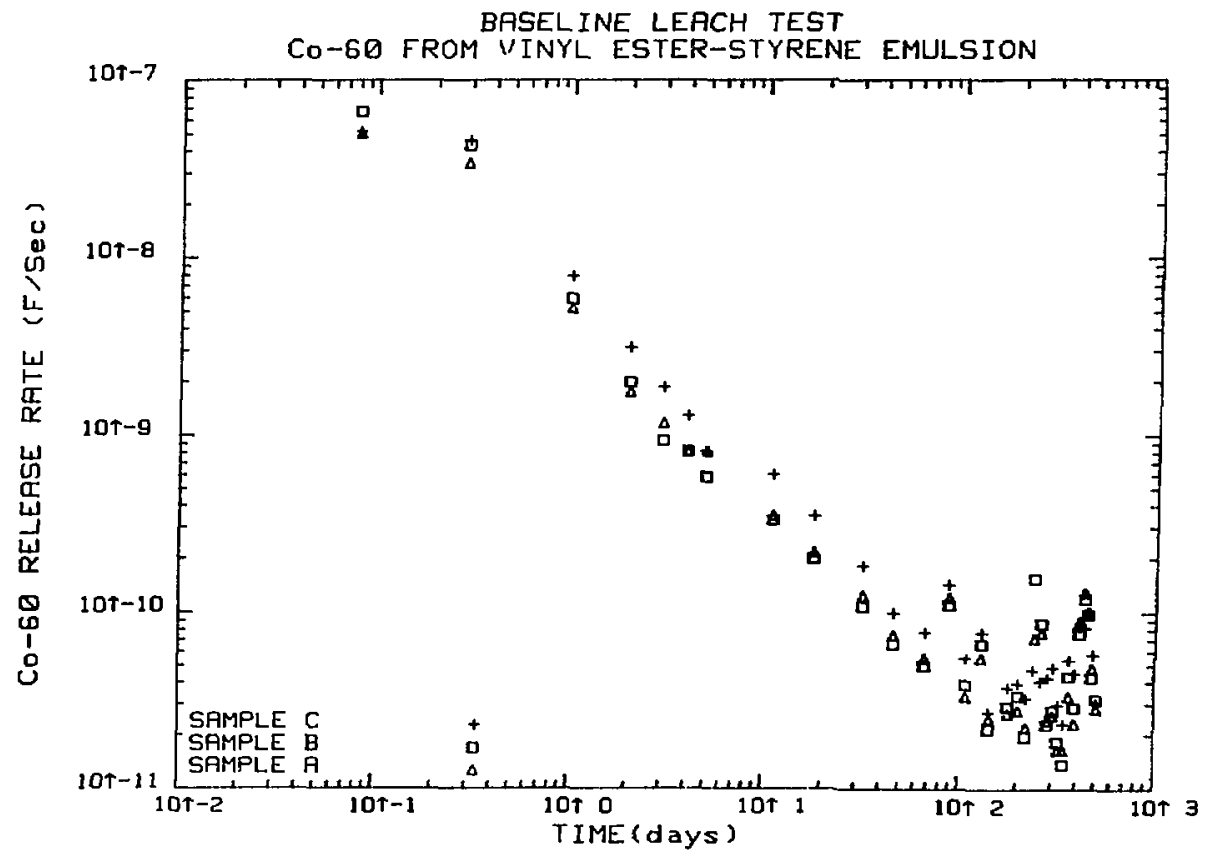

Figure 4.12 Release rates of Co-60 from triplicate vinyl ester-styrene samples. Scatter at the bottom right is due to relatively large counting errors resulting from low release rates. 


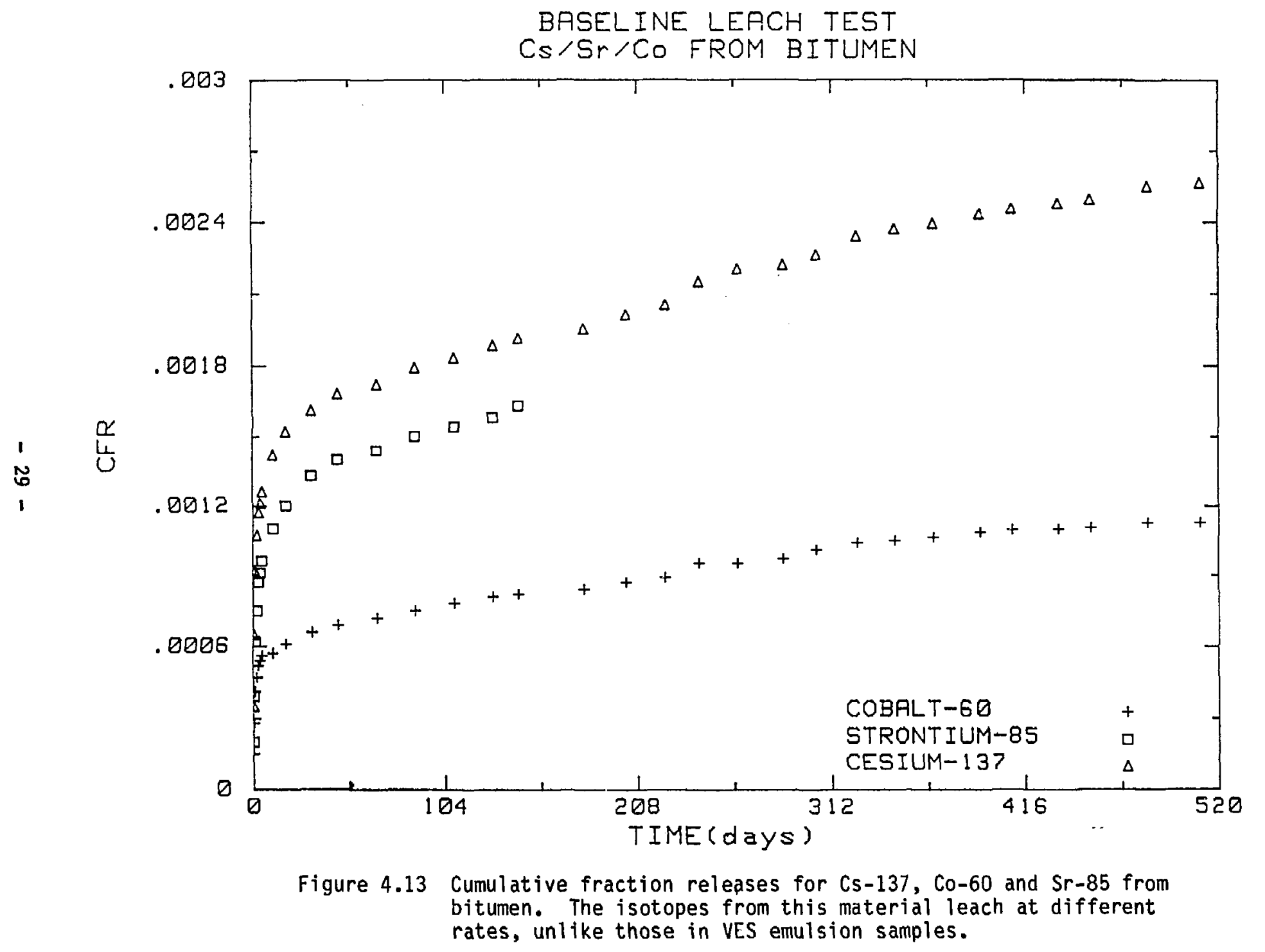


Cumulative fraction released of Cs-137 from triplicate samples are shown in Figure 4.14 and the release rates for those samples are shown in Figure 4.15. Figures 4.16 and 4.17 show CFR and release rates for Sr-85, respective$1 y$, while Figures 4.18 and 4.19 show this information for Co-60.

Analysis of the scatter of the triplicate samples at the final sampling interval gave a standard deviation of $0.002 \%$ of the total activity for Cs-137, $0.003 \%$ for $\mathrm{Sr}-85$ at 109 days and $0.002 \%$ for $\mathrm{Co}-60$.

4.2.4 Vinyl Ester-Styrene/Dry Waste. Leach tests were conducted on VES samples that were produced as a solid block of polymer, not as an emulsion. Results, however, are not shown because release rates were so low that the isotopes were not detected in the leachate. In later sections of this report results will be discussed for samples made of this material plus sulfate salts. As a means of comparison, the estimated detection limit will be used as a maximum value for the baseline.

Comparisons of the cumulative fraction releases of Cs-137 from portland cement, bitumen and VES emulsion are shown in Figure 4.20. Release of Cs-137 from cement are high and approach $100 \%$ after 510 days. Bitumen and VES release this isotope much slower, by a factor of more than 200 . Strontium-85 releases from cement are also higher than those from bitumen and VES, but only by a factor of 20 for the 144 day period during which it could be followed.

\subsection{Leaching of Solidification Agent Components}

For each triplicate set of samples, containing radioactive tracers, another sample without tracers was also leached. These "Blanks" were used for solid phase analysis and their leachates were used for chemical analysis. These samples leached for 471 days. Analyses were performed according to Table 3.3.

4.3.1 ANS 16.1 Leachate Analysis. Results of chemical analyses on cement leachates are given in Table 4.2 , through sampling interval 25, giving leaching data for one year. Leachates from bitumen and VES samples were "spot checked" for these element. None were found to have concentrations above detection limits. VES and bitumen were also analyzed for Total Organic Carbon $(T O C)$. In the case of both materials TOC was found to be below $1.5 \mathrm{ppm}$, indicating that mass loss due to matrix dissolution is insignificant. In cement leachates, as well as those from VES and bitumen samples, Fe, Mg and Cs were below detection limits. Conductance was measured in leachates of the blank samples and results are shown in Table 4.3.

4.3.2 Solubility Considerations. Another type of leach test was used to determine solubility limits of various components of the cement. It was based on the MCC-3 Agitated Powder Leach test in which pulverized samples are allowed to leach without changing the leachant. Samples were withdrawn and passed through a $0.2 \mu \mathrm{m}$ filter. 


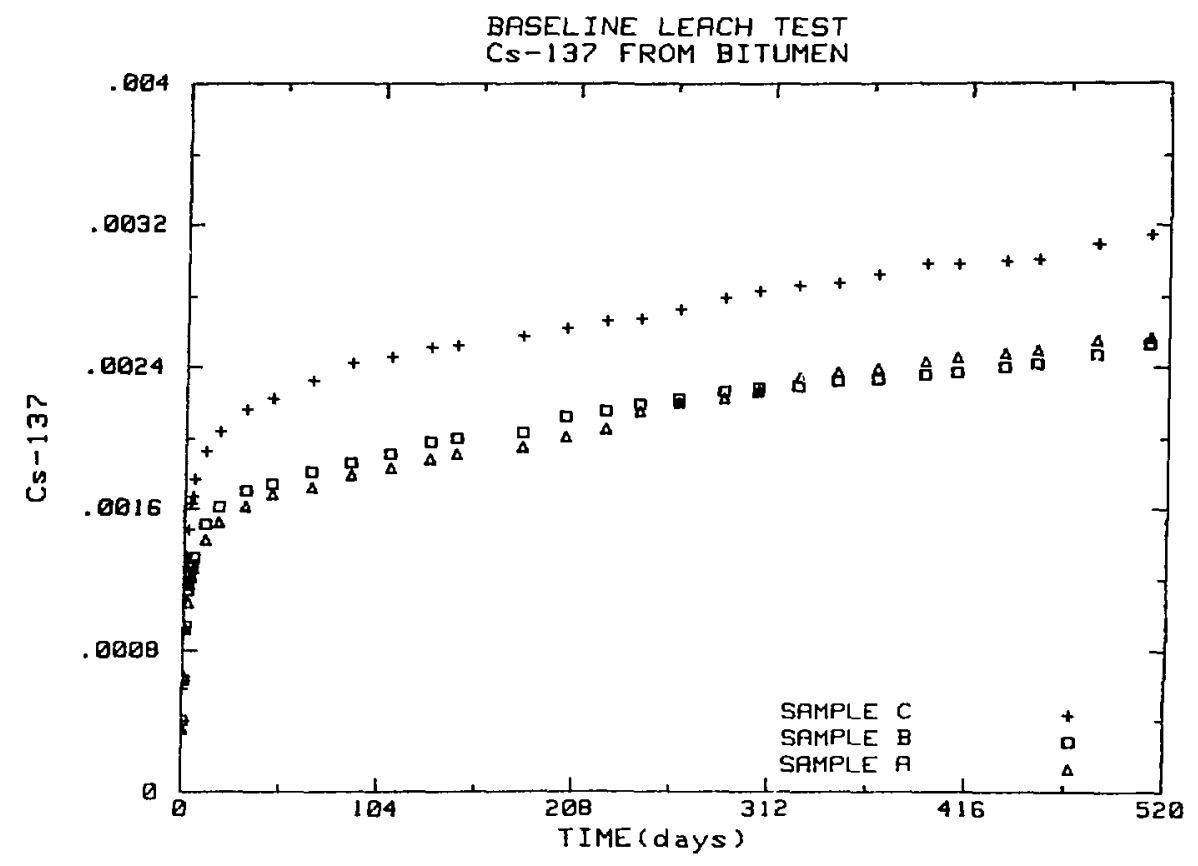

Figure 4.14 Cumulative fraction releases of Cs-137 from triplicate bitumen waste forms. Note the scale of the $y$-axis indicating that intersample variability is quite small.

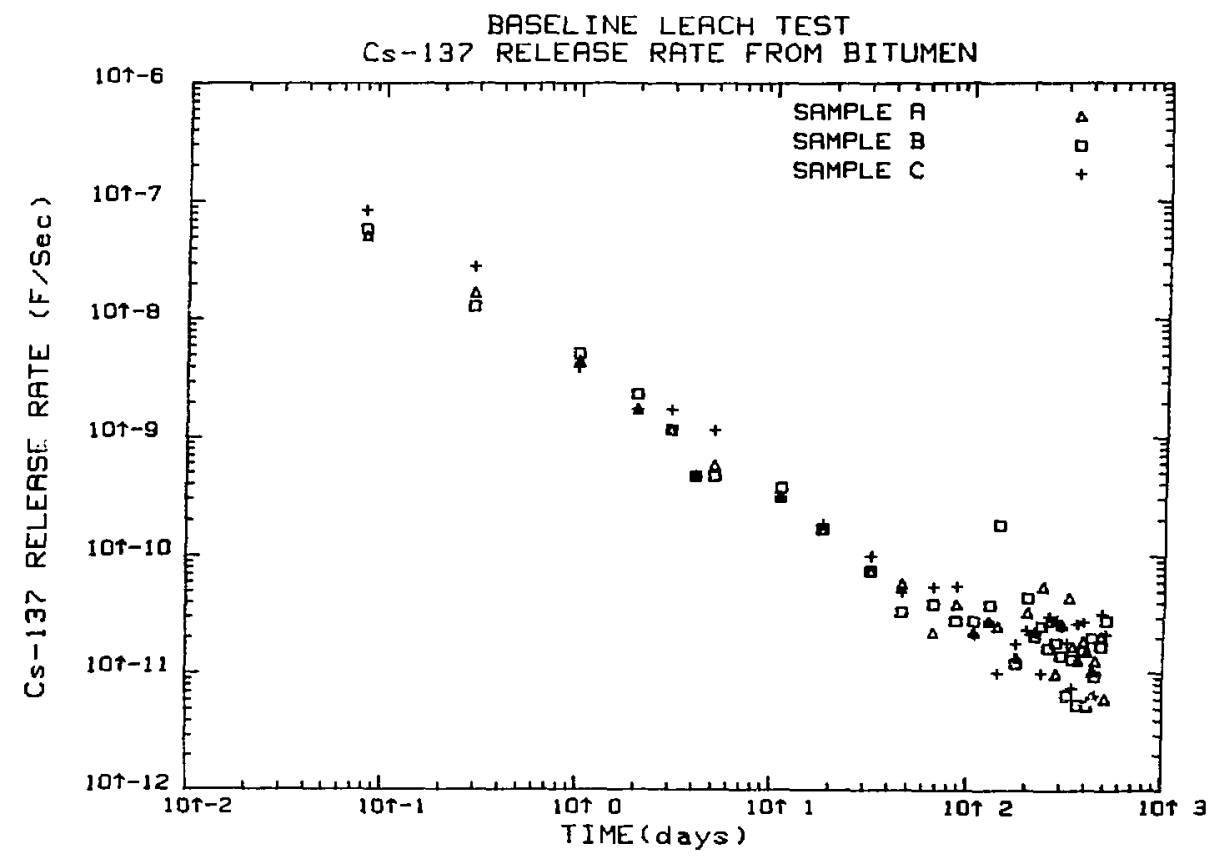

Figure 4.15 Release rates of Cs-137 from triplicate bitumen samples. 


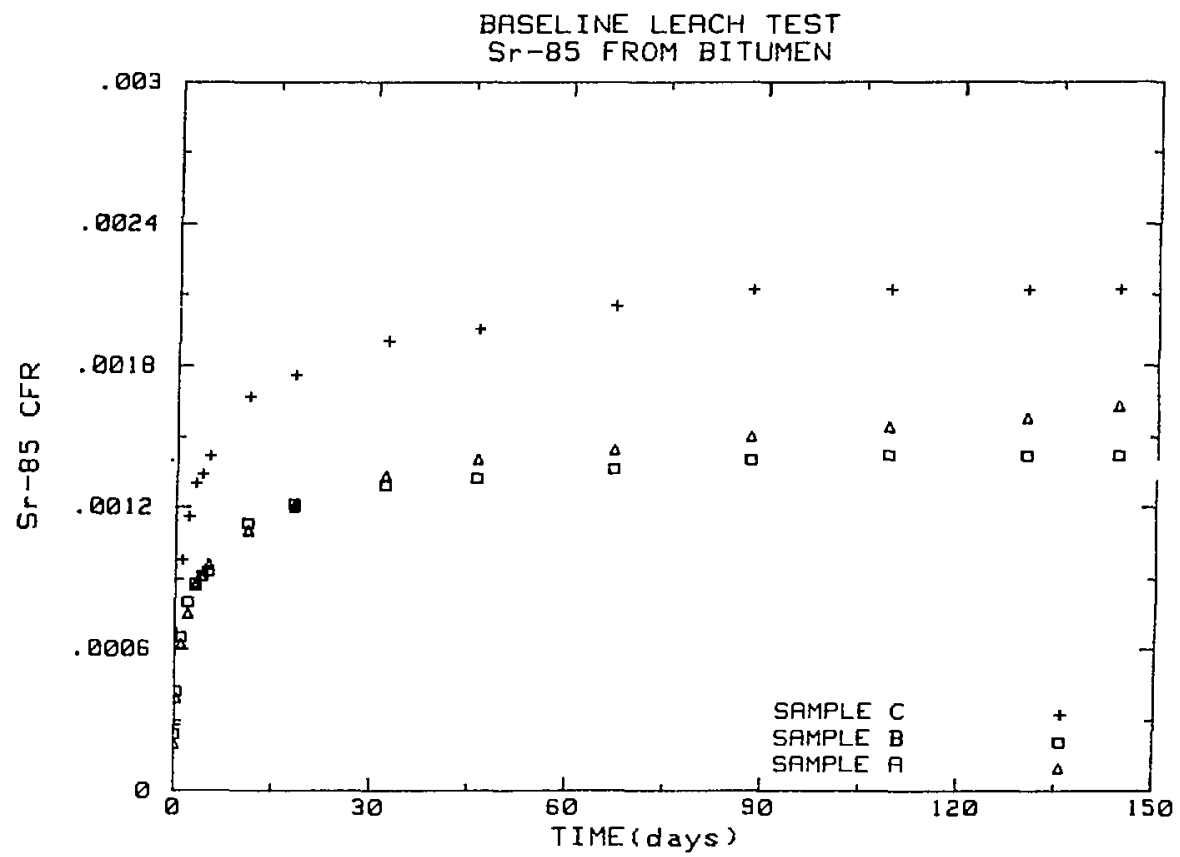

Figure 4.16 Cumulative fraction releases of $\mathrm{Sr}-85$ for triplicate bitumen samples.

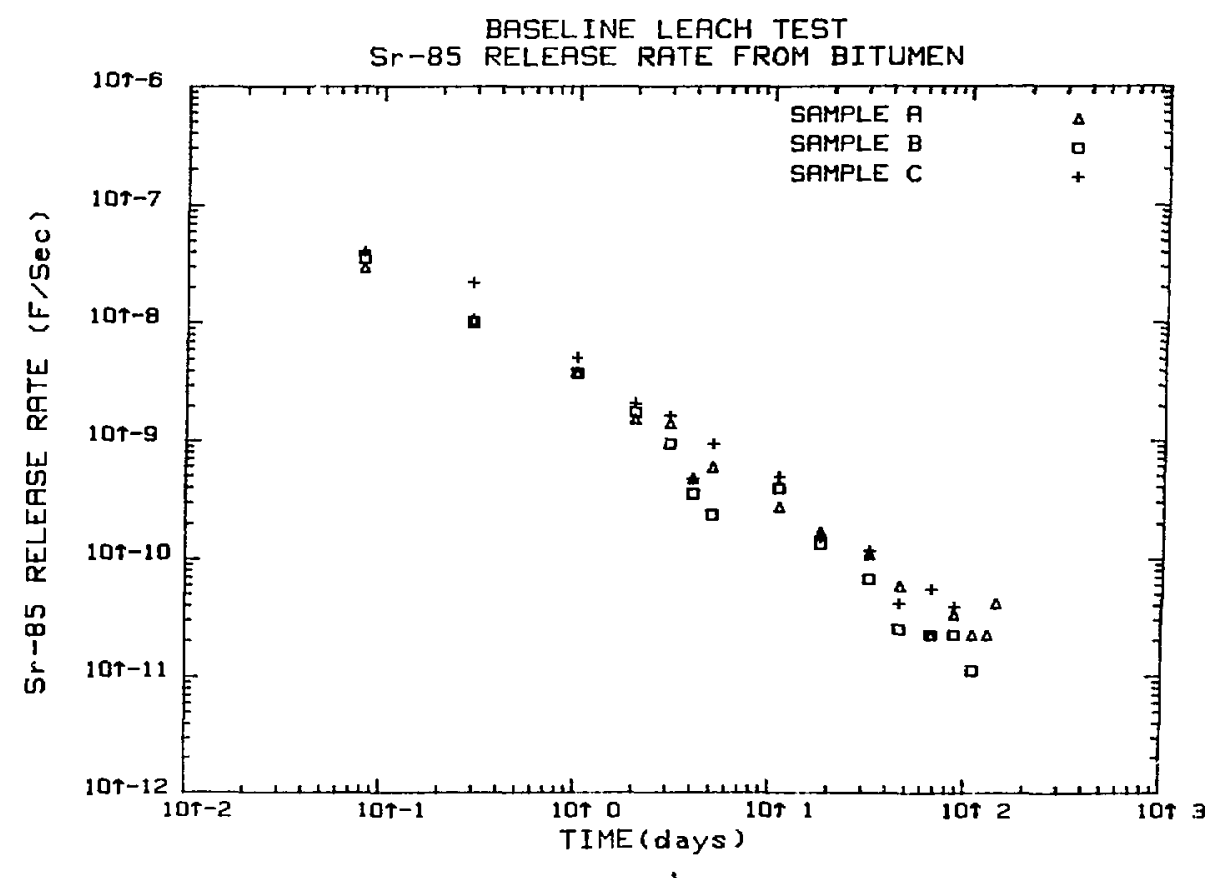

Figure 4.17 Release rates of $\mathrm{Sr}-\stackrel{8}{8}$ for triplicate bitumen samples. 


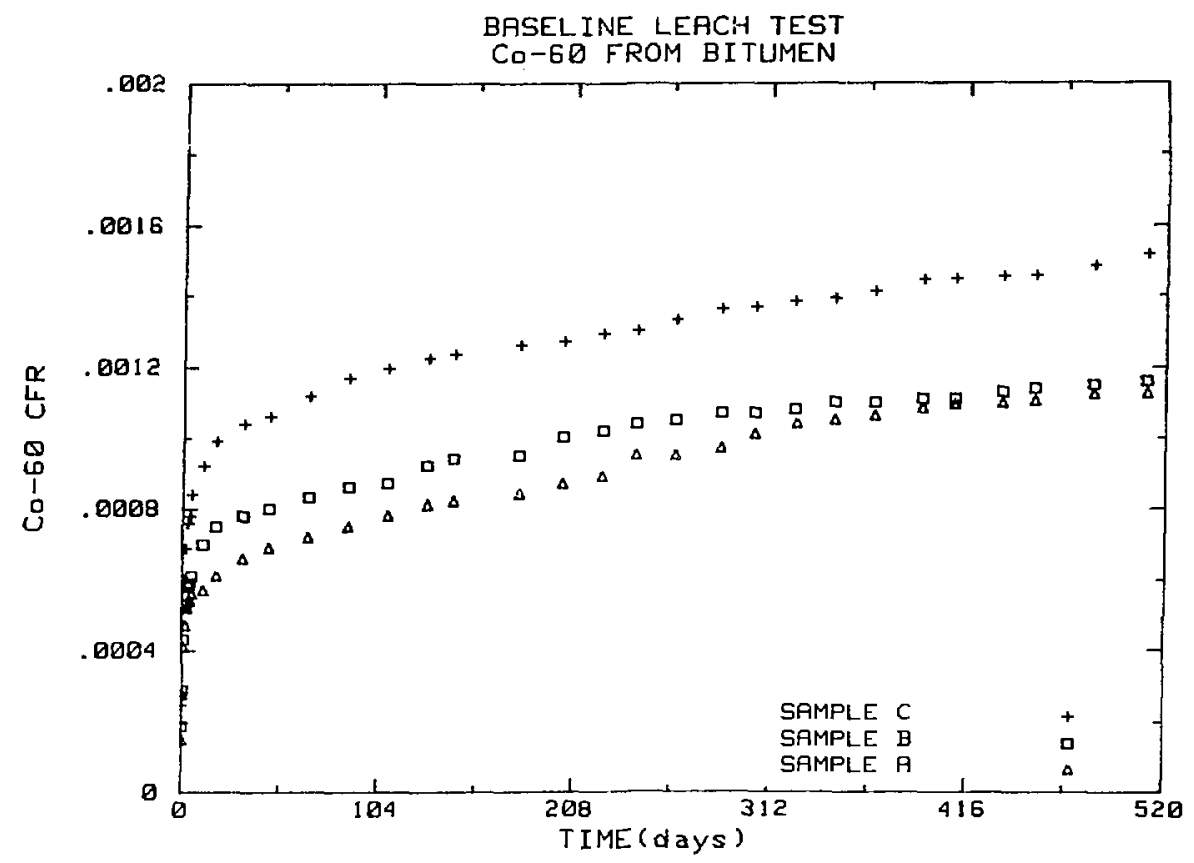

Figure 4.18 Cumulative fraction releases of Co-60 from triplicate bitumen waste forms. Note the scale of the $y$-axis.

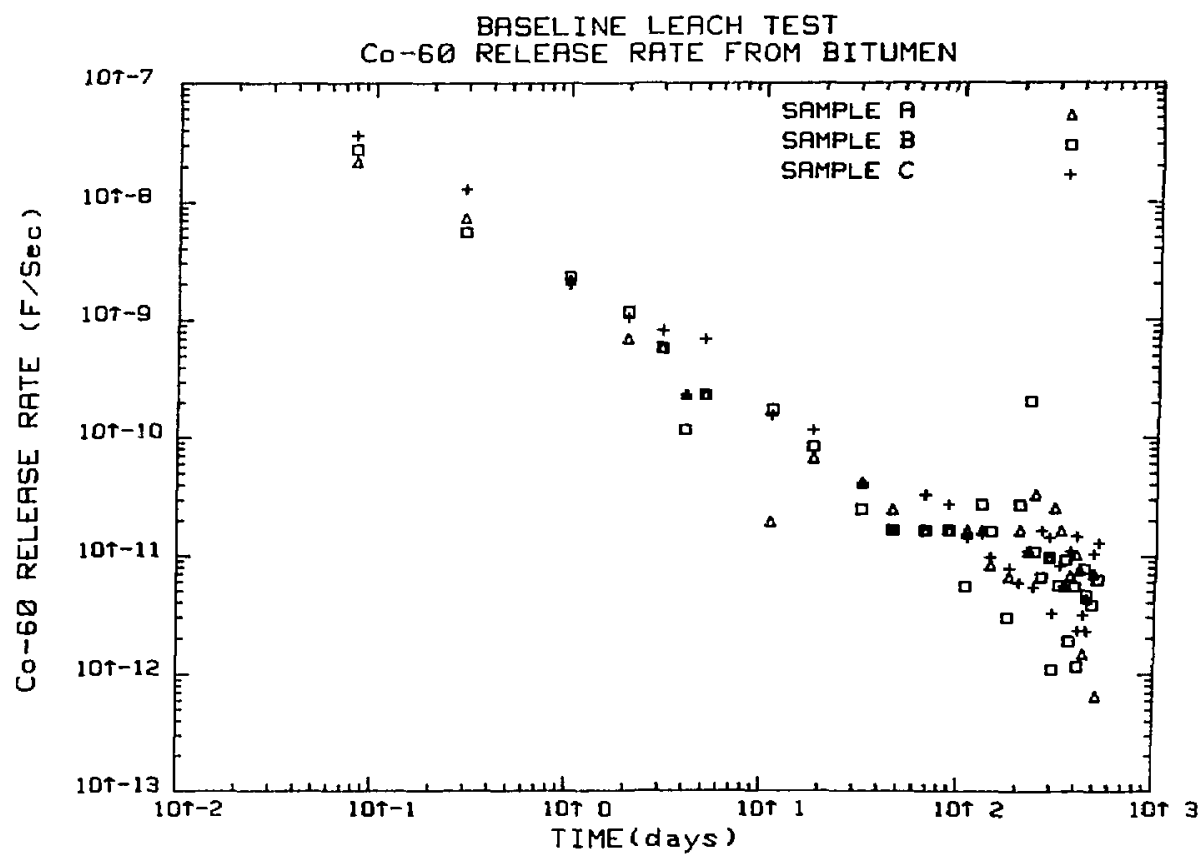

Figure 4.19 Release rates of Co-60 from triplicate bitumen samples. The scatter at the bottom right is due to large counting errors caused by low release rates. 


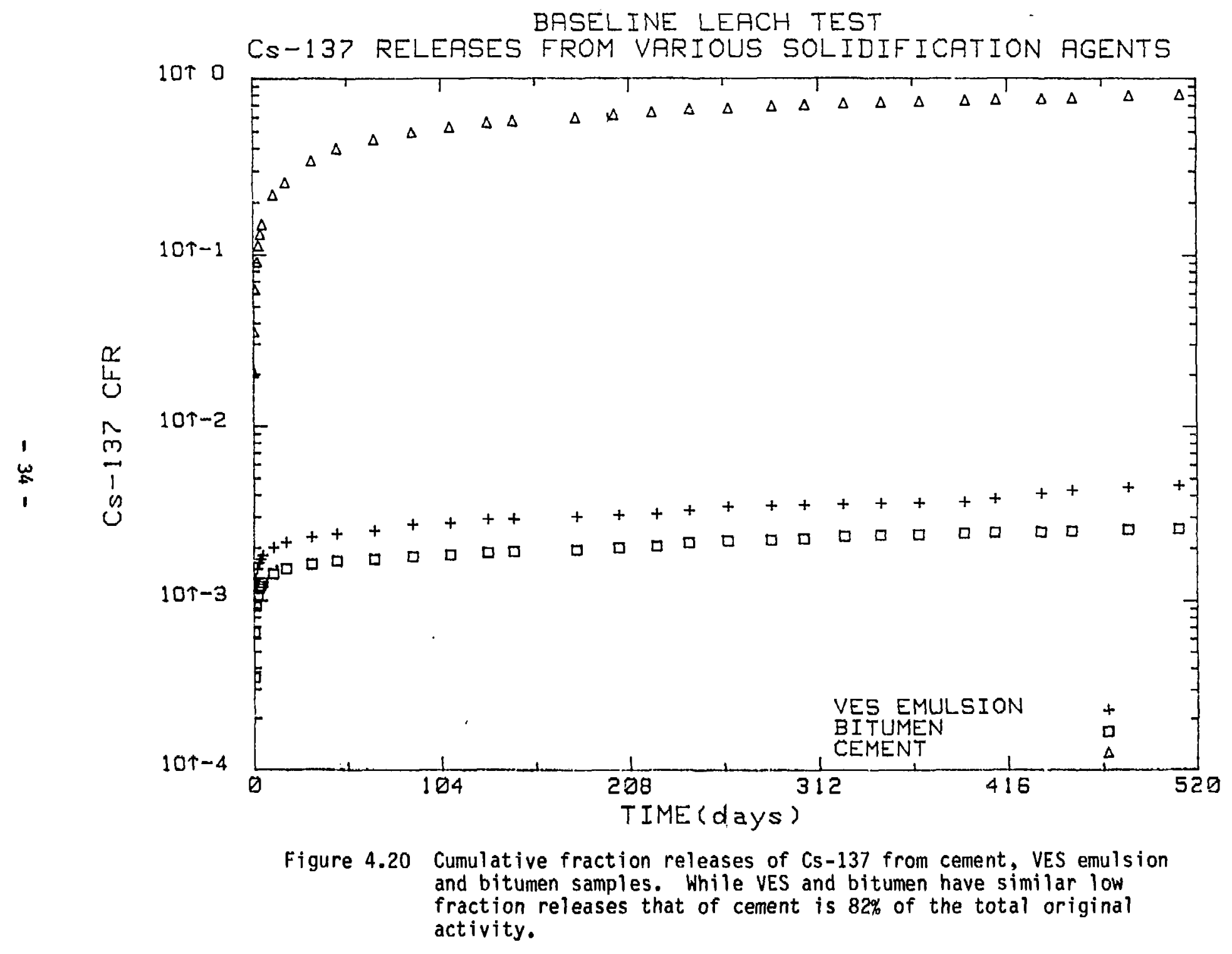


Baseline Leaching Experiments

Elemental Analysis of Portland Cement Leachate

Time (days) Int. $\underline{\mathrm{Ca}(\mathrm{ppm})} \underline{\mathrm{Si}(\mathrm{ppm})} \underline{\mathrm{Al}(\mathrm{ppm})} \underline{\mathrm{Na}(\mathrm{ppm})} \underline{\mathrm{K}(\mathrm{ppm})} \underline{\operatorname{Sr}(\mathrm{ppm})} \underline{\text { Alkal inity }}$

$\begin{array}{rrlllllll}0.00 & \mathrm{R} & 11 & \mathrm{DL} & \mathrm{DL} & 0.7 & 2.6 & \mathrm{DL} & \mathrm{DL} \\ 0.08 & 1 & 25 & \mathrm{DL} & \mathrm{DL} & 2.5 & 8.9 & 0.5 & 0.02 \\ 0.29 & 2 & 60 & \mathrm{DL} & \mathrm{DL} & 2.7 & 9.3 & 0.7 & 0.04 \\ 1.0 & 3 & 78 & \mathrm{DL} & \mathrm{DL} & 5.2 & 20 & 1.1 & 0.10 \\ 2.0 & 4 & 99 & \mathrm{DL} & 0.7 & 6.3 & 23 & 1.2 & 0.10 \\ 3.0 & 5 & 59 & 1.5 & 0.6 & 4.2 & 18 & 0.8 & 0.07 \\ 4.0 & 6 & 61 & 1.6 & 0.6 & 4.6 & 17 & 0.9 & 0.07 \\ 5.0 & 7 & 54 & 1.5 & 0.6 & 4.5 & 17 & 0.8 & 0.05 \\ 11 & 8 & 112 & 1.2 & 1.2 & 15 & 71 & 2.5 & 0.14 \\ 18 & 9 & 98 & 2.8 & 1.4 & 11 & 49 & 2.0 & 0.11 \\ 32 & 10 & 59 & 2.8 & 1.2 & 7.6 & 26 & 1.3 & 0.07 \\ 46 & 11 & 57 & 2.6 & 1.3 & 11 & 41 & 1.6 & 0.08 \\ 67 & 12 & 42 & 2.3 & 1.2 & 12 & 47 & 1.5 & 0.06 \\ 92 & 13 & 32 & 2.6 & 1.4 & 1.8 & 39 & 1.3 & 0.06 \\ 102 & 14 & 33 & 2.5 & 1.1 & 3.7 & 12 & 0.9 & 0.04 \\ 137 & 15 & 4.1 & - & 1.1 & 7.1 & 11 & 1.9 & - \\ 161 & 16 & 56 & - & 1.2 & 4.5 & 6.2 & 2.2 & - \\ 181 & 17 & 14 & - & 0.9 & 4.5 & 6.2 & 2.4 & - \\ 202 & 18 & 2.1 & - & 0.7 & 4.2 & 6.0 & 1.2 & - \\ 223 & 19 & 33 & - & 1.3 & 4.3 & 6.1 & 3.2 & - \\ 244 & 20 & 17 & - & 1.0 & 3.9 & 5.9 & 2.0 & - \\ 265 & 21 & 19 & - & 0.7 & 2.9 & 4.1 & 2.4 & - \\ 289 & 22 & 30 & - & 1.4 & 3.4 & 4.8 & 2.1 & - \\ 307 & 23 & 3.8 & - & 0.8 & 2.4 & 3.2 & 1.9 & - \\ 328 & 24 & 32 & - & 1.4 & 2.9 & 3.6 & 2.7 & - \\ 353 & 25 & 20 & - & 1.3 & 3.4 & 3.8 & 2.2 & -\end{array}$

1. As meq of $\mathrm{CaCO}_{3}$. 
Baseline Leaching Experiments

Conductance $(\mu \mathrm{mhos} / \mathrm{cm})$ Analysis of Leachates

\begin{tabular}{|c|c|c|c|c|c|}
\hline $\begin{array}{l}\text { Time } \\
\text { (days) } \\
\end{array}$ & Interval & Cement & Bitumen & $\begin{array}{c}\text { VES } \\
\text { Emulsion } \\
\end{array}$ & $\begin{array}{l}\text { VES } \\
\text { Dry } \\
\end{array}$ \\
\hline 0.00 & Rinse & 17 & 4.05 & 0.08 & 1.70 \\
\hline 0.08 & 1 & 60 & 0.15 & 0.17 & 0.13 \\
\hline 0.29 & 2 & 90 & - & 2.26 & 1.55 \\
\hline 1.0 & 3 & 510 & 1.53 & 1.84 & 1.53 \\
\hline 2.0 & 4 & 800 & 1.95 & 1.84 & 1.50 \\
\hline 3.0 & 5 & 110 & 1.80 & 1.86 & 1.52 \\
\hline 4.0 & 6 & 280 & 1.75 & 1.63 & 1.51 \\
\hline 5.0 & 7 & 160 & 1.67 & 1.85 & 1.42 \\
\hline 11 & 8 & 1100 & 0.14 & 0.17 & 0.14 \\
\hline 18 & 9 & 720 & 2.04 & 3.28 & 1.52 \\
\hline 32 & 10 & 360 & 1.87 & 4.02 & 1.52 \\
\hline 46 & 11 & 470 & 1.22 & 1.13 & 1.00 \\
\hline 67 & 12 & 240 & 3.77 & 2.45 & 1.32 \\
\hline 92 & 13 & - & 0.12 & 0.18 & 0.17 \\
\hline 137 & 15 & 69 & 0.77 & 1.20 & 1.10 \\
\hline 102 & 14 & 95 & 2.08 & 1.39 & 2.31 \\
\hline 161 & 16 & - & 1.18 & 1.21 & 1.08 \\
\hline 181 & 17 & 70 & 1.31 & 1.11 & 1.27 \\
\hline 202 & 18 & 110 & 1.22 & 1.23 & 88.0 \\
\hline 223 & 19 & - & 3.52 & 3.34 & 3.0 \\
\hline 244 & 20 & 78 & 1.11 & 1.11 & 1.17 \\
\hline 265 & 21 & 94 & 1.28 & 1.18 & 1.25 \\
\hline 289 & 22 & - & 1.42 & 1.38 & 1.32 \\
\hline 307 & 23 & 110 & 0.18 & 1.03 & 0.98 \\
\hline 328 & 24 & 230 & 2.08 & 1.18 & 1.11 \\
\hline 353 & 25 & 160 & 1.21 & 1.20 & 1.07 \\
\hline 370 & 26 & 65 & 2.18 & 2.30 & 1.84 \\
\hline 395 & 27 & 170 & 1.05 & 1.41 & 82.0 \\
\hline 412 & 28 & 240 & 1.10 & 1.46 & 1.86 \\
\hline 442 & 29 & 170 & 5.28 & 0.97 & 1.13 \\
\hline 471 & 30 & 350 & 1.20 & 2.68 & 1.12 \\
\hline
\end{tabular}


Results are shown in Table 4.4. Elemental concentrations in leachates from the MCC-3 tests were compared to those from the modified ANS 16.1 tests to determine the degree of chemical saturation achieved in the ANS 16.1 samples. The highest concentrations, in the baseline tests, relative to saturation were: $16 \%$ for $\mathrm{Ca}, 11.7 \%$ for $\mathrm{Na}, 10.8 \%$ for $\mathrm{K}, 4.1 \%$ for $\mathrm{Sr}$ and $11.7 \%$ for conductance.

Concentrations of both $\mathrm{Si}$ and $\mathrm{Al}$ were significantly higher in the ANS 16.1 leachates than in those from the MCC-3 tests, in which these elements were below detection limits. Increased alkalinity in the MCC-3 leachates may have reduced the solubility of these elements relative to those of the ANS 16.1 tests or a back reaction may have reprecipitated $A 1$ and $S i$ onto the solid sample.

Mass losses, after one year of leaching, of the most soluble elements in the cement are shown in Table 4.5. The masses of the elements in the waste form were calculated from acid digests of the cement powder. Most of the sodium was released after one year while only a small percentage of the calcium was lost. However, since calcium comprises a large part of the cement itself, it accounted for the largest mass loss.

Table 4.5

Percentage of Elements Leached After One Year From Portland Cement

$\begin{array}{ccccc}\text { Element } & \begin{array}{c}\text { Concentration } \\ \text { in Cement } \\ (\mathrm{mg} / \mathrm{g})\end{array} & \begin{array}{c}\text { Total in } \\ \text { Waste Form } \\ (\mathrm{g})\end{array} & \begin{array}{c}\text { Total } \\ \text { Leached } \\ (\mathrm{g})\end{array} & \% \text { Removed } \\ \mathrm{Ca} & 419 & 58.7 & 1.38 & 2.4 \\ \mathrm{Sr} & 2.10 & 0.294 & 0.054 & 18.4 \\ \mathrm{Na} & 2.26 & 0.315 & 0.190 & 60.3 \\ \mathrm{~K} & 14.3 & 2.00 & 0.600 & 30.0\end{array}$

4.3.3 Statistical Correlations. A statistical comparison of radionuclides and components of cement in the leachate, for the first fifteen sampling intervals of the baseline experiment, is shown in Table 4.6. This is a correlation matrix which, in this case, indicates how closely the leaching behavior of various dissolved species are associated. The values given are the correlation coefficients obtained when linear regression analysis is applied to a comparison of any two species 1isted. These comparisons can best be illustrated by a graph where the leachate concentration of one specie is plotted against the leachate concentration of another, as in Figure 4.21 for 
Table 4.4

Baseline Leaching Experiments

MCC -3 Agitated Powder Test for Saturation Limits

\begin{tabular}{|c|c|c|c|c|c|c|c|c|c|c|}
\hline Time & $\underline{\mathrm{Ca}(\mathrm{ppm})}$ & $\underline{S i(p p m)^{\perp}}$ & $\mathrm{Al}^{(\mathrm{ppm})^{2}}$ & $\underline{\mathrm{Na}(p p m)}$ & $K(p p m)$ & $\underline{S r}-(\mathrm{ppm})$ & $\underline{\mathrm{Cs}(p p m)^{3}}$ & $\underline{\operatorname{Mg}(p p m)^{4}}$ & Alkalinity 5 & $\begin{array}{l}\text { Conduct ance } \\
(\mu \text { mhos } / \mathrm{cm}) \\
\end{array}$ \\
\hline 1 & 730 & $\mathrm{DL}$ & $\mathrm{DL}$ & 129 & 215 & 58 & $\mathrm{DL}$ & $\mathrm{DL}$ & 1.10 & 9340 \\
\hline 2 & 695 & $\mathrm{DL}$ & $\mathrm{DL}$ & 130 & 215 & 61 & $\mathrm{DL}$ & $\mathrm{DL}$ & $1.0 i^{\circ}$ & 9320 \\
\hline 3 & 690 & $\mathrm{DL}$ & DL & 131 & 214 & 63 & $\mathrm{DL}$ & $\mathrm{DL}$ & 1.05 & 9760 \\
\hline 4 & 670 & $\mathrm{DL}$ & $\mathrm{DL}$ & 133 & 218 & - & $\mathrm{DL}$ & DL & 1.06 & 9100 \\
\hline
\end{tabular}

1. Detection limit for $S i=1.0 \mathrm{ppm}$.

2. Detection limit for $A 1=0.6 \mathrm{ppm}$.

3. Detection limit for $\mathrm{Cs}_{\mathrm{s}}=0.4 \mathrm{ppm}$.

4. Detection limit for $\mathrm{Mg}=0.5 \mathrm{ppm}$.

5. Results reported as $\mathrm{mg} \cdot \mathrm{CaCO}_{3} / \mathrm{ml}$. 


\section{Table 4.6}

Baseline Leaching Experiments

Correlation Matrix (R) of Elemental Releases From Portland Cement Leached at $20^{\circ} \mathrm{C}$

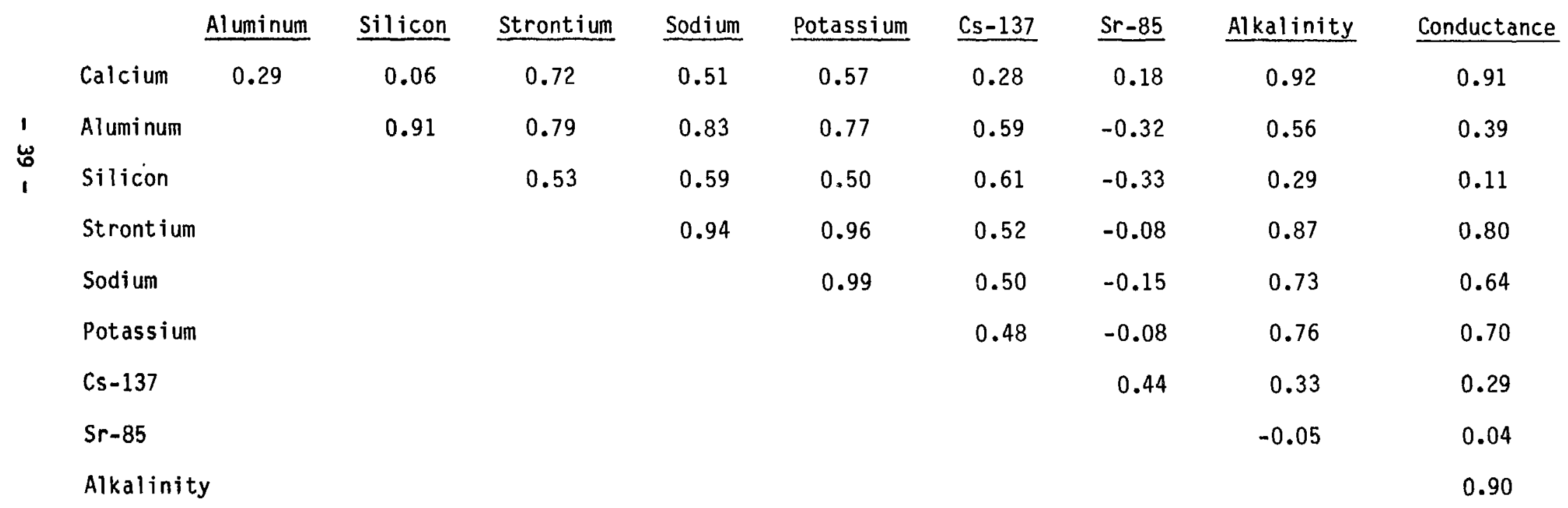




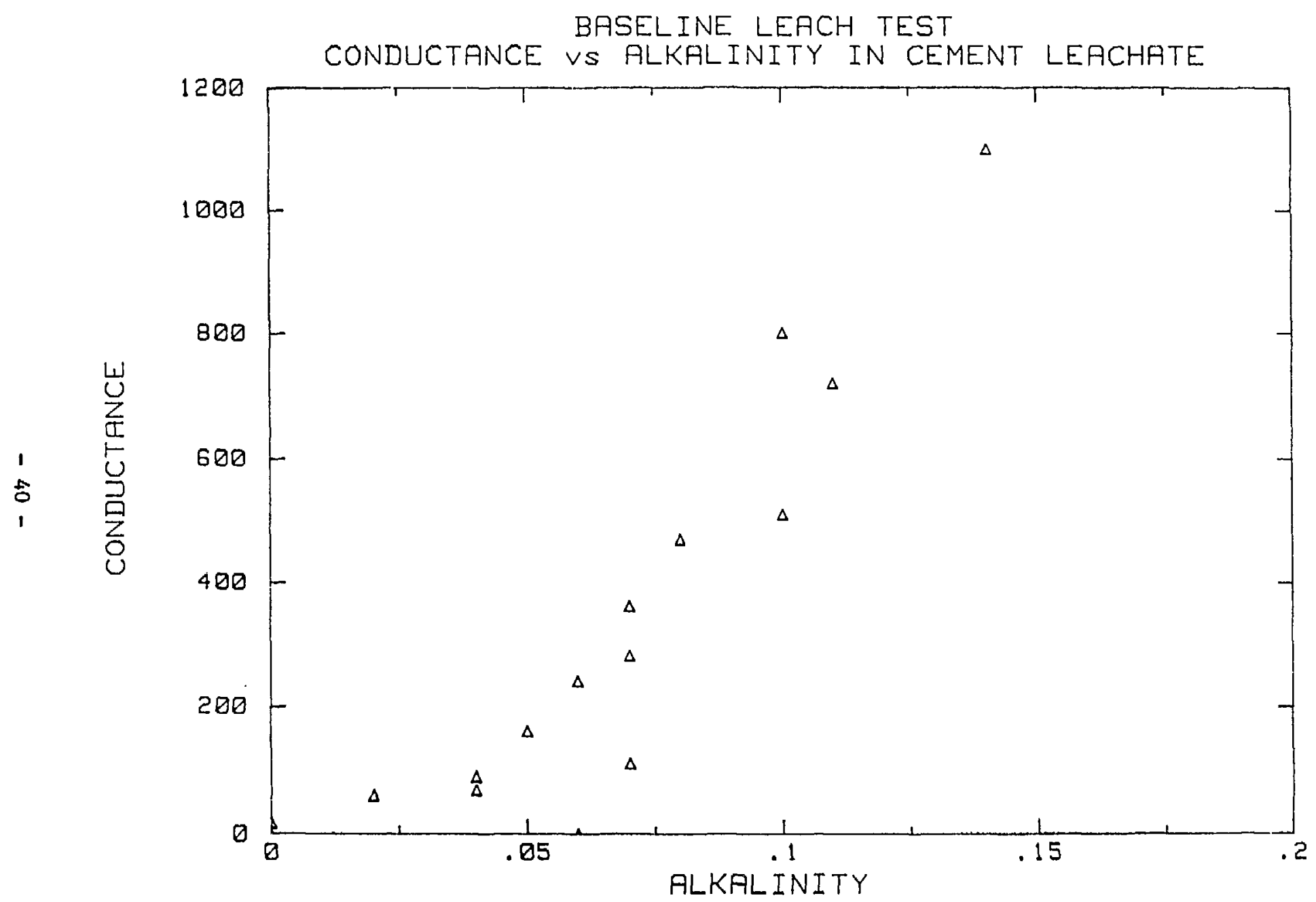

Figure 4.21 Plot of conductance (umhos/cm) versus alkalinity (as $\mathrm{mgCaCO}_{3} / \mathrm{L}$ ) for portland cement leachates. 
alkalinity plotted against conductance. If the points fall in a linear manner, as they do in Figure 4.21 , a good correlation between the two species plotted is indicated. The correlation coefficient (R) approaches 1 as the correlation between the two species improves. For Figure $4.21, R=0.90$ which can be found in Table 4.6 at the intersection of the conductance column and the alkalinity row. For purposes of this analysis a correlation coefficient of 0.85 or greater is considered to be significant.

Correlation coefficients that show significant relationships as determined in this study are:

$\mathrm{Al} / \mathrm{Si}=0.91, \mathrm{Na} / \mathrm{Sr}=0.94, \mathrm{~K} / \mathrm{Sr}=0.96, \mathrm{~K} / \mathrm{Na}=0.99, \mathrm{Sr} / \mathrm{alkal}$ inity $=$ 0.87 , alkalinity/Ca $=0.92$, conductance $/$ alkalinity $=0.90$ and conductance $/$ calcium $=0.91$.

It is particularly noteworthy that none of the radionuclides exhibit a correlation with any component of the cement matrix. Even $\mathrm{Sr}-85$, the radioactive tracer, has no relationship with leaching of the strontium or calcium from the cement itself. Moreover, the leaching behavior of Sr-85 does not appear to be controlled by the overall alkalinity or conductance of the leachate. This lack of correlation of radionuclide releases with those of the matrix elements implies that specific mechanisms governing releases of elements in the matrix material are different from those regulating releases of chemically similar elements added as radioactive tracers. For example, sodium, potassium and cesium should leach similarly since they are all alkali. However, no statistical correlation is seen between the leaching behavior of the $\mathrm{Cs}$ tracer and that of the $\mathrm{Na}$ and $\mathrm{K}$ from the matrix.

This may be explained by the chemical form in which these elements are held in the cement matrix. The sodium and potassium are present, in part, in minerals that formed at high temperatures when the cement clinker was fired. They need to pass into solution before leaching out of the waste form. The Cs-137 is probably present in solution in pore water so no dissolution step is required prior to leaching. This same mechanism, but involving different minerals with different solubilities, may also be used to explain differences in leaching among the various radionuclides.

\subsection{Solid Phase Analysis of Solidification Agent/Matrices}

Replicate waste forms from the baseline experiment were sectioned before and after leaching and were examined by Scanning Electron Microscope (SEM) and Energy Dispersive $X$-ray Analysis (EDAX) to determine physical and chemical changes due to leaching.

4.4.1 Portland Cement. Solidified portland cement is a multicomponent, multi-phase system of considerable variety and complexity as hydration occurs and new compounds form as the cement sets and cures. Chemical interactions in cement can go for years, so cement cannot be viewed as a static material. Changes can be dramatic if not well understood. 
The surface of a fresh cement sample, that had formed against the wall of a polyethylene container, is shown in Figures 4.22 and 4.23 at magnifications of 400 and 1900 times, respectively. To the eye, the sample was smooth and glazed by contact with the container. Never-the-less it is apparent from the micrographs that there is significant porosity. The smooth appearance resulted from relatively few areas where the setting gel took the shape of the container. Particularly in Figure 4.23 it is clear that cement consists of a myriad of particles that have grown together as hydration proceeds. Porosity in this material is tortuous and pores vary in diameter from about $10 \mu \mathrm{m}$ downward.

The chemistry of this material is best examined with EDAX, for these purposes, over relatively large areas (10 $\mathrm{mm}^{2}$ ) to provide an averaging effect. This multi-phase material and the rough surfaces require that EDAX results be viewed as semi-quantitative and should be examined as ratios of elements, not as concentrations. Figure 4.24 is an EDAX spectrum of the outer surface of an unleached cement sample. Calcium and silicon predominate the composition but potassium, aluminum and sulfur are also present. Iron is only seen as a trace and sodium is undetected. The unlabeled peak between aluminum and sodium is magnesium.

After leaching for 471 days the cement sample had undergone significant changes. For example, in one year it had lost $2.4 \%$ of its total calcium (see Table 4.5). Other changes had also occurred throughout the waste form. A reaction rim had formed along the outside surface of the waste form, as shown in Figure 4.25. This is pictured in Figure 4.26 from a sectioned waste form and shows a thin zone that has a different color and texture than the interior. From visual observation it appears to be approximately $1 \mathrm{~mm}$ thick. At magnification of 400 times (Figure 4.26) the cement surface appears to have become smoother and less porous than it was before leaching. This outer coating is shown in Figure 4.27 at a magnification of $1300 x$ at an oblique angle. It is very fine grained compared to an unleached sample. Chemical analysis of this layer by EDAX show that there are substantial chemical differences between the leached and unleached surfaces. Comparison of the spectrum of an unleached cement sample (Figure 4.24) with Figure 4.28 , which is a spectrum of the leached surface, shows that the less soluble elements, especially silicon, are relatively enriched. Conversely, the more soluble elements are relatively depleted. Calcium was substantially reduced and potassium was undetected. Sulfur, while still detected, was much diminished. Exact mineralogy of this surface remains to be determined by $x$-ray diffraction, but it is a distinctly altered zone characterized by depletion of the more soluble elements. Nevertheless, the remaining material filled in the original waste form surface to form what appears to be much less porous layer.

At the center of this same waste form the cement was unaffected by leaching. Comparing a spectrum (Figure 4.24) of unleached cement with one from the center of the leached waste form (Figure 4.29), there is little change noticeable except the sulfur peak is lower in the leached sample. of particular interest is that potassium is still present in the center of the leached sample even though $30 \%$ of the original mass of potassium had been leached out (Table 4.5). This element was below detection limits in the center of an an 


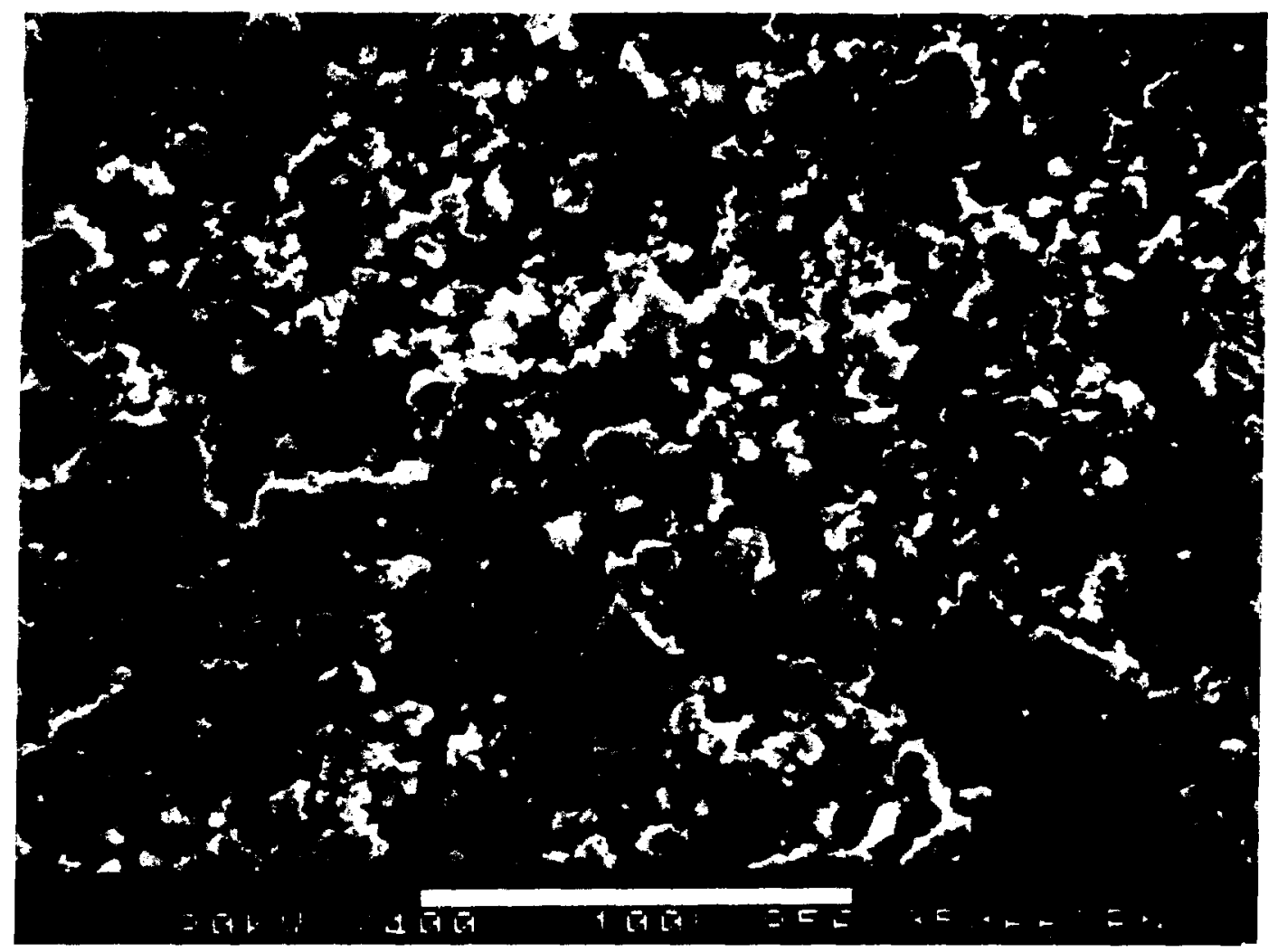

Figure 4.22 Surface of unleached portiland cement at a magnification of 400 times. 


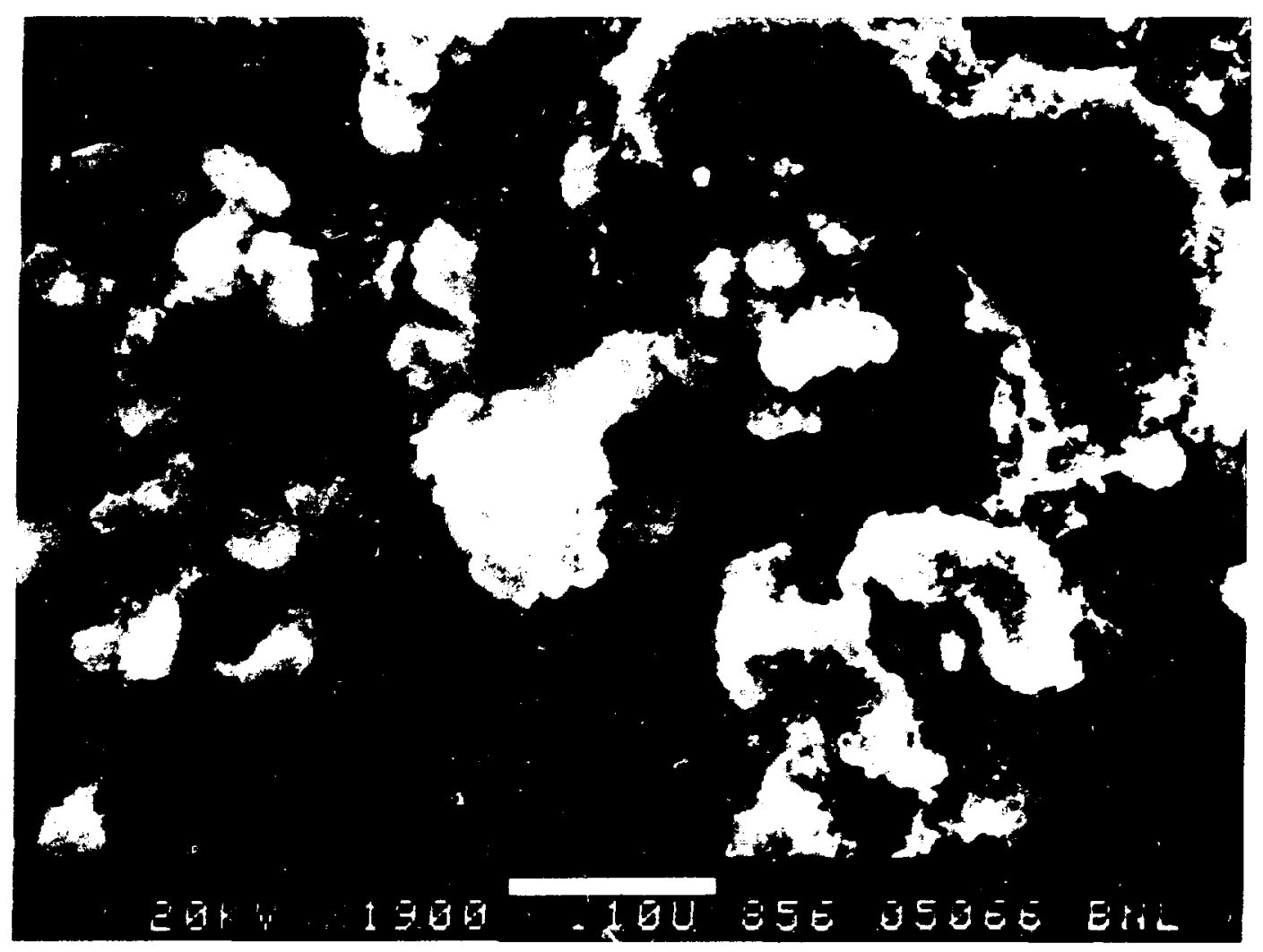

Figure 4.23 Surface of unleached portland cement at a magnification of 1900 times. Note the great porosity and granular texture of the material. 


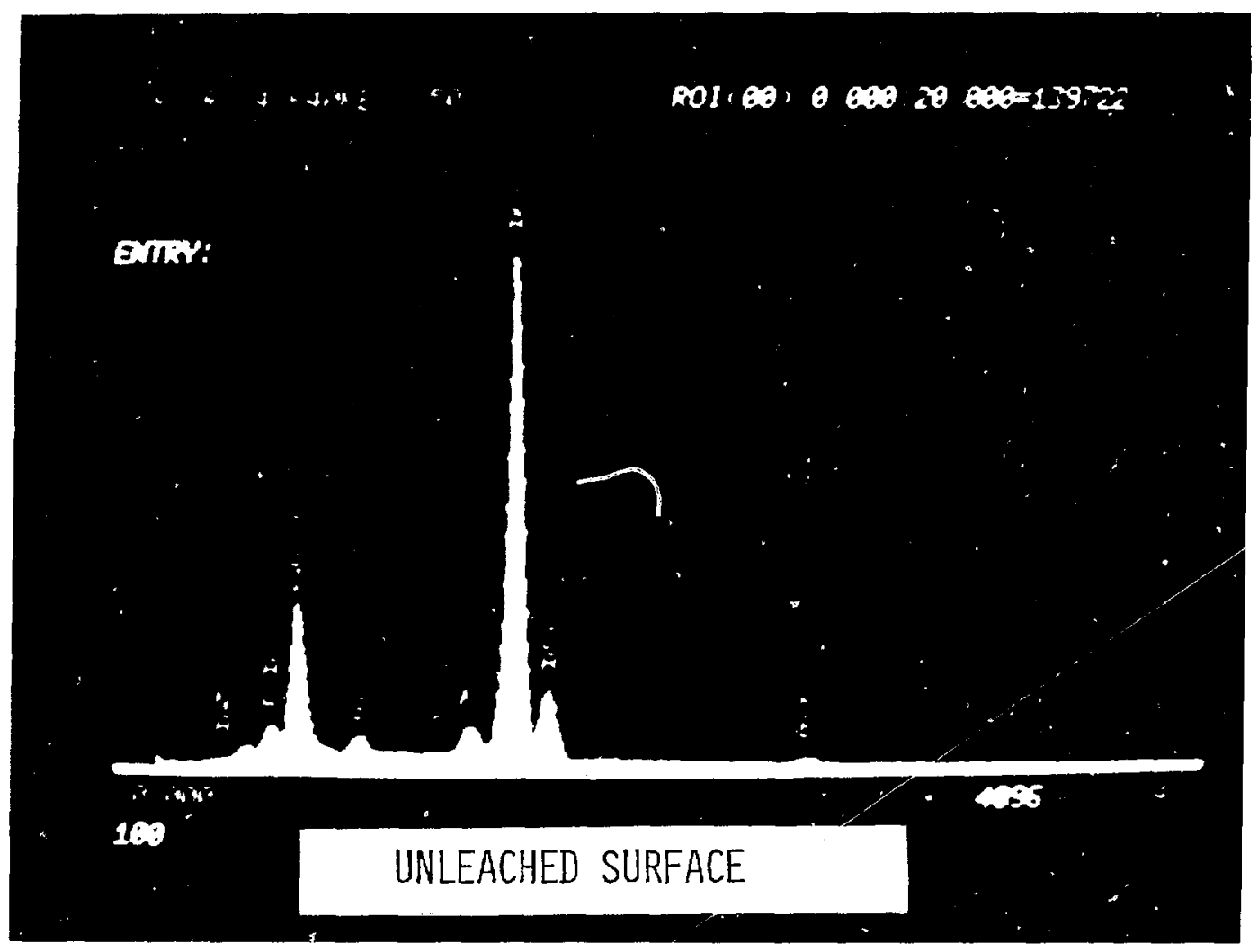

Figure 4.24 Spectrum of unleached cement surface. Note the presence of potassium (K) and the relative peak heights of calcium (Ca) and silicon (Si). 


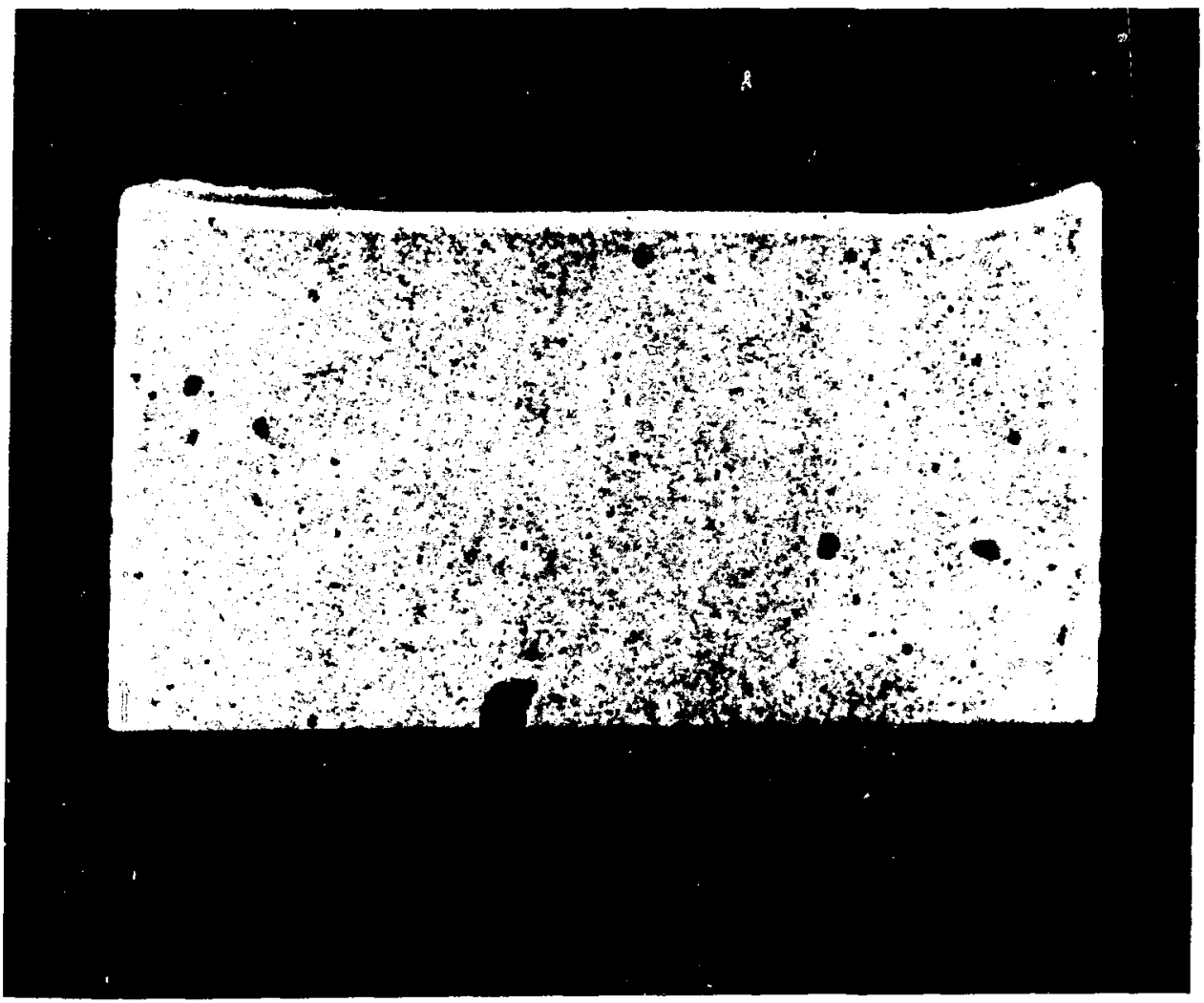

Figure 4.25 Part of a sectioned waste form after leaching for 471 days. Note the reaction rim around the top and sides which were exposed to water. 


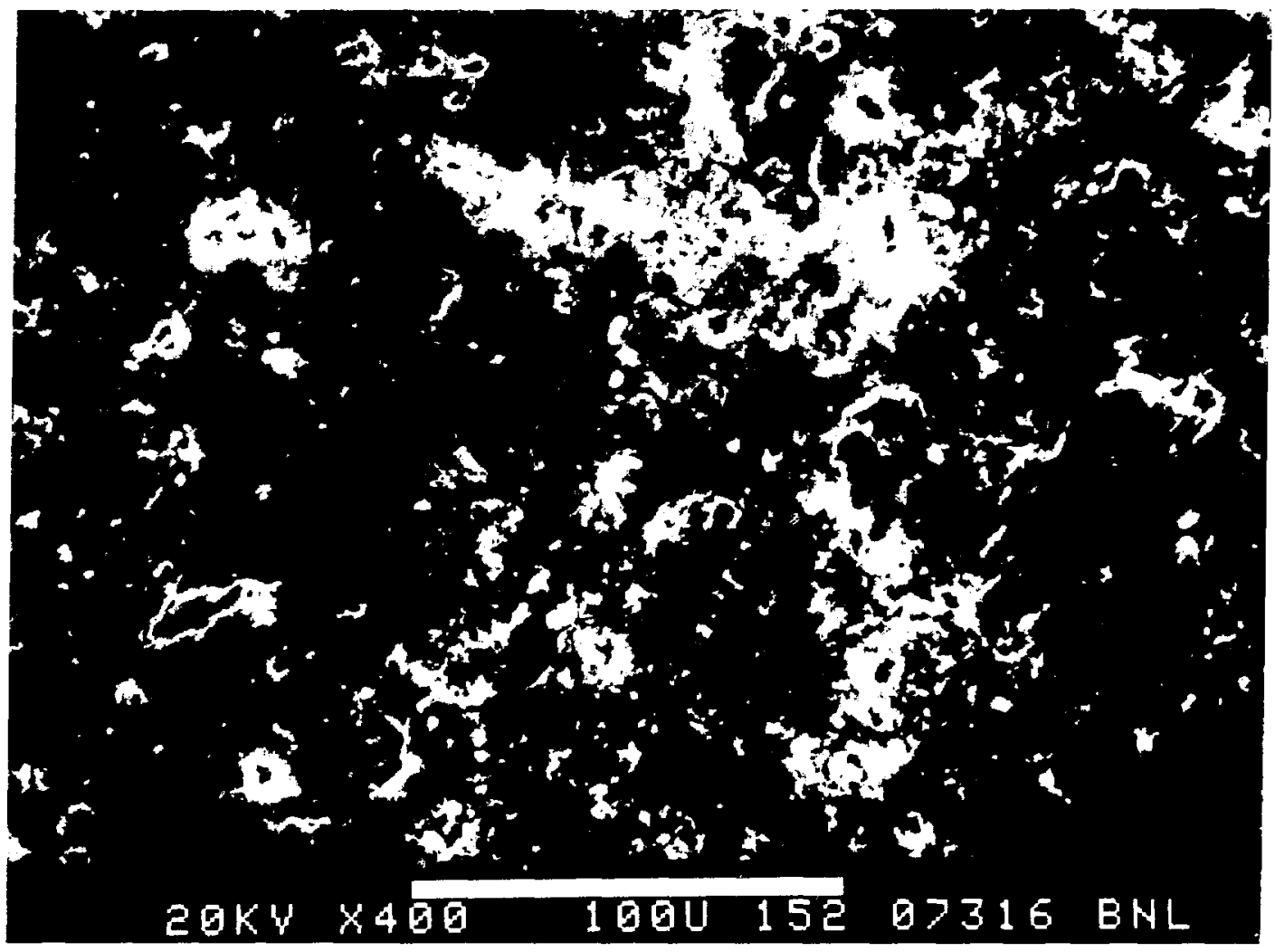

Figure 4.26 Outer slirface of a cement sample leached for 471 days. Compare this to Figure 4.21. The texture is much smoother and grain is finer. 


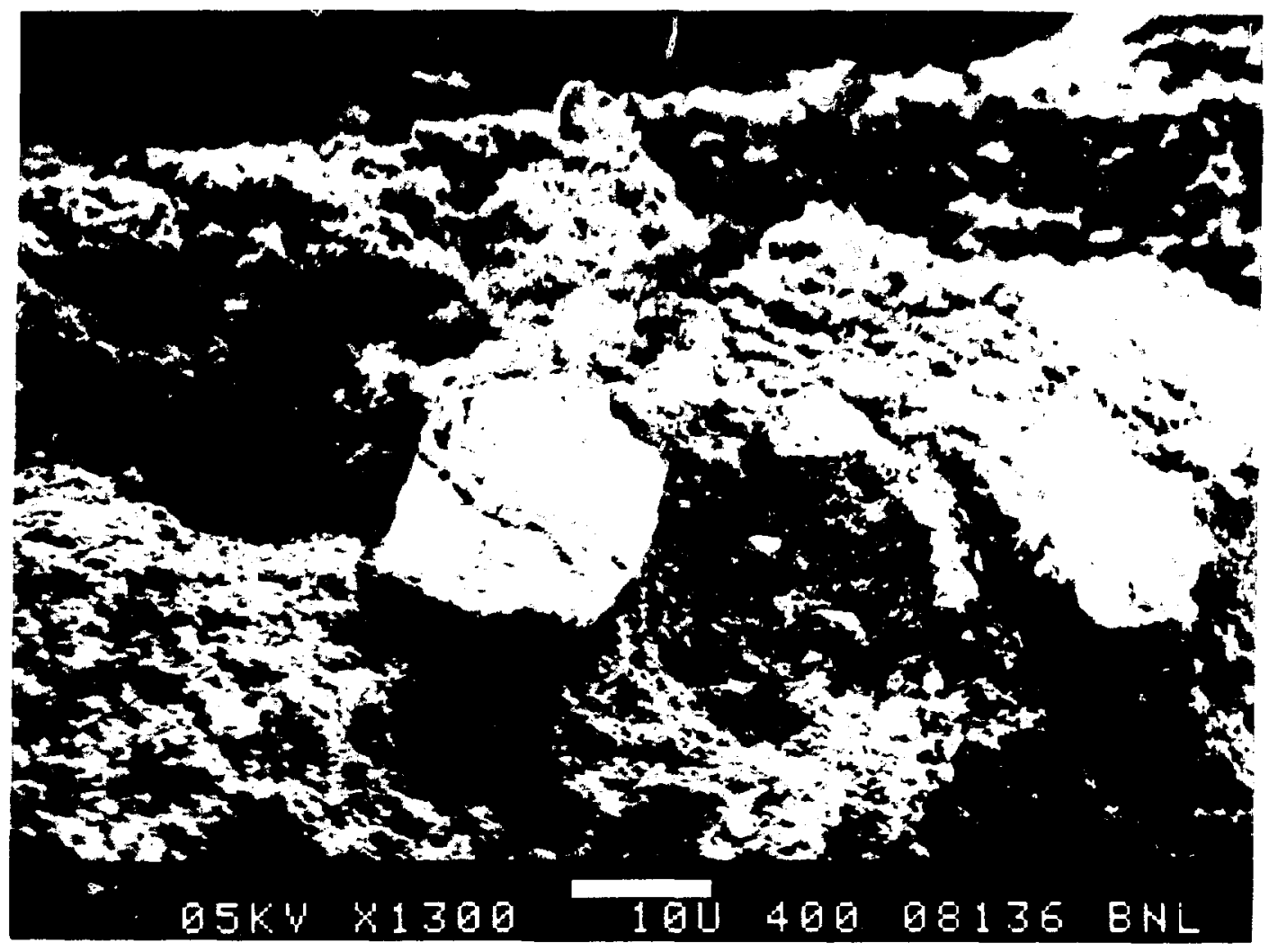

Figure 4.27 0blique angle of the leached surface at a magnification of 1300 times. The porosity is much lower than prior to leaching. 


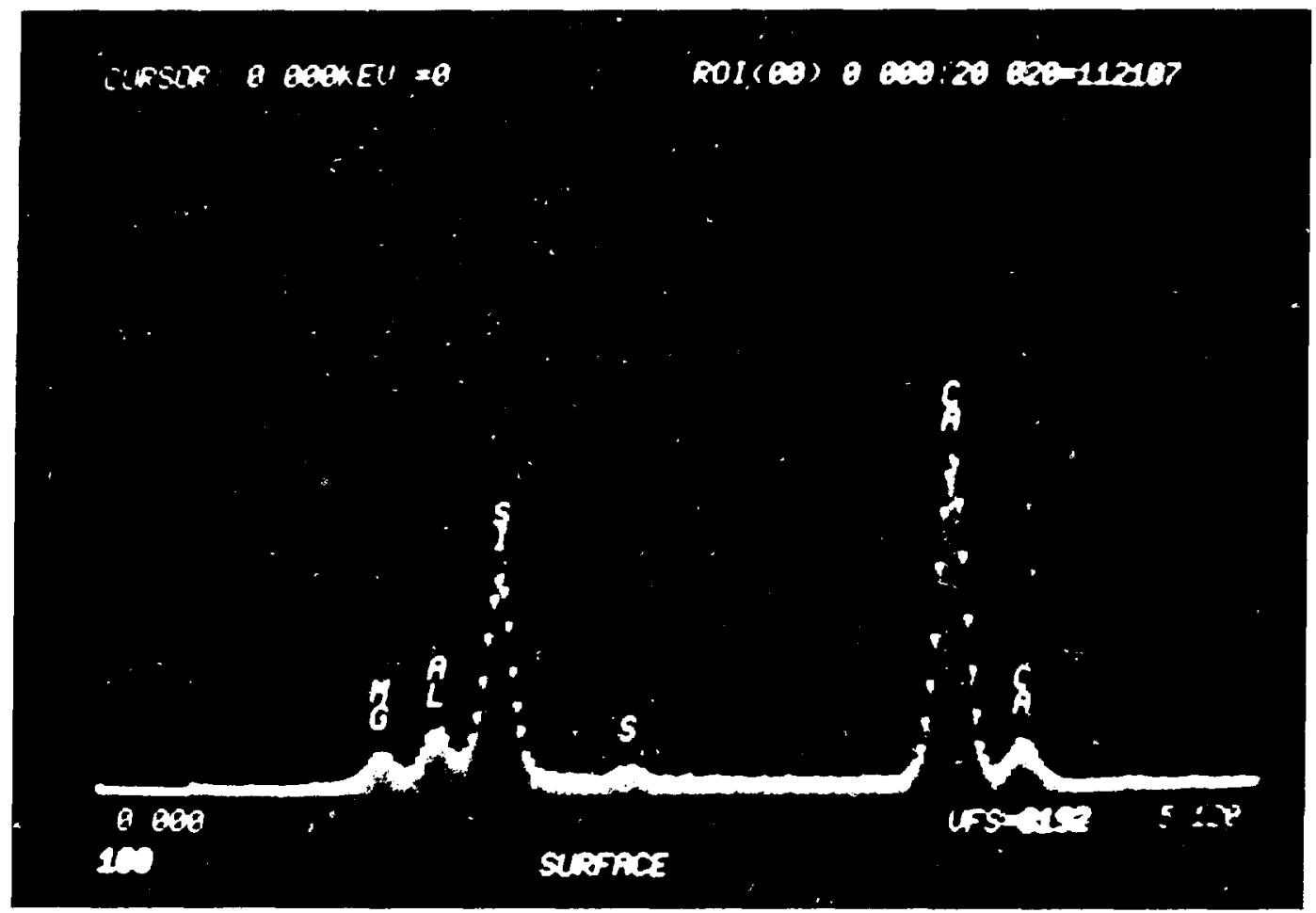

Figure 4.28 Spectrum of the surface of: a cement sample leached for 471 days. Compare this to Figure 4.23. The potassium (K) peak is gone and the calcium $(\mathrm{Ca})$ peak is reduced. 


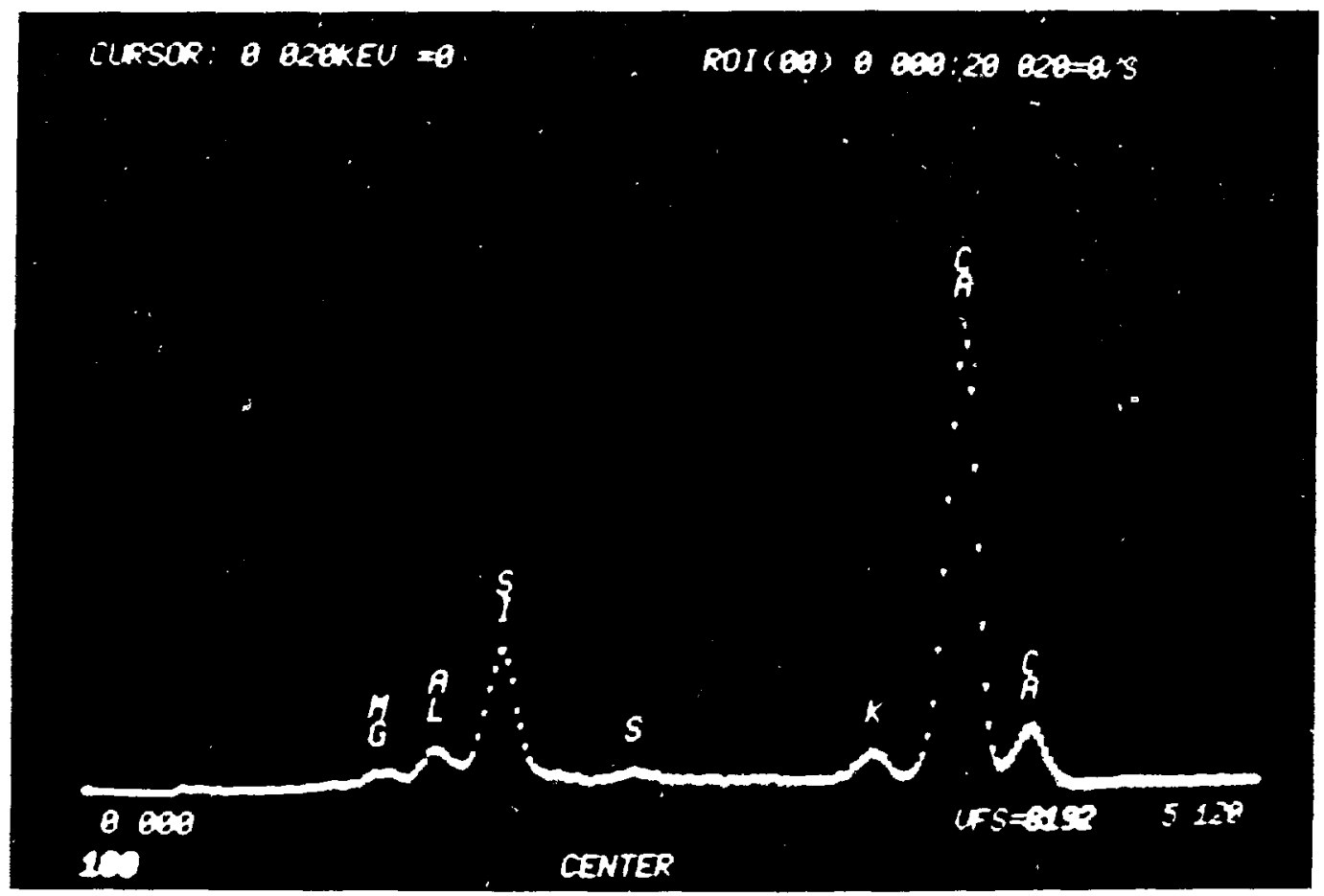

Figure 4.29 Spectrum of the center of the leached cement sample. It more closely resembles the spectrum of the unleached cement in Figure 4.23 than it resembles the outer edge of the leached sample. Note that potassium is still present. 
identical cement sample that had been leached at $70^{\circ} \mathrm{C}$ for 18 days was as discussed in the 1985 annual report [3] for this program.

A bubble near the center of this waste form was examined by SEM/EDAX. The cavity was empty, but there were some bladelike crystals deposited on its edges (Figure 4.30) which showed only calcium when examined by EDAX (Figure 4.31). This material is probably Portlandite $\left(\mathrm{Ca}(\mathrm{OH})_{2}\right)$ which is highly soluble. If much leaching had occurred at the center of the waste form the Portlandite should have been readily leached. It is possible, however, that it was redeposited during the drying process of sample preparation. This material has been noted in cavities in unleached cement.

Solid phase analysis of cement leached at room temperature for protracted times has been shown to result in a surface layer of different coniposition than the bulk of the cement. This layer is relatively depleted in the more soluble elements such as calcium, potassium and sulfur (presumably as $\mathrm{SO}_{4}^{-2}$ ). The porosity of this layer is lower than that of the original surface and the material is finer grained.

4.4.2 Vinyl Ester-Styrene/Water Emulsion. Vinyl ester-styrene emulsion is a two-phase material consisting of a solidified network of polymer and aqueous waste. Electron microscope images were obtained using blank samples, before and after leaching. Figure 4.32 shows the outer surface of a VES waste form at a magnification of 400 times. Pores at the surface of the sample typically range from $12 \mu \mathrm{m}$ to about $30 \mu \mathrm{m}$. Inside the surficial pores other openings can be seen that are much smaller and appear to be less than $1 \mu \mathrm{m}$ in diameter. Figure 4.33 is an 180 fold magnification of the VES surface. Many small pores can be seen inside the larger pores and in the polymer forming the network around the larger pores. Arother view of this material, taken of a cut section at the interior of the waste form, is shown in Figure 4.34. There is a large amount of cutting debris shown in this image. The polymer is somewhat elastic and tears rather than cuts clearly. Nevertheless, the interior contains pores of the same size range and configuration as does the surface. It is unclear if the water/waste solution is held in the large pores or in the network formed by the polymer. Releases from VES are relatively low indicating that either there is little connection between pores or the pores were formed by air being mixed into the material in the processes of forming the emulsion. Often polymers that can form an emulsion with water will form a skin around the cast form that is less porous than the bulk of the material. This could also reduce leachability. In the case of the blank VES sample shown in Figures 4.32 through 4.34 , there does not appear to be any skin formation.

No physical changes were observed in polymer samples that had leached for 471 days. These organic materials released less than $2 \mu \mathrm{g} / \mathrm{ml}$ total organic carbon in leaching intervals that typically show high releases for soluble components. Therefore, it is not surprising that no change in physical form was found.

4.4.3 Bitumen and Vinyl Ester-Styrene/Dry Waste. Imaging of bitumen and VES (dry) samples by SEM, both before and after Teaching, showed no significant surface features or porosity. None of these images is shown. 


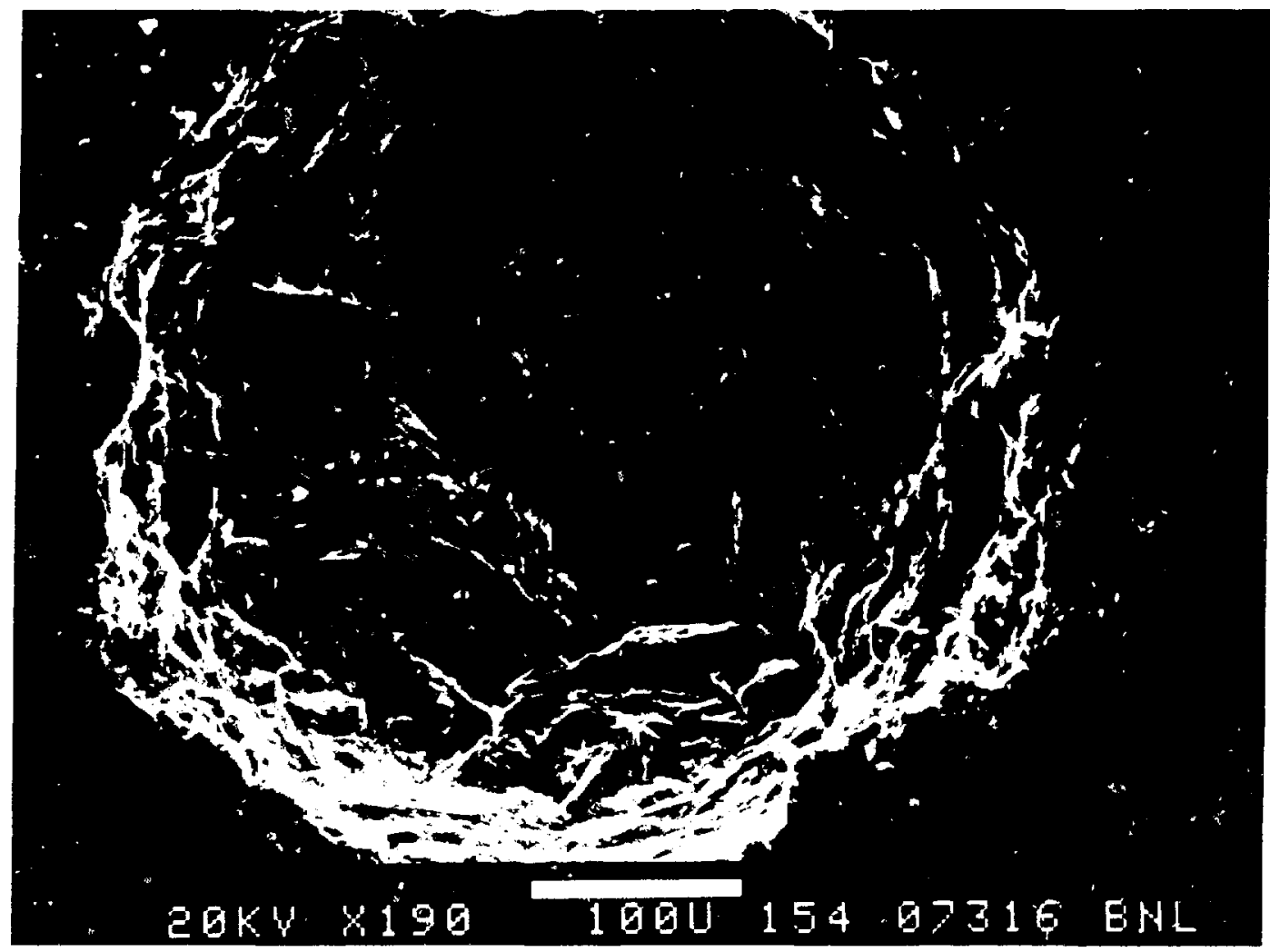

Figure 4.30 A cavity in the center of the leached cement sample. Crystals inside are thought to be portlandite $\left(\mathrm{Ca}\left(\mathrm{OH}_{2}\right)\right)$ a highly soluble mineral. 


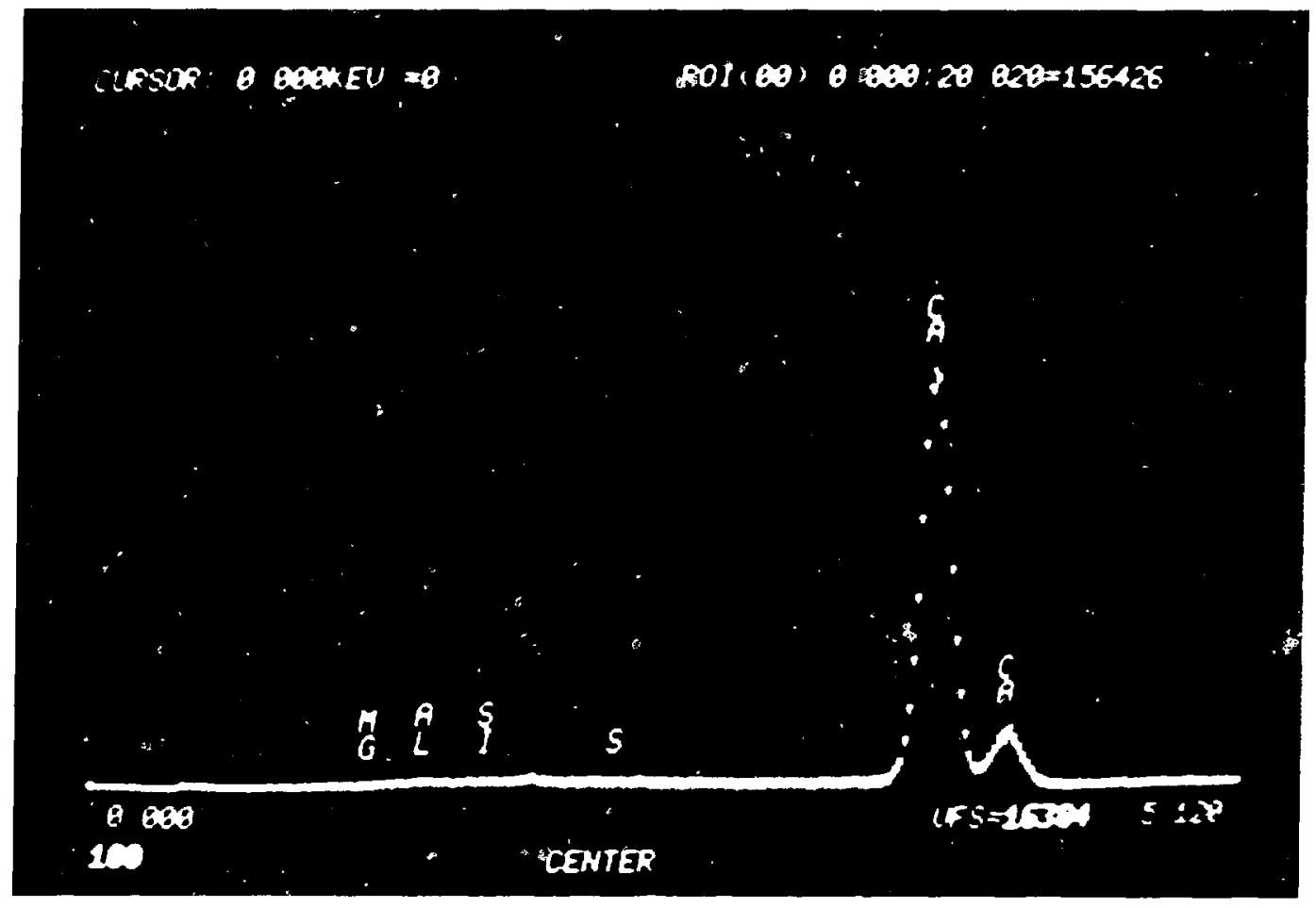

Figure 4.31 Spectrum of a small area on one of the crystals shown in Figure 4.29. Only calcium is present. 


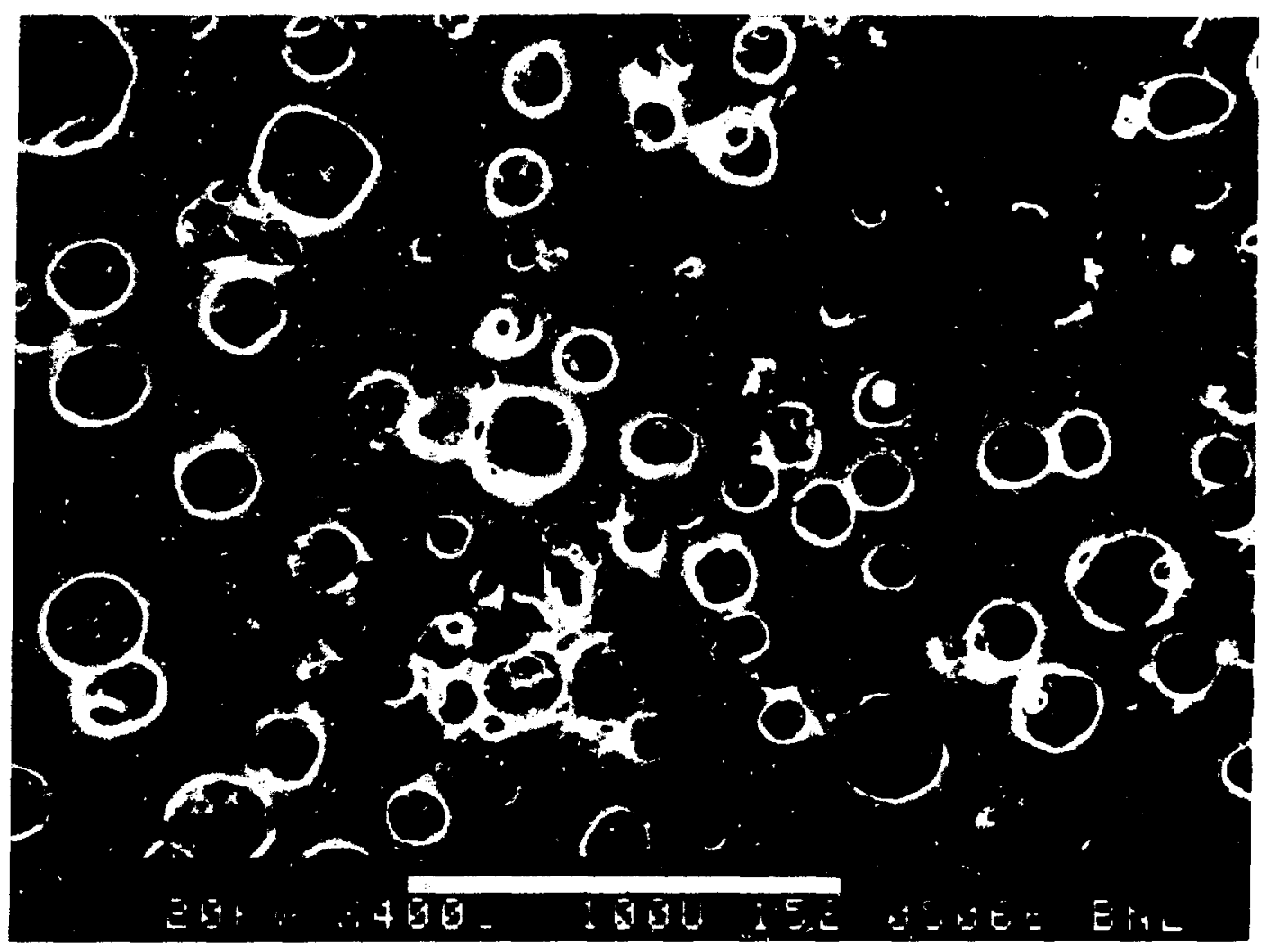

Figure 4.32 Surface of a vinyl ester-styrene emulsion at a magnification of 400 times. Most pores appear to be between 5 and $10 \mu \mathrm{m}$ in diameter. 


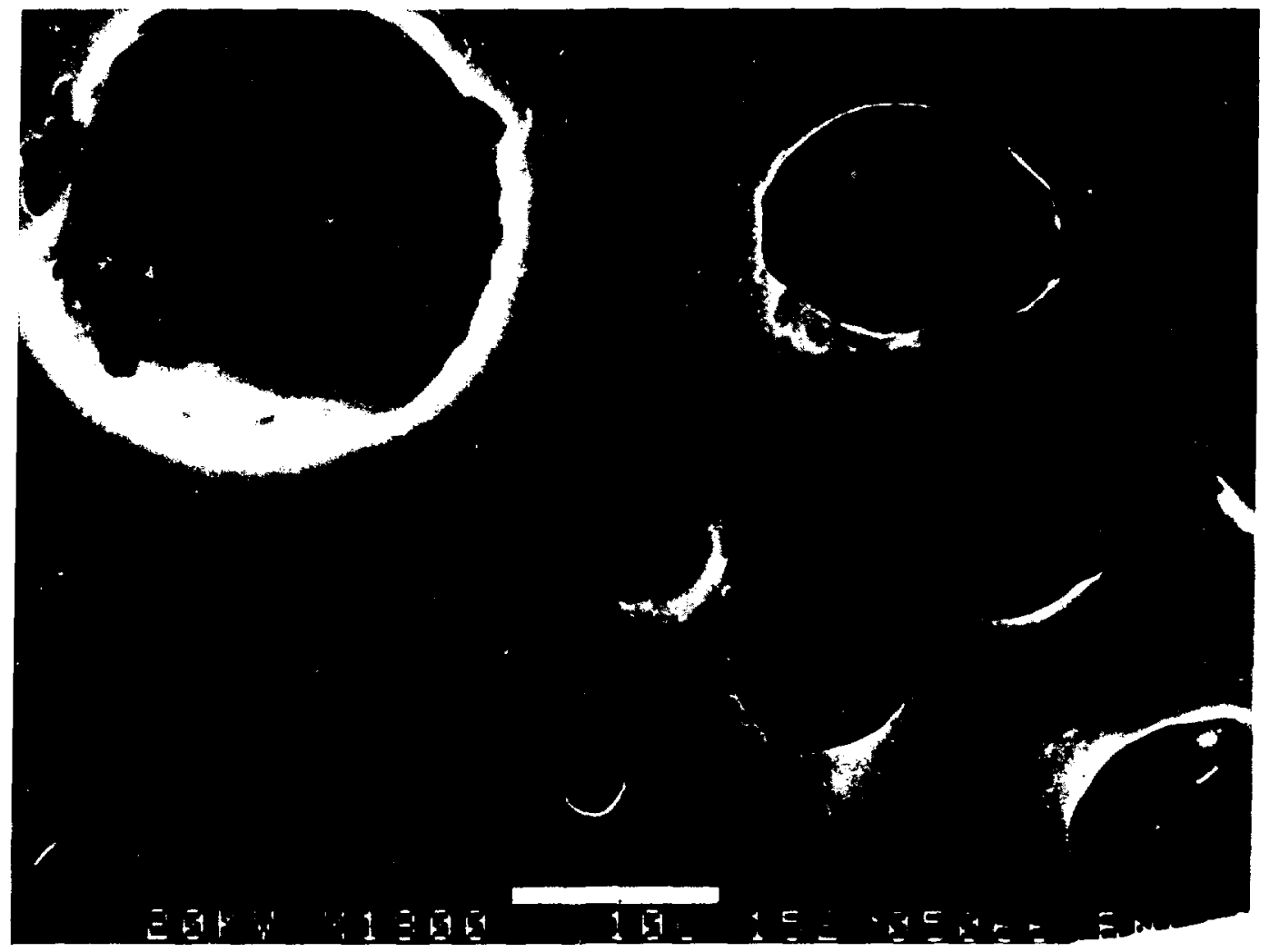

Figure 4.33 The surface of a vinyl ester-styrene emulsion sample at 1800 fold magnification. Much smaller pores are visible with diameters less than $1 \mu \mathrm{m}$. 


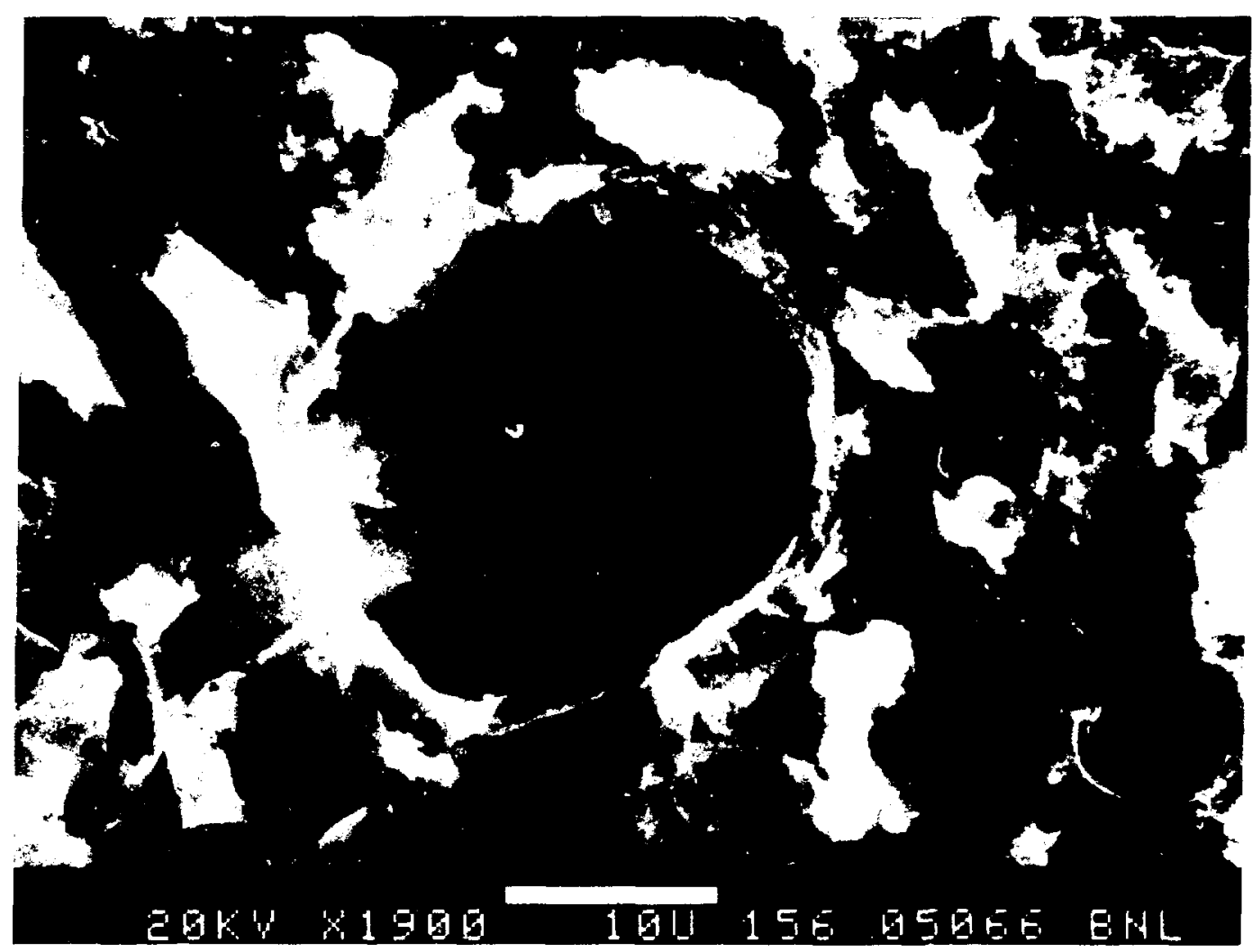

Figure 4.34 Interior of a vinyl ester-styrene emulsion. There is considerable saw debris, but the pores are in the same size range as those at the surface of the sample. 
In the previous section the leaching behavior of radionuclide tracers from several solidification agents was discussed. In this section the leaching behavior of those solidification agents, with wastes added is examined. As described in Section 3, the waste forms consisted of:

- Portland Type I Cement +5 wt\% $\mathrm{Na}_{2} \mathrm{SO}_{4}$ salt

- Portland Type I Cement + 15 wt\% Incinerator Ash

- Bitumen +20 wt\% $\mathrm{Na}_{2} \mathrm{~B}_{4} \mathrm{O}_{7}$ salt

- Bitumen + 40 wt\% $\mathrm{Na}_{2} \mathrm{~B}_{4} \mathrm{O}_{7}$ salt

- Vinyl Ester-Styrene Emulsion $+50 \% \mathrm{Na}_{2} \mathrm{SO}_{4}$ salt

- Vinyl Ester-Styrene (dry) + $40 \% \mathrm{Na}_{2} \mathrm{SO}_{4}$ salt

- Soda Lime Glass + Incinerator Ash

The leaching behaviors of these materials is analyzed relative to the baseline studies presented in Section 4. Also, some preliminary results from the solid phase analysis for some of these materials are presented. Although no detailed chemical analysis has yet been performed on these samples data are available for conductance, which is the single most useful indicator of bulk leaching of salts.

\subsection{Portland Cement $+\mathrm{Na}_{2} \mathrm{SO}_{4}$ Salt}

Sulfate salts are a major component of some reactor wastes. Although sulfate salts are not generally compatible with cement, except in small quantities, they are commonly solidified with cement. Potassium and sodium sulfates often occur in small amounts in portland cements as contaminants from the raw materials from which the cement is produced [25]. Of greater consequence is the $\mathrm{CaSO}_{4}$ added to cement to control the set time. ASTM limits on $\mathrm{SO}_{3}$ in cement are typically between 2.3 and $3.0 \%$ [25].

Care must be taken with formulations in which sulfate salts are incorporated into cement waste forms since too much sulfate results in swelling, cracking and ultimately (if enough salt is present) catastrophic failure [26]. This occurs as the salt particles hydrate and swell. Moreover, the reaction of sulfate with tricalcium aluminate in the cement results in etteringite formation, which also is accompanied by a significant increase in volume $[26,27]$. For this reason, cements produced to be "sulfate resistant" contain a reduced amount of tricalcium aluminate. 
5.1.1 Leaching Results, Cement $+\mathrm{Na}_{2} \mathrm{SO}_{4}$ Salt. Releases of Cs-137 from triplicate cement waste forms containing $5 \mathrm{wt \%} \mathrm{Na}_{2} \mathrm{SO}_{4}$ salt are shown in Figure 5.1 along with results from the triplicate baseline samples presented in the previous chapter for reference. After 108 days of leaching the samples containing the sulfate salts had released about 20\% more Cs-137 than the baseline samples. Release rates of Cs-137 from these samples are shown in Figure 5.2 again compared to the baseline data. On the scale of this plot, little difference is noticed although the rate change in the baseline samples is more pronounced after 10 days than it is for the samples containing sulfate salt. The incremental fraction releases of Cs-137 from samples containing sulfate salt are shown in Figure 5.3. Each set of data for similar sampling intervals produces a distinct pattern on this plot. Specifically, the activity leached in the first sampling of the daily intervals is greater than that in the next, and so on until the longer sampling intervals start. However, this pattern breaks down toward the end of the experiment.

Releases of $\mathrm{Sr}-85$ were different from $\mathrm{Cs}-137$ releases relative to those of the baseline. In Figure 5.4, no difference between the two sets is observed. Average cumulative fraction released for sulfate-containing samples was 0.041 while the CFR for the baseline was 0.043 over the same time period. However, releases from the samples containing the salt increased in the 1 ast two samplings. Sr-85 release rates are shown in Figure 5.5 compared to release rates from a baseline sample. As in the baseline experiments, no cobalt tracer was measured in the leachate.

5.1.2 Conductance. Values of leachate conductance for duplicate cement samples containing sulfate salt are given in Table 5.1. Leachate conductance values from cement samples containing sulfate salts are substantialiy higher than those of the baseline, indicating that the salts are leaching from the cement and contributing significantly to the ionic strength of the leachate. The high sulfate concentrations in the pore water of these waste forms may have helped keep the strontium leachability at the level of the baseline samples by limiting its solubility. Cesium releases from the sulfate-containing samples may be higher than the baseline due to increased porosity as the salt dissolves. Cesium is 1 ittle affected by chernical reactions with cement waste forms. This increased porosity would have no efiect on strontium releases if its leaching is limited by solubility.

5.1.3 Solid Phase Arralysis. Solid phase analysis has not been performed on these samples yet because the leaching experiments are continuing, however, a replicate sample of cement with $5 \%$ sodium sulfate salt has been tested for immersion stability. The solid phase analysis of this sample gives insight into processes that can occur in cement waste forms under immersion, which includes leach testing.

Before leaching, the surface of the cement waste form containing 5 wt\% sodium sulfate salt (Figure 5.6) looked similar to that of the baseline cement sample which contained no added salt (Figure 4.21). Even at high magnification no discrete particles of salt were observed. Figure 5.7 shows the typical texture of cement, with fibrils intergrown to form the material. 


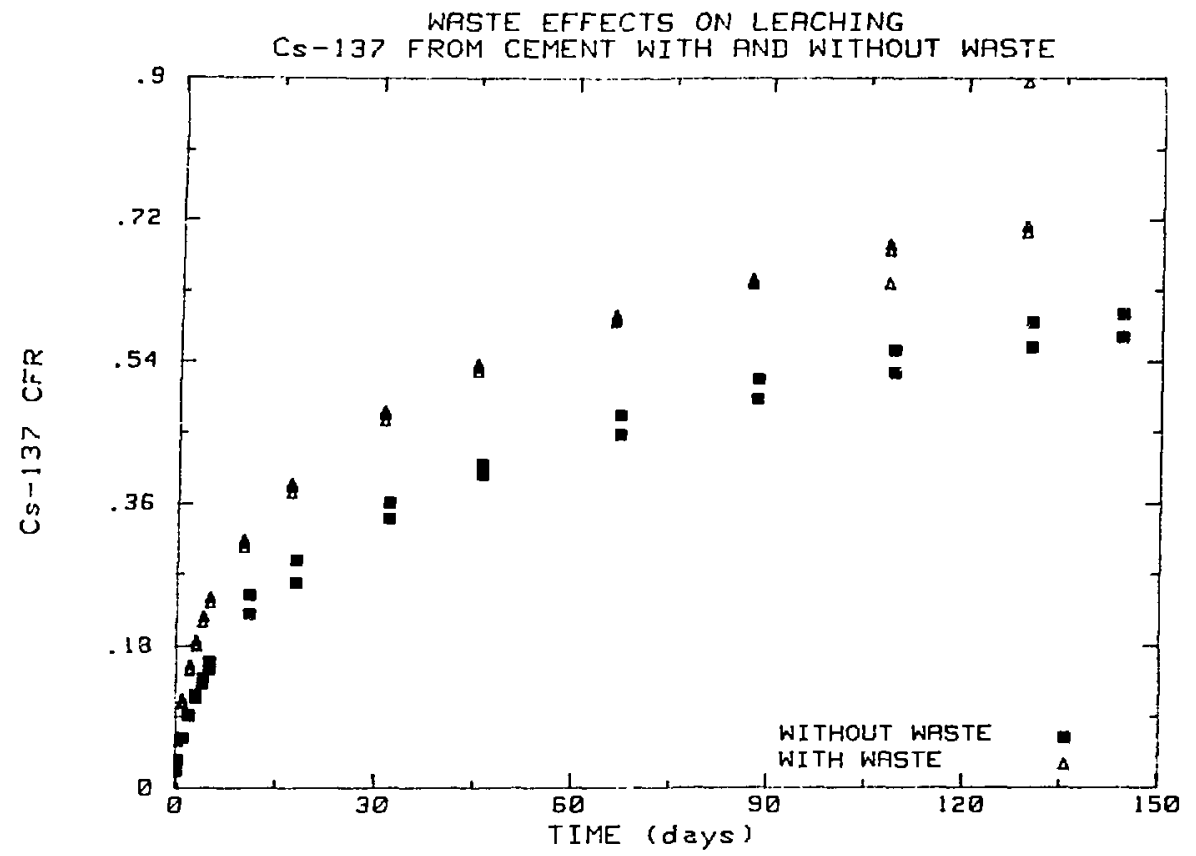

Figure 5.1 Cumulative fraction release of Cs-137 from cement samples containing $5 \%$ sodium sulfate and from baseline sample.

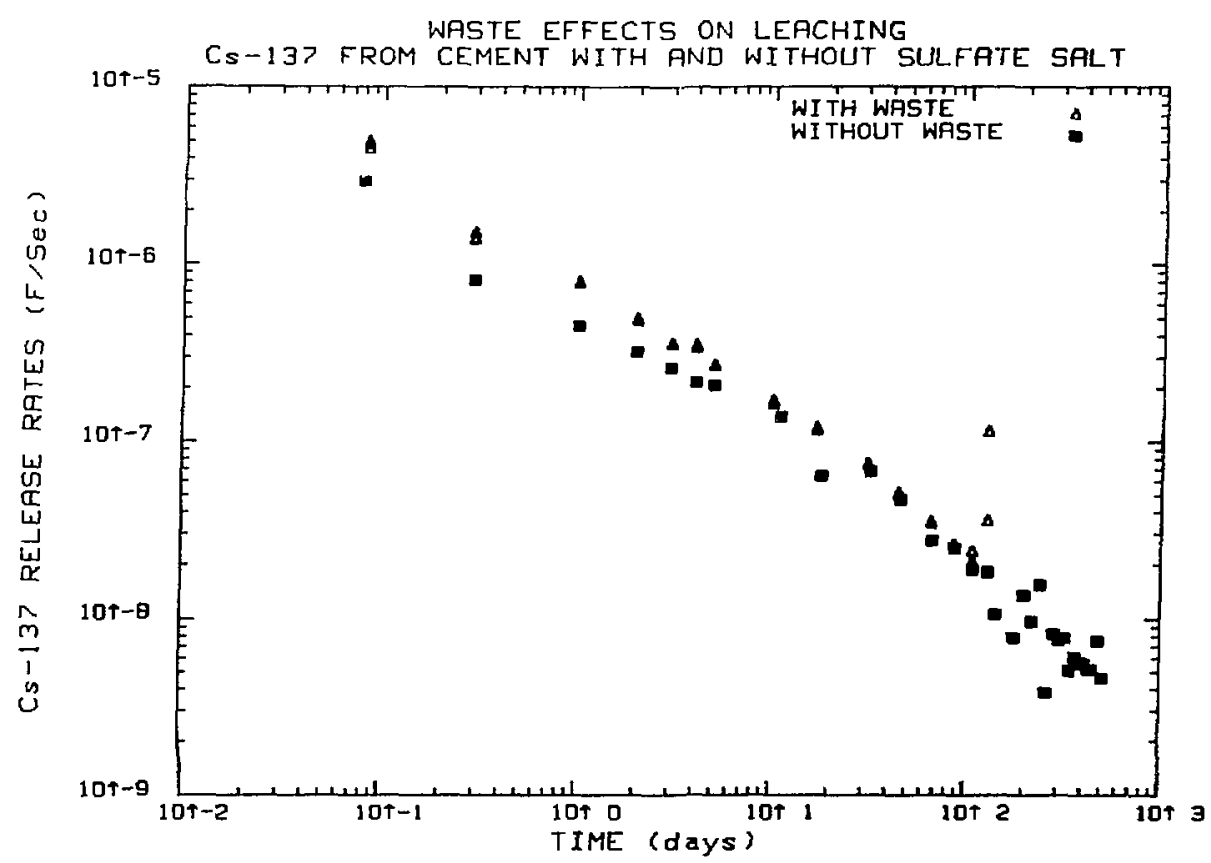

Figure 5.2 Release rates of Cs-137 from cement samples containing $5 \%$ sodium sulfate and from a baseline sample. 


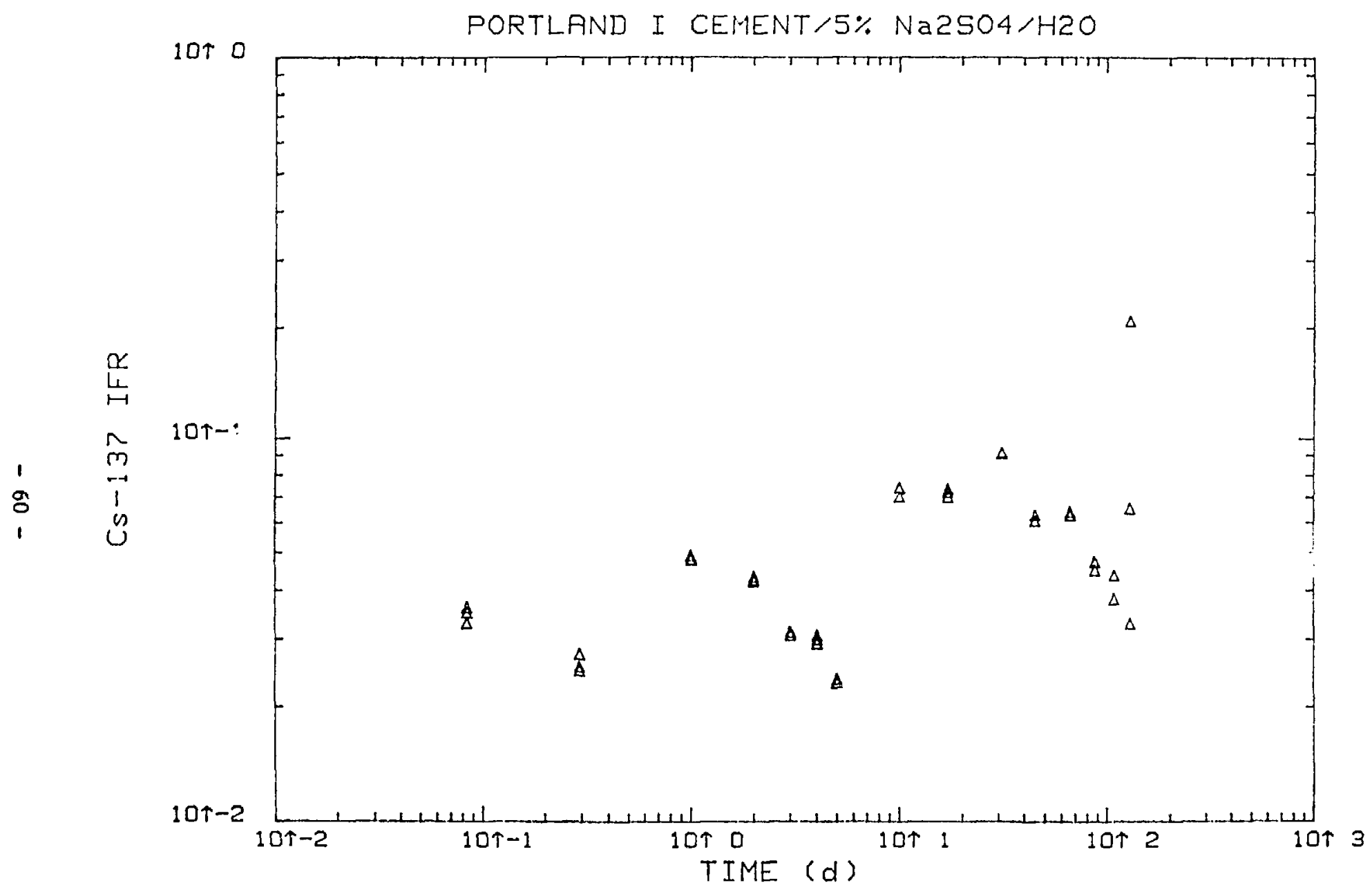

Figure 5.3 Incremental fraction releases of Cs-137 from cement samples containing $5 \%$ sodium sulfate. Note that the IFR is related to sampling interval. 


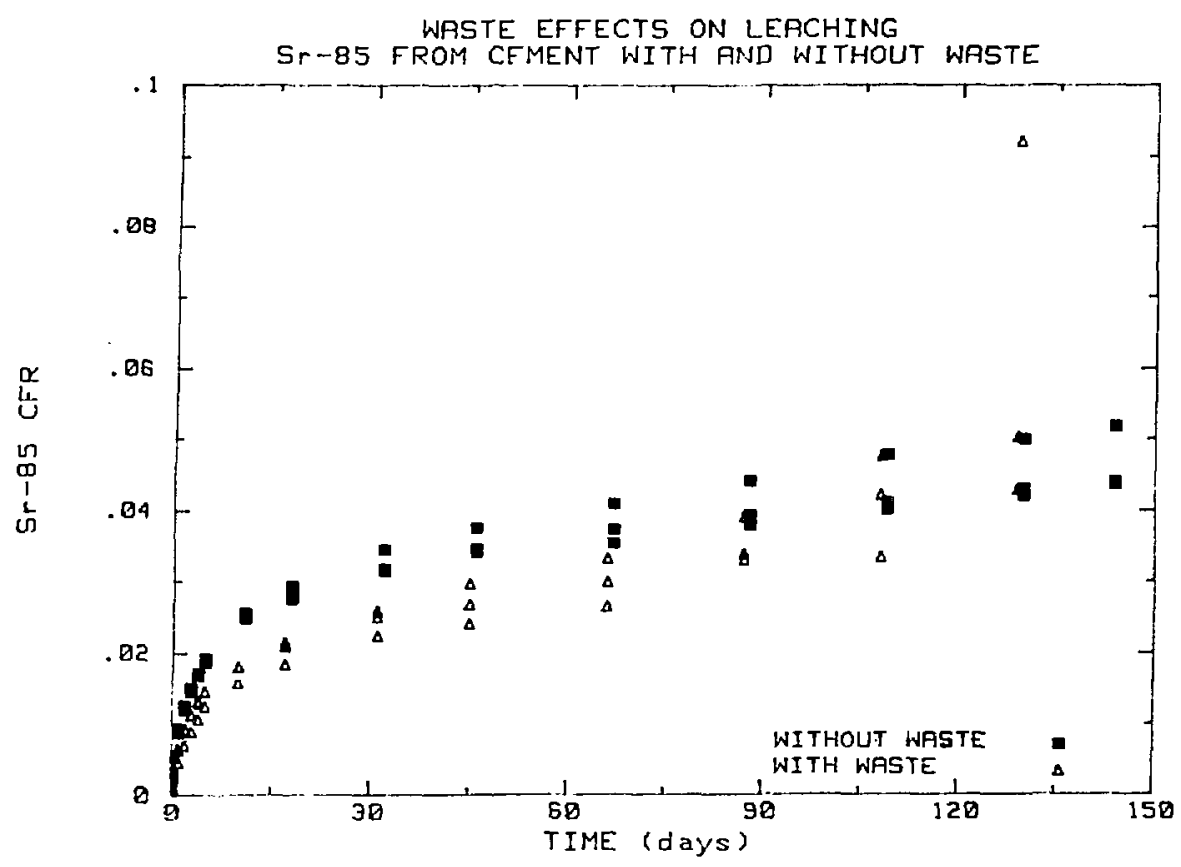

Figure 5.4 Cum inetive fraction release of Sr-85 from cement samples containini, $5^{\circ}$ sodium sulfate and from baseline samples.

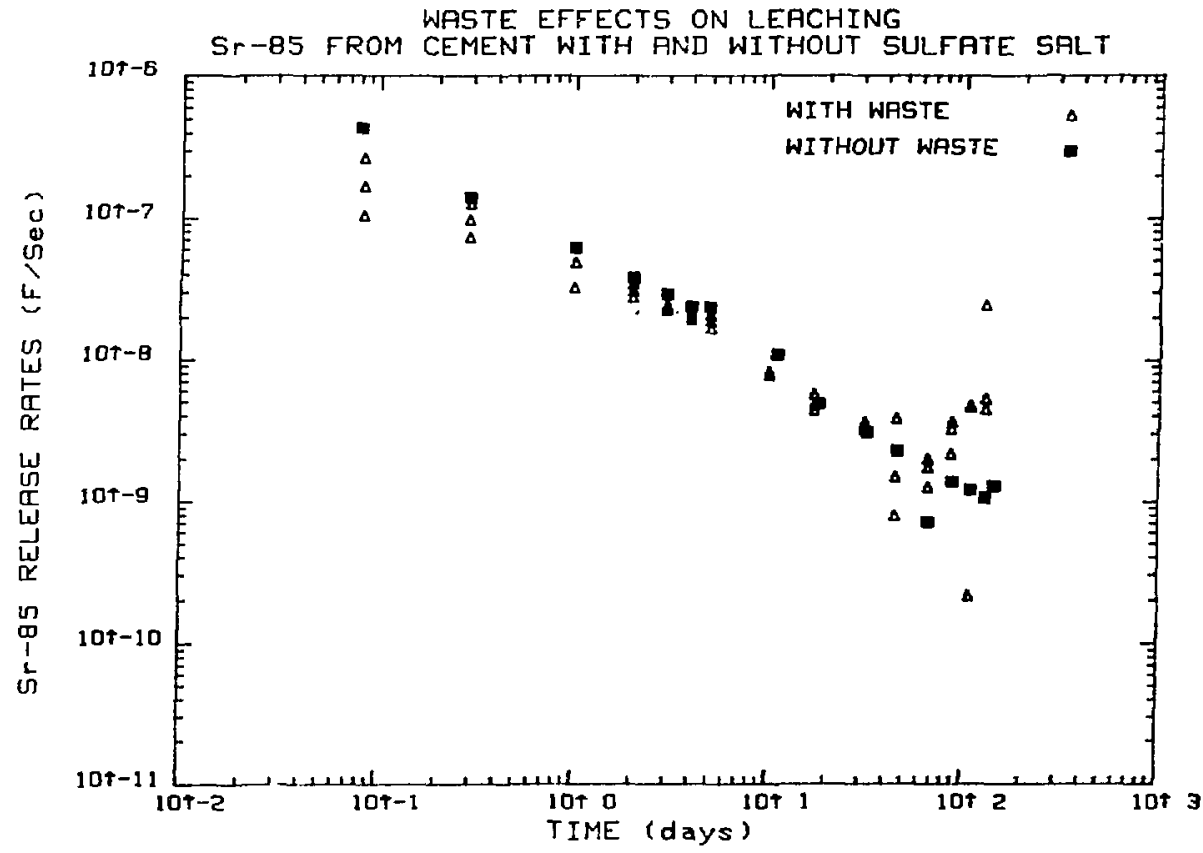

Figure 5.5 Release rates of $\mathrm{Sr}-85$ from cement samples containing $5 \%$ sodium sulfate and from a single baseline sample. The rate of the last three sampling intervals appear to have increased over the baseline. 


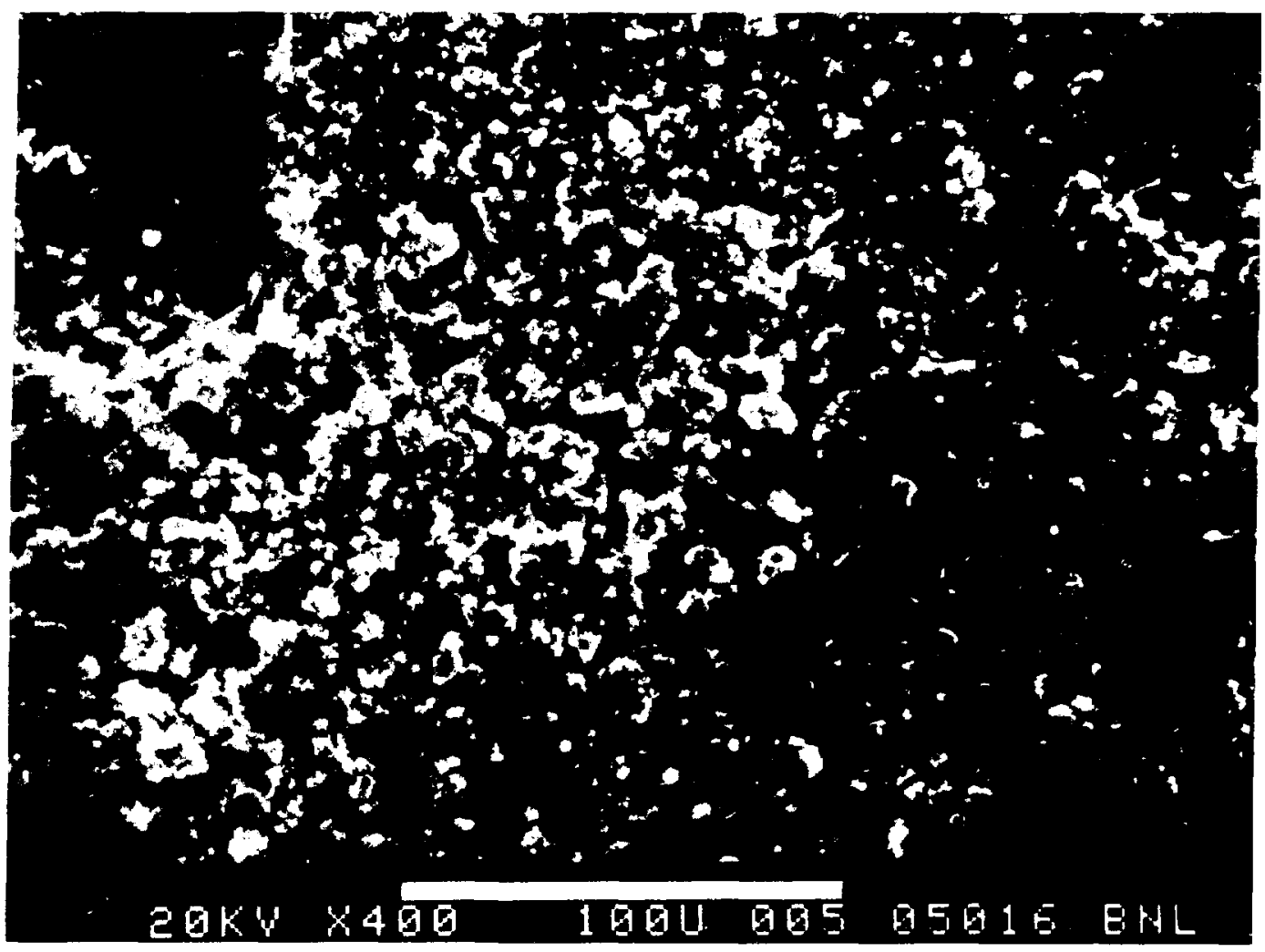

Figure 5.6 Outer surface of an unleached cement sample containing $5 \%$ sodium sulfate at a magnification of 400 times. This surface is indistinguishable from the unleached baseline cement surface (Figure $4.21)$. 


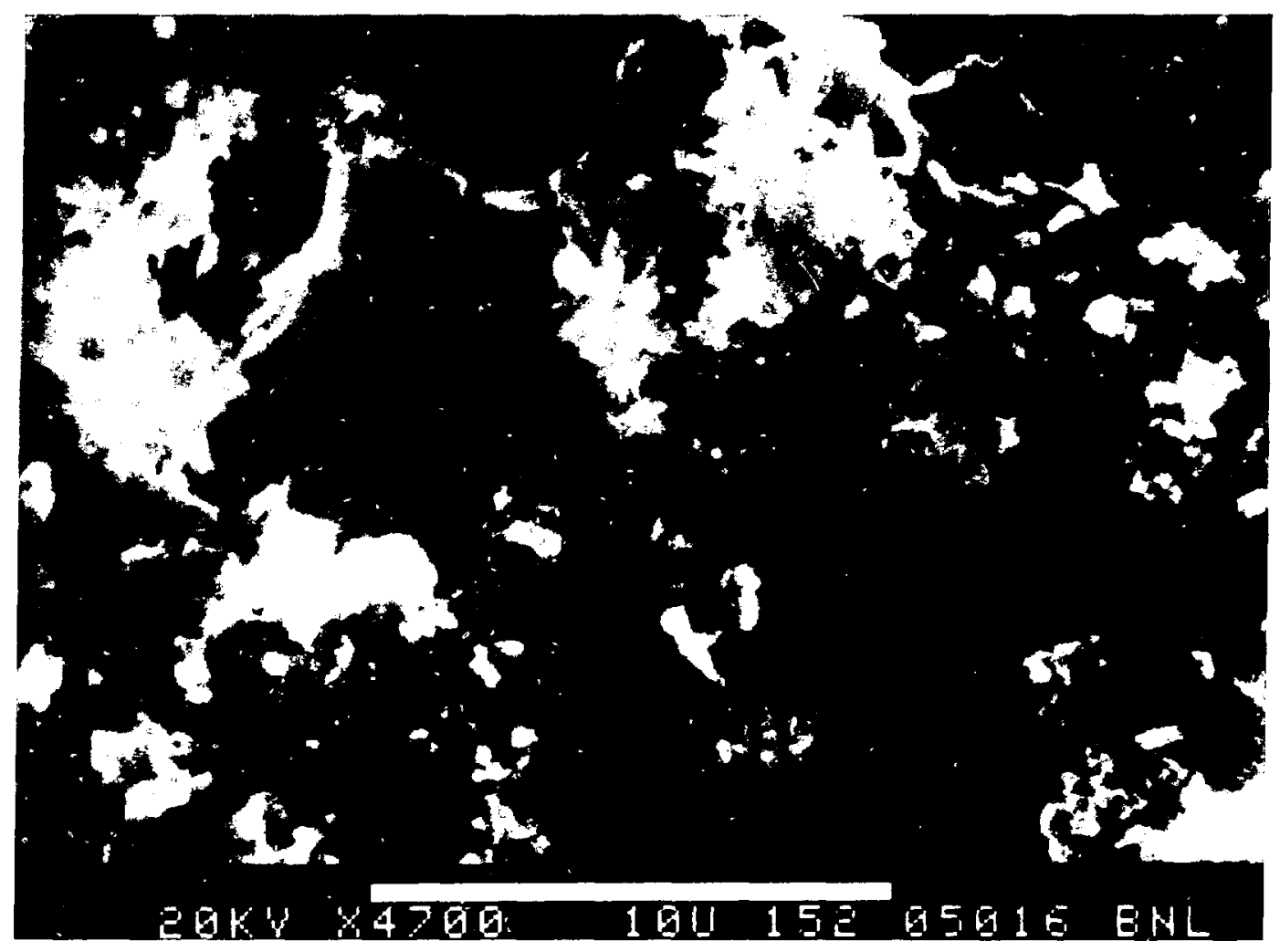

Figure 5.7 Outer surface of an unleached cement sample containing $5 \%$ sodium sulfate at a magnification of 4700 times. 
Table 5.1 Conductance (umhos/cm) of Leachates from Cement Samples Containing
$5 \%$ Sodium Sulfate

\begin{tabular}{|c|c|c|c|}
\hline $\begin{array}{c}\text { Time } \\
\text { (Days) } \\
\end{array}$ & Interval & $\begin{array}{l}\text { Sample } 0 \\
\text { Conductance ( } \mathrm{\mu} \text { mhos } / \mathrm{cm})\end{array}$ & $\begin{array}{l}\text { Sample } E \\
\text { Conductance ( } \mu \text { mhos } / \mathrm{cm} \text { ) }\end{array}$ \\
\hline 0 & Rinse & 70.7 & 81.7 \\
\hline 0.08 & 1 & 840 & 990 \\
\hline 0.29 & 2 & 610 & 800 \\
\hline 1 & 3 & 1610 & 1630 \\
\hline 2 & 4 & 1190 & 990 \\
\hline 3 & 5 & 2500 & 2780 \\
\hline 4 & 6 & 1080 & 1870 \\
\hline 5 & 7 & 520 & 710 \\
\hline 10 & 8 & 2840 & 2760 \\
\hline 17 & 9 & 2240 & 2050 \\
\hline 31 & 10 & 3130 & 3190 \\
\hline 45 & 11 & 2110 & 2410 \\
\hline 66 & 12 & 2640 & 2750 \\
\hline 87 & 13 & 2340 & 2210 \\
\hline 108 & 14 & 2280 & 2360 \\
\hline 129 & 15 & 2650 & 2810 \\
\hline
\end{tabular}


Elemental analysis of the surface (Figure 5.8) shcws some enrichment of sulfur over the baseline cement content. A low intensity sodium peak was also observed in the salt-containing sample, whereas none was seen in the baseline sample. Prior to leaching, pores and bubbles in the salt-containing cement were empty or occasionally exhibited a few portlandite crystals. This is also the case with unleached plain cement samples.

After immersion for 55 days at $50^{\circ} \mathrm{C}$ a replicate of the sample discussed above was examined. Slight cracking around the bottom of the sample was noted. Figure 5.9 shows the leached surface at a magnification of 400 times and Figure 5.10 shows it at 1900 times. This surface which, prior to leaching, was porous and open, was covered by a profuse growth of crystals after leaching. Little porosity was evident.

Cut surfaces from inside this waste form were also examined. Figure 5.11 shows a sample of this material that was taken about $2 \mathrm{~mm}$ from the surface. There is much cracking, apparently the result of swelling. No grains of salt were found. On examining this section at high magnification and using EDAX it was observed that there were distinct chemical differences. Areas near the cracks were depleted of sulfur compared to spectra of the unleached cement/ sulfate salt waste form.

Examination of larger bubbles, which were empty in the unleached sample, revealed that most were filled with crystals. Figures 5.12 and 5.13 show a typical bubble at magnifications of 400 and 1100 times, respectively. The spectrum shown in Figure 5.14 is from an EDAX analysis of a single crystal in this cavity. It is significantly different than the spectrum of the unleached waste form. No potassium or sodium are observed and the silicon peak is much reduced. The sulfur from the waste had apparently reacted with aluminum, silicon and calcium to form a new phase that preferentially grew into the open cavities in the waste form. It is thought that this growth is ettringite, but $x$-ray diffraction mineralogy of this material has yet to be performed.

5.1.4 Conclusions. Preliminary conclusions are based on 129 days of leaching and on solid phase analysis of statically immersed samples. Cesium-137 releases were initially slightly lower than the baseline samples but jncreased rapidly after 100 days of leaching. The triplicate samples showed a large variability in incremental release at the final sampling interval. This may suggest that one waste form in particular suffered significant internal damage due to swelling. Releases of Sr-85 were not noticeably different than those of the baseline experiments. However, the increase in $\mathrm{Sr}-85$ release in the last sampling intervals paralleled those of cesium.

Solid phase analysis indicates that a new phase forms on the cement that is composed of bladelike crystals. This growth appears to reduce the porosity present prior to leaching. Inside the waste form there are new crystalline materials formed from reactions of the cement and the waste. These materials are most obvious in cavities where crystals form but may be present throughout the structure. The internal cracking observed upon immersion may be the result of this material forming in the solid phase of the waste form. 


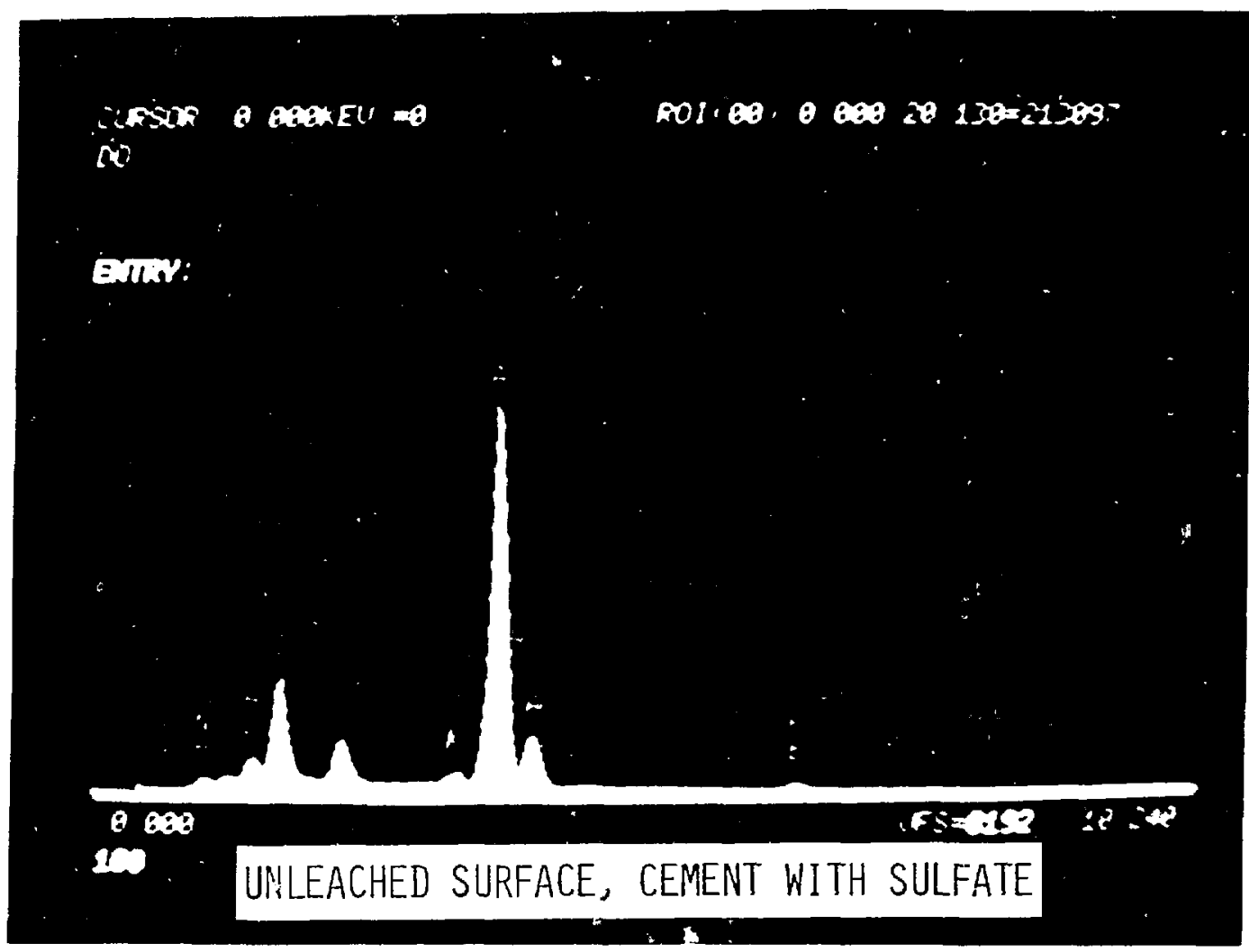

Figure 5.8 EDAX spectrum of the outer: surface of an unleached cement sample containing $5 \%$ sodium sulfate. Note that a small sodium peak is present as well as a potassium peak. The sulfur is enriched compared to the baseline cement (Figure 4.23). 


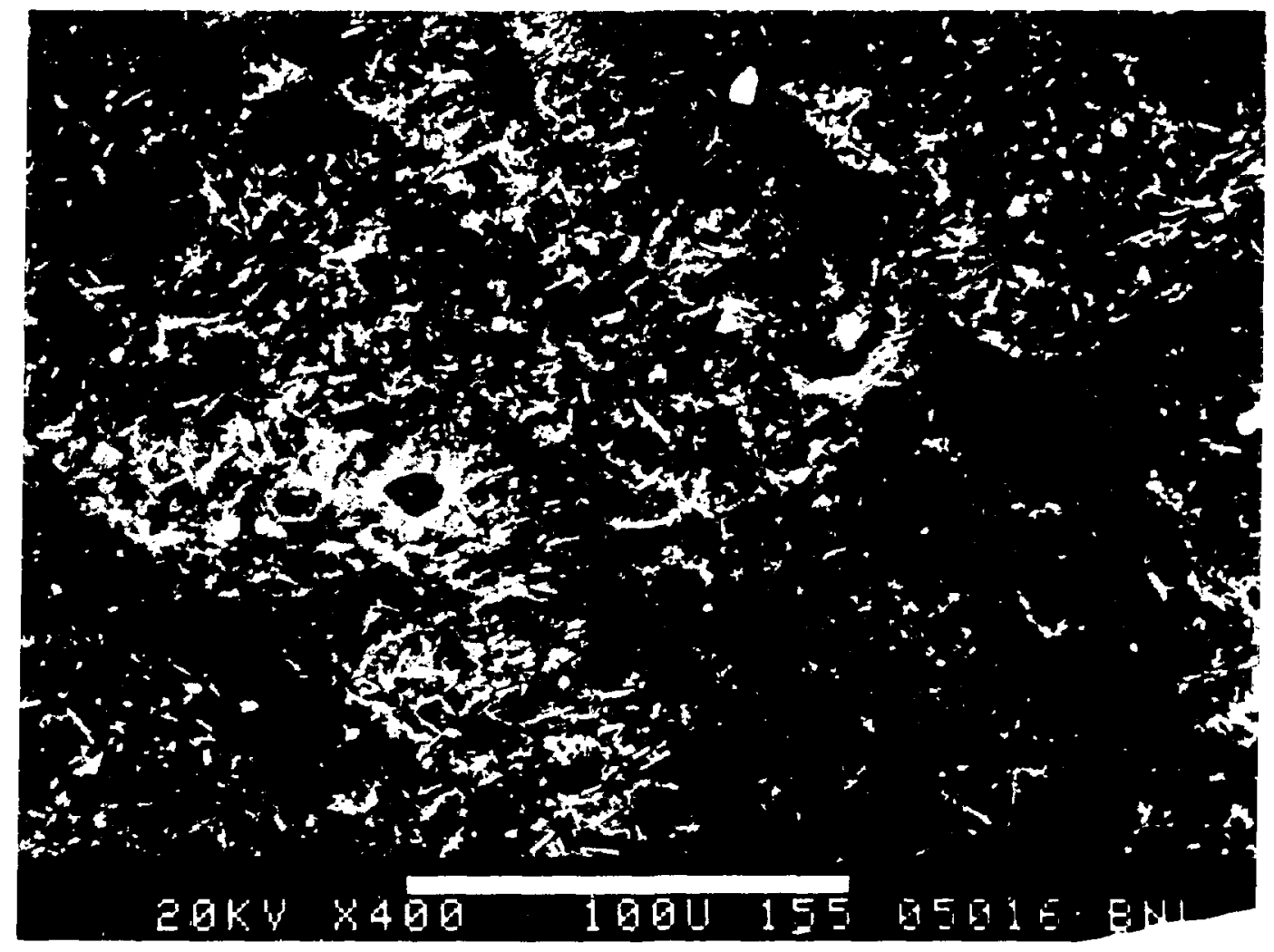

Figure 5.9 Outer surface of a cement sample containing $5 \%$ sodium sulfate after static leaching for 55 days at $50^{\circ} \mathrm{C}$. There is profuse crystal growth covering the entire outer surface of the sample. Magnification is 400 times. 


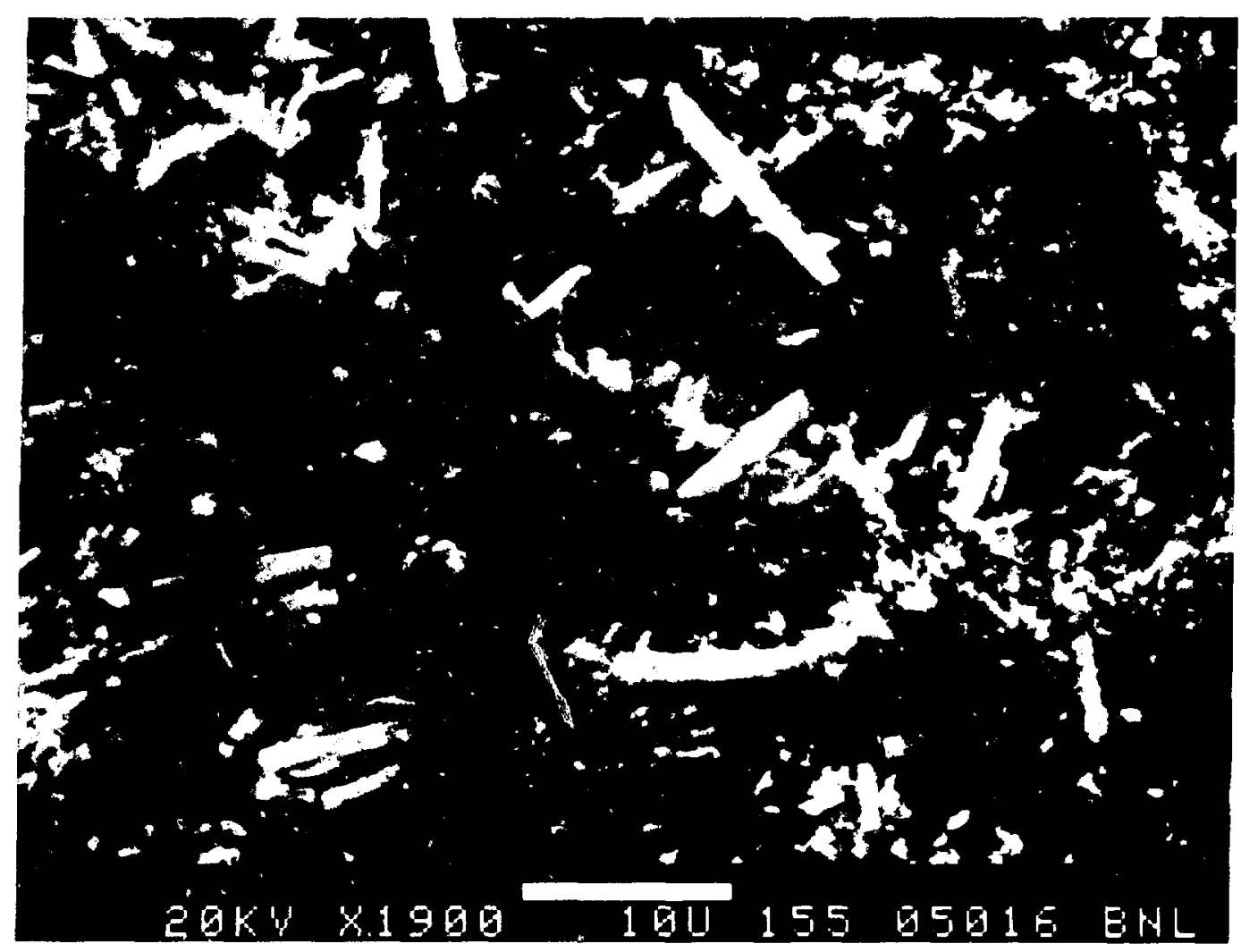

Figure 5.10 Outer surface of a cement sample containing $5 \%$ sodium sulfate after static leaching for 55 days at $50^{\circ} \mathrm{C}$. Magnification is 1900 $t$ imes. 


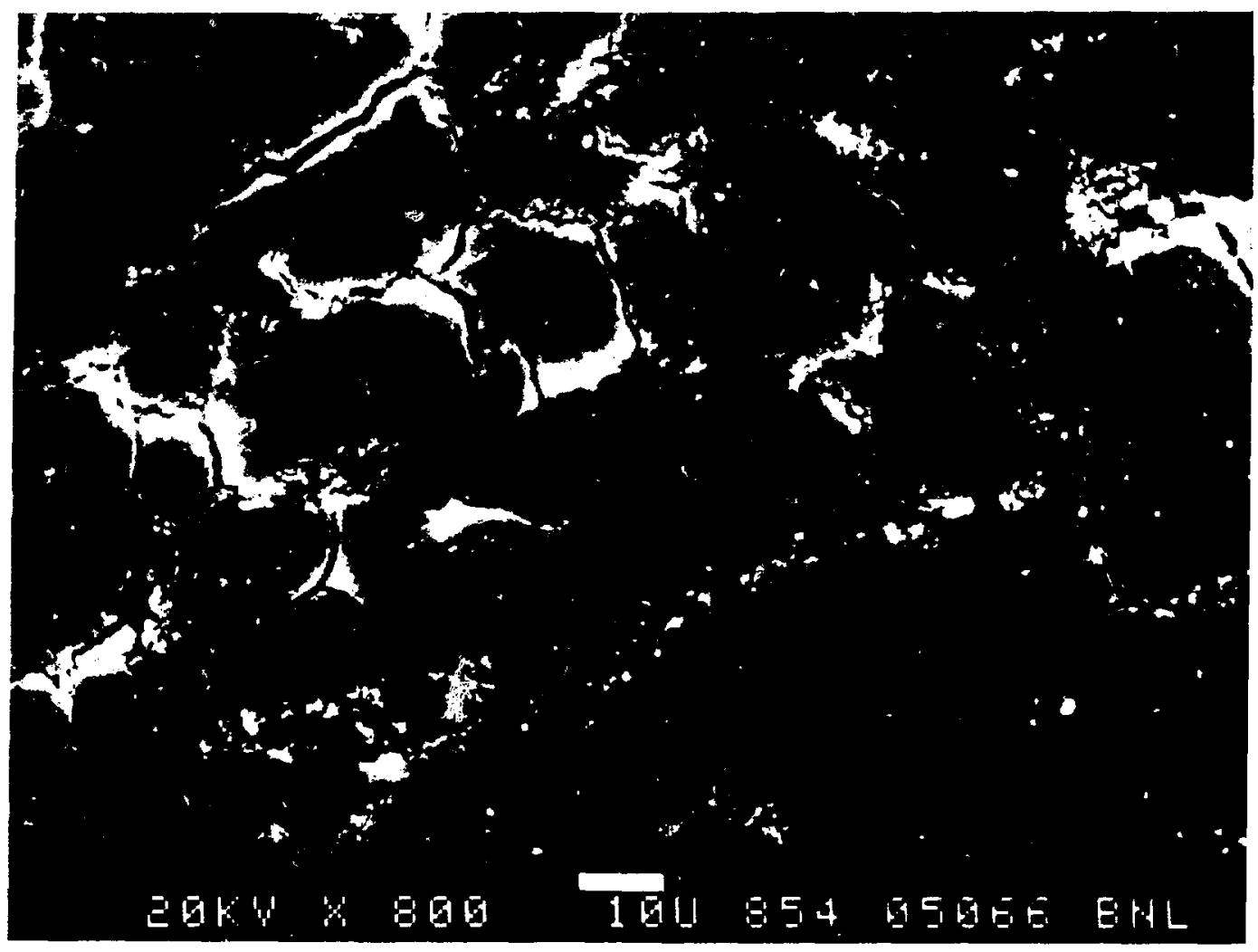

Figure 5.11 Interior of a cement sample containing $5 \%$ sodium sulfate after static leaching for 55 days at $50^{\circ} \mathrm{C}$. This is a cut sample from 2 $\mathrm{mm}$ inside the outer edge. Note the many cracks. 


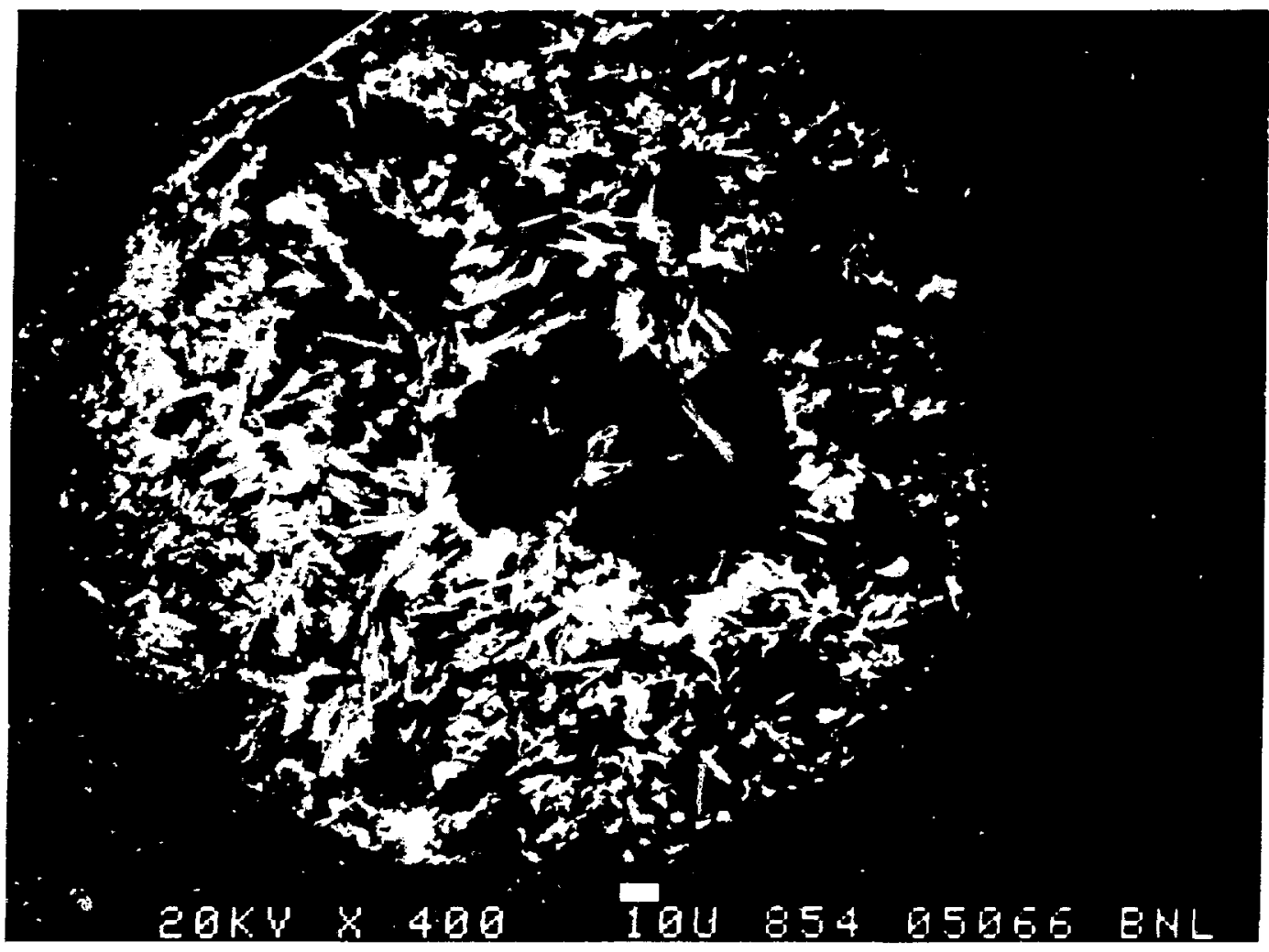

Figure 5.12 A bubble that after leaching was full of crystals. This was typical of any voids in the sample. 


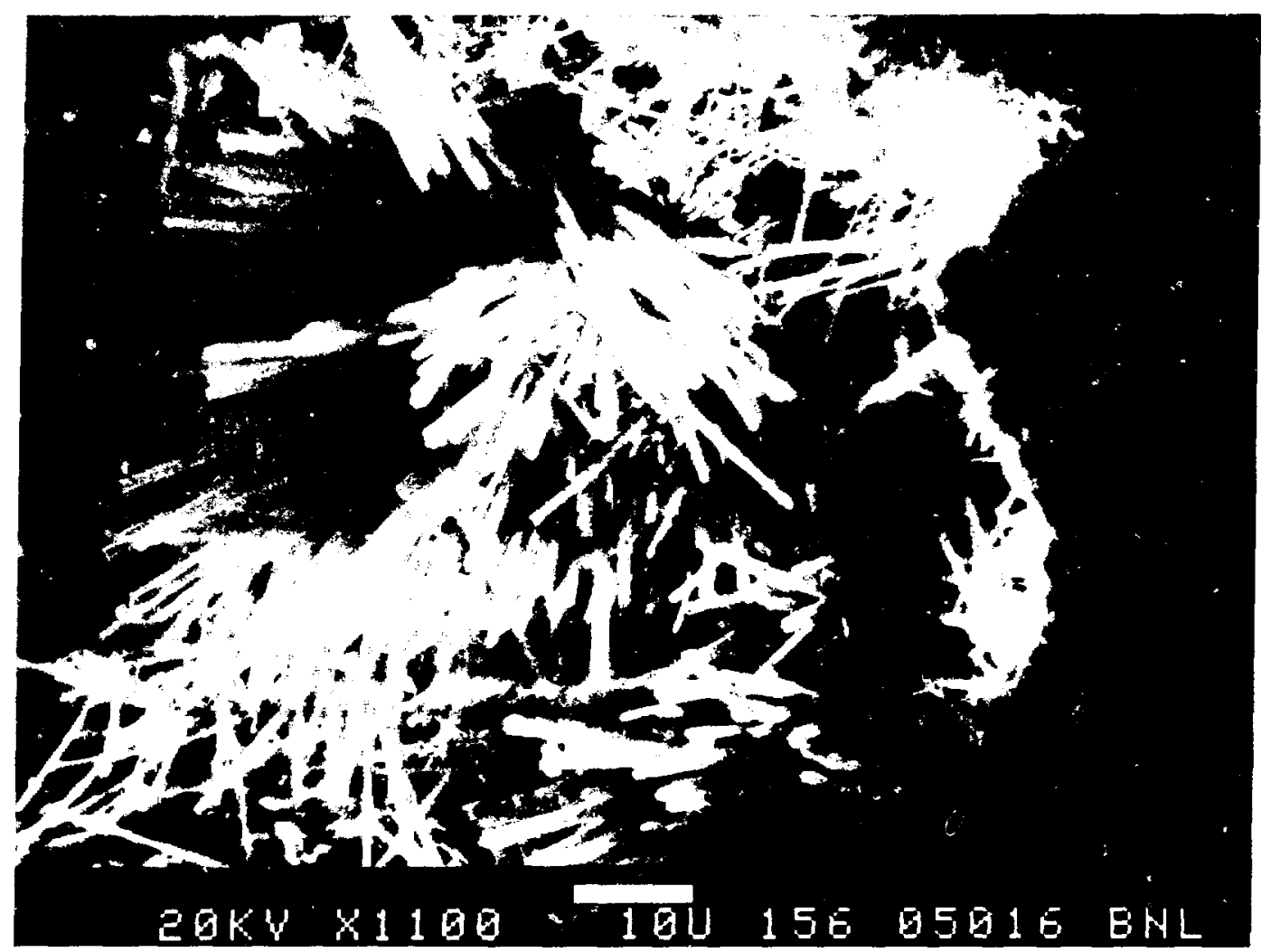

Figure 5.13 A close-up view of the bladelike crystals filling a pore in the leached sample. Their morphology suggest that the mineral is ettringite. 


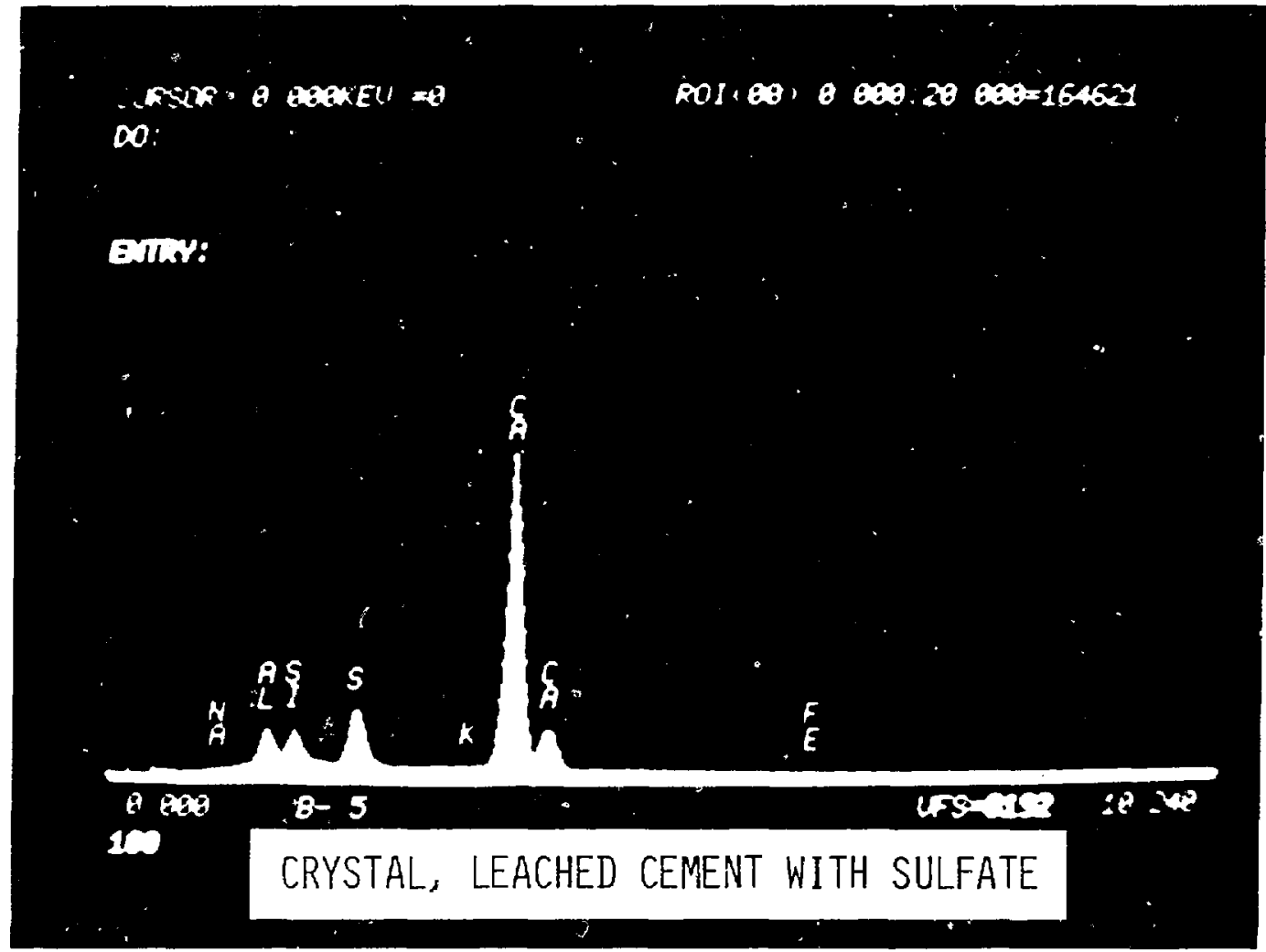

Figure 5.14 EDAX spectrum of one of the crystals from Figure 5.13. This spectrum is significantly different from that of the unleached cement containing sodium sulfate shown in Figure 5.8. Sulfur and aluminum are enriched and silicon is depleted beyond normal cement composition. 


\subsection{Portland Cement $+15 \%$ Incinerator Ash}

Incinerator ash is composed of a broad range of materials depending on the waste fed to the incinerator and on the conditions of combustion. Some of the materials typically found in ash can react with cement by supplying additional silica to the cementitious reactions. For this reason fly ash is sometimes used as an additive to improve cement. Incinerator ash, however, is much less homogeneous than fly ash and cannot be counted on to improve a waste form.

5.2.1 Leaching Results. Cs-137 releases from triplicate samples of cement containing incinerator ash are shown in Figure 5.15. When compaied to the baseline releases at 129 days there is little difference in the final cumulative fraction releases, however, the curve shapes are different. It is unclear if the data will begin to diverge beyond 150 days. Release rates are shown in Figure 5.16 for $\mathrm{Cs}-137$ and it appears that release rates for samples containing ash are falling below the baseline by the later part of the experiment. This experiment is continuing and further data should clarify the differences in curve shape.

Sr-85 releases are 15 times lower than Cs-137 releases. This is similar to the baseline cement samples as well as cement samples containing sodium sulfate salts. Figure 5.17 shows the cumulative fraction release of $\mathrm{Sr}-85$ from cement samples containing $15 \%$ incinerator ash. Strontium releases are about $20 \%$ higher than the baseline and look to be steadily increasing. This is more apparent in Figure 5.18 where the release rates are plotted. The rate curves are significantly different and the strontium releases have exceeded the baseline.

No cobalt was observed in the leachate as is the case with other cement waste forms.

5.2.2 Conductance. Conductance values from the leachate for duplicate samples are shown in Table 5.2. Conductance is higher in leachates from samples containing ash than from those of baseline samples. However, it is lower than in leachate from cement samples containing sulfate salt. It is unclear why $\mathrm{Sr}-85$ releases are elevated since the high conductance indicates large quantities of material leaching out of the waste form. This should inhibit not accelerate leaching. Similarly $\mathrm{Cs}-137$ releases are not significantly different from the baseline. The higher ionic strength of the leachate should inhibit release of this isotope as well.

5.2.3 Conclusions. Conclusions regarding the leaching of waste forms containing incinerator ash are preliminary. More information, such as extended leaching results and solid phase analysis, are required. Early information indicates that $\mathrm{Cs}-137$ leaching is not altered by the presence of incinerator ash. Releases of $\mathrm{Sr}-85$, however, appear to be changed by incinerator ash. Cumulative fraction releases of triplicate samples all show greater fraction releases than the baseline. Moreover, the curve shape appears to be significantly different. It is unclear if this is a change in mechanism, or the result of somewhat different interior morphology due to inclusion of the ash. 


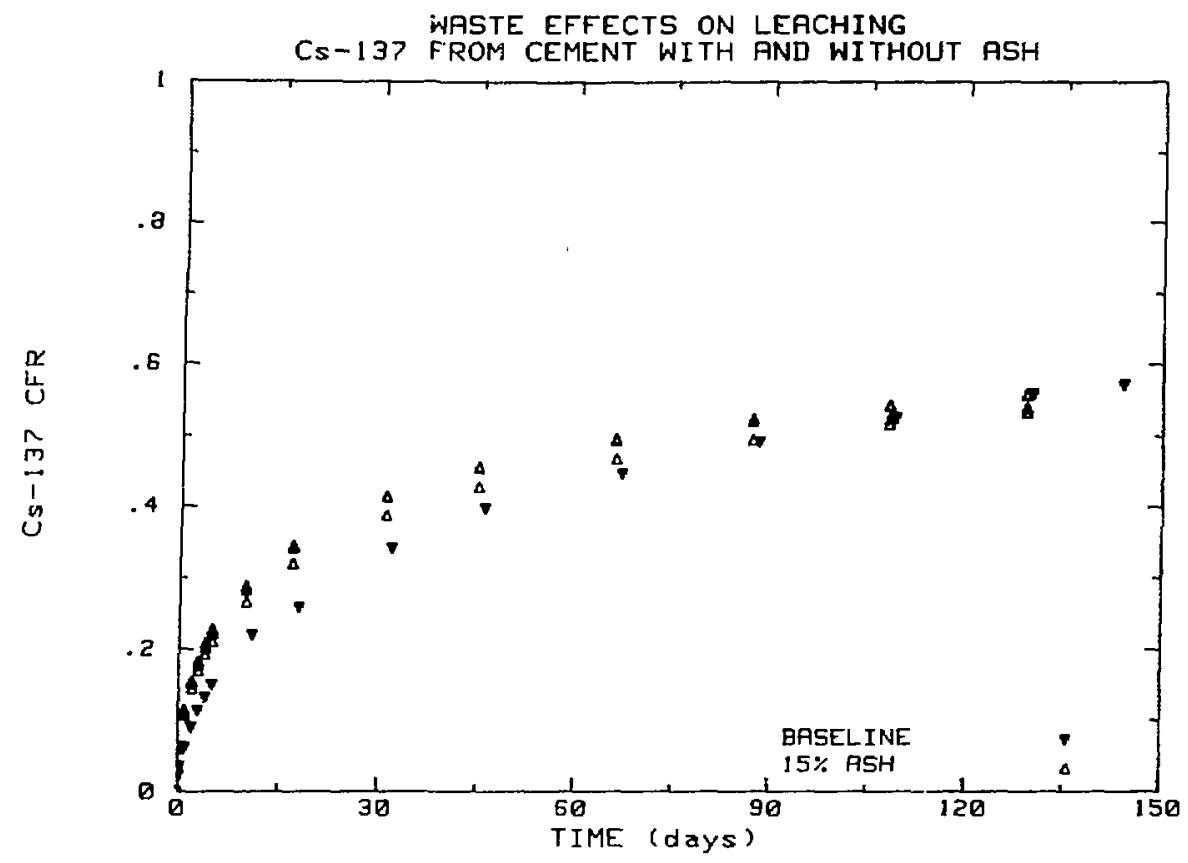

Figure 5.15 Cumulative fraction release of $\mathrm{Cs}-137$ from triplicate cement waste forms containing 15\% incinerator ash compared to CFR of a baseline sample.

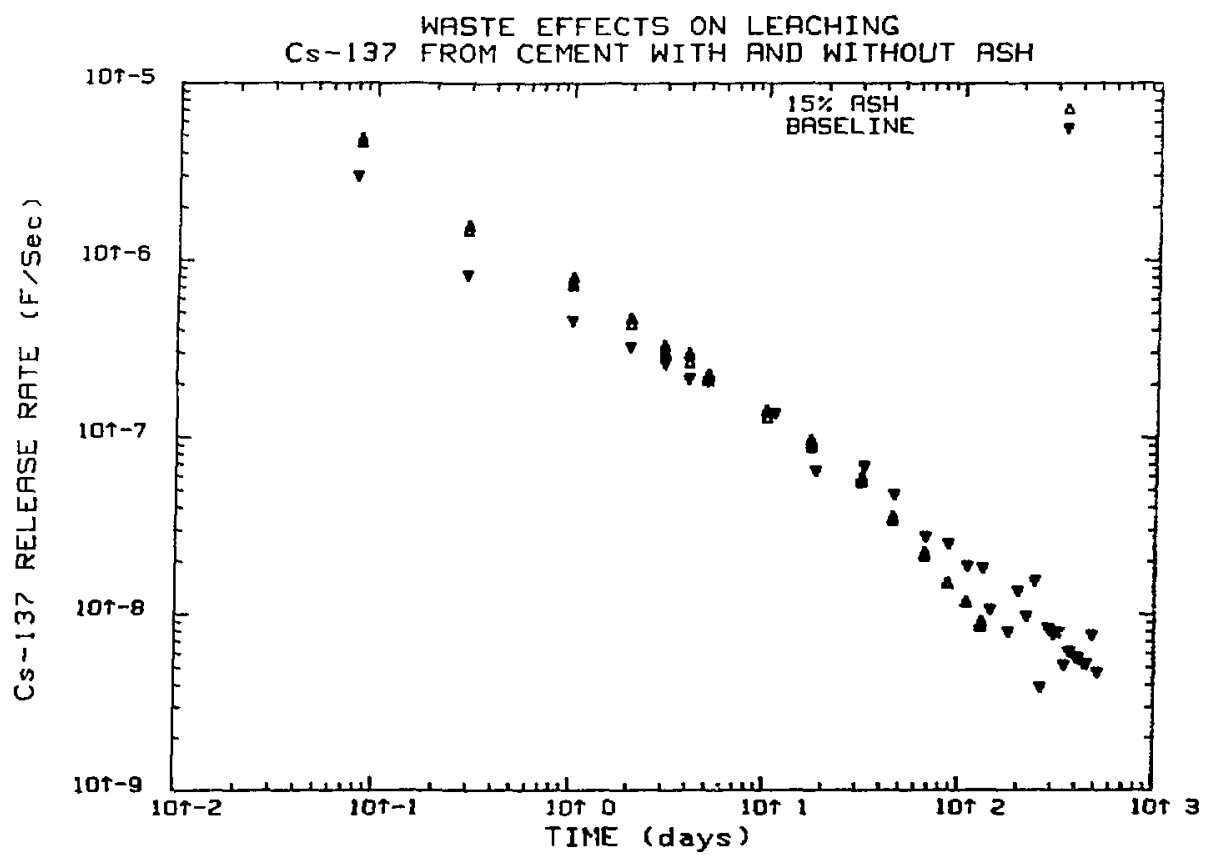

Figure 5.16 Release rates of Cs-137 from triplicate cement waste forms containing $15 \%$ incinerator ash compared to the release rate of Cs-137 from a baseline sample. 


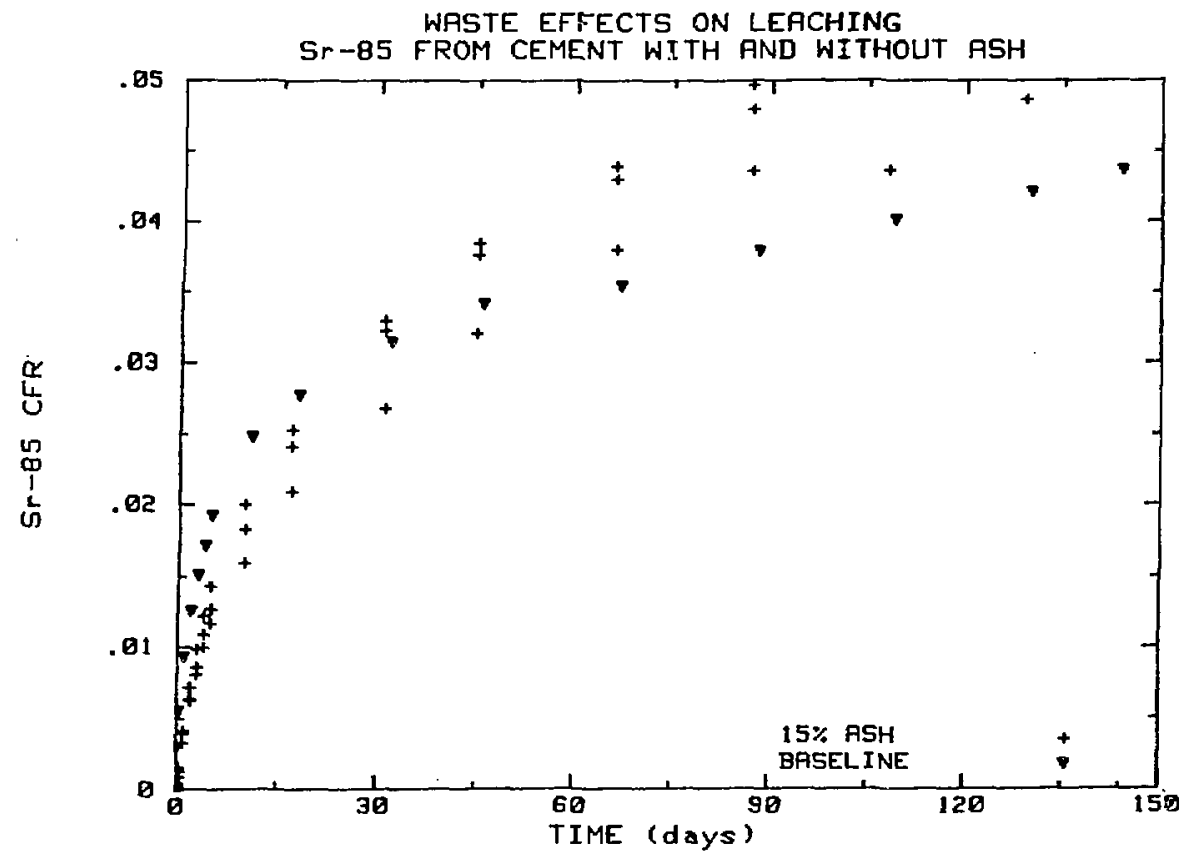

Figure 5.17 Cumulative fraction release of $\mathrm{Sr}-85$ from triplicate cement waste forms containing $15 \%$ incinerator ash compared to $\mathrm{Sr}-85 \mathrm{CFR}$ of a baseline sample.

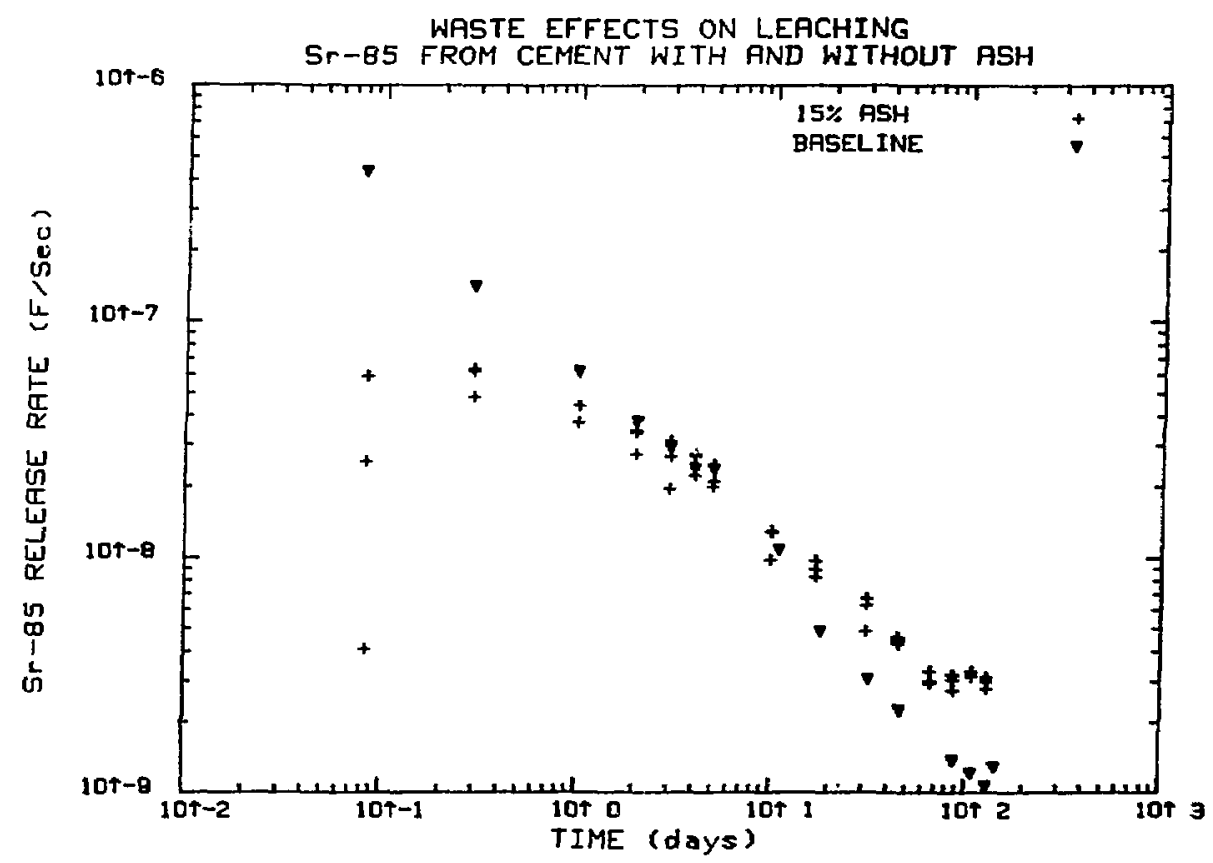

Figure 5.18 Release rates of $\mathrm{Sr}-85$ from triplicate cement waste forms containing $15 \%$ incinerator ash compared to the $\mathrm{Sr}-85$ release rate from a baseline sample. 
Conductance $(\mu \mathrm{mhos} / \mathrm{cm})$ of Leachates from Portland Cement Samples Containing $15 \%$ Incinerator Ash

\begin{tabular}{l}
$\begin{array}{c}\text { Time } \\
\text { (Days) }\end{array}$ \\
\hline Rinse \\
0.08 \\
0.29 \\
1 \\
2 \\
3 \\
4 \\
5 \\
10 \\
17 \\
31 \\
45 \\
56 \\
87 \\
108 \\
129
\end{tabular}

\begin{tabular}{r} 
Sample D \\
Conductance ( $\mathrm{m}$ mos $/ \mathrm{cm}$ ) \\
\hline 18 \\
330 \\
2310 \\
590 \\
490 \\
1250 \\
490 \\
100 \\
1120 \\
900 \\
1080 \\
1180 \\
1270 \\
1150 \\
1120 \\
1080
\end{tabular}

Sample E
Conductance $(u$ mhos $/ \mathrm{cm})$
29
330
350
900
510
2700
680
200
1130
940
1440
1070
1320
1060
970
1030




\subsection{Bitumen + Borate Salt}

Waste forms with two salt concentrations, $20 \%$ and $40 \% \mathrm{Na}_{2} \mathrm{~B}_{4} \mathrm{O}_{7}$ were leached in this study. Results of the two will be discussed together. No solid phase analysis has been performed on the bitumen samples as the tests are continuing.

5.3.1 Leaching Results. Figure 5.19 is a comparison of the cumulative fraction releases of the three isotopes from bitumen containing $40 \%$ borate salts. Cobalt leaches more slowly than cesium and strontium. This was also the case for the baseline experiments.

Data for samples containing salts are limited since the $40 \%$ samples have been leaching for 129 days while the $20 \%$ samples have leached for only 46 days. This preliminary data shows that dramatically different leaching behavior was observed for waste forms containing the two salt concentrations. Cumulative fraction releases of $\mathrm{Cs}-137$ for triplicate samples containing $20 \%$ and $40 \%$ borate salts and a baseline sample, which contained no salts, are shown in Figure 5.20. Release rates are shown in Figure 5.21.

When viewed on a $10 \mathrm{~g} / \mathrm{log}$ plot (Figure 5.22) this data helps show the dif ferences in behavior. Samples with $40 \%$ salt started leaching slowly but water quickly penetrated the sample and leaching began to accelerate after a few days. After 40 days the incremental fraction release started to decline, presumably due to depletion, since the samples had lost $40 \%$ of the tracer. By 100 days these samples had lost most if not all of the Cs-137.

In contrast to these samples are the $20 \%$ borate salt samples and the baseline. As far as the data goes these two sets of samples have identical leaching behavior. Longer term data will be required to determine if leaching of the samples containing $20 \%$ borate salt will follow the baseline or if it will begin to increase after an initial period during which water penetrates to the salt particles.

A $\log / \log$ plot of $\mathrm{Sr}-85$ release is shown in Figure 5.23. These releases are similar to those of cesium but there is more scatter in the data from the $20 \%$ salt samples. Cumulative fraction release and release rates for this radionuclide are shown in Figures 5.24 and 5.25 .

Cobalt fraction releases are shown in figure 5.26 while the release rates are shown in Figure 5.27. As with the other isotopes, the samples containing $20 \%$ salt leached at a rate similar to the baseline samples. However, there is more scatter in the data.

5.3.2 Conductance. Conductance measurements on leachates from the bitumen waste forms provided a good overall measurement of releases of the borate salts from the matrix. The values 1 isted in Table 5.3 reflect what was observed in the radionuclide leaching data. Conductance of the $20 \%=31 t$ samples remained low through 87 days and was comparable to the baseline conductance. Values for the leachate from the $40 \%$ borate samples, however, were extremely high, making a dramatic jump after five days. Conductance peaked at 66 days and had dropped 6-fold by day 145, reflecting sample depletion. 


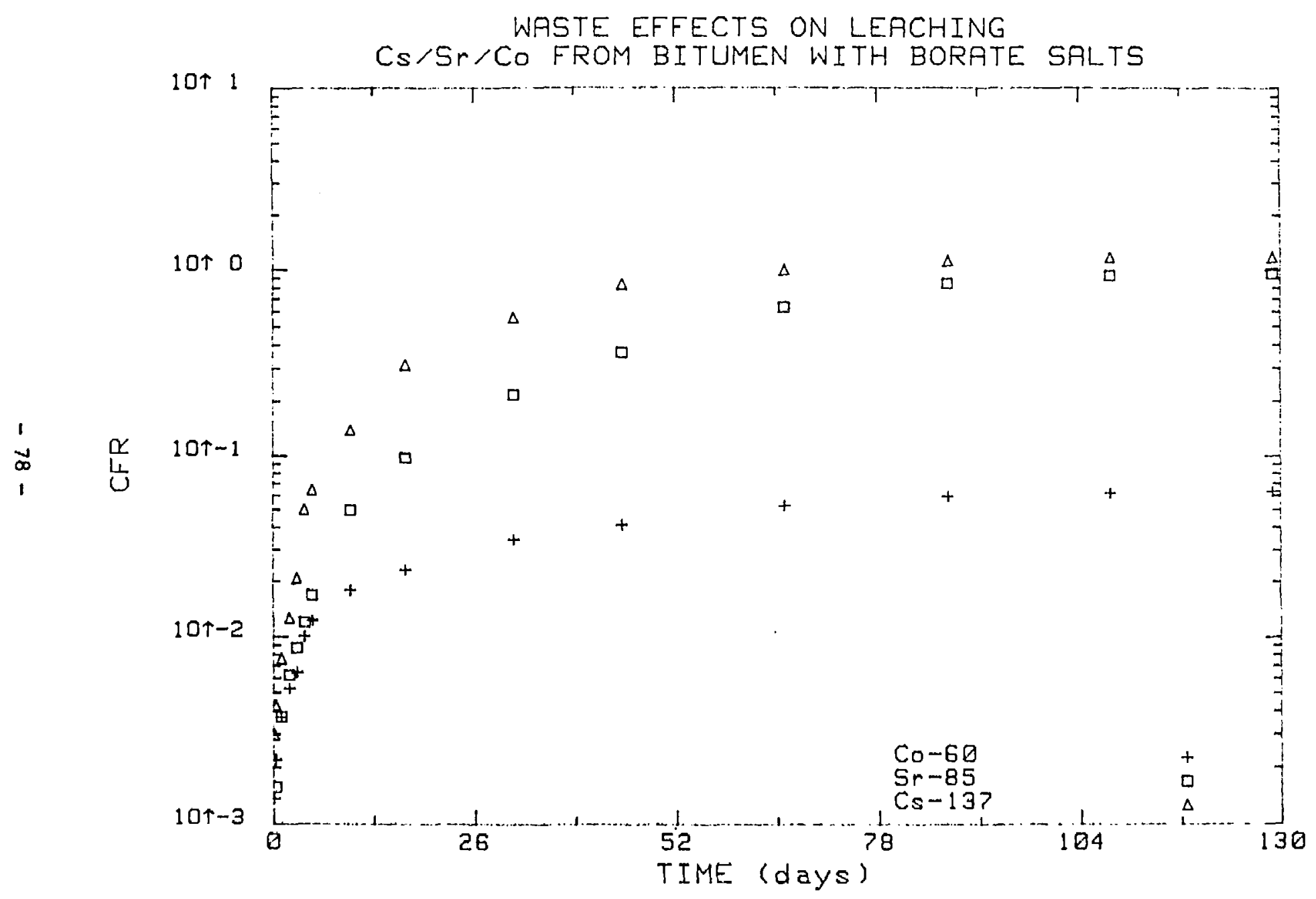

Figure 5.19 Cumulative fraction release of $\mathrm{Cs}-137, \mathrm{Co}-57$ and $\mathrm{Sr}-85$ from a single bitumen waste form containing $40 \%$ sodium tetraborate. 


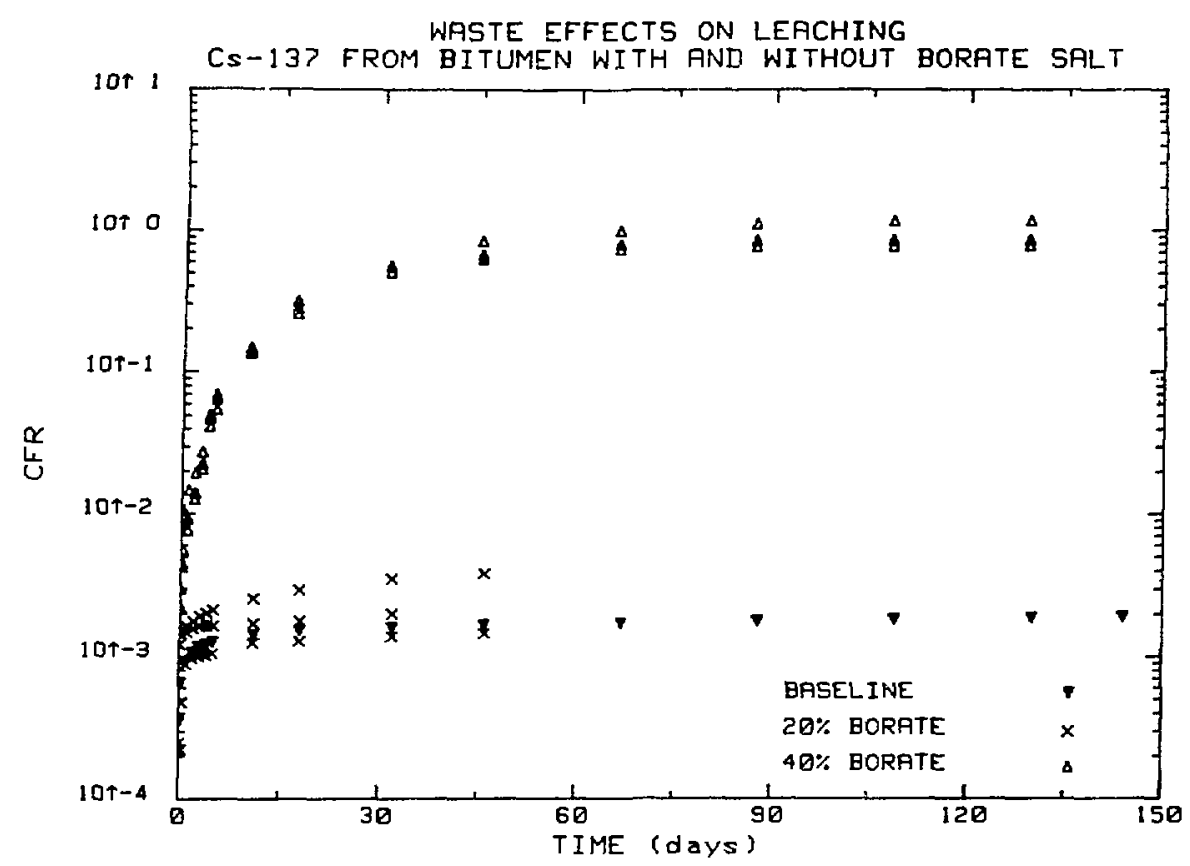

Figure 5.20 Cumulative fraction release of Cs-137 from triplicate bitumen samples containing $40 \%$ and $20 \%$ sodium tetraborate compared to CFR of Cs-137from a baseline sample.

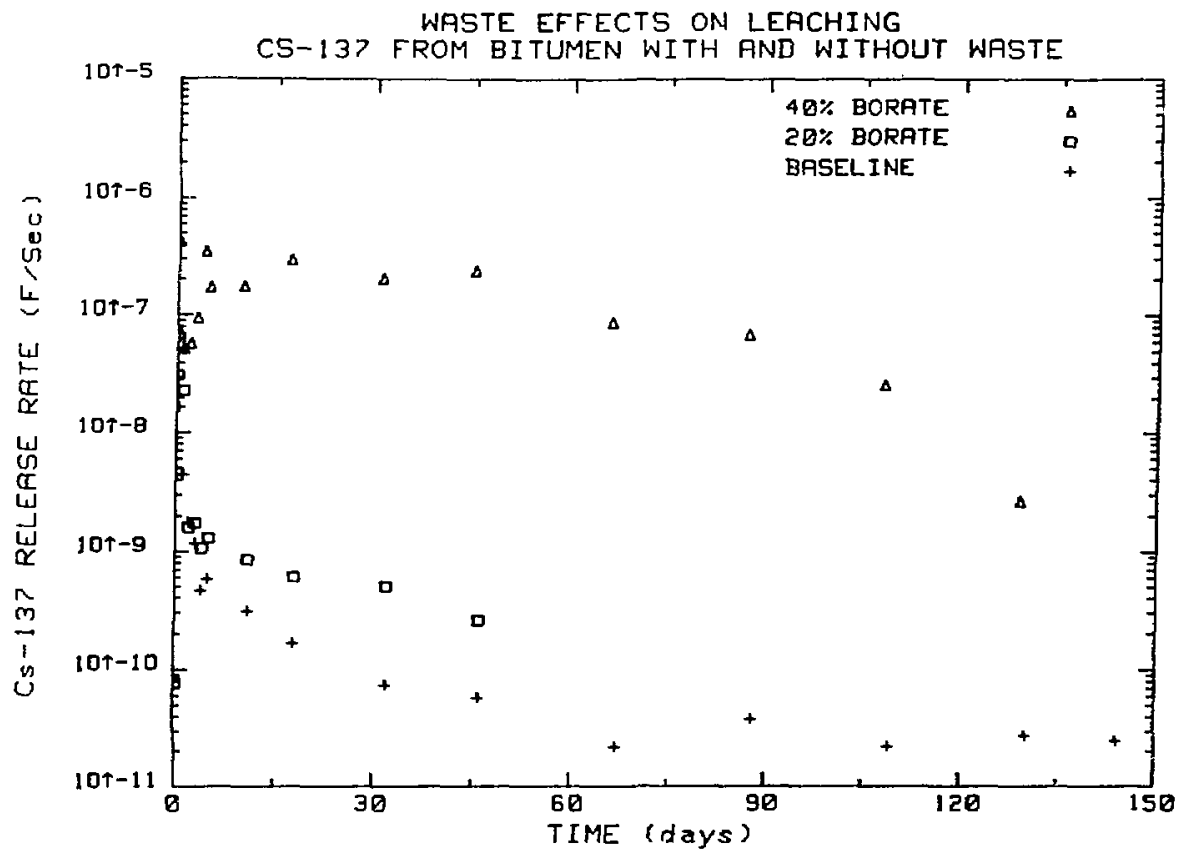

Figure 5.21 Release rates of Cs-137 from single bitumen samples containing $20 \%$ and $40 \%$ sodium tetraborate compared to a baseline sample. 


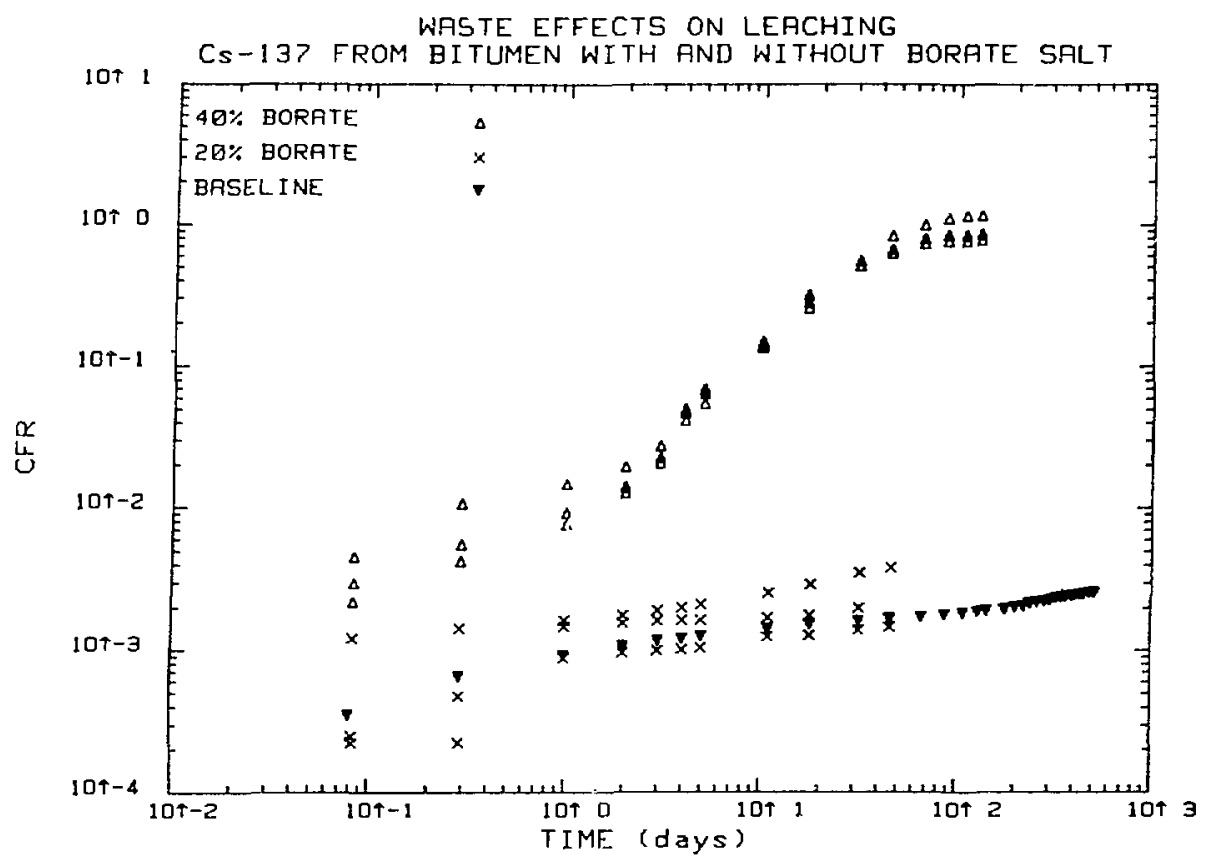

Figure 5.22 Cumulative fraction release of Cs-137 from triplicate samples of bitumen containing $10 \%$ and $40 \%$ sodium tetraborate and for a baseine sample. The log/log scales show the differences in leaching dramatically.

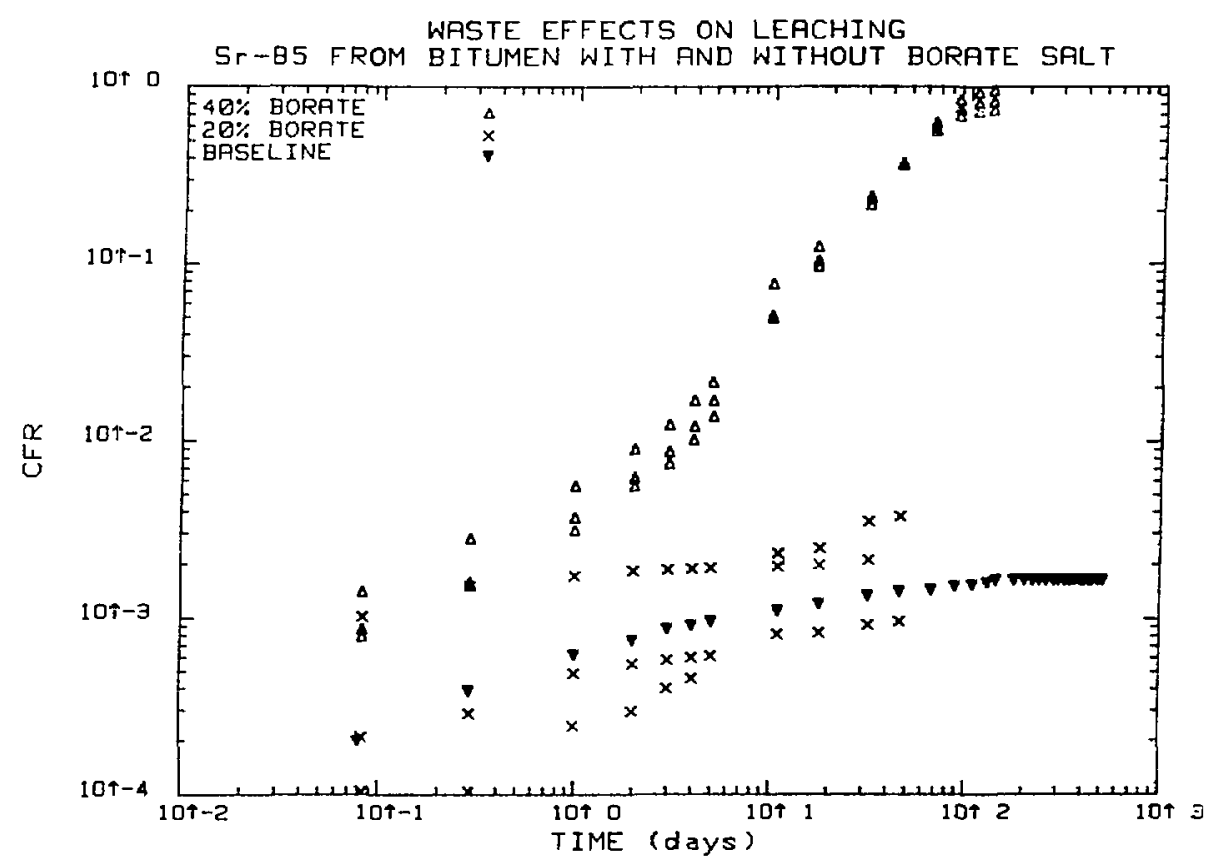

Figure 5.23 Cumulative fraction release of Sr-85 from samples containing $20 \%$ and $40 \%$ sodium tetraborate and from a baseline sample. 


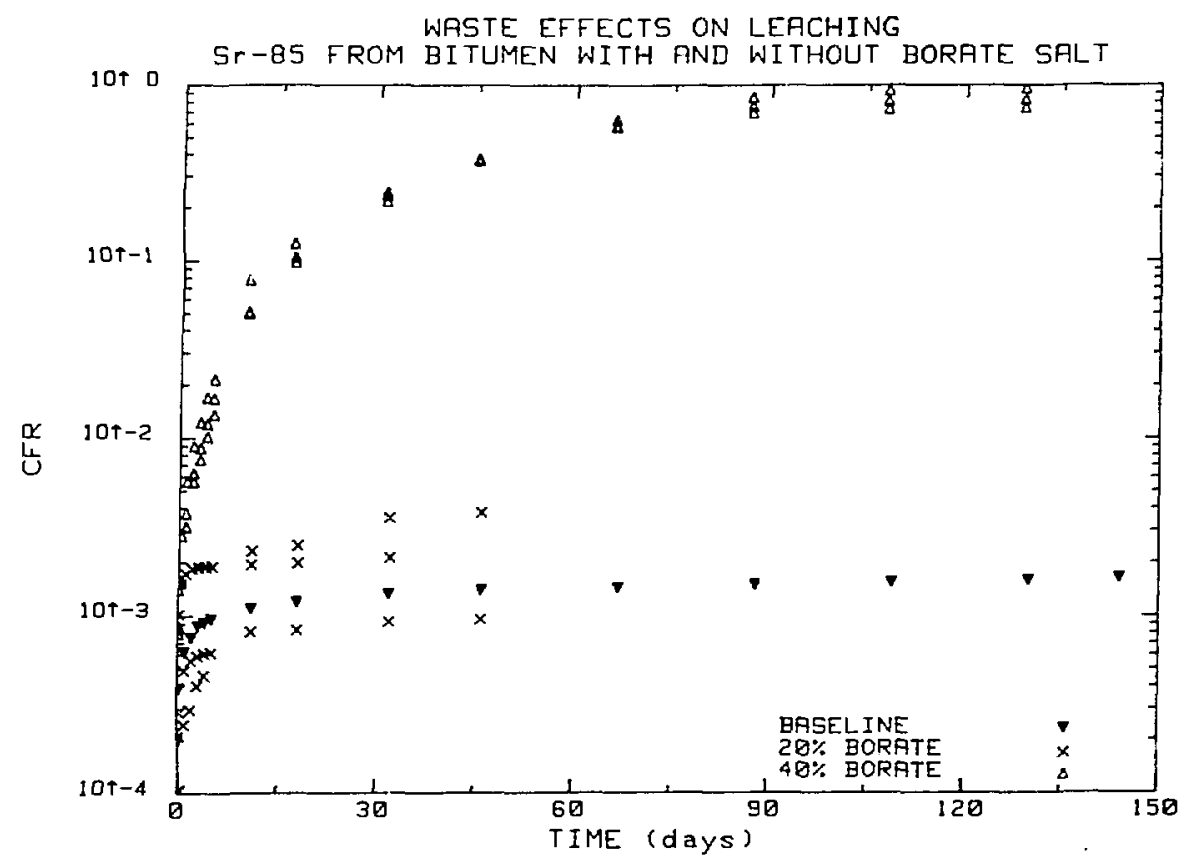

Figure 5.24 Cumulative fraction release of Sr-85 from samples containing $20 \%$ and $40 \%$ sodium tetraborate and from a baseline sample.

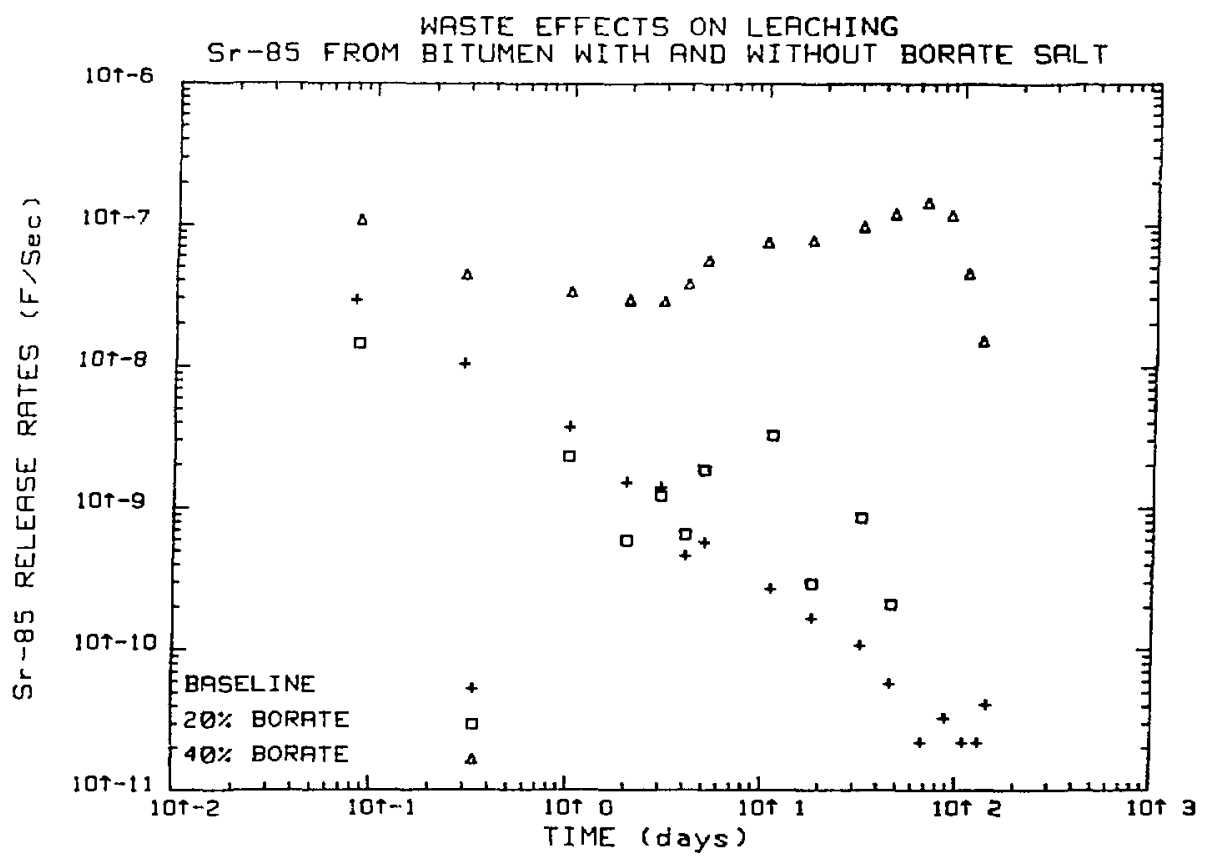

Figure 5.25 Release rates of Sr-85 from bitumen samples containing $20 \%$ and $40 \%$ sodium tetraborate and from a baseline sample. 


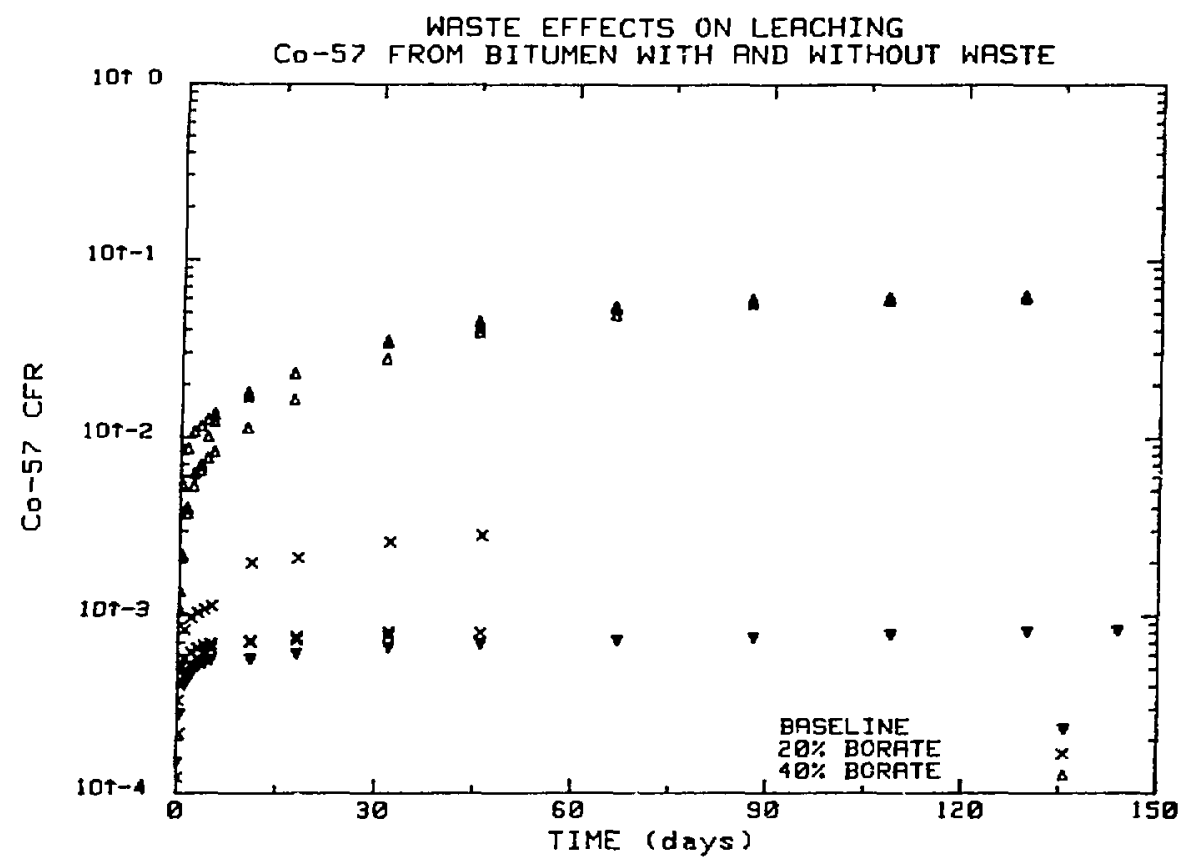

Figure 5.26 Cumulative fraction releases of Co-57 from bitumen samples containing $20 \%$ and $40 \%$ sodium tetraborate and Co-60 from a baseline sample.

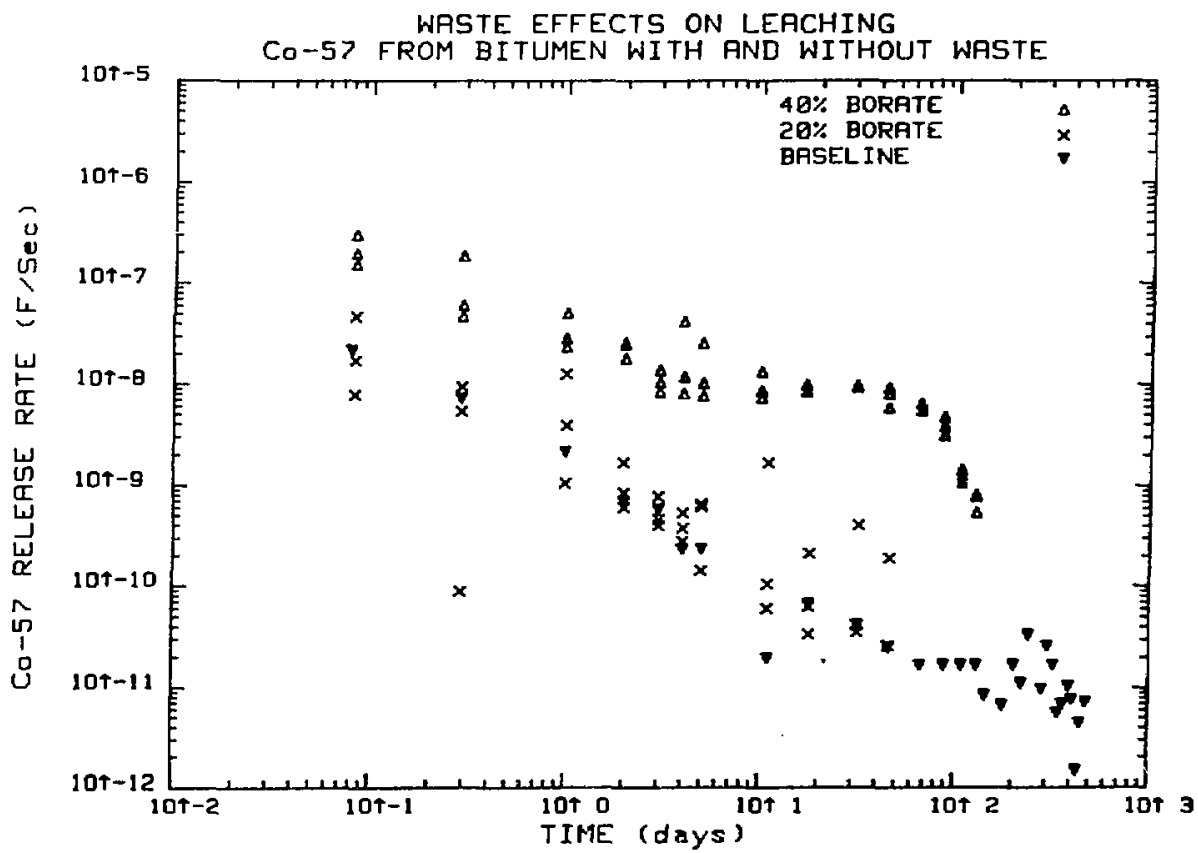

Figure 5.27 Release rates of Co-57 from bitumen samples containing $20 \%$ and $40 \%$ sodium tetraborate and Co-60 from a baseline sample. 
Table 5.3

Conductance (umhos/cm) of Leachates from Bitumen Samples Containing $20 \%$ and $40 \%$ Sodium Tetraborate

\begin{tabular}{cccc}
$\begin{array}{c}\text { Time } \\
\text { (Days) }\end{array}$ & Interval & $\begin{array}{c}\text { Conductance } \\
20 \% \text { borate }\end{array}$ & $\begin{array}{c}\text { Conductance } \\
40 \% \text { borate }\end{array}$ \\
\cline { 2 - 4 } 0 & Rinse & 2.15 & 1.28 \\
0.08 & 1 & 1.25 & 96.7 \\
0.29 & 2 & 2.02 & 69.4 \\
1 & 3 & 0.20 & 92.7 \\
2 & 4 & 1.60 & 17.9 \\
3 & 5 & 1.40 & 1.55 \\
4 & 6 & 1.25 & 2.00 \\
5 & 7 & 1.35 & 3.70 \\
10 & 8 & --5 & 85.0 \\
17 & 9 & 2.00 & 1280 \\
31 & 10 & 1.61 & 2600 \\
45 & 11 & 1.35 & 3170 \\
66 & 12 & $-\cdots$ & 4100 \\
87 & 13 & 1.65 & 3750 \\
108 & 14 & -- & 2510 \\
129 & 15 & --1 & 1630 \\
145 & 16 & -- & 693
\end{tabular}


5.3.3 Conclusions. Although results of the leaching experiments, particularly those for the $20 \%$ sodium tetraborate samples, were relatively short-term, substantial waste effects have been observed. Samples containing $20 \%$ salt leached much like the baseline samples which contained no salt. Those containing $40 \%$ salt leached at a much greater rate and were near depletion by 100 days. After 129 days the cumulative fraction released from the $40 \%$ salt samples were 450 times those of the baseline. From Figure 5.22 it can be seen that after approximately half of the $\mathrm{Cs}-137$ had been released there was a sharp decrease in leach rate, presumably due to depletion. The extreme difference in leaching behavior between $20 \%$ and $40 \%$ salt samples can be explained by the number of interconnected salt particles that provide a pathway for water. Conversely this same phenomena may be viewed in terms of the average thickness of bitumen coatings on individual grains of salt.

\subsection{Vinyl Ester-Styrene/Emulsion with Sulfate Salt Solution}

Vinyl ester-styrene samples containing $15 \% \mathrm{Na}_{2} \mathrm{SO}_{4}$ made as an $50 \%$ emulsion with a solution of $\mathrm{Na}_{2} \mathrm{SO}_{4}$, are being leached. Preliminary leaching results have been obtained to 129 days. The samples discussed in this section are still being leached so solid phase analysis is not available.

5.4.1 Leaching Results. Figure 5.28 shows cumulative fraction released from VES emulsion for the three isotopes used in this study. Cobalt and strontium had similar releases at about $9 \%$. Cesium releases were slightly higher at $10.3 \%$.

Cumulative fraction released for Cs-137 from the VES/sodium sulfate solution emulsion are shown in Figure 5.29. Releases are about 35 times greater than from the baseline samples after 129 days. Figure 5.30 shows the release rates of both sets of samples. The baseline samples had a linear drop in release rate with time that was independent of sampling frequency. This is reasonable because only tracer quantities of material were moving into the leachate. Therefore, there was no reduction in leach rate due to increased zoncentration in the leachant. Samples containing sulfate salts had greater release rates, but they also evidenced a distinct change in release rate at about 10 days.

Strontium releases shown as CFR and as release rates are presented in Figures 5.31 and 5.32. Cobalt releases were similar to those for strontium and are not shown.

5.4.2 Conductance. Values for leachate conductance are given in Table 5.4 for duplicate VES emulsion samples. Conductance values are typically 100 times those of the VES baseline. They are equivalent to, or slightly lower than, the cement baseline values which exhibit a similar trend of changing release rate with sampling intervals greater than one day.

5.4.3 Conclusions. Leaching of C5-137 from VES emuision samples was 35 times greater when sodium sulfate solution was included in the waste form than when distilled water was used. The release rate of this material was 
WASTE EFFECTS ON LEACHING

$\mathrm{C} s / \mathrm{S} r / C O$ FROM VES WITH SULFATE SALTS

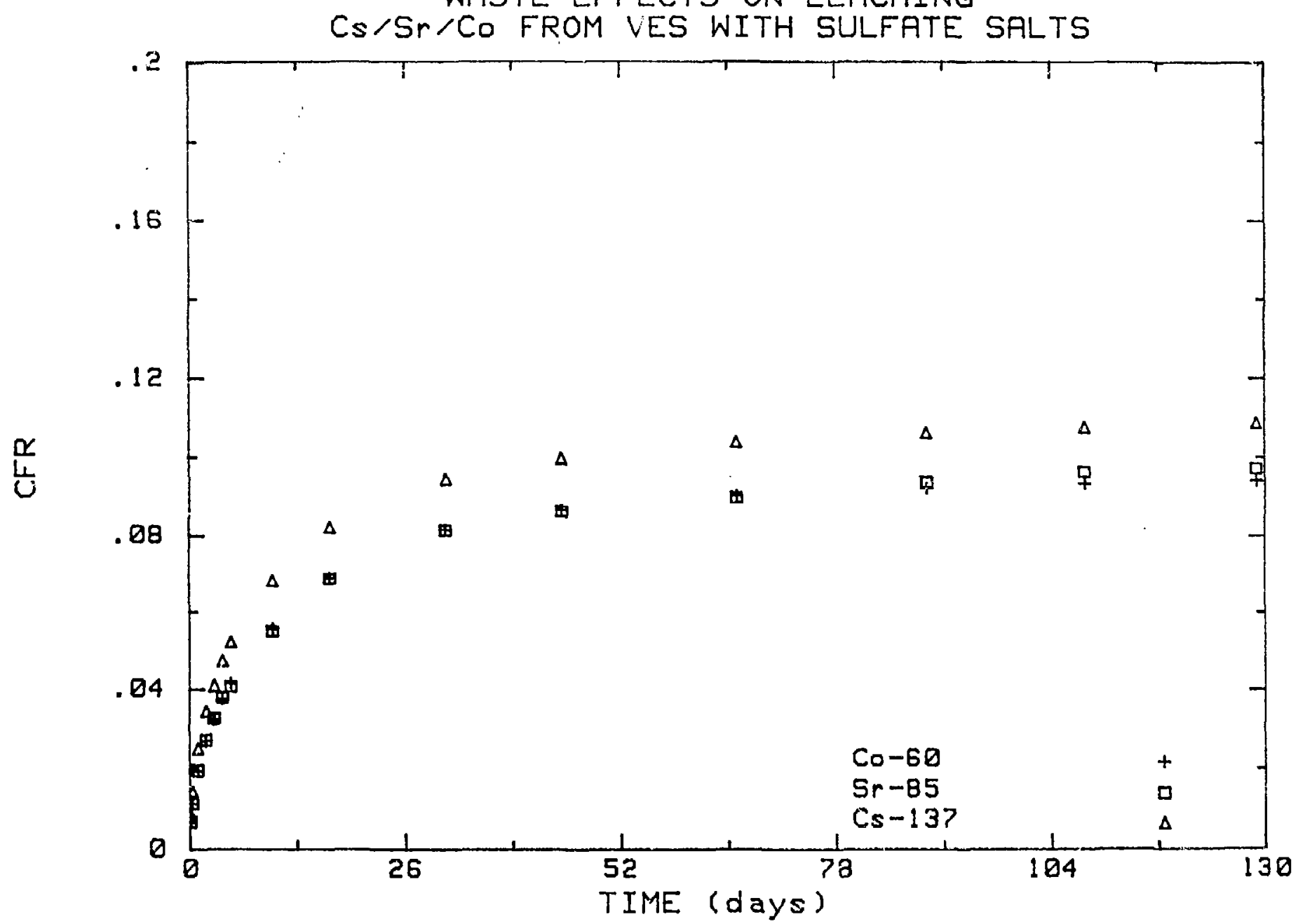

Figure $5.28 \mathrm{Cs}-137$, Co-57 and Sr-85 from a single VES emulsion sample containing sodium sulfate salts. Cesium releases are slightly faster than the other isotopes. 


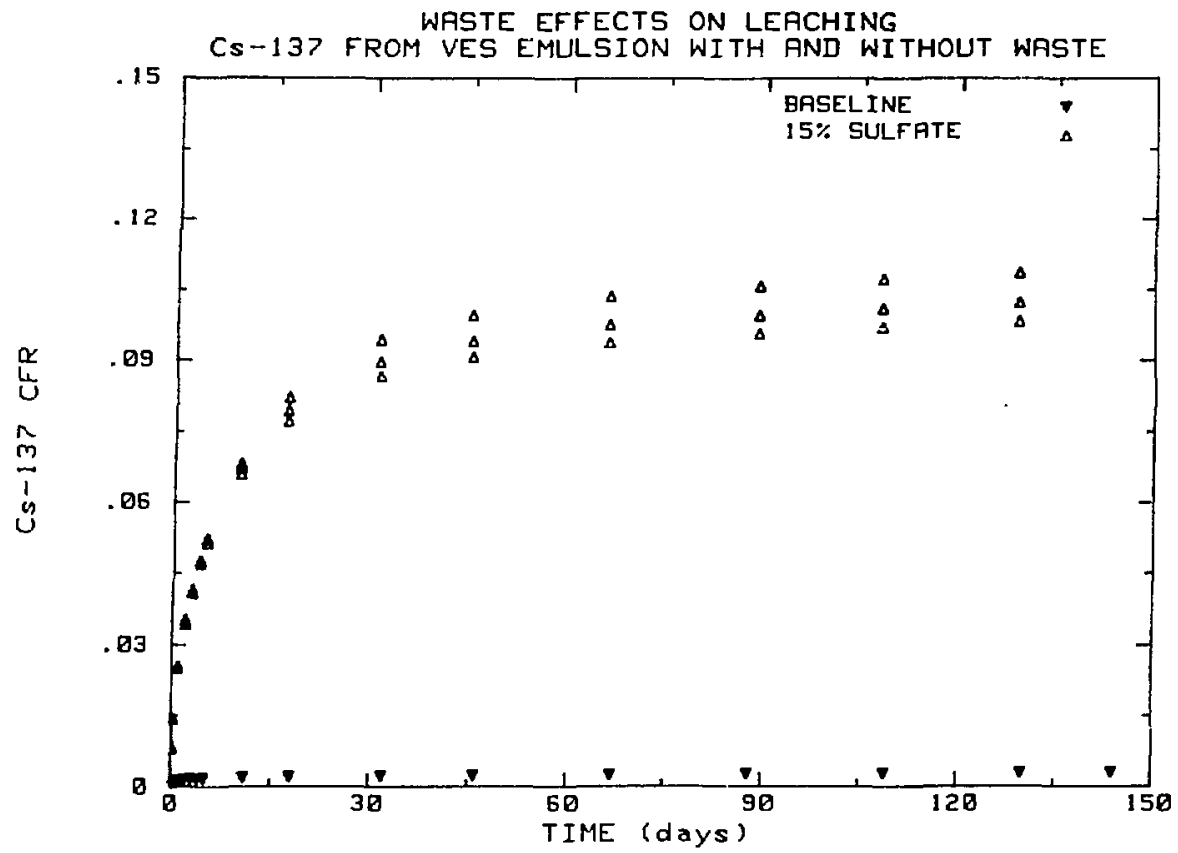

Figure 5.29 Cumulative fraction release of Cs-137 from triplicate VES emulsion samples containing $15 \mathrm{wt} \%$ sodium sulfate compared to a VES baseline.

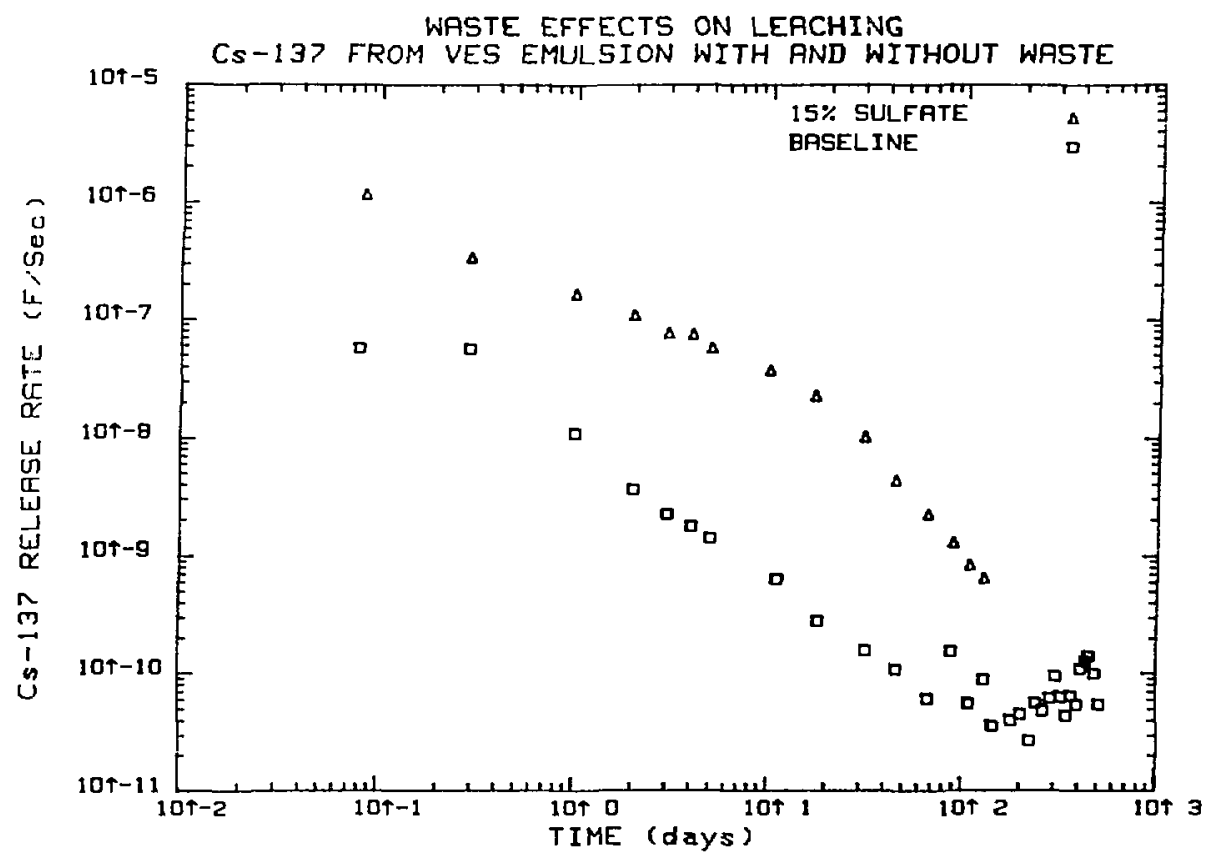

Figure $5.30^{\circ}$-Release rates of $\mathrm{Cs}-137$ from a single VES emulsion sample compared to release of VES baseline sample. 


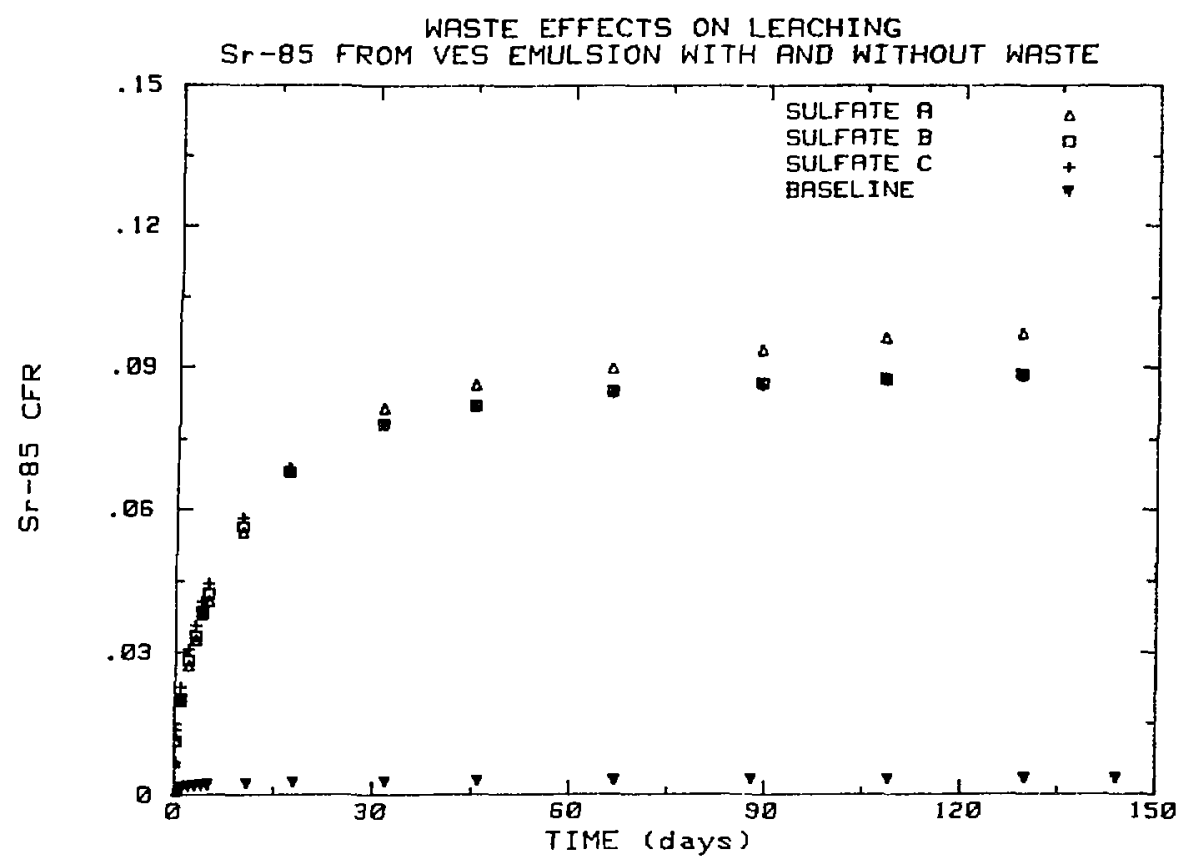

Figure 5.31 Cumulative fraction release of $\mathrm{Sr}-85$ from triplicate VES emulsion samples compared to CFR from a baseline sample.

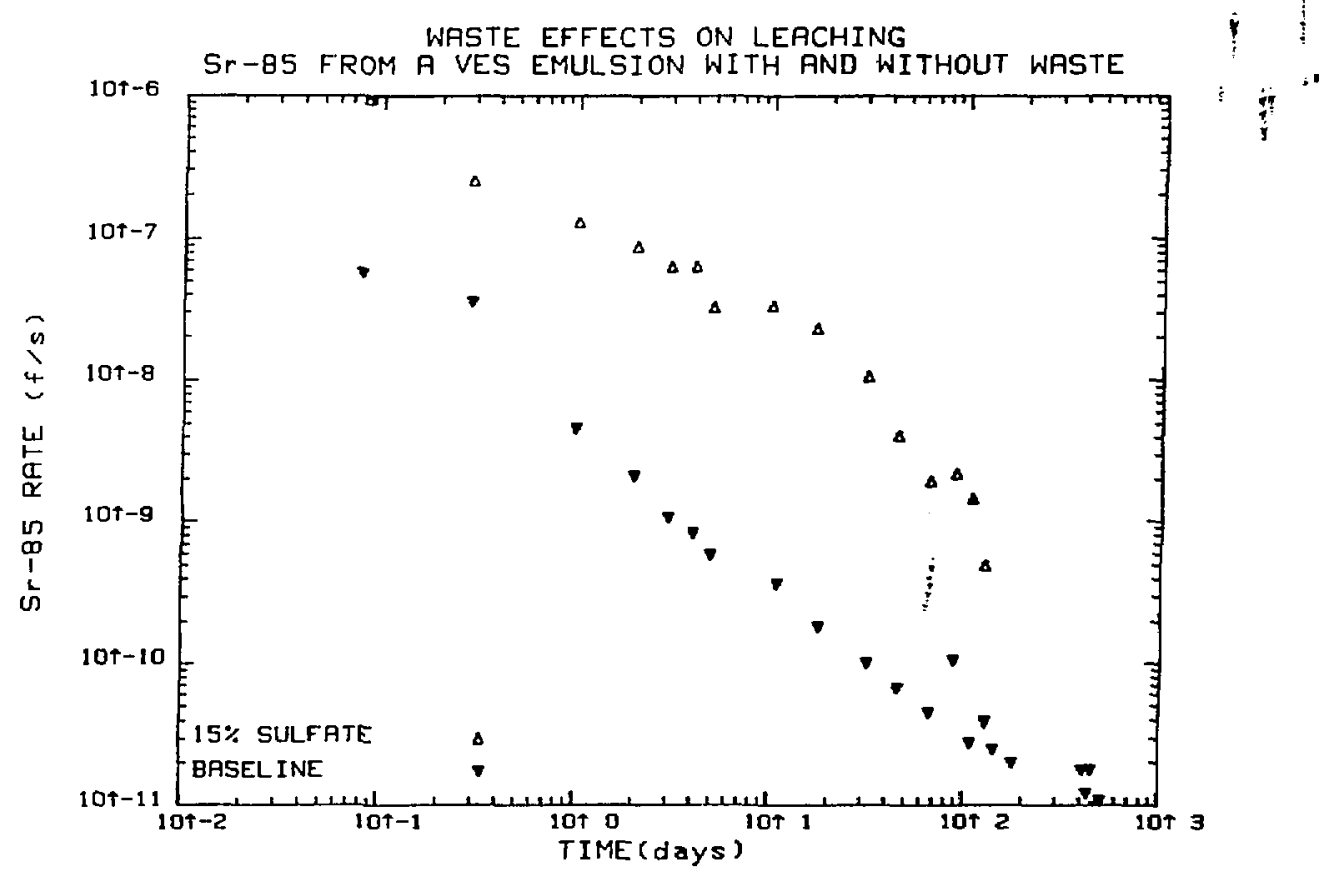

Figure 5.32 Release rates of Sr-85 from triplicate VES emulsion samples and from a baseline sample. 
Table 5.4

Conductance (umhos/cm) of Leachates from Vinyl Ester-Styrene Emulsion Samples Containing Sodium Sulfate

\begin{tabular}{cccc}
$\begin{array}{c}\text { Time } \\
\text { (Days) }\end{array}$ & Interval & $\begin{array}{c}\text { Conductance } \\
\text { Sample } D^{1}\end{array}$ & $\begin{array}{c}\text { Conductance } \\
\text { Sample } E^{2}\end{array}$ \\
\cline { 2 - 4 } 0 & Rinse & 76 & 38 \\
0.08 & 1 & 260 & 310 \\
0.29 & 2 & 190 & 210 \\
1 & 3 & 360 & 340 \\
2 & 4 & 230 & 230 \\
3 & 5 & -10 & -2 \\
4 & 6 & 310 & 310 \\
5 & 7 & 120 & 130 \\
10 & 8 & 520 & 510 \\
17 & 9 & 250 & 190 \\
31 & 10 & 190 & 240 \\
45 & 11 & 89 & 120 \\
66 & 12 & 71 & 48 \\
87 & 13 & 48 & 14 \\
108 & 14 & 39 & 64 \\
129 & 15 & 20 & 53 \\
145 & 16 & 52 & 54
\end{tabular}

$1 \mathrm{D}$ and $\mathrm{E}$ are duplicate samples 
influenced by the concentration of salt in the leachate with the rate changing as sampling intervals changed. This was not the case for the release rate from baseline samples which decreased linearly on the log/log plot. Solid phase analysis may be important in resolving why the behavior of the waste bearing samples is different than that of the baseline.

\subsection{Vinyl Ester-Styrene + Dry Sulfate Salts}

The vinyl ester-styrene copolymer system was used to solidify $40 \mathrm{wt} \%$ dry sulfate salts. Leaching data for these samples extends to only 67 days, but releaes are quite high, approaching $80 \%$ for one sample. These leaching experiments are continuing, therefore, no solid phase anlays is have been obtained.

5.5.1 Leaching Results. Figure 5.33 shows cumulative fraction released for cobalt, strontium and cesium from a VES/dry salt sample containing 40 wt\% sodium sulfate salts. For this sample strontium leached the fastest followed by cobalt and then cesium. This trend is not repeated by other samples and the overall scatter in the data is such that no pattern, of any single isotope leaching fastest, was observed. Therefore only Cs-137 releases will be discussed.

Cumulative fraction released of $\mathrm{Cs}-137$ from triplicate samples are shown in Figure 5.34. Also shown is an estimated maximum release for a VES dry sample which contained no salt. Releases from the actual baseline samples were below detection limits (for a 1000 minute count), therefore, an estimated maximum release was calculated based on these minimal count rates. Releases of radionuclides by samples containing salt are 200 to 300 times the estimated maximum baseline release. There is wide spread among replicate samples. For example, the 67 day cumulative fraction releases of three samples were $47 \%$, $71 \%$ and $77 \%$. Release rates are shown in Figure 5.35 .

5.5.2 Conductance. Conductance values of leachates from duplicate VES samples containing $40 \%$ sodium sulfate salt are shown in Table 5.5 . These high conductance values indicate that significant quantities of salt leached from the waste form. Further analysis by atomic absorption spectrophotometry will determine the fraction of salts released to determine if releases of salt and radionuclides are closely related.

5.5.3. Conclusions. Releases of various isotopes from VES containing dry sodium sulfate salts were similar; there does not appear to have been any preferential retention of a particular isotope. There were significant effects due to waste loading on leaching. Releases of Cs-137 from VES samples containing $40 \%$ salts were 325 times larger than releases from the baseline and reached an average of $65 \%$ release. Release rates decreased linearly on the $\log / \log$ plot (Figure 5.35) to 11 days then increased. The subsequent decrease, after 50 days, is probably due to depletion. 


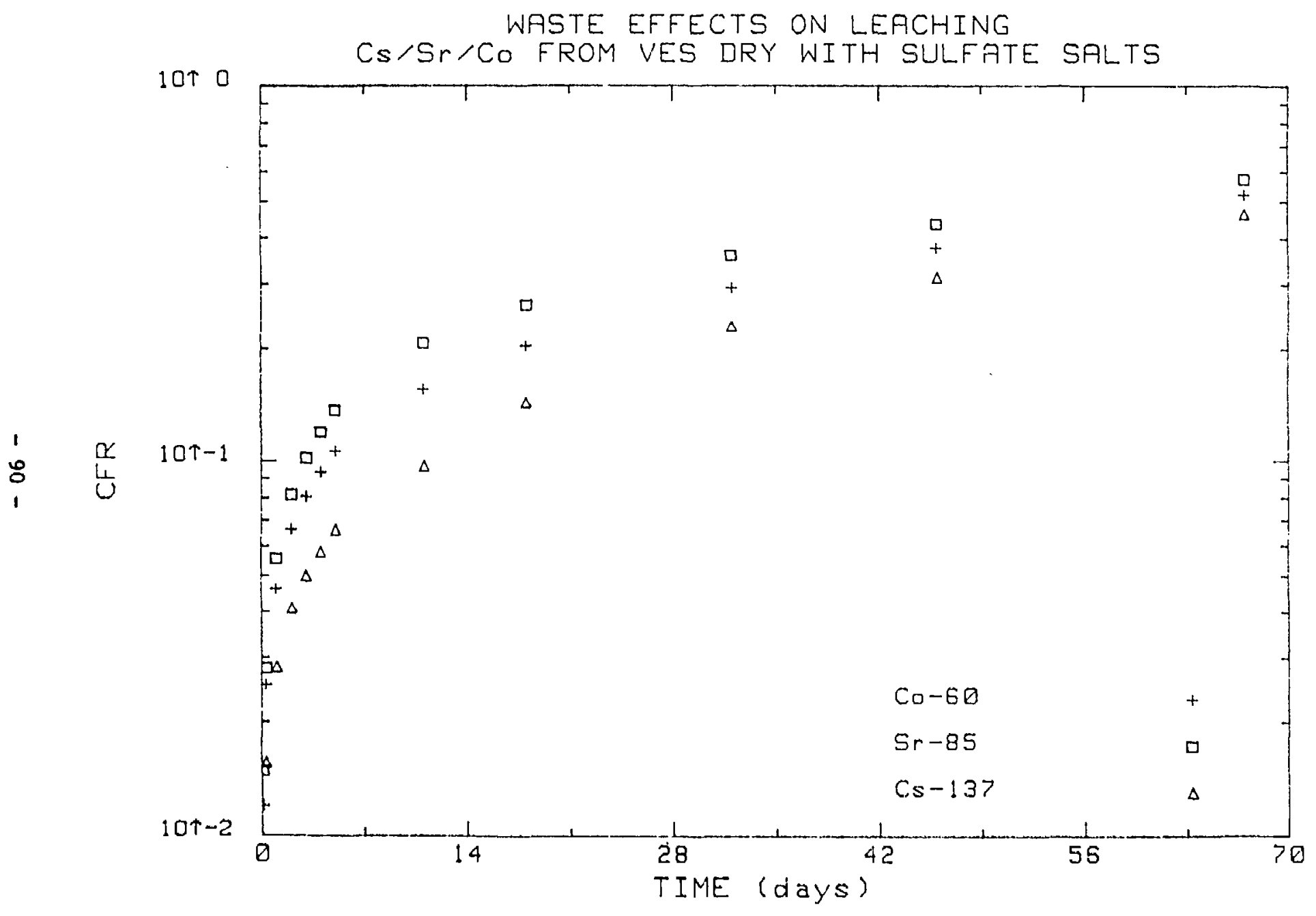

Figure $5.33 \mathrm{Cs}-137, C_{0}-60$ and $\mathrm{Sr}-85$ cumulative fraction releases from a VES dry sample containing $40 \%$ sodium sulfate salt. 


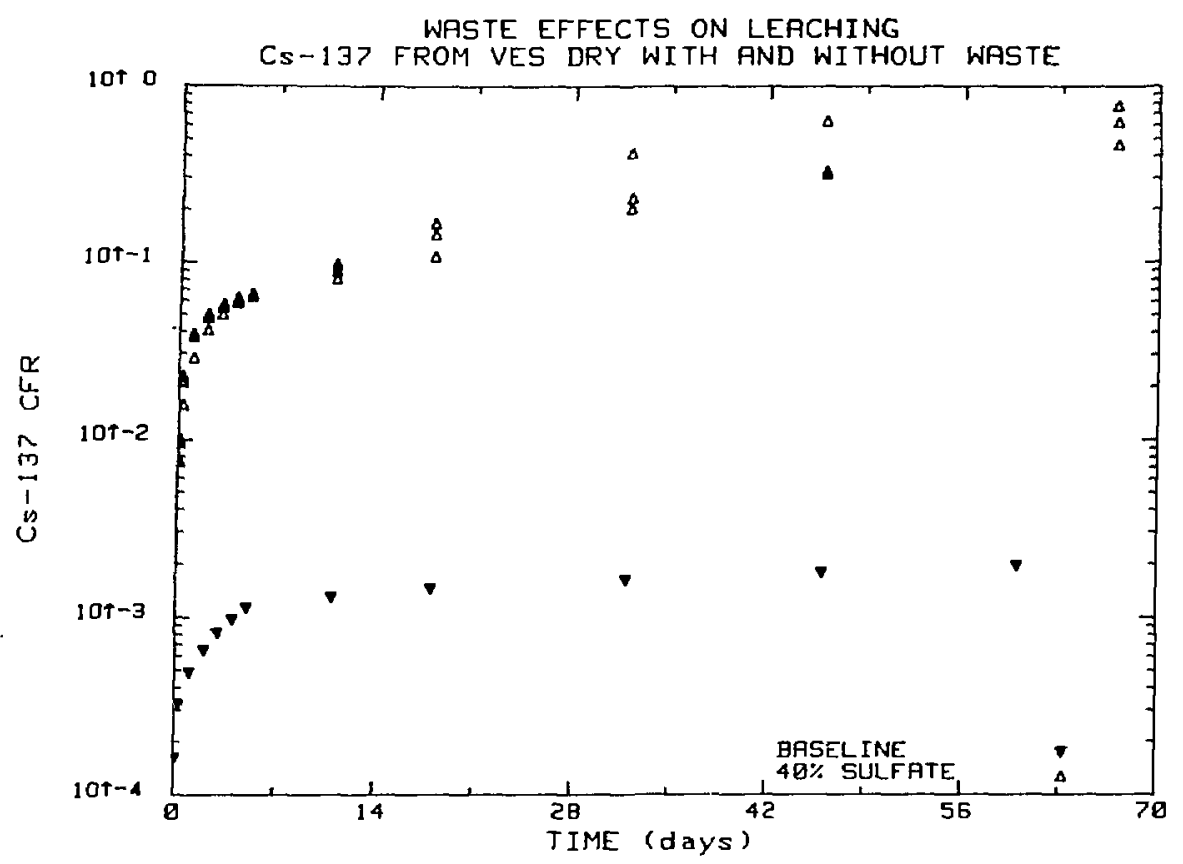

Figure 5.34 Cumulative fraction releases of CS-137 from triplicate VES dry sample containing $40 \%$ sodium sulfate salts compared to an est $i$ mated baseline derived from detection limits.

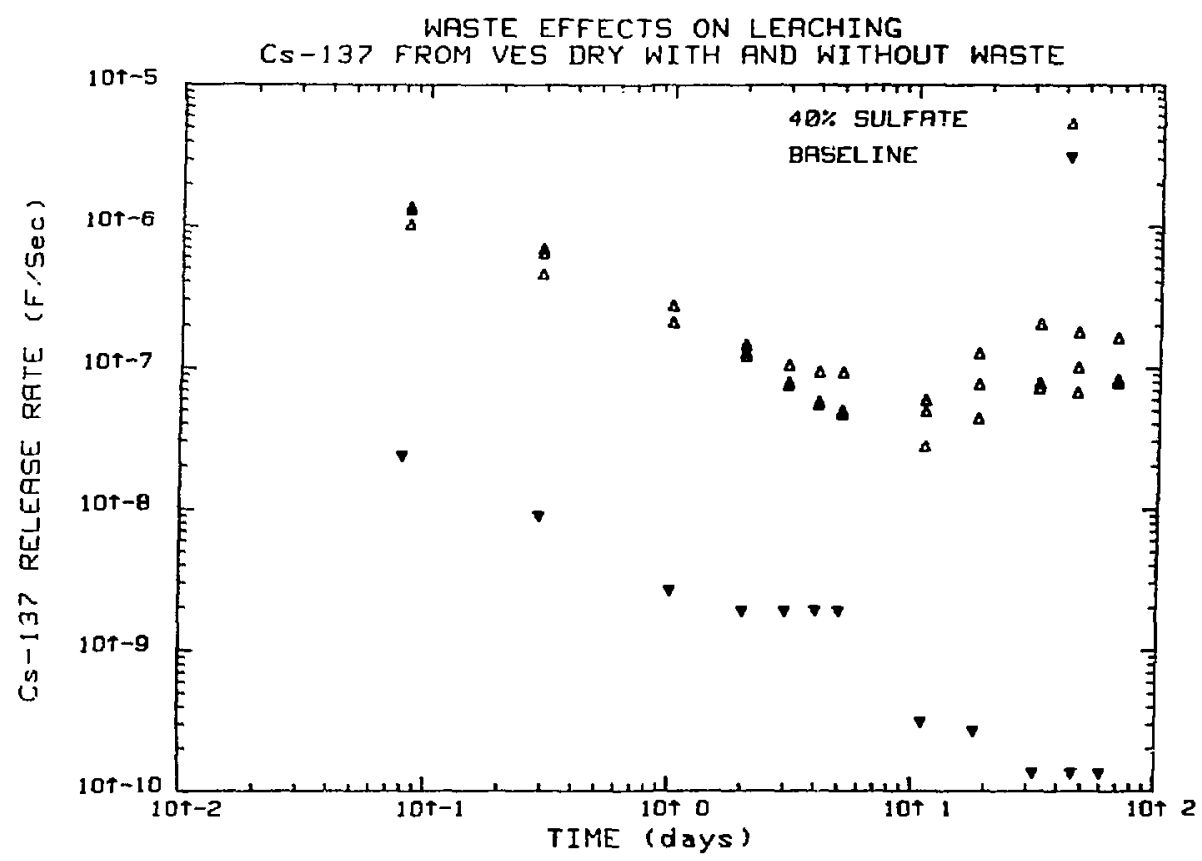

Figure 5.35 Releases rates of Cs-137 from triplicate VES dry samples compared to an estimated baseline. 
Conductance ( $u$ mhos/cm) of Leachates from VES Samples Containing $40 \%$ Sodium Sulfate

Time

(Days)

0

0.08

0.29

I

2

3

4

5

11

18

32

44
Interval.

Rinse

1

2

3

4

5

6

7

8

9

10

11

\section{Conductance \\ Sample D}

70

480

420

680

450

320

230

270

$---$

1280

550

220
Conductance

Sample E

62

550

450

740

540

350

260

200

$-\cdots$

870

340

290

\subsection{Soda Lime Glass + Incincator Ash}

Low leach rates were expected for soda 1 ime glass/ash waste forms.

Elevated temperatures and leaching of a pulverized sample waste were tried in separate tests.

\section{6 .1 Leaching Results}

A glass/ash waste form was leached at $50^{\circ} \mathrm{C}$ in deionized water using the modified ANS 16.1 test. Cs-137 was not observed in the leachates after 67 days.

A second sample was leached at $90^{\circ} \mathrm{C}$ for 28 days in deionized water. Cs-137 was not observed in the leachate.

A third sample was pulverized to a fine powder and leached in deionized water in accordance with the ACC3 Agitated Powder Leach Test. Again, Cs-137 was not observed in the leachate.

\subsubsection{Conclusions}

The low leach rate expected for glass and the relatively low initial source terms for Cs-137 in the glass/ash waste forms may account for the lack of observable $\mathrm{Cs}-137$ in the leachates. 
6. THE EFFECT OF DISPOSAL ENVIRONMENT ON THE LEACHING BEHAVIOR OF WASTE FORMS

\subsection{Simulated Groundwater Leaching of Radionuclides}

A major objective of this program is to determine the leaching behavior of low-level waste forms in disposal environments. Contact of the waste forms with the local groundwater initiates leaching of radionuclides after disposal in a shallow land burial site. For the purposes of this discussion the waters in contact with the buried waste forms can be considered to be of two types: first, a well-oxygenated local groundwater formed by percolation of rainwater through the soil; second, anoxic trench water formed by the reaction of biodegradable wastes in contact with the groundwater.

The initial leaching experiments were conducted using a well-oxygenated simulated groundwater. Future leaching experiments using a leachant which simulates anoxic trench water are planned since these may be more aggressive leachants.

A review of the properties of groundwater and trench water is presented to provide information for understanding groundwater effects.

6.1.1 Selection of a Representative Groundwater. The discussion presented in this section will be used as background for the design of a method to prepare a simulated water representative of burial site conditions. The simulated water will be used to determine waste form leaching behavior using a modified ANS 16.1 leach test to approximate leaching in a naturai environment.

6.1.2 Major Ion Constituents of Groundwater. The composition of a natural water at any specific site is a function of the varieties of soil, vegetation and other matter present at and near the site. Aithough the compositions of natural waters are quite variable, some generalities regarding composition are available. For example, virtually all natural waters have been said to contain sulfate, chloride and carbonate and bicarbonate salts. Representative concentrations of these anions in a "typical" natural water are listed in Table $6.1[6,28]$.

Although the information in Table 6.1 is not very useful for any specific site, it does serve to point out that groundwater and trench water may be expected to contain significant amounts of these anions.

The ionic composition of well waters is derived from two major processes: the dissolution of carbonates and feldspars by soluble carbon dioxide derived from the atmosphere. Representative dissolution and precipitation reactions are the dissolution of calcite $\left(\mathrm{CaCO}_{3}\right)$ and the formation of Kaolinite [29]. 
Table 6.1

Representative Concentrations (ppm) of Chloride, Sulfate and Bicarbonate Plus Carbonate Anions in Natural Waters

\begin{tabular}{lcc} 
Chloride & Rainwater & \multicolumn{1}{c}{$\begin{array}{c}\text { Terrestrial } \\
\text { Waters }\end{array}$} \\
\cline { 2 - 3 } Sulfate & 1 & 6 \\
$\begin{array}{l}\text { Bicarbonate } \\
\text { plus Carbonate }\end{array}$ & 4 & 12 \\
& 1 & 35
\end{tabular}

Wedepohl, K.H., Geochemistry, Holt, Reinhart and Winston, Inc., New York, 1967.

$$
\begin{aligned}
& \mathrm{CaCO}_{3}+\mathrm{CO}_{2}+\mathrm{H}_{2} \mathrm{O}+\mathrm{Ca}_{+}+2 \mathrm{HCO}_{3}^{-} \\
& \text {calcite } \\
& \begin{aligned}
\mathrm{NaAlSi}_{3} \mathrm{O}_{8}(\mathrm{~S})+\mathrm{CO}_{2}+11 / 2 \mathrm{H}_{2} \mathrm{O}+\mathrm{Na}^{+}+\mathrm{HCO}_{3}^{-} \\
+1 / 2 \mathrm{Al}_{2} \mathrm{Si}_{2} \mathrm{O}_{5}(\mathrm{OH})_{4}(\mathrm{~S}) \\
\text { Kaolinite }
\end{aligned}
\end{aligned}
$$

More specific information is available from studies of trench waters and well waters from the low-level waste burial sites at Barnwell, South Carolina, Maxey Flats, Kentucky and Oak Ridge National Laboratory, Tennessee [30,31,32]. For purposes of discussion, groundwaters are defined as water from the shaliow land environment which has not been affected by the buried waste. The groundwater compositions are all dominated by calcium, magnesium, sodium and potassium cations and sulfate, chloride and bicarbonate anions. The groundwater compositions are qualitatively consistent with the representative anion compositions listed in Table 1 for terrestrial waters in that sulfate, chloride and bicarbonate account for virtually all of the inorganic anion content even though the quantities and relative fractional compositions vary.

A typical groundwater composition is given in Table 6.2 for well $313(6.3$ meters deep) at the ORNL Area 6 Engineered Test Faci] ity [31]. 
Concentrations of the Major Cations and Anions in Groundwater from ORNL Well 313

Species

$\mathrm{Na}$

$\mathrm{K}$

$\mathrm{Ca}$

$\mathrm{Mg}$

C1

$\mathrm{SO}_{4}-2$

$\mathrm{HCO}_{3}{ }^{-1}$

$\frac{\text { Concentration }}{(\mathrm{ppm}) \quad(\mathrm{meq} / \mathrm{L})}$

3.80

0.165

0.012

2.844

57.00

0.235

2.86

0.065

2.30

3.20

$120.0^{\mathrm{a}}$

a. Calculated from the total alkalinity (as $\mathrm{CaCO}_{3}$ ) of $172 \mathrm{ppm}$.

In sum, available evidence indicates that trench water compositions at the shallow land burial sites vary considerably from the ambient groundwaters at these sites. The trench waters had relatively low Eh values and contained ferrous and ammonium cations but little, if any, sulfate whereas the groundwaters were relatively oxidizing and contained substantial amounts of sulfate, but no ferrous or ammonium ions. These trench water characteristics probably result from chemical decomposition and/or biodegradation of the waste. Such degradative processes also tend to produce significant amounts of soluble organic matter. Such compositional characteristics need to be accounted for in any leachant formution intended to mimic disposal environments.

6.1.3 Degradation Processes at a Waste Landfil1. Since the purpose of this task is to design a method to prepare a synthetic groundwater leachate it is useful to review the processes which may occur at a hypothetical disposal site. Hemm and others [33] have considered those processes which may occur during the aging of a landfill. The following biological stages were envisioned along with representative reactions.

1. Aerobic decomposition of waste

$$
\mathrm{C}_{\text {org }}+\mathrm{O}_{2}+\mathrm{CO}_{2}
$$

2. Anaerobic decomposition

$$
\mathrm{SO}_{4}^{-2}+2 \mathrm{Corg}+\mathrm{H}_{2} \mathrm{~S}+2 \mathrm{HCO}_{3}^{-}+\mathrm{H}_{2} \mathrm{O}
$$


3. Anaerobic methane production

$$
\mathrm{C}_{\text {org }}+\mathrm{H}_{2} \mathrm{O} \rightarrow \mathrm{CO}_{2}+\mathrm{CH}_{4}
$$

4. Final aerobic stage due to incoming oxygenated waters and cessation of biological activity

$$
\mathrm{Fe}^{+2}+3 / 2 \mathrm{O}_{2}+2 \mathrm{Fe}(\mathrm{OH})_{3}+3 \mathrm{H}^{+}+3 \mathrm{H}_{2} \mathrm{O}
$$

Site conditions will alter the theoretical degradation pattern considerably. Nutritional deficiencies in the waste may impede the microbial population.

The final aerobic state in a disposal site will be reached when biological activity has ceased due to depletion of the substrates. Aerobic conditions are reestablished by oxygen and carbon dioxide in the infiltrating water. However, anaerobic conditions at a waste disposal site may exist for considerable lengths of time, up to several decades or even longer. Thus, although the leaching of solidified waste will be by the alibient groundwater of the disposal area in the very long term, anoxic trenchwater may be responsible for release of a significant amount or even most of the activity from the waste forms.

6.1.4 pH-Eh Characteristics of Fresh Waters. Eh is a measure of the aqueous oxidation-reduction (redox) potential. Functionally,

$$
\begin{aligned}
& E h=E \text { (mcasured) }+E_{C} \\
& \text { where } \\
& E \text { (measured) }=\text { redox potential measured with a platinum electrode }
\end{aligned}
$$

and a secondary reference electrode

$$
E_{C}=\text { standard half cell potential of the reference electrode }
$$

The oxidation and reduction reactions of organic carbon, iron and sulfur are significant in determining Eh.

The $\mathrm{pH}$ is a measure of the aqueous hydrogen ion concentration.

$$
\mathrm{pH}=-\log \left[\mathrm{H}^{+}\right]
$$

The $\mathrm{pH}$ may be controlled by biochemical reactions in environments rich in organic biodegradable matter.

In the absence of biodegradable organic matter, the $\mathrm{pH}$ is determined by the weathering or alternation of aluminum silicate materials, the dissolution and precipitation of carbonates and cation exchange reactions with finegrained sediments or clays (Carver, 1971) [34]. 
The $\mathrm{pH}$ of most natural waters lies between 4.5 and 8.2 . In this $\mathrm{pH}$ range, a major contributor to the buffering capacity of water is the first dissociation of carbonic acid

$$
\mathrm{H}_{2} \mathrm{CO}_{3}(\mathrm{aq})+\mathrm{H}^{+}+\mathrm{HCO}_{3}^{-}
$$

The first dissociation constant of carbonic acid is

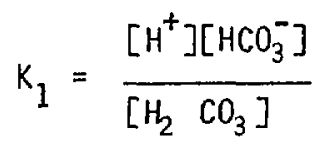

Taking logarithms and introducing the definition of $\mathrm{pH}$ and the value of $\mathrm{K}_{1}$ at $25^{\circ} \mathrm{C}$ (Langmuir, 1968) [35] we find,

$$
\mathrm{pH}=6.36+\log \frac{\left[\mathrm{HCO}_{3}^{-}\right]}{\left[\mathrm{H}_{2} \mathrm{CO}_{3}\right]}
$$

A convenient way to compare the pH-Eh condition of natural water is given in Figure $6.1[36]$. The Eh conditions of shallow groundwater at disposal sites are generally between those of an Eh range of 0 to 0.4 volts. Trench waters are generally more reducing with an Eh in the range of 0 to 0.2 volts $[30,31]$.

6.1.5 Organic Matter: Occurrence and Identity. Most natural waters contain some dissolved organic carbon (DOC) [37]. A comparison of several sources of water is made in Table 6.3 .

The dissolved organic substances in natural waters encompass a wide range of compounds from $\mathrm{CH}_{4}$ to high molecular weight polymers. Humic substances made up high percentage of the total dissolved organic carbon (DOC) in natural waters and appear to be the single most abundant organic constituent of these waters $[38,39]$. Humic substances are the major organic constituent of soils and sediment and are widely distributed over the earth's surface in both the terrestrial and aquatic environment. Humic substances are hydrophillic, polyelectrolyte materials in the molecular weight range of a few hundred to several thousand $[40]$.

Complexes of inorganic ions with organic molecules constitute a substantial fraction of the total amount of some elements in groundwater. Using filters that allow only molecules smaller than a molecular weight of 1000 to pass, found that $20 \%$ of the $\mathrm{Mg}, \mathrm{Ca}, \mathrm{Sr}$, and $\mathrm{Ba}$ and much of the $\mathrm{SO}_{4}(80 \%)$ in groundwaters from basaltic rock formations remained associated with water enriched in organic molecules.

The complexing of radionuclides with humic substances has been investigated using many analytical techniques. These studies have been review by Boggs [41]. Concentrations as $10 \mathrm{w}$ as $1 \mathrm{mg} / \mathrm{L}$ can produce a detectable increase in the mobility of some actinide elements by forming soluble complexes that 


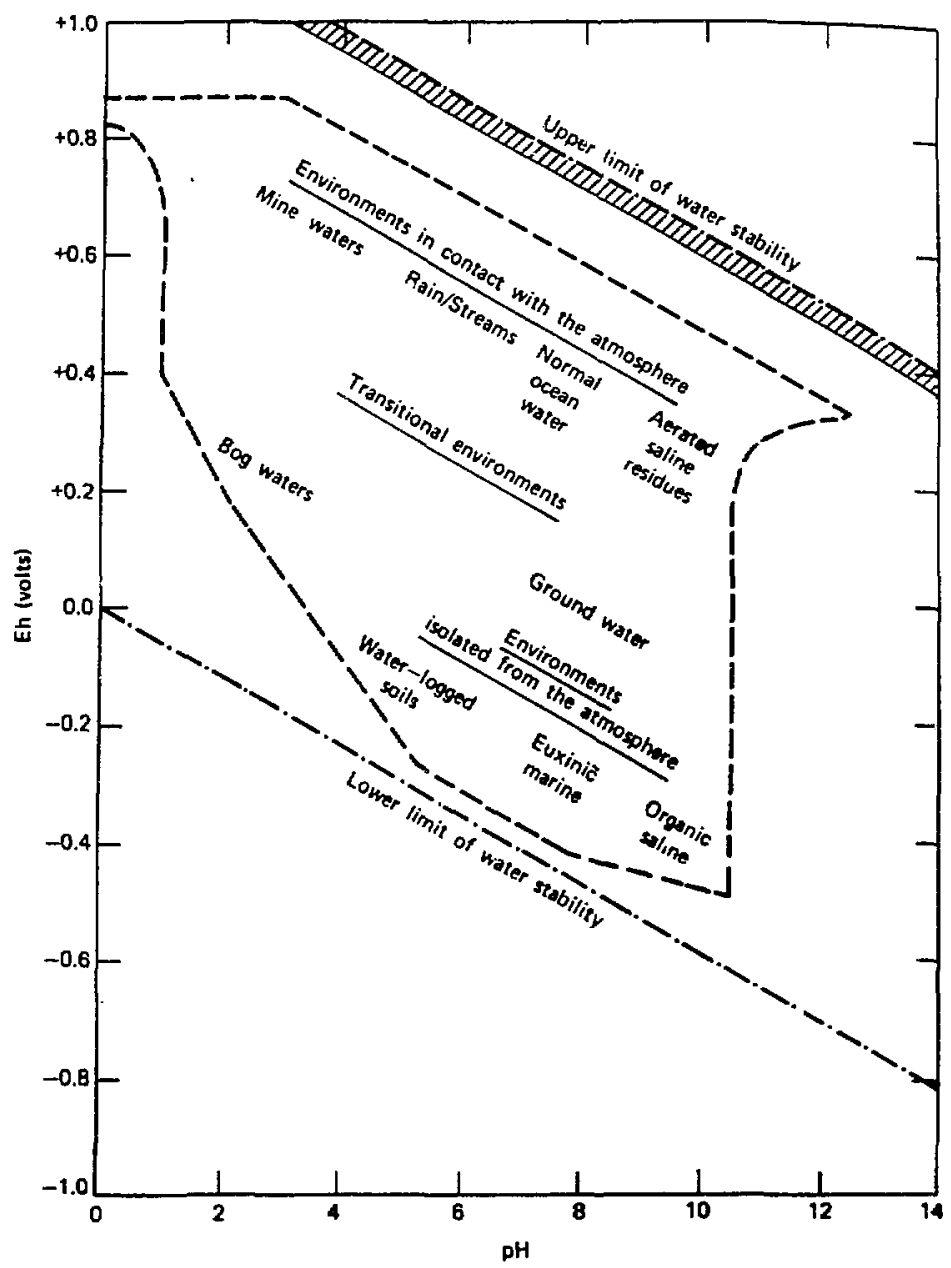

Figure 6.1 Approximate position of some natural environments in terms of Eh and $\mathrm{pH}$, (Garrels, 1960 and Bass Becking, et al., 1960). 
Table 6.3

Typical Dissolved Organic Carbon (DOC) Concentrations in Natural Waters

\begin{tabular}{lc} 
Water Type & DOC (mg/1) \\
\cline { 2 - 2 } Seawater & 0.1 \\
Groundwater & 1.0 \\
Lakes \& Streams & 5.8 \\
$\begin{array}{l}\text { U.S. Southeastern } \\
\text { Coastal plain rivers }\end{array}$ & 45 \\
$\begin{array}{l}\text { Typical LLW } \\
\text { deposit site }\end{array}$ & $200-3000$
\end{tabular}

inhibit adsorption of the radionuclides onto rock materials. Chebatina [42] reported that plant extracts increase the movement of Co through soil and also desorbs co from the soil.

6.1.6 Colloids and Suspended Particulate. Colloids are particles less than $10 \mu \mathrm{m}$ in size that commonly remain suspended because their gravitational settling is less than $10^{-2} \mathrm{~cm} / \mathrm{sec}$. Colloids in natural waters are generally humic substance or clay particles [43]. Particles of colloidal dimensions are important vehicles for the transport of sorbed radionuclides (Cs, Sr, Am) in soil and groundwater. Little information is available but Schnitzer and Khan [44] briefly discussed the behavior of organic colloids in metal ion binding.

6.1.7 Comparative Summary nf Oxic Groundwater Versus Anoxic Trenchwater. A comparison of the trench water compositions with their respective groundwaters shows substantial differences, as listed in the following observations.

- The sulfate content of the trench water is substantially reduced compared to the groundwater.

- Ferrous iron and ammonium cations appear in significant concentration in trench water whereas they do not appear in groundwaters.

- The En values (i.e., oxidation potential) of both the shallow land burial site trench waters are reduced from those of the groundwaters.

The reduced Eh values of the trench waters compared to the groundwaters explain the presence of ferrous iron and ammonium cations, which do not survive in the more oxidizing well waters. Conversely, sulfate, which is a highly oxidized species, is abundant in the well waters but is much reduced in the less oxidizing trench waters. 
In suin, both types of groundwater (oxygenated and anoxic) may be expected to contribute to waste form leaching. Anoxic leachants may dominate in the relatively near term following disposal, up to approximately a century. Following this, the ambient (oxygenated) groundwater of the area will dominate leaching.

\subsection{Experiment Description}

6.2.1 Leach Test Procedure. The ANS 16.1 test procedure was used to conduct leaching test with waste forms containing simulated waste using a modified sampling schedule. The test specimens were cylinders approximately 5.1 $\mathrm{cm}$ in diameter by $6.4 \mathrm{~cm}$ in height. The simulated oxygenated groundwater described below was used as the leachant and the tests were conducted at $20^{\circ} \mathrm{C}$ using a leachant volume of 1.3 liters.

6.2.2 Preparation of a Simulated Groundwater. Humic substances were obtained from a local top soil. Prior to extraction the soil was air dried at room temperature and sieved to pass a $2.38 \mathrm{~mm}$ standard sieve to remove gravel and roots. The dried soil (10 kg) was leached with 40 liters of deionized water for two weeks. The soil leachate was filtered sequentially to pass 30 $\mu \mathrm{m}, 5 \mu \mathrm{m}$ and $0.2 \mu \mathrm{m}$ filters to remove suspended soil particles.

The mineral content of the groundwater was simulated by addition of the salts listed in Table 6.4 to deionized water. The solution was saturated with $\mathrm{CO}_{2}$ (dry ice) to dissolve the $\mathrm{Ca}(\mathrm{OH})_{2}$ as $\mathrm{Ca}\left(\mathrm{HCO}_{3}\right)_{2}$. To this solution, 20 liters of the filtered soil leachate was added. The resulting solution was stirred and diluted to a final volume of 200 liters.

Table 6.4

Inorganic Salts Used to Prepared $200 \mathrm{~L}$ of Simulated Groundwater

\begin{tabular}{lc}
\multicolumn{1}{c}{ Salts } & Weight $(\mathrm{g})$ \\
${(\mathrm{OH})_{2}} }$ & 21.08 \\
$\mathrm{MgSO}_{4} \cdot 7 \mathrm{H}_{2} \mathrm{O}$ & 2.909 \\
$\mathrm{KCl}$ & 0.173 \\
$\mathrm{NaHCO}_{3}$ & 1.920 \\
$\mathrm{FeCl}_{3} \cdot 6 \mathrm{H}_{2} \mathrm{O}$ & 0.169
\end{tabular}

\subsection{Simulated Groundwater Leaching - Radionuclide Results}

The leaching results obtained for leaching with the simulated groundwater are described below. The results were compared with those obtained for deionized water. 
6.3.1 Portland I Cement/5\% Na $\mathrm{SO}_{4}$ Leaching. Figure 6.2 shows the cumulative fraction released (CFR) for Cs-137 from Type I portland cement incorporating $5 \% \mathrm{Na}_{2} \mathrm{SO}_{4}$. The Cs-137 CFR fraction at 88 days was $48 \%$. Reproducibility of the data from triplicate samples appears to be fair although statistical analysis has not yet been done. The average Cs-137 CFR for this groundwater leaching test is about $15 \%$ lower than that observed using deionized water at 80 days.

Very low to undetectable concentrations of Sr-85 were found in the groundwater leachates. Co-57 was also not found in the leachates, probably due to its low solubility at $\mathrm{pH} 10$ to 12 .

6.3.2 Portland I Cement/15\% Ash Leaching. Figure 6.3 shows the CFR for Cs-137 from portland type I cement incorporating $15 \%$ incinerator ash. The Cs-137 CFR at 88 days was $38 \%$. The reproducibility of the data appears to be good although a statistical analysis has not yet been performed. The average Cs-137 CFR for groundwater leaching is about $10 \%$ lower than that observed using deionized water at 80 days.

6.3.3 Vinyl Ester-Styrene/15\% $\mathrm{Na}_{2} \mathrm{SO}_{4} / \mathrm{H}_{2} \mathrm{O}$ Emulsion. Figure 6.4 shows the the Cs-137 CFR plotted against time from vinyl ester-styrene, water emulsion waste forms incorporating $15 \% \mathrm{Na}_{2} \mathrm{SO}_{4}$ for triplicate samples. The CS-137 CFR at 88 days was $57 \%$. The Cs -137 release from groundwater leaching was significantly lower than that observed using deionized water. The scatter in the data is due to both counting errors as well as microscopic inhomogenities in the samples.

6.3.4 Vinyl Ester-Styrene/40\% $\mathrm{Na}_{2} \mathrm{SO}_{4}$. Figure 6.5 shows the $\mathrm{CS}-137 \mathrm{CFR}$ plotted against time from vinyl ester-styrene incorporating $40 \% \mathrm{Na}_{2} \mathrm{SO}_{4}$ as anhydrous salt The Cs-137 leaching is significantly lower in the groundwater than in deionized water. The scatter in the leaching data, particularly that observed in deionized water, is likely due to the inhomogeneous nature of the samples.

6.3.5 Bitumen $/ 20 \% \mathrm{Na}_{2} \mathrm{~B}_{4} \mathrm{O}_{7}$. Figure 6.6 shows the Cs-137 CFR plotted against time from bitumen incorporating $20 \%$ sodium tetraborate $\left(\mathrm{Na}_{2} \mathrm{~B}_{4} \mathrm{O}_{7}\right)$ as the anhydrous salt. The leaching of $\mathrm{Cs}-137$ appears to be somewhat greater in groundwater. Considerable uncertainty in the data is due to significant counting errors due to low activities observed in the leachates and the inhomogeneous nature of the samples.

6.3.6 Bitumen $/ 40 \% \mathrm{Na}_{2} \mathrm{~B}_{4} \mathrm{O}_{7}$. Figure 6.7 shows the CS-137 CFR plotted against time from bitumen incorporating $40 \%$ by weight sodium tetraborate $\left(\mathrm{Na}_{2} \mathrm{~B}_{4} \mathrm{O}_{7}\right)$. Uncertainties in the data are probably due to the inhomogeneous nature of the samples. The leaching of $\mathrm{Cs}-137$ in groundwater is less than that observed in deionized water. 


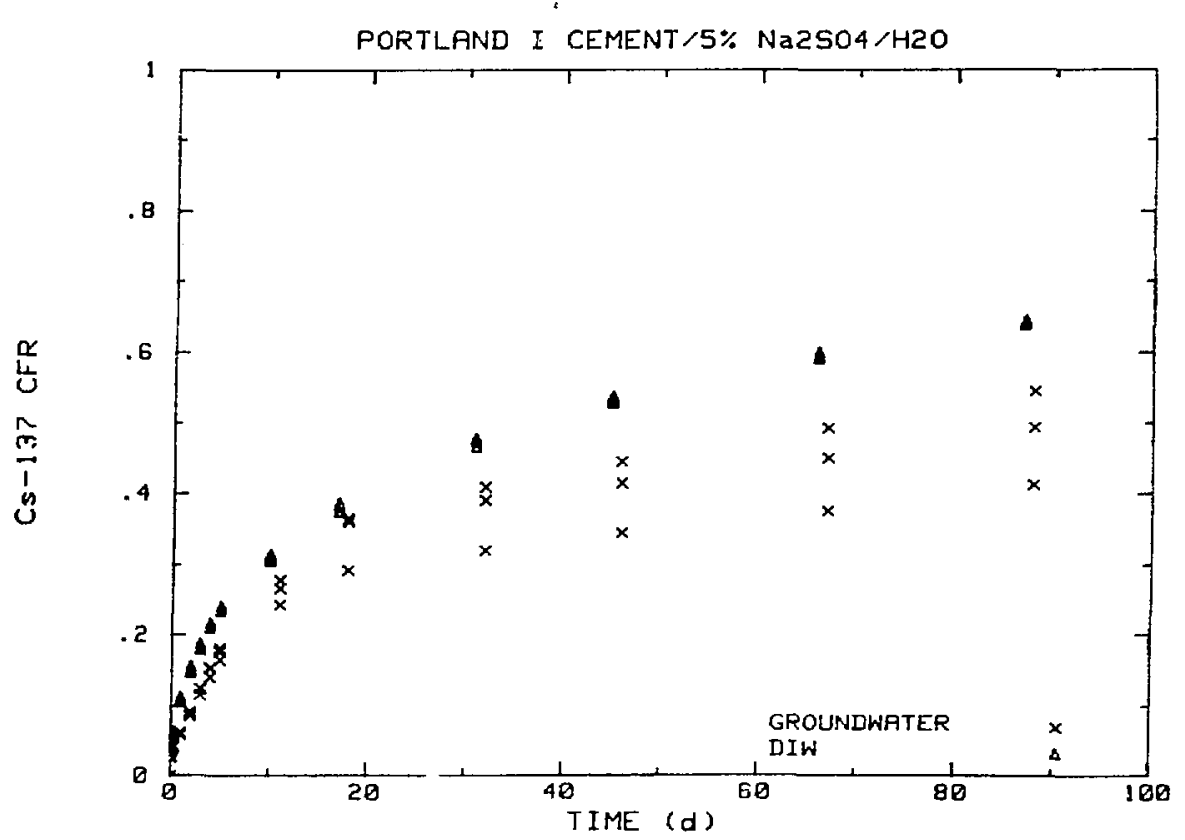

Fjgure 6.2 Cs-137 cumulative fraction release (CFR) versus time for trjplicate portland type I cement incorporating $5 \%$ by weight of $\mathrm{Na}_{2} \mathrm{SO}_{4}$ leached with a simulated groundwater compared to resuits for deionized water leaching.

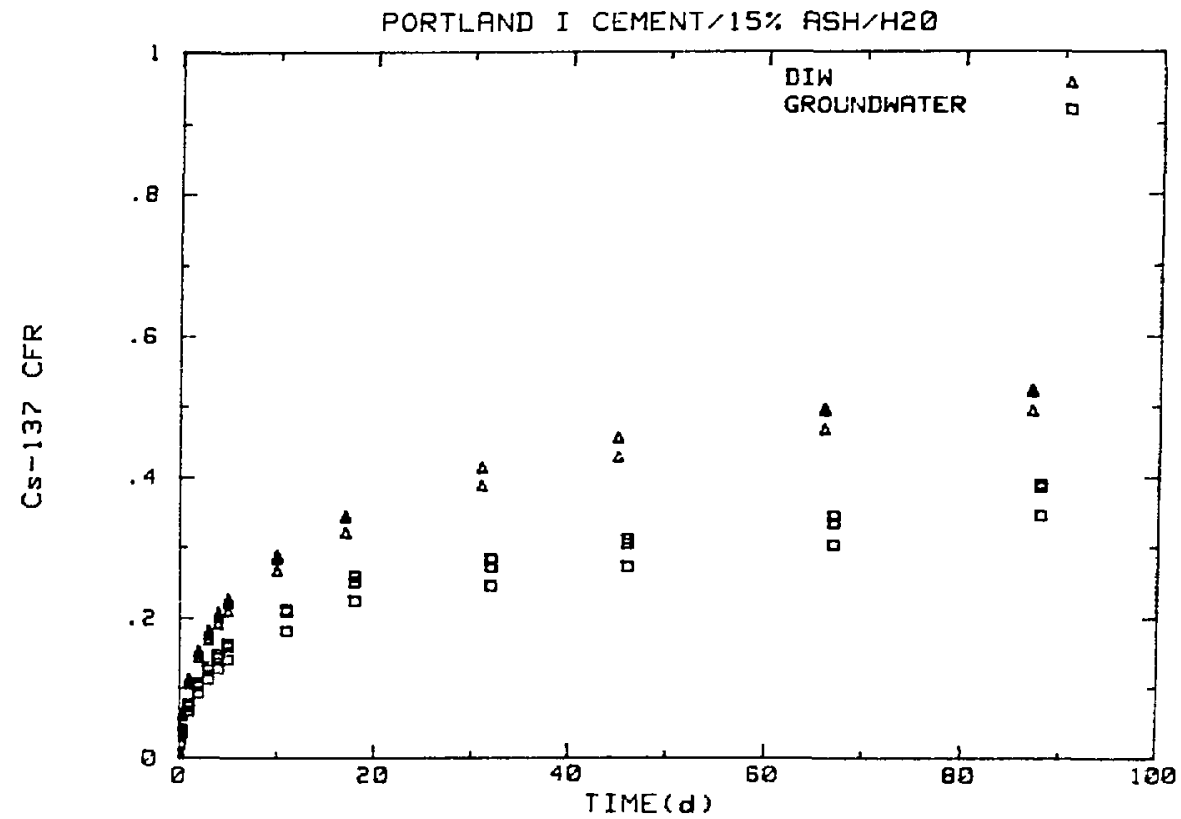

Figure 6.3 Cs-137 cumulative fraction released (CFR) versus time from triplicate portland type I cement incorporating $15 \%$ by weight incinerator ash leached with a simulated groundwater compared to results for deionized water leaching. 


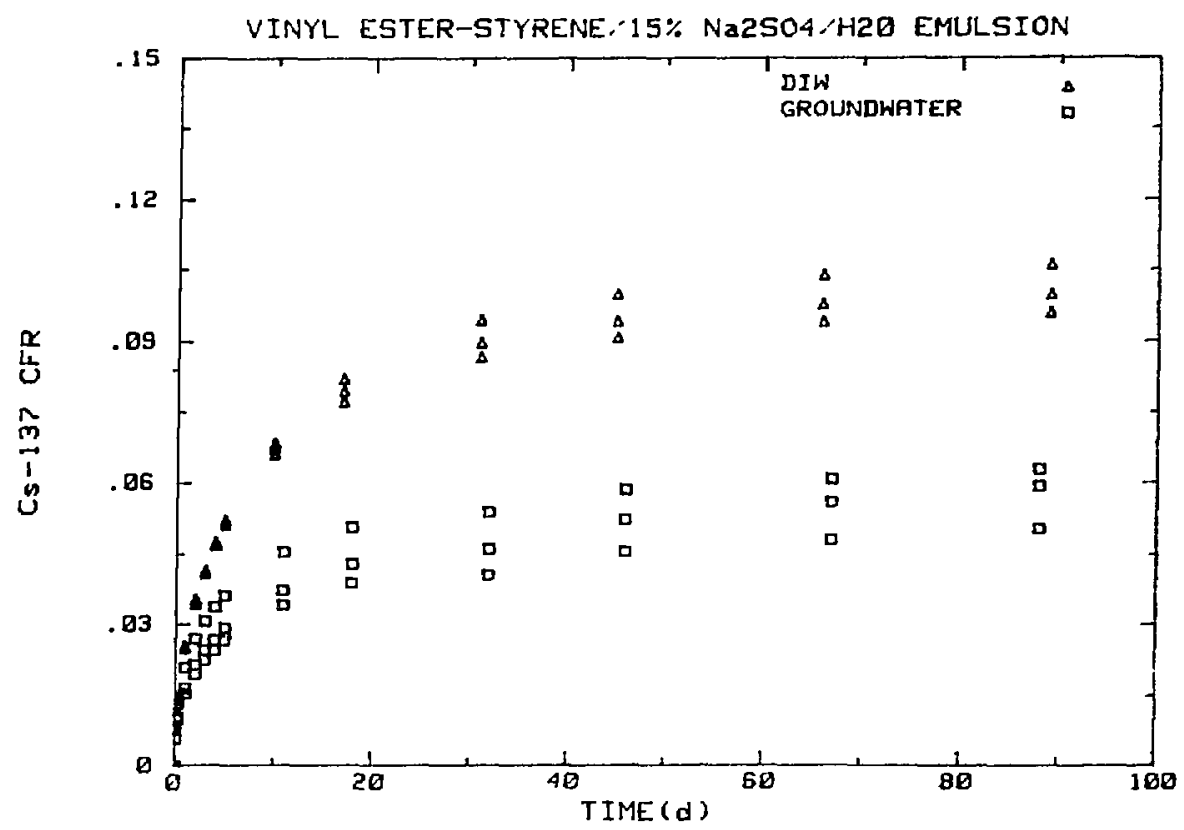

Figure 6.4 CS-137 cumulative fraction released (CFR) versus time from triplicate vinyl ester-styrene waste forms incorporating $40 \% \mathrm{Na}_{4} \mathrm{SO}_{4}$ leached with a simulated groundwater compared to results for deionized water leaching.

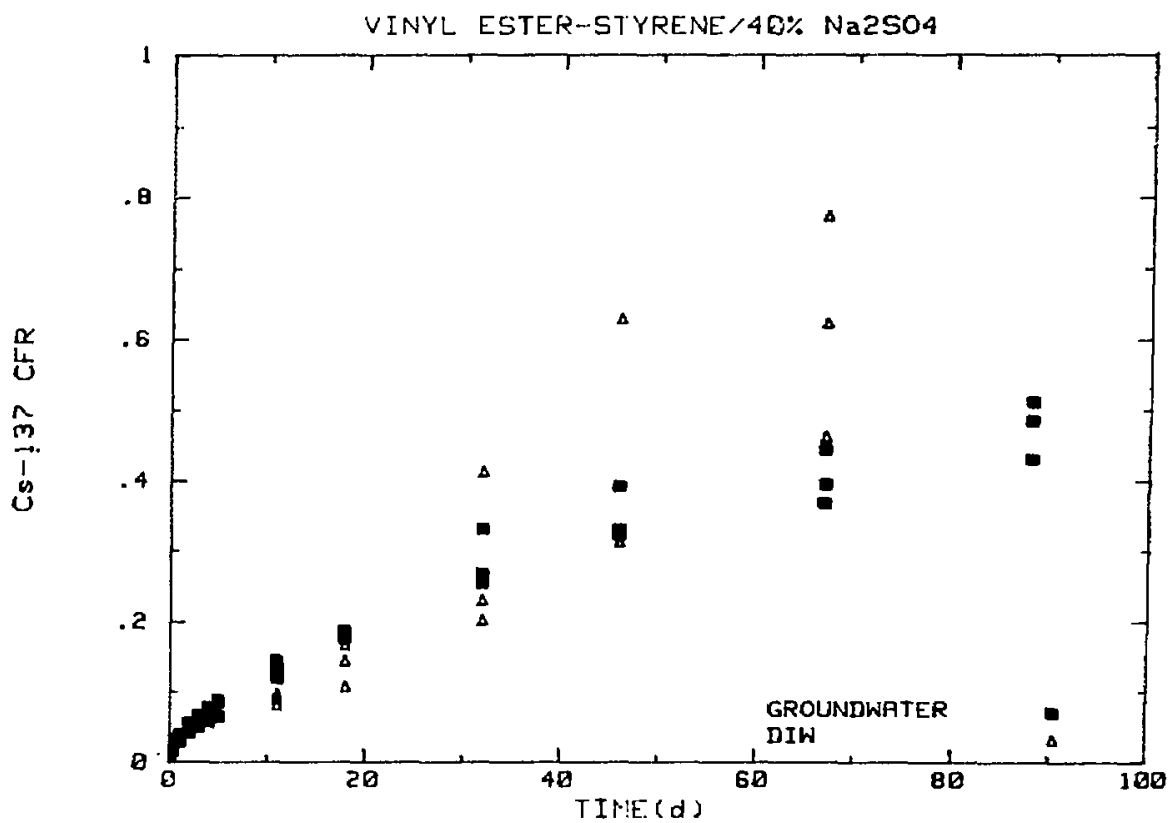

Figure 6.5 Cs-137 cumulative fraction released (CFR) versus time from triplicate vinyl ester-styrene waste forms incorporating $40 \%$ by weight $\mathrm{Na}_{2} \mathrm{SO}_{4}$ leached a simulated groundwater compared to results for deionized water leaching. 


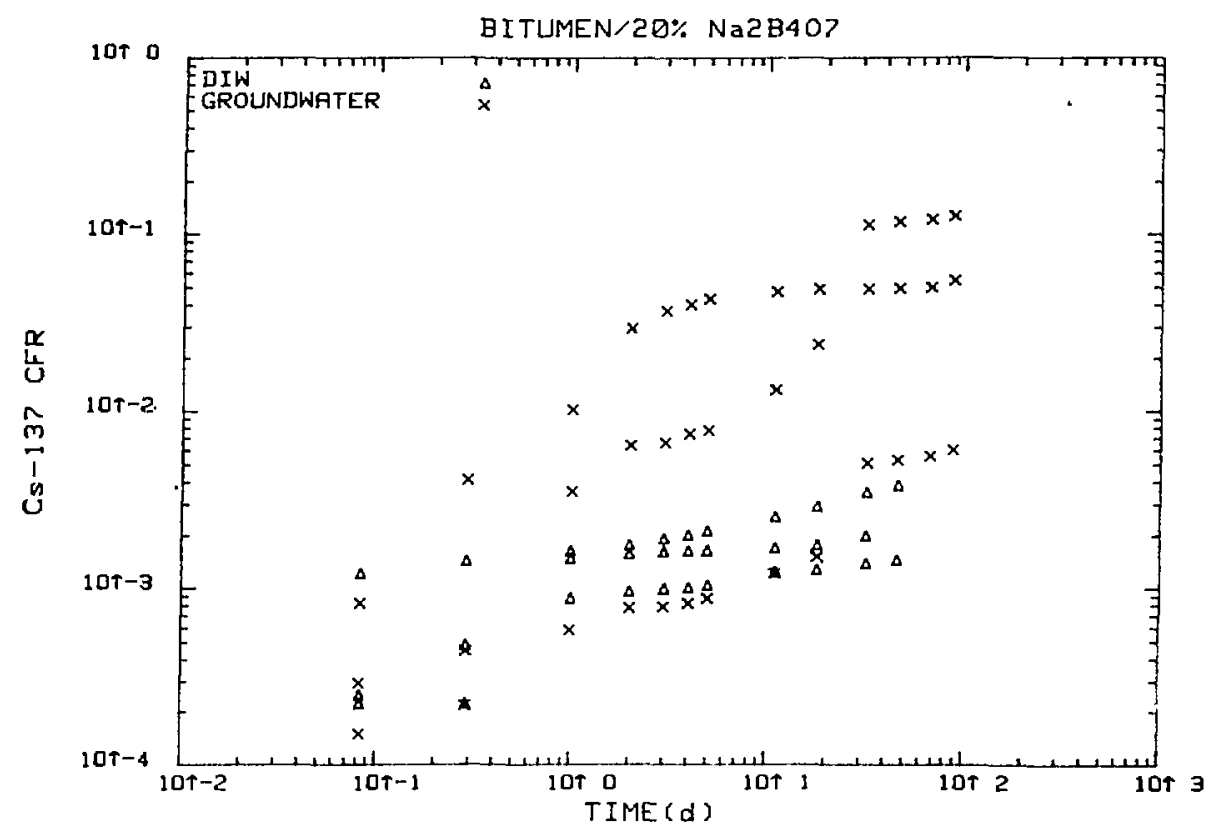

Figure 6.6 Cs-137 cumulative fraction released CFR) versus time for triplicate bitumen waste forms incorporating $20 \%$ by weight sodium tetraborate $\left(\mathrm{Na}_{2} \mathrm{~B}_{4} \mathrm{O}_{3}\right)$ leached with a simulated groundwater and compared to results for deionized water leaching.

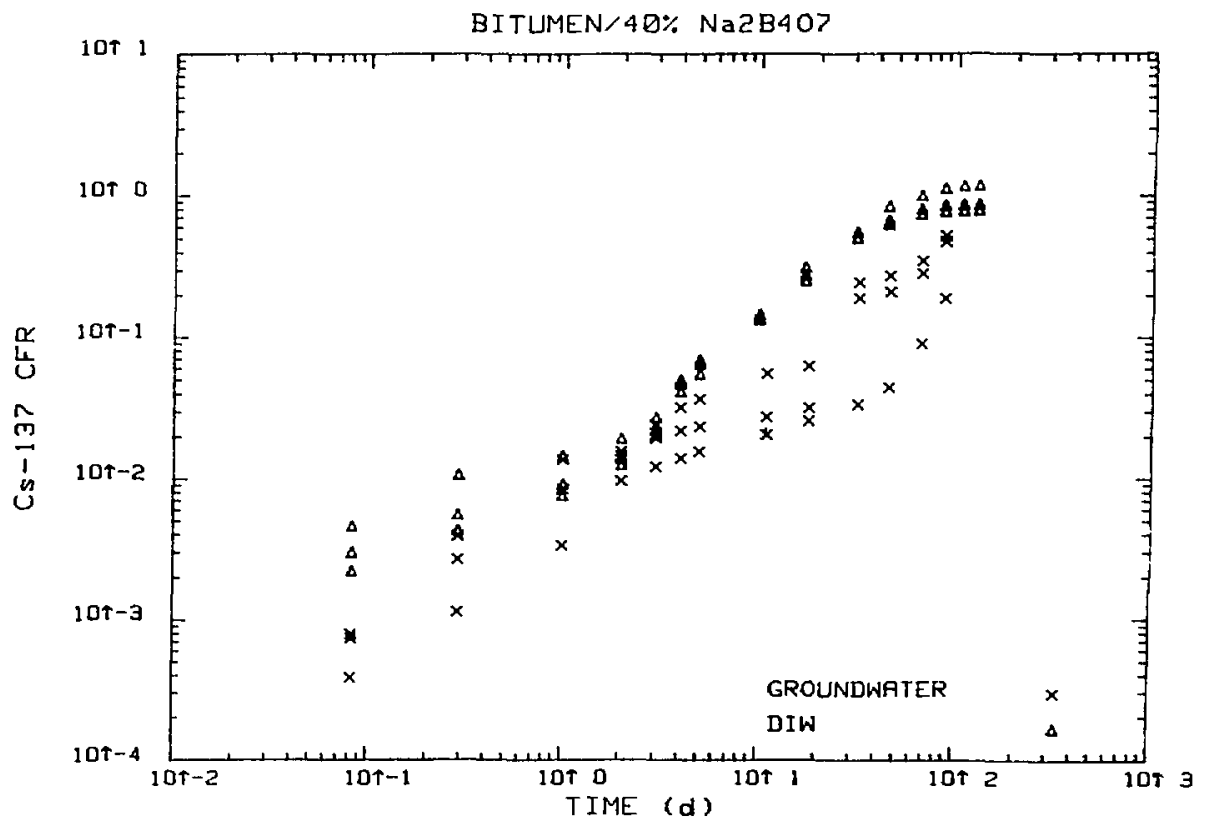

Figure 6.7 CS-137 cumulative fraction released (CFR) versus time for triplicate bitumen waste forms incorporating $40 \%$ by weight sodium tetraborate $\left(\mathrm{Na}_{2} \mathrm{~B}_{4} \mathrm{O}_{7}\right)$ leached with a simulated groundwater and compared to results for deionized water leaching. 


\section{EVALUATION OF LEACH RATE CONTROLLING FACTORS}

A qualitative review of factors that affect leaching is available [2]. These factors deal with three aspects of the total leaching test: the system, leachant and waste form.

System factors include time, temperature, radiation envirorment, pressure, and the ratio of leachant volume to waste form area. Time is considered in Sections 4 and 5 of this report. The effects of pressure on leachability is considered to be negligible, with the possible exception of bitumen waste forms for shallow 7 and burial. Radiation doses of up to $10^{8}$ rads are have been shown to be of little significance for leachability. The effects of temperature and leachant volume are examined in this section.

Leachant factors include $\mathrm{pH}$, Eh, flow or replacement frequency and leachant composition. The leachant factors of $\mathrm{pH}$ and flow are discussed in this section. Experimental work on the effect of Eh is planned for the future. The effect of leachant composition has been discussed in Section 6 in the context of groundwater effects on leaching.

Waste form factors include composition, surface condition, porosity and waste form surface area to volume ratio. The effects of composition are discussed in Section 5 of this report. Surface condition is discussed in Sections 4 and 5 of this report dealing with solid phase analysis. Waste form surface area to volume ratio is discussed in this section for the leaching of samples of differing size and shape. This section reviews results obtained for leaching $\mathrm{Cs}-137$. Results for $\mathrm{Co}-57$ and $\mathrm{Sr}-85$ will be discussed in reports to be issued.

\subsection{Temperature Effects on Leaching}

Temperature has been identified as a significant factor which effects the rate of leaching from solidified waste. Short-term scoping experiments were performed using specimens consisting of only the solidification matrix and radionuclide tracers [3]. This section reports on experiments using waste forms which contain simulated waste in addition to radioactive tracers.

7.1.1 Experiment Description. The ANS 16.? leaching test was used to determine the leaching of $\mathrm{Co}-57, \mathrm{Sr}-85$ and $\mathrm{Cs}-137$ from solidified waste forms incorporating simulated waste. The waste form specimens were cylinders approximately $5.1 \mathrm{~cm}$ in diameter by $6.4 \mathrm{~cm}$ in height. The leaching tests were run at 20,40 and $50^{\circ} \mathrm{C}$ using 1.31 iters of deionized water as the leachant.

\subsubsection{Temperature Effects - Radionuclide Leaching}

7.1.2.1 Portland I Cement and $5 \mathrm{wt} \% \mathrm{Na}, \mathrm{SO}_{4}$. Plots of $\mathrm{Cs}-137$ cumulative fraction release (CFR) results versus time for portland type I cement samples containing $5 \%$ by weight $\mathrm{Na}_{2} \mathrm{SO}_{4}$ leached at elevated temperature are presented in Figure 7.1. Releases of $\mathrm{Cs}-137$ increased with increasing temperature. A statistical analysis of the replicate variability along with the results for Sr-85 will be reported at a later date. Co-57 was not observed in the leachate. 


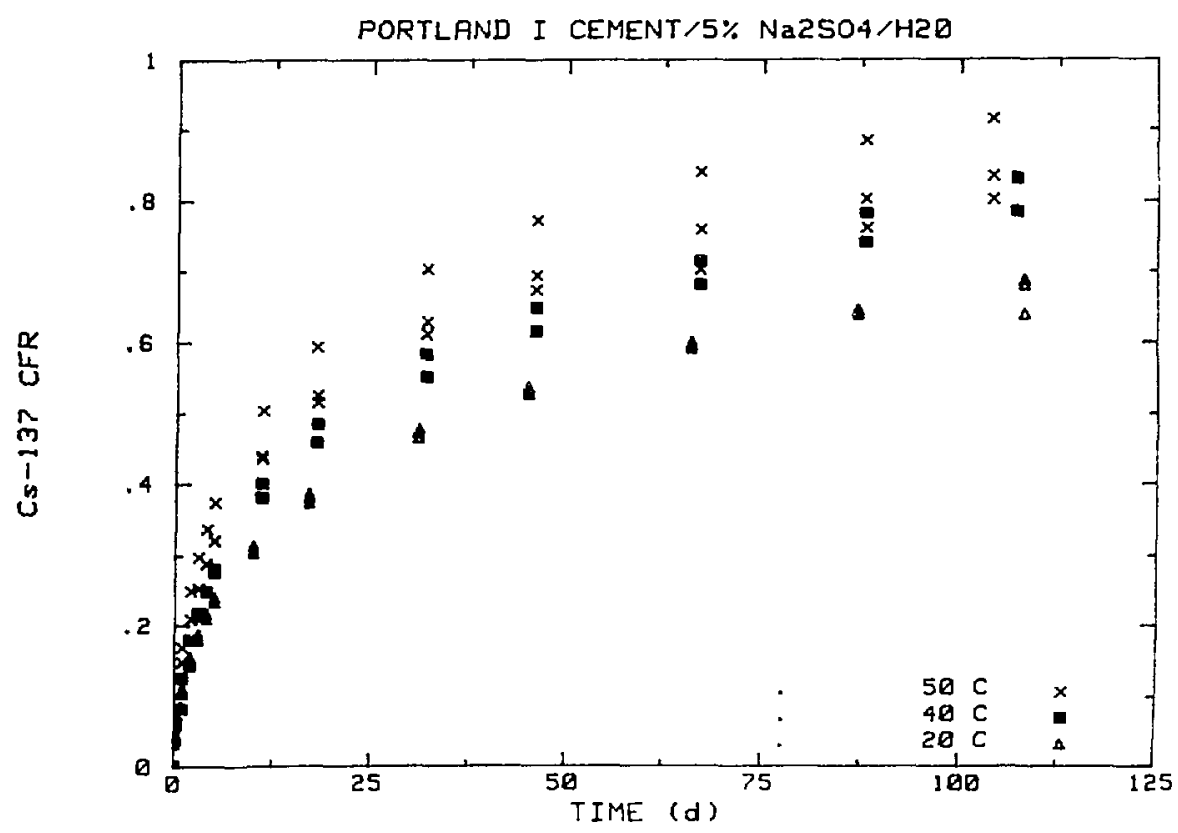

Figure 7.1 Cumulative fraction released (CFR) of Cs-137 versus time from portland type I cement waste forms, incorporating $5 \%$ by weight $\mathrm{Na}_{2} \mathrm{SO}_{4}$, leached at 20,40 and $50^{\circ} \mathrm{C}$ in deionized water.

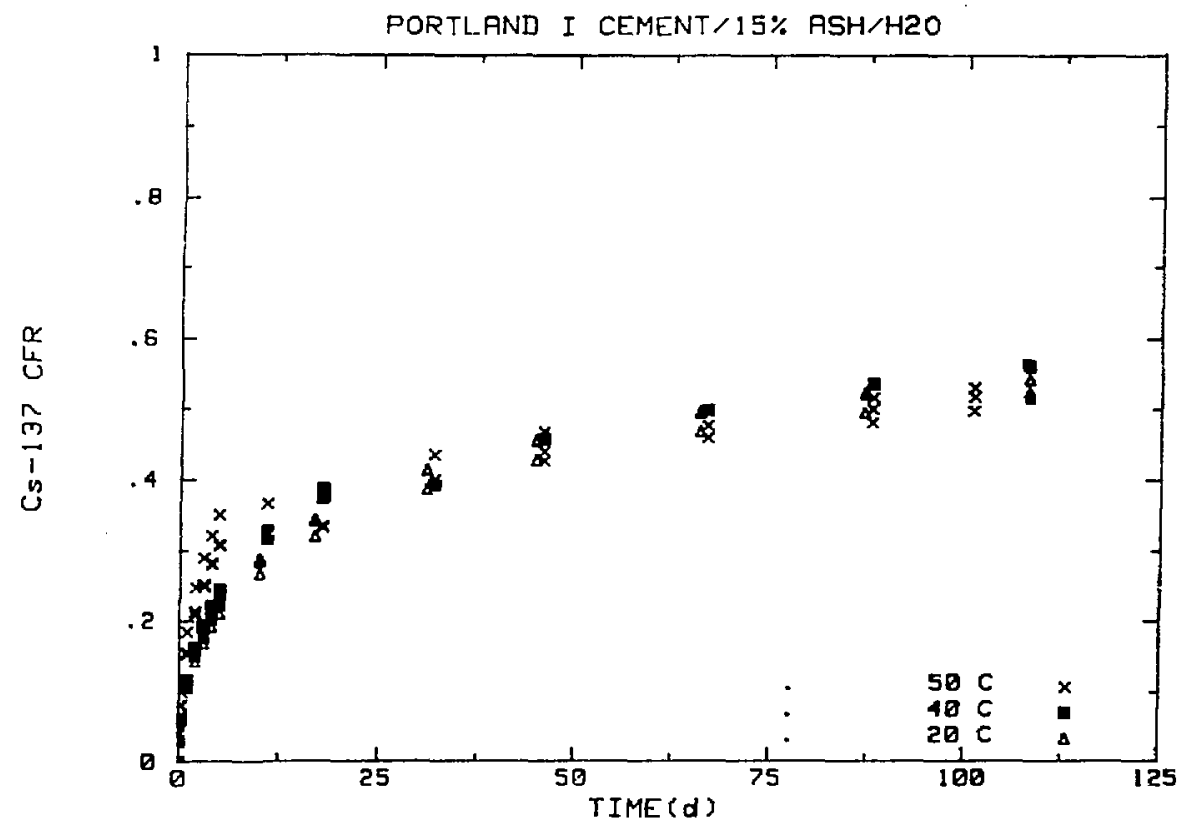

Figure 7.2 Cs-137 cumulative fraction released (CFR) versus time from portland type I cement waste forms, incorporating $15 \%$ by weight incinerator ash, leached at 20,40 and $50^{\circ} \mathrm{C}$ in deionized water. 
7.1.2.2 Portland I Cenent and 15\% Incinerator Ash. Plots of Cs-137 CFR versus time for portland type I cement samples containing $15 \%$ by weight incinerator ash leached at elevated temperature are presented in Figure 7.2. Releases of $\mathrm{Cs}-137$ showed little, if any, increase with increasing temperature. Replicate precision for all samples appears to be good but a statistical analysis has yet to be performed. Results for $\mathrm{Sr}-85$ will be reported at a later date. Co-57 was not observed in the leachates.

\subsubsection{Vinyl Ester-Styrene/15\% $\mathrm{Na}_{2} \mathrm{SO}_{4} / \mathrm{H}_{2} \mathrm{O}$ Emulsion. Plots of $\mathrm{Cs}-137$}

CFR versus time for vinyl ester-styrene water emulsion waste forms, containing $15 \% \mathrm{Na}_{2} \mathrm{SO}_{4}$, leached at elevated temperatures are presented in Figure 7.3. Releases of $\mathrm{Cs}-137$ did not consistently increase with temperature. In fact, $\mathrm{Cs}-137 \mathrm{CFR}$ at $40^{\circ} \mathrm{C}$ and $50^{\circ} \mathrm{C}$ were consistently lower than those observed at $20^{\circ} \mathrm{C}$ at leaching times less than 100 days. Failure to respond to temperature as an accelerating factor may be related to changes induced in the structure of the matrix caused by elevated temperatures. The variability of the CFR from replicates makes accessment of the temperature effects on leaching uncertain.

7.1.2.4 Vinyl Ester-Styrene/40\% $\mathrm{Na}_{2} \mathrm{SO}_{4}$. Plots of CS-137 CFR from vinyl ester-styrene waste forms with $40 \%$ by weight $\mathrm{Na}_{2} \mathrm{SO}_{4}$ leached at several temperatures are shown in Figure 7.4. The release of $\mathrm{Cs}_{5}-137$ appears to increase monotonically with temperature. However, there is considerable scatter in the 20 and $50^{\circ} \mathrm{C}$ data. This is due to the inhomogeneous nature of the samples, which consist of anhydrous sodium sulfate particles dispersed in the solid plastic matrix, the nature of the leaching process, and changes induced in the structure of the matrix caused by elevated temperatures. As with the vinyl ester-styrene water emulsion matrix variability of the data makes the temperature effect on the material uncertain.

7.1.2.5 Bitumen/20\% Sodium Tetraborate. Plots of cumulative fraction release of Cs-137 versus time from bitumen waste forms containing $20 \%$ by weight sodium tetraborate $\left(\mathrm{Na}_{2} \mathrm{~B}_{4} \mathrm{O}\right.$, ) at 20,40 and $50^{\circ} \mathrm{C}$ are shown in Figure 7.5. The fraction released is very small compared to the inherent variability of the leaching system. Cs-137 releases at 40 and $50^{\circ} \mathrm{C}$ are erratic and inconsistent, but generally higher than observed at $20^{\circ} \mathrm{C}$. Uncertainties due to low release rates of $\mathrm{Cs}-137$ make the assessment of temperature effects somewhat unreliable and limits the usefulness of temperature as an accelerating factor for these bitumen waste forms.

7.1.2.6 Bitumen/40\% Sodium Tetraborate. Plots of cumulative fraction release of Cs -137 versus time from bitumen waste forms containing $40 \%$ by weight sodium tetraborate $\left(\mathrm{Na}_{2} \mathrm{~B}_{4} \mathrm{O}_{7}\right)$ at 20,40 and $50^{\circ} \mathrm{C}$ are shown in Figure 7.6. The fractional releases are not monotonic with increasing temperature. At 100 days all the waste forms are approaching depletion of $\mathrm{Cs}-137$. As described in Section 5, these samples swelled and cracked on being leached. At the $40 \%$ waste loading, salt particles may be in physical contact allowing relatively rapid water permeation which may be responsible for the swelling of the waste forms and the rapid release of $\mathrm{Cs}-137$. Such a rapid release mechanism overwhelms any statistical possibility of observing temperature effects with any precision. 


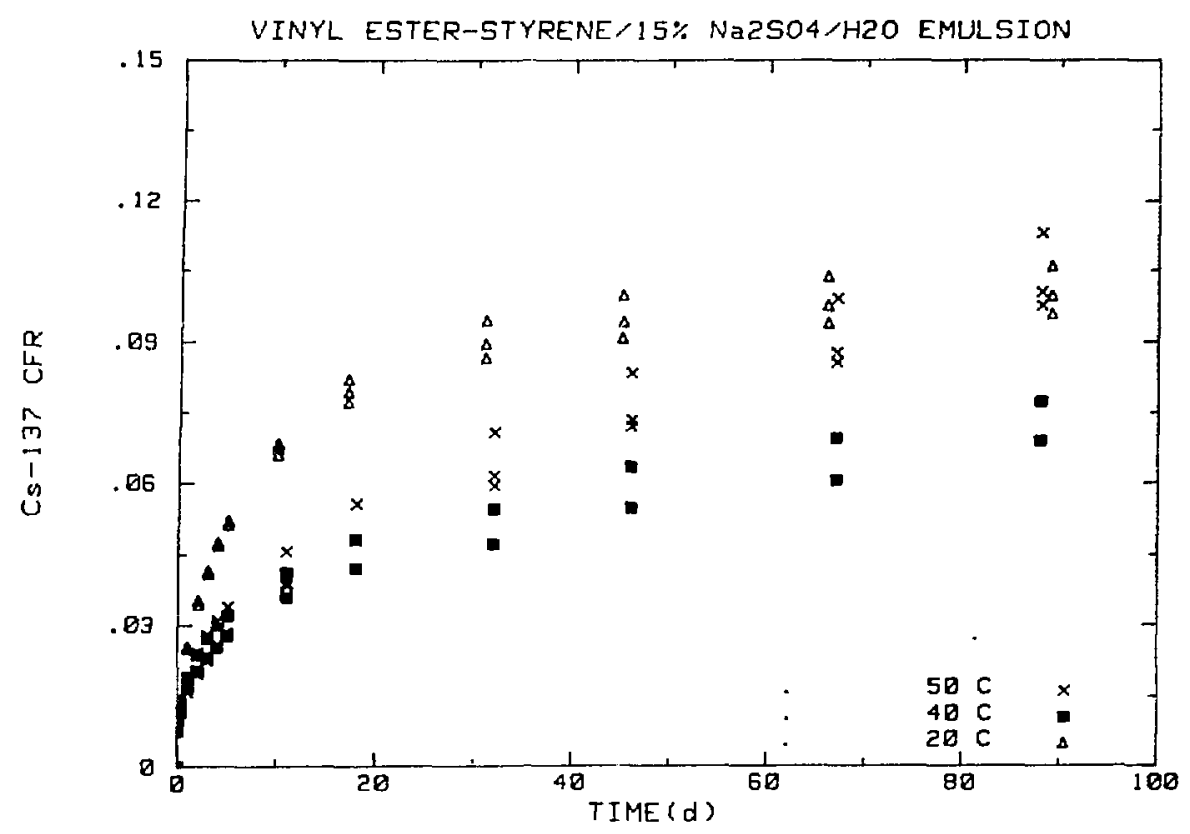

Figure 7.3 Cs 137 cumulative fraction released (CFR) versus time from viny] ester-styrene water emulsion waste forms, incorporating $15 \%$ by weight $\mathrm{Na}_{2} \mathrm{SO}_{4}$, leached at 20,40 and $50^{\circ} \mathrm{C}$ in deionized water.

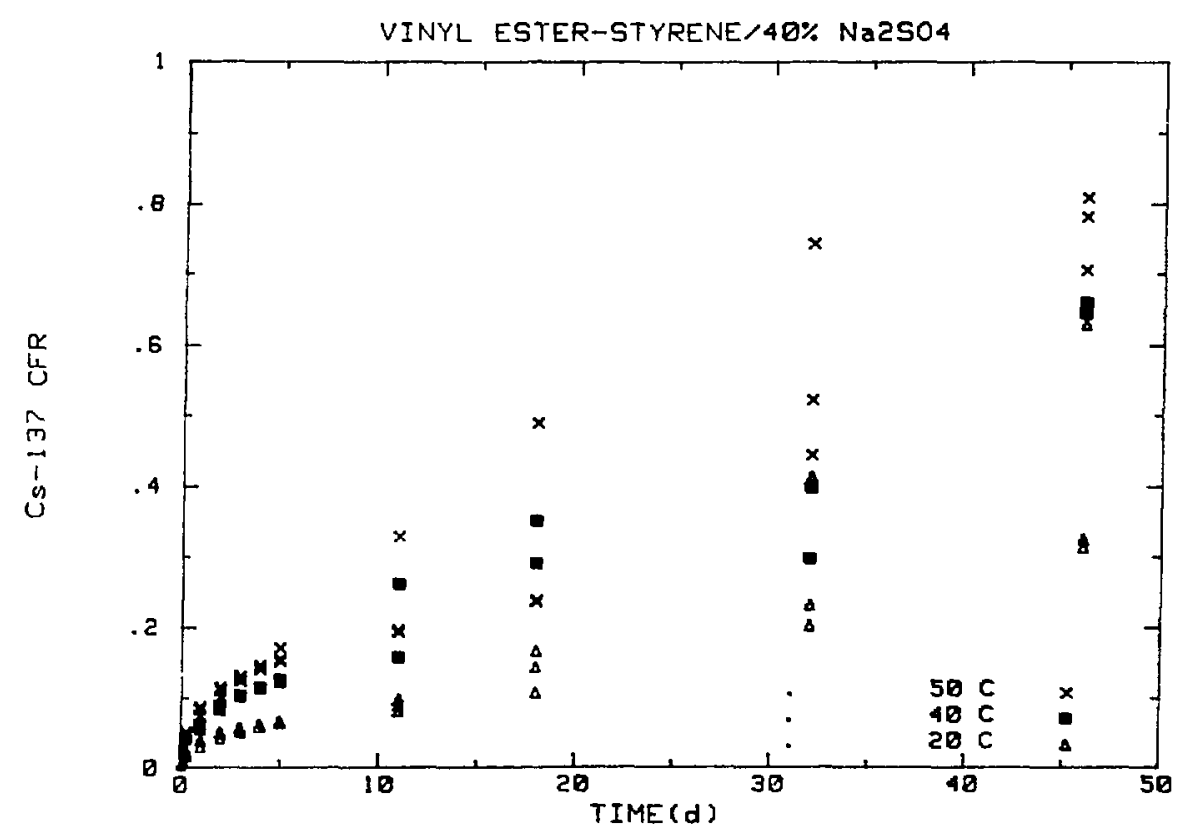

Figure 7.4 Cs-137 cumulative fraction released (CFR) versus time from vinyl ester-styrene waste forms, incorporating $40 \%$ by weight sodium suifate, leached at 20,40 and $50^{\circ} \mathrm{C}$ in deionized water. 


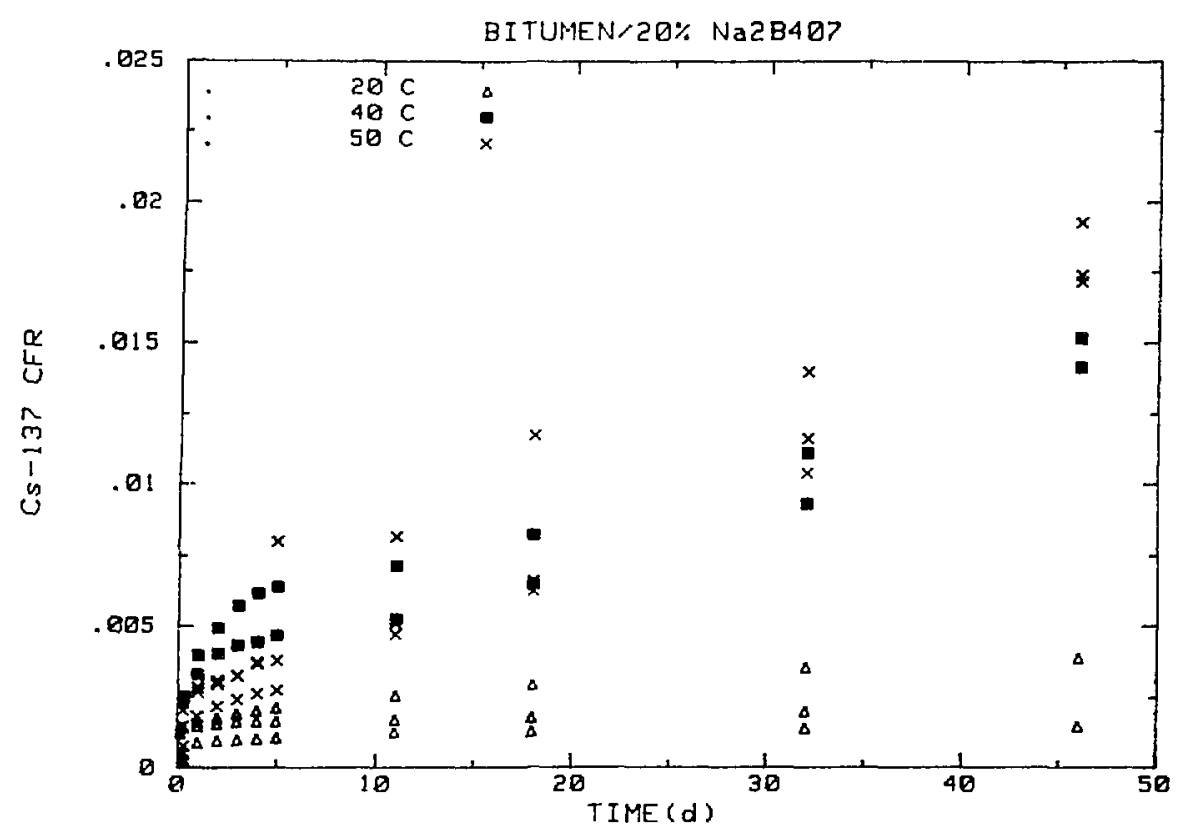

Figure 7.5 CS-137 cumulative fraction released (CFR) versus time from bitumen waste forms, incorporating $20 \%$ by weight sodium tetraborate $\left(\mathrm{Na}_{2} \mathrm{~B}_{4} \mathrm{O}_{7}\right)$, leached at 20,40 and $50^{\circ} \mathrm{C}$ in deionized water.

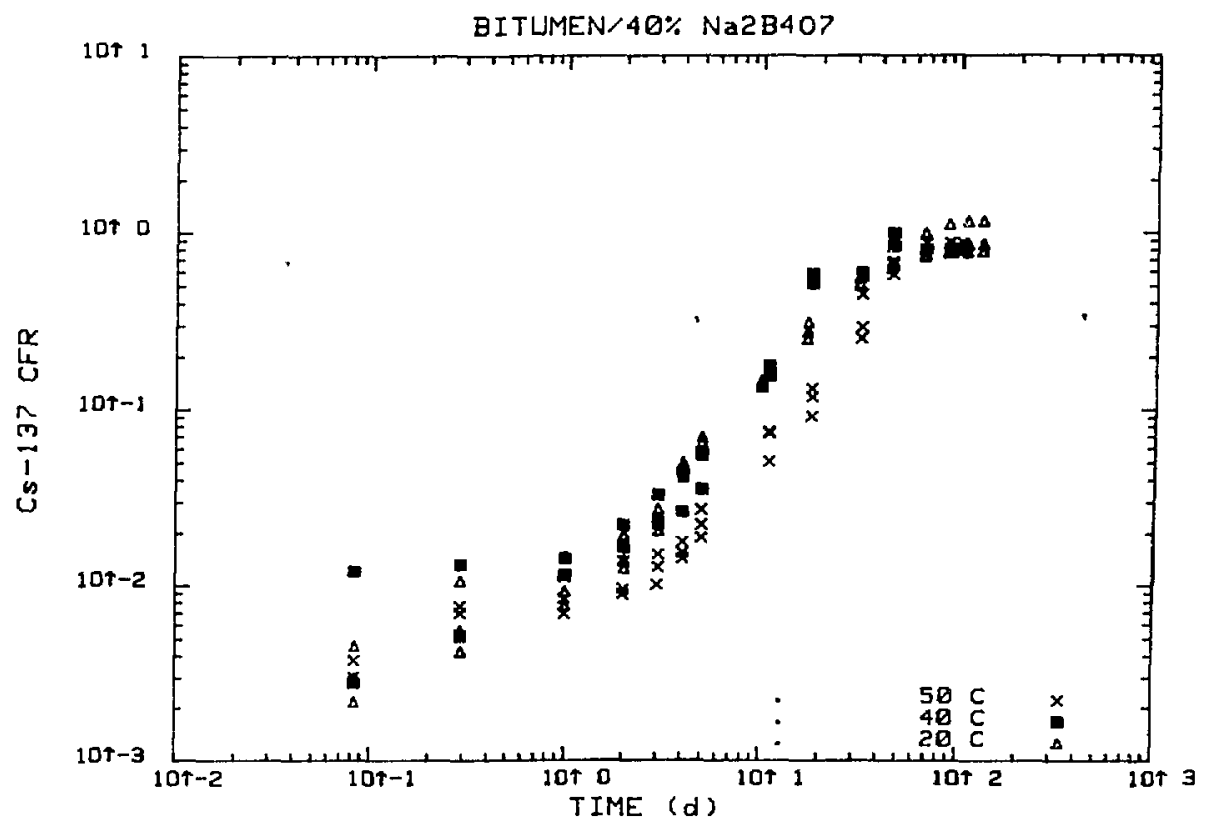

Figure 7.6 Cs-137 cumulative fraction released (CFR) versus itime from bitumen waste forms, incorporating $40 \%$ by weight sodium tetraborate $\left(\mathrm{Na}_{2} \mathrm{~B}_{4}, 0_{7}\right)$, leached at 20,40 and $50^{\circ} \mathrm{C}$ in deionized water. 


\subsection{Scoping Study of the Effect of the Ratio of Waste Form Surface Area to Leachant Volume}

The rate at which the leachant becomes saturated with leached materials directly affected by the ratio of waste form surface area to leachant volume. This factor is closely related to the replacement frequency or flow of the leachant which also controls how fast the leaching system approaches a steady state.

7.2.1 Experiment Description. The leaching of Co-57, Sr-85 and Cs-137 was determined using the ANS 16.1 leach test with increasing leachant volumes to waste form surface area. Deionized water $(1.3 \mathrm{~L}, 2.6 \mathrm{~L}$ and $3.9 \mathrm{~L})$ was used as the leachant at $20^{\circ} \mathrm{C}$ with waste forms containing simulated waste. The waste form specimens were cylinders approximately $5.1 \mathrm{~cm}$ in diameter by $6.4 \mathrm{~cm}$ in height.

\subsubsection{Leachant Volume Effects-Radionuclide Leaching Scoping Tests Results \\ 7.2.2.1 Portl and I Cement and 5\% Na, SO, Plots of the Cs-137} CFR versus time for portland type I cement waste forms containing $5 \%$ by weight $\mathrm{Na}_{2} \mathrm{SO}_{4}$, leached with increasing volumes of deionized water are shown in Figure 7.7a. Equivalent Sr-85 CFR versus time data is shown in Figure 7.7b. The releases of both $\mathrm{Cs}-137$ and $\mathrm{Sr}-85$ were both decreased by increasing leachant volume contrary to expectations. This effect could be explained by the formation of insoluble carbonates at the waste form surface. The increasing volumes of leachant increases the availability of dissolved $\mathrm{CO}_{2}$ precipitate $\mathrm{CaCO}_{3}$ and block surface pores which allow the diffusion of Cs-137 and $\mathrm{Sr}-85$. In addition, $\mathrm{Sr}-85$ could be coprecipitated along with calcite $\left(\mathrm{CaCO}_{3}\right)$.

\subsubsection{Vinyl Ester-Styrene/40\% $\mathrm{Na}_{2} \mathrm{SQ}_{4}$. Plots of the Cs-137 CFR} for vinyl ester-styrene containing $40 \%$ by weight $\mathrm{Na}_{2} \mathrm{SO}_{4}$ leached with increasing volumes of deionized water are shown in Figure 7.8a. The release of Cs-137 did not consistently increase with larger volumes of leachant. It should be noted that the rate of leaching of Cs-137 is rapidly increasing, Figure $7.8 \mathrm{~b}$ on approaching 180 days of leaching. The rate of leaching apparently overwhelms any acceleration effect due to increases in the leachate volume. Also, the statistical scattering in the data due to inhomogeneties in the samples further obscure any effects.

\subsection{Scoping Study of the Effects of $\mathrm{pH}$ on Radionuclide Leaching}

The effects of $\mathrm{pH}$ are expected to result from the interaction between leachant ions, waste components and solidification agent. Low pH is expected to enhance the solubilization of most metal cations while high pH limits the solubility of most cations except those of the alkali metals. Since carbon dioxide, bicarbonate and carbonate ions are majors contributor to the buffering capacity of natural groundwater, the $\mathrm{pH}$ range of natural waters lies between 4.5 and 8.2. The sensitivity of leaching to $\mathrm{pH}$ was tested over approximately the range expected for natural waters. 


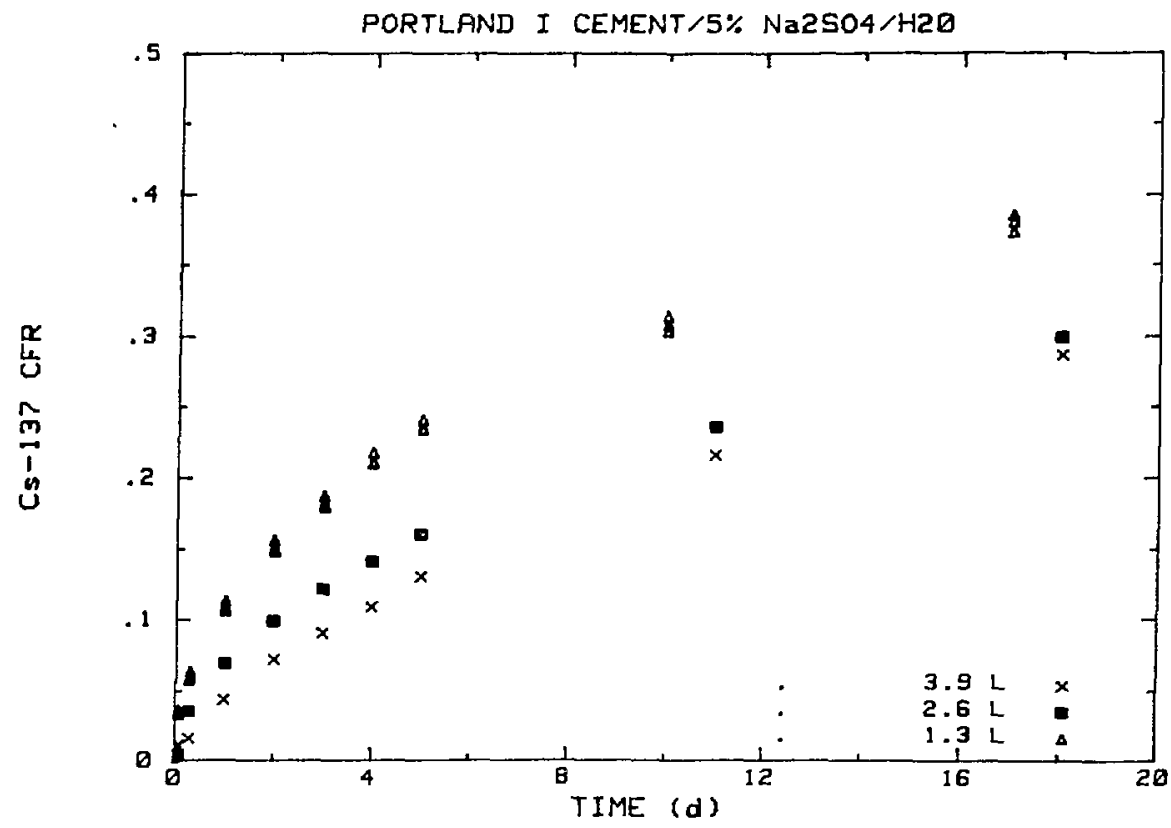

Figure 7.7a Cumulative fraction release (CFR) of Cs-137 versus time for portland I cement waste forms containing $5 \%$ by weight $\mathrm{Na}_{2} \mathrm{SO}_{4}$ leached with increasing leachant volumes $(1.3,2.6$ and $3.9 \mathrm{~L})$ of deionized water.

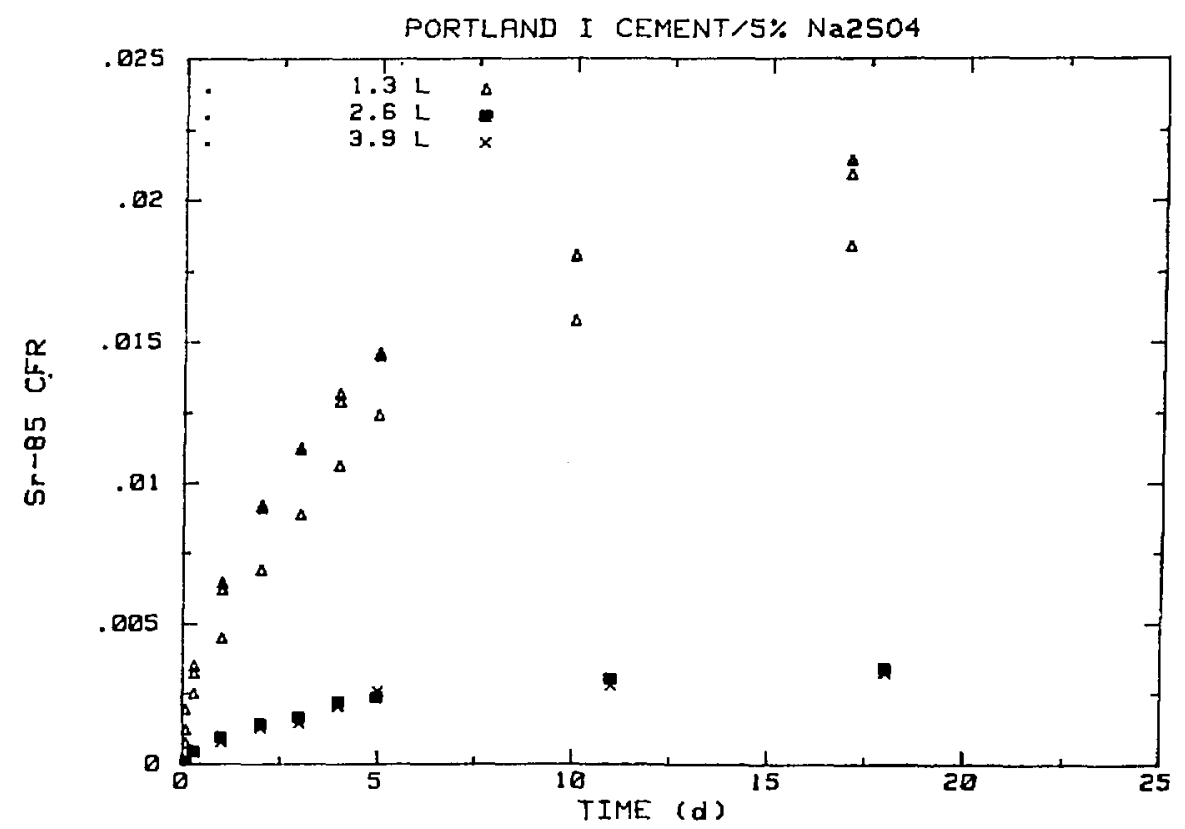

Figure $7.7 \mathrm{~b}$ Cumulative fraction release (CFR) of $\mathrm{Sr}-85$ versus time for portland I cement waste forms containing $5 \%$ by weight $\mathrm{Na}_{2} \mathrm{SO}_{4}$ leached with increasing leachant volumes $(1.3,2.6$ and $3.9 \mathrm{~L})$ of deionized water. 


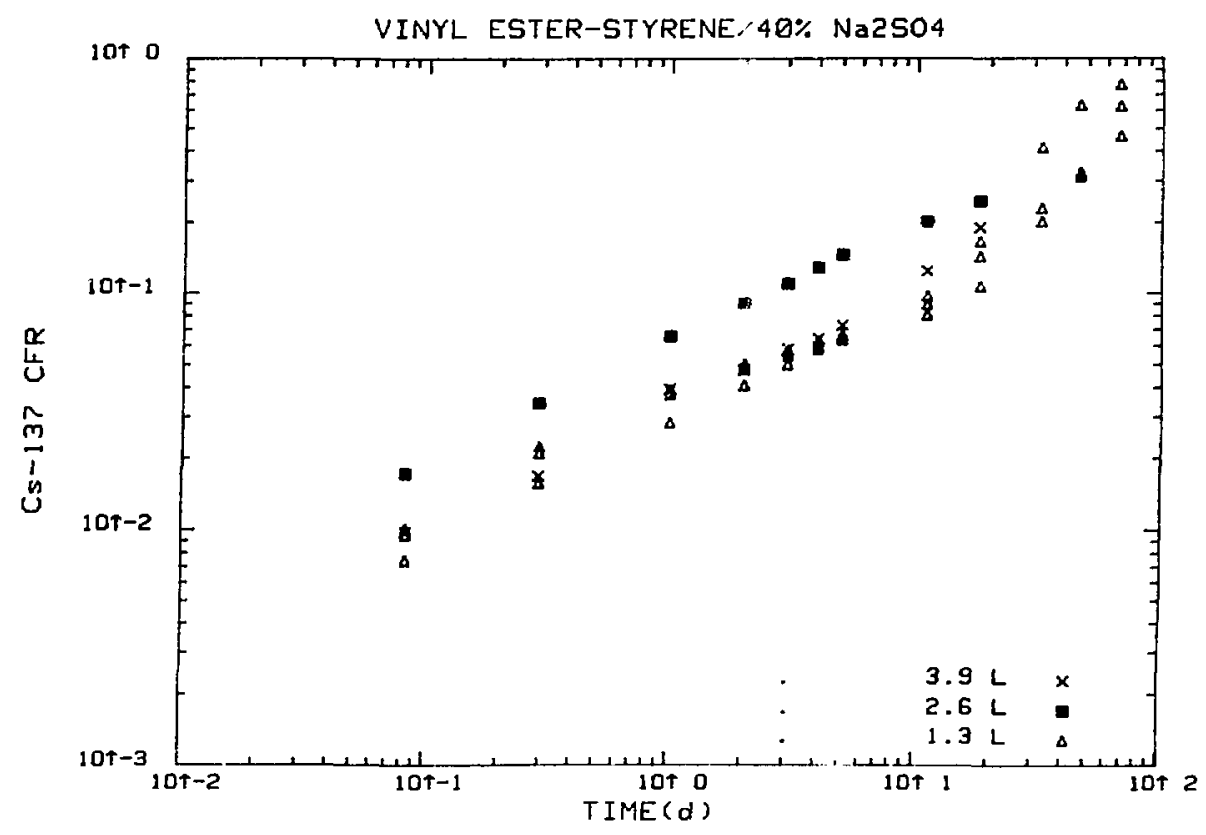

Figure 7.8a Cumulative fraction releases (CFR) versus time of Cs-137 from vinyl ester-styrene waste forms containing $40 \%$ by weight $\mathrm{Na}_{2} \mathrm{SO}_{4}$ leached with increasing leachant volumes $(1.3,2.6$ and $3.9 \mathrm{~L})$ of deionized water.

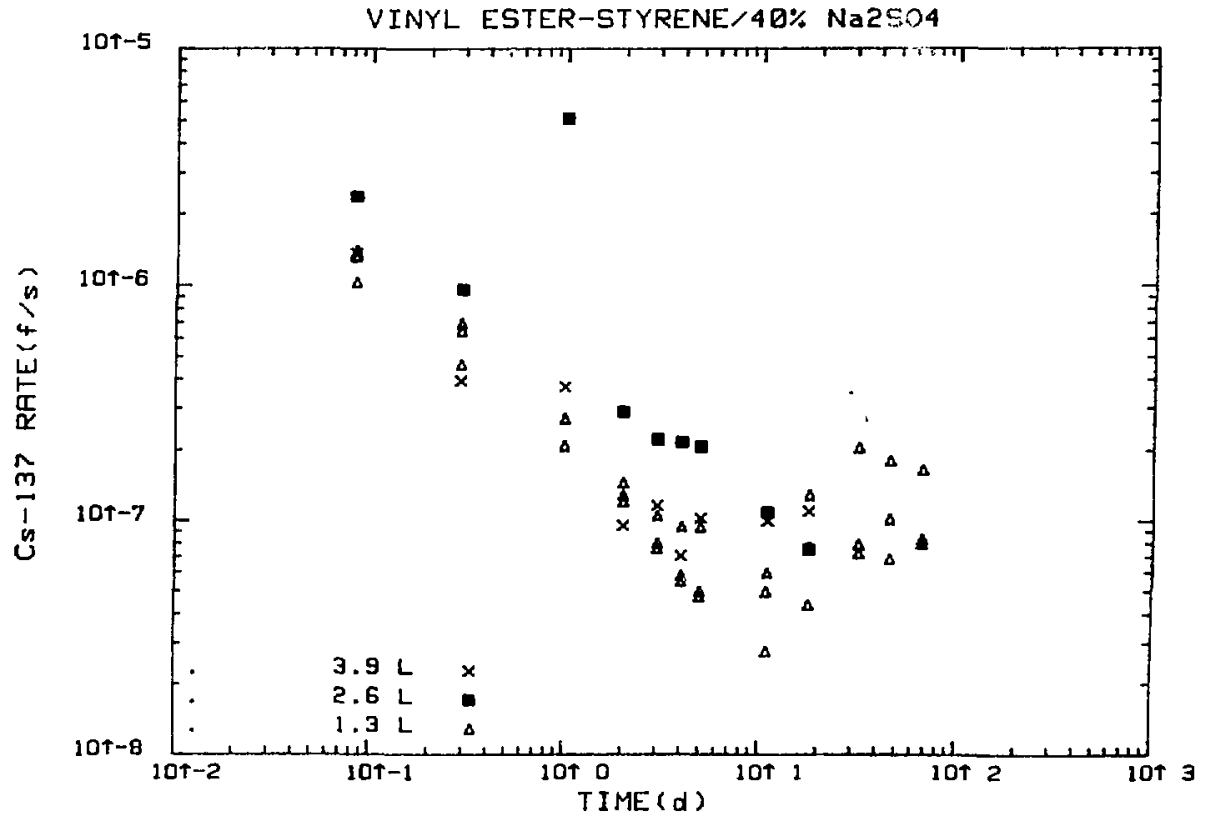

Figure 7.8b Incremental fraction releases (RATE $(f / s)$ ) versus time of Cs-137 from vinyl ester-styrene waste forms containing $40 \%$ by weight. $\mathrm{Na}_{2} \mathrm{SO}_{4}$ leached with increasing leachant volumes $(1.3,2.6$ and $3.9 \mathrm{~L})$ of deionized water. 
The effect of $\mathrm{pH}$ on leaching operates simultaneously with the effect of solution ionic strength. The ionic strength of solution is defined as

$$
\mu=1 / 2 \sum_{i} C_{i} z^{2}
$$

where

$C_{j}=$ concentration of ion species $i$ (moles $/ L$ )

$Z_{i}=$ charge of the $i$ on

Ionic strength is a measure of the total ionic concentration in solution. Diffusion from solids into solution is expected to decrease with increasing ionic strength for common and/or competing reacting ions. In fact, solutions prepared from deionized water by the addition of acids or bases will have greater ionic strength than deionized water. Consequently, whether pH or ionic strength dominates the leaching process depends strongly on the waste form characteristics.

\subsubsection{Experiment Description}

7.3.1.1 Test Procedure. The ANS 16.1 leaching procedure was used to conduct $\mathrm{pH}$ sensitivity tests with waste forms containing simulated waste using a modified sampling schedule. The test specimens were cylinders approximateiy $5.1 \mathrm{~cm}$ in diameter by $6.4 \mathrm{~cm}$ in height. Test were conducted at $20^{\circ} \mathrm{C}$ using a leachant volume of 1.3 liters.

\subsubsection{Leachants. Leachants of initial pH 3, 4 and 5 were pre-} pared by dilution of concentrated nitric acid deionized water. A dilute solution of sodium bicarbonate $(0.006 \mathrm{~N})$ in deionized water was used as the leachant with an initial $\mathrm{pH}$ of 8 .

\subsection{2 pH Effects Scoping Study of Radionuclide Leaching}

$7.3,2.1$ Portland I Cement $/ 5 \% \mathrm{Na}_{2} \mathrm{SO}_{4} / \mathrm{H}_{2} \mathrm{O}$. The effect of the initial $\mathrm{pH}$ of the leachant solution may have little effect on the leaching of cement waste forms since the $\mathrm{pH}$ of hydrated cement due to the presence of a saturated solution of $\mathrm{Ca}(\mathrm{OH})_{2}$ in the pore fluid is 12.5. The Cs-137 CFR versus time results for portland I cement containing $5 \%$ by weight $\mathrm{Na}_{2} \mathrm{SO}_{4}$ are shown in Figure 7.9. Leachant solutions with an initial pH of 3,4 and 5 slightly decreased the amount of $\mathrm{Cs}-137$ released possibly because increased solubilization of matrix and waste components increased the ionic strength of the leachant and thereby suppressed the diffusion of Cs-137 from the waste form. The alkaline solution of sodium bicarbonate $(\mathrm{pH}=8)$ also suppressed the leaching of $\mathrm{Cs}-137$ from the waste forms, possibly due to the formation of calcite $\left(\mathrm{CaCO}_{3}\right)$ at the waste form surface which could reduce the waste form's permeability. The deionized water solution $(\mathrm{pH}=6)$ showed the maximum release for $\mathrm{Cs}-137$ leaching. 


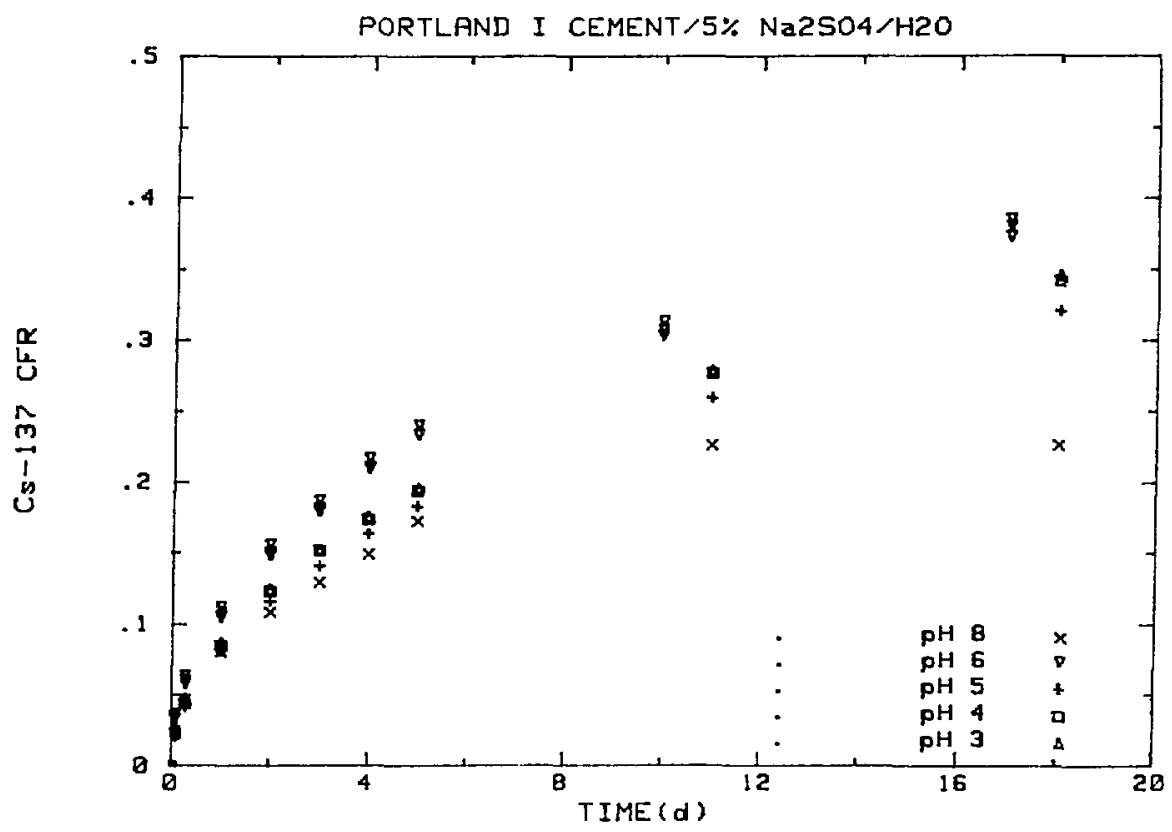

Figure 7.9 Cumulative fraction release (CFR) of Cs -137 versus time for

Portland type I cement containing $5 \%$ by weight $\mathrm{Na}_{2} \mathrm{SO}_{4}$ leached with solutions of increasing initial $\mathrm{pH}(3,4,5,6$ and 8$)$.

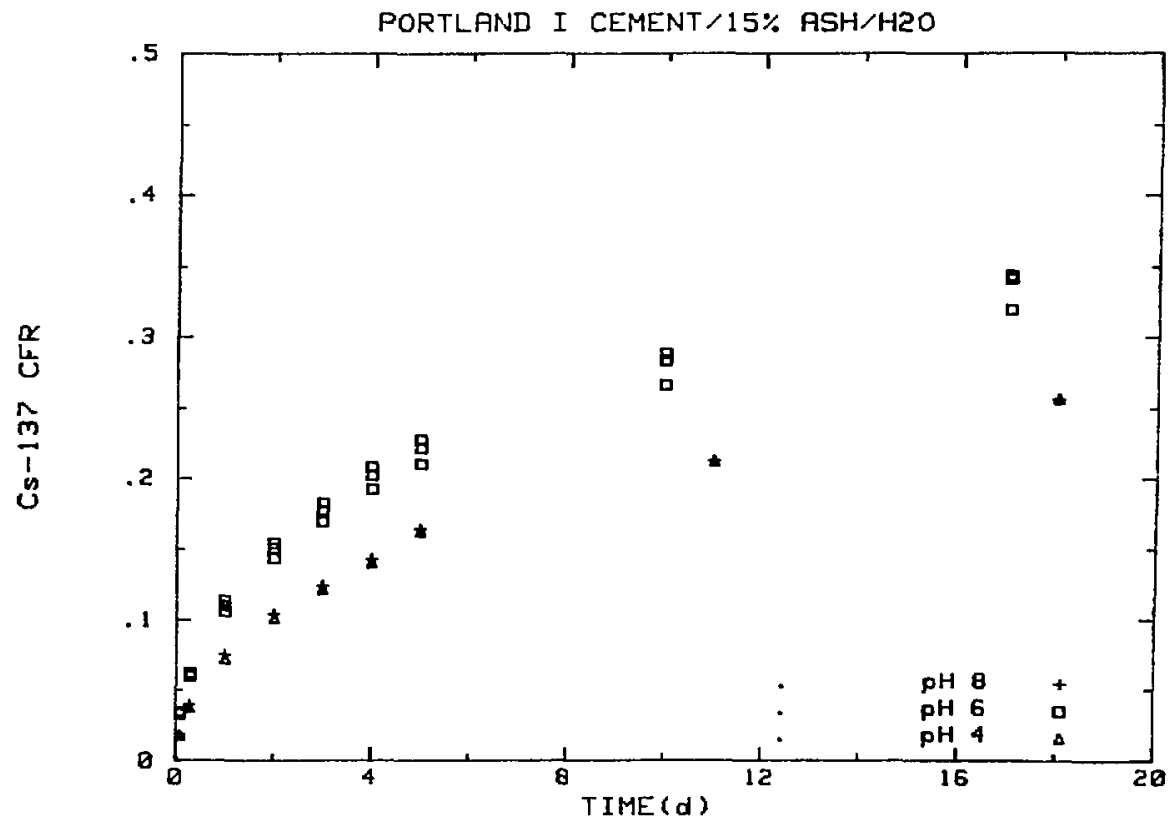

Figure 7.10 Cumulative fraction release (CFR) of Cs-137 versus time for Portland type I cement containing $15 \%$ incinerator ash leached with solutions of increasing initial $\mathrm{pH}(4,6$ and 8$)$. 
7.3.2.2 Portland I Cement/15\% Incinerator Ash. Plots of the Cs-137 CFR versus time for portland type I cement waste forms containing $15 \%$ by weight incinerator ash for leaching with solutions of increasing initial pH $(4,6$ and 8$)$ are shown in Figure 7.10 . The deionized water solution $(\mathrm{pH}=6)$ showed the largest release of $\mathrm{Cs}-137$. As with the portland I cement forms containing $5 \%$ by weight $\mathrm{Na}_{2} \mathrm{SO}_{4}$ both the $\mathrm{pH} 4$ and $\mathrm{pH} 8$ leachants suppressed the release of Cs-137 (Section 7.3.2.1).

7.3.2.3 Vinyl Ester-Styrene/15\% Na, $\mathrm{SO}_{4} / \mathrm{H}, 0$ Emulsion. Plots of the Cs-137 CFR versus time from vinyl ester-styrene water emulsion waste forms containing $15 \%$ by weight $\mathrm{Na}_{2} \mathrm{SO}_{4}$ leached with solutions of increasing $\mathrm{pH}(4,6$ and 8) are shown in Figure 7.11. Clearly, the ionic strength of solution dominates the short-term leaching of these waste forms. Deionized water produced the largest release of Cs-137. For both $\mathrm{pH} 4$ and $\mathrm{pH} 8$ the release of Cs-137 was significantly reduced.

\subsubsection{Vinyl Ester-Styrene/40\% $\mathrm{Na}, \mathrm{SO}_{4}$. Plots of $\mathrm{Cs}-137 \mathrm{CFR}$ versus} time from vinyl ester-styrene waste forms containing $40 \mathrm{wt} \% \mathrm{Na}_{2} \mathrm{SO}_{4}$ leached with solutions of increasing initial $\mathrm{pH}(4,6$ and 8$)$ are shown in Figure 7.12. The release of $\mathrm{Cs}-137$ was not consistent with $\mathrm{pH}$ and may be dominated by the solubilization effects on the waste salt of low pH. The maximum release of $\mathrm{Cs}-137$ observed for the alkaline $\mathrm{NaHCO}_{3}$ solution $(\mathrm{pH}=8)$ is not clearly understood and needs further investigation. It should be noted that the substantial increase in the incremental release rate after 10 days of leaching, noted in Section 5, could possibly be overwhelming any pH effects. Also, statistical scattering in the Cs-137 CFR due to the inhomogeneous nature of the samples may contribute to this uncertainty.

7.3.2.5 Bitumen $/ 20 \% \mathrm{Na}, \mathrm{B}_{4} \mathrm{O}_{7}$. Plots of $\mathrm{Cs}-137$ CFR versus time from bitumen waste forms containing $20 \mathrm{wt} \%$ sodium tetraborate $\left(\mathrm{Na}_{2} \mathrm{~B}_{4} \mathrm{O}_{7}\right)$ leached with solutions of increasing initial pH $(4,6$ and 8$)$ are shown in Figure 7.13. The release of $\mathrm{Cs}-137$ at $\mathrm{pH} 4$ was clearly greater than that at pH 6 and $\mathrm{pH}$ 8. Since the ionic strength of these leachates is expected to be smal?, the solubilization by $1 \mathrm{ow} \mathrm{pH}$ is expected to dominate the release process.

\subsubsection{Bitumen $/ 40 \% \mathrm{Na}, \mathrm{B}_{4} \mathrm{O}_{7}$. Plots of $\mathrm{Cs}-137$ CFR versus time from} bitumen waste forms containing $40 \%$ by weight sodium tetraborate ( $N a, \mathrm{~B}_{4} \mathrm{O}_{3}$ ) leached with solutions of increasing $\mathrm{pH}(4,6$ and 8$)$ are shown in Figure 7.14. No consistent effect due to $\mathrm{pH}$ was observed. The $\mathrm{pH}$ and ionic strength effects have probably been overwhelmed by the rapid release of Cs-137 due to the high waste loading. The rate of release of $\mathrm{Cs}_{s}-137$ increases substantially after 10 days of leaching as noted in Section 5.

\subsection{Leachant Flow Effects}

The ideal condition for leaching solidified waste forms occurs when the concentration of leached material in the leachant is negligible. Maximum leach rates will be observed when the concentration of the diffusant in the leachant approaches zero. Ideally, flowing leach tests maintain low concentrations of leached substances in the leachant. 


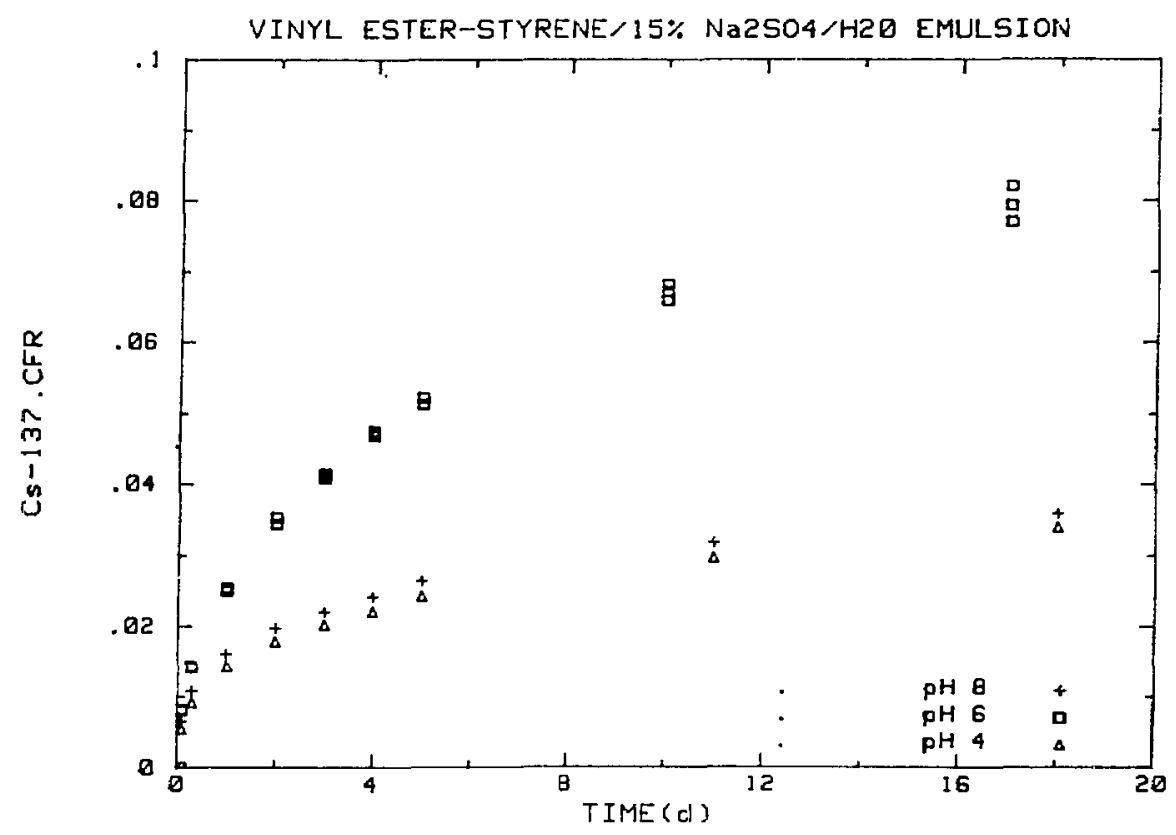

Figure 7.11 Cumulative fraction release (CFR) versus time from vinyl esterstyrene water emulsion waste forms containing $15 \% \mathrm{Na}_{2} \mathrm{SO}_{4}$ leached with solution of increasing $\mathrm{pH}\{4,6$ and 8$\}$.

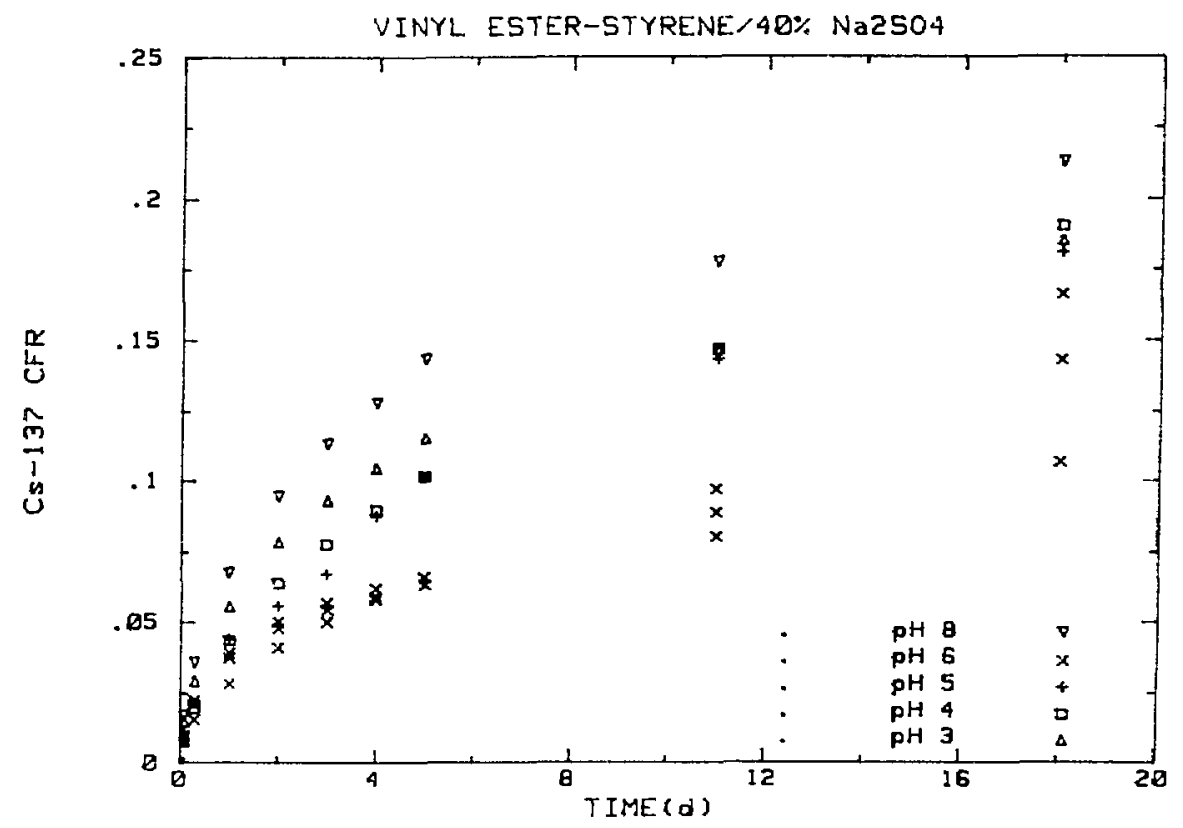

Figure 7.12 Cumulative fraction release (CFR) versus time from vinyl esterstyrene waste forms containing $40 \% \mathrm{Na}_{2} \mathrm{SO}_{4}$ leached with solutions of increasing $\mathrm{pH}(3,4,5,6$ and 8$)$. 
BITUMEN/2D\% Na2B4D?

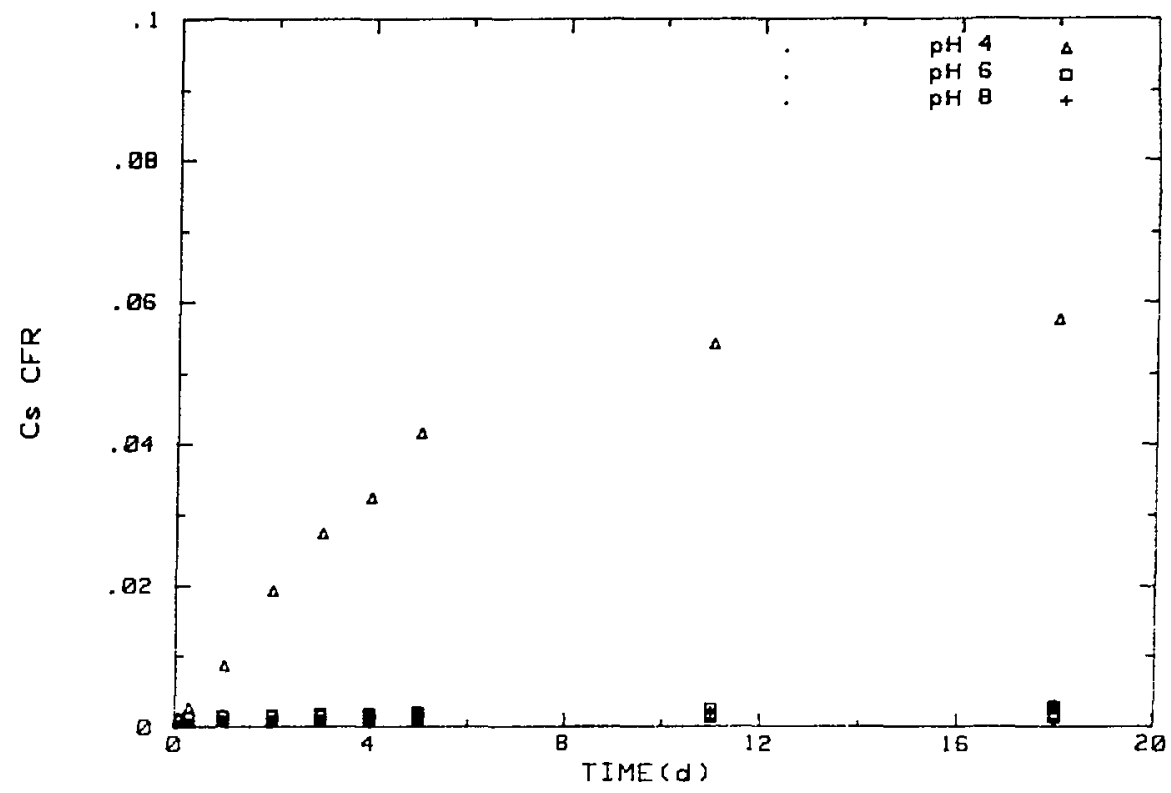

Figure 7.13 Cumulative fraction release (CFR) of Cs-137 versus time from bitumen waste forms containing $20 \%$ by weight sodium tetraborate $\left(\mathrm{Na}_{2} \mathrm{~B}_{4} \mathrm{O}_{7}\right)$ leached with solutions of increasing initial $\mathrm{pH}(4,6$ and 8 ).

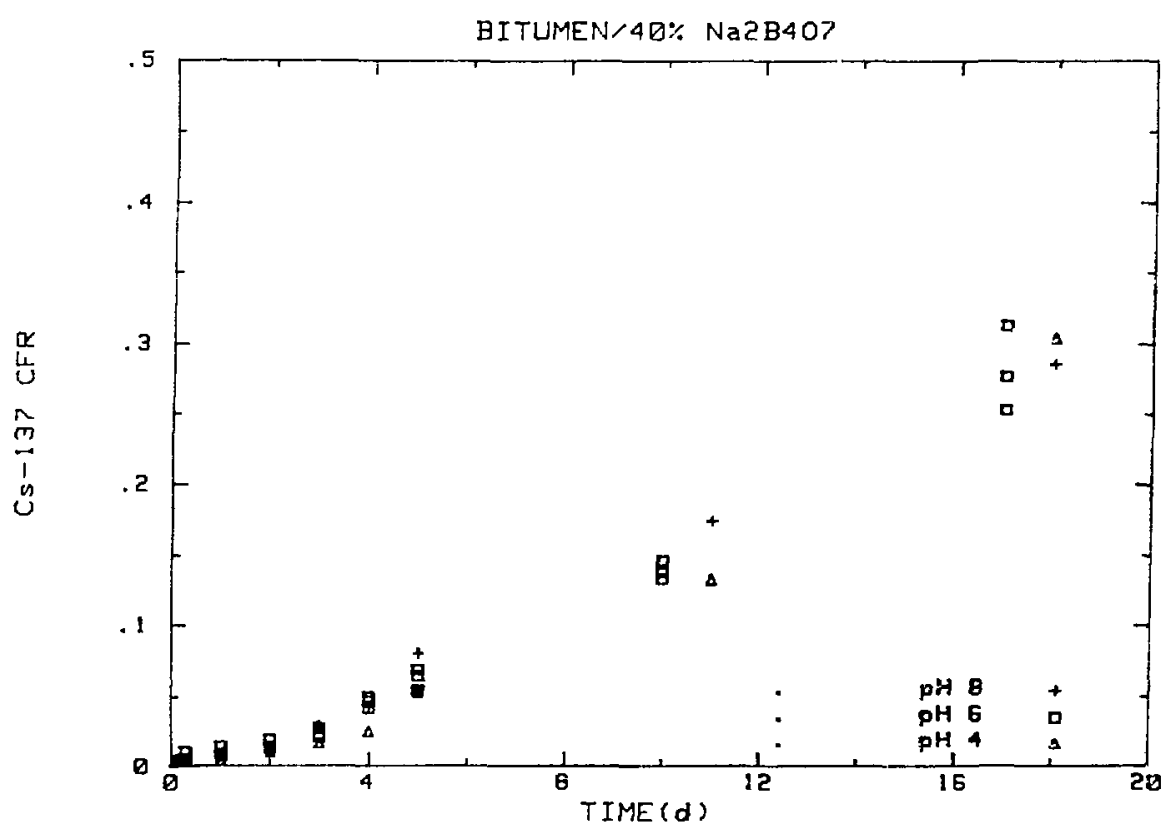

Figure 7.14 Cumulative fraction release (CFR) of CS-137 versus time from bitumen waste forms containing $40 \%$ by weight sodium tetraborate $\left(\mathrm{Na}_{2} \mathrm{~B}_{4} \mathrm{O}_{7}\right)$ leached with solutions of increasing initial $\mathrm{pH}(4,6$ and 8 ). 
The MCC-4S leaching test assumes a well mixed, constant flow rate system with a fixed leachate volume [16]. The leachate volume to sample surface area is large to keep the linear flow small. The leaching effluent is assumed to be the average concentration inside the leaching vessel.

The data analyses procedure in MCC-4S which calculates the leach rate is formally correct only when the leach rate is constant. If the leach rate is changing with time then the calculated rate is either: (i) greater than the actual rate for the case in which the leach rate is decreasing with $t$ ime or, (ii) less than the actual rate when the leach rate is increasing.

This is clear upon examining the analytical procedure specified in $M C C-4 S$. The amount of a species leached from a waste form at any point in $t$ ime is :

Quantity in solution in leaching vessel

$$
\begin{aligned}
& \left(C_{2} V\right)=\begin{array}{l}
\text { Quantity } \\
\text { Initialiy solution }
\end{array}+\begin{array}{l}
\text { Quantity } \\
\text { Leached } \\
\text { from form }
\end{array}-\begin{array}{l}
\text { Quantity lost } \\
\text { by flow from } \\
\text { vessel }
\end{array} \\
& C_{2} V=C_{1} V+\text { LA } t-F \bar{C}_{\Delta} t
\end{aligned}
$$

where

$$
\begin{aligned}
& C_{2}=\text { concentration in the leaching vessel at time } t_{2}\left(\mathrm{~g} / \mathrm{cm}^{3}\right) \\
& C_{1}=\text { concentration in the leaching vessel at time } t_{1}\left(\mathrm{~g} / \mathrm{cm}^{3}\right) \\
& V=\text { volume of leachate }\left(\mathrm{cm}^{3}\right) \text { in the leaching vessel } \\
& \vec{C}=\text { average of } C_{2} \text { and } C_{1} \\
& L=\text { leach rate }\left(\mathrm{g} / \mathrm{sec} \mathrm{cm}^{2}\right) \\
& A=\text { surface area of the waste form }\left(\mathrm{cm}^{2}\right) \\
& \Delta t=t_{2}-t_{1}=1 \text { eaching interval }(\mathrm{sec}) \\
& F=f 10 w \text { rate }\left(\mathrm{cm}^{2} / \mathrm{sec}\right)
\end{aligned}
$$

At the start of the experiment, ( $i . e ., t=0$ and $c_{1}=0$ ), the concentration in the leaching vessel is changing rapidly.

At some time later, depending on leach rate and flow rate, the system may approach a steady state. The approach to steady state, including its dependence on leach rate and flow rate has been reported by Seefeldt [45]. 
1) For the case of a constant leach rate at steady state

$$
\begin{aligned}
& \frac{d C}{d t}=0 \\
& C_{1}=C_{2} \\
& L=\frac{F \bar{C}}{A}
\end{aligned}
$$

Which is the MCC-4S equation for leach rate.

However, for leaching real waste forms the leach rate is generally not constant. This is so for two reasons: (a) the source term is finite, therefore, depletion resuits in a decreasing leach rate and (b) if the leach rate is dependent on diffusion, as is generally assumed, then the leach rate is never constant based on the diffusion mechanism for leaching.

The leach rate derived from Equaticn 7.1 is.

$$
L=\frac{C_{2} V-C_{1} V+F \bar{C} \Delta t}{A \Delta t}
$$

Preliminary examination of experimental data for LLW suggests that there can be significant differences between leach rates calculated by Equation 7.2.

Since the leach rate of LLW is never constant over any significant length of time, the error introduced by approximating Equation 7.3 with Equation 7.2 is not known. Therefore, it is not clear how well Equation 7.2 approximates actual leach rates for low-level wastes.

Additonally, the incremental fraction released (cumulative fraction released is not calculated in the method) is obtained from the experimental data for the MCC-4S flow test by measuring small grab samples from the flowing leachate stream. This introduces an uncertainty in the calculations not only because not everything is being counted, but also because any change in leachability between sampling intervals is not measured directly but, must be extrapolated for the uncounted leachant. Consequently, there exists no accurate manner of determining CFR.

7.4.1 Experimental Description. The MCC-4S flow leach test was used to determine the leachability of $\mathrm{Co-57}, \mathrm{Sr}-85$ and $\mathrm{Cs}-137$ from solidified waste forms prepared from both solidification agents and from solidification agents containing simulated wastes. The waste form specimens were cylinders approximately $5.1 \mathrm{~cm}$ in diameter by $6.4 \mathrm{~cm}$ in height. The leaching test were run at $20^{\circ} \mathrm{C}$ using deionized water at flow rate of about one liter per day. 


\subsubsection{Flow Test - Radionuclide Leaching Results}

7.4.2.1 Portland I Cement. The incremental fractional release rates (Rate $(\mathrm{f} / \mathrm{s})$ ) of $\mathrm{Cs}-137$ from portland I cement waste forms, shown in Figure 7.15a, were calculated using Equation 7.3. The Cs-137 results for the flow test were in good agreement with those obtained from the modified ANS 16.1 semidynamic leach test up to 60 days of leaching. After 60 days the rate dropped more rapidly for the flow test possibly indicating that the waste form was being depleted. Unfortunately, the drop in the Cs-137 leach rate could also be due to other causes, for example, the buildup of leachable salts from the waste form because of inadequate mixing and dilution. Since CFR values for the flow test are not available the results are inconclusive.

Results for the incremental fractional release rates of Cs-137 using the $\mathrm{MCC}-4 \mathrm{~S}$ test equation ( $\mathrm{Eq} .7 .2$ ), although formally inadequate for low-level waste forms, produced similar results, Figure $7.15 \mathrm{~b}$.

\subsubsection{Vinyl Ester-Styrene Water Emulsion Polymer. Plots of} incremental fraction release (Rate $(\mathrm{f} / \mathrm{s})$ ) of $\mathrm{Cs}-137$ from vinyl ester-styrene water emulsion waste forms, are shown in Figure 7.16a. Leach rates were calculated using the modified flow test rate equation (Eq. 7.3). Leach rates for the flow test were considerably higher than from the Modified ANS 16.1 Leach Test, indicating an acceleration in the release of $\mathrm{Cs}-137$.

Results for $\mathrm{Cs}-137$ incremental release rates using the $M C C-4 S$ flow test test equation ( $\mathrm{Eq} .7 .2$ ), although formally inadequate for low-level waste forms, produced similar results, Figure $7.16 \mathrm{~b}$.

\subsubsection{Portland I Cement and 5\% Na, $\mathrm{SO}_{4}$. Plots of Incremental} fraction release rates (Rate $(\mathrm{f} / \mathrm{s})$ ) of $\mathrm{Cs}-137$ from portland I cement waste forms containing $5 \%$ by weight $\mathrm{Na}_{2} \mathrm{SO}_{4}$ were calculated, using the modified flow test rate equation (Eq. 7.3), are shown in Figure 7.17. Duplicate samples were used for the flow test. The release rates for the flow test agree with those observed for the modified ANS 16.1 semidynamic leach test after 10 days leaching. No acceleration of the leach rate was observed. The scattering in the rate data from the flow test is indicative of the experimental difficulties encountered with simulated waste containing waste form during flow test. The statistical reliability of the results is being further investigated.

7.4.2.4 Portland I Cement and 15\% Incinerator Ash. Plots of incremental fractional release rates (Rate $(\mathrm{f} / \mathrm{s})$ ) of $\mathrm{Cs}-137$ from portland I cement waste forms containing $15 \mathrm{wt} \%$ incinerator ash are shown in Figure 7.18 . Leach rates were calculated using the modified flow test rate equation (Eq. 7.3 ). The rate results agree well with those from the modified ANS 16.1 leach test. No increase in the release rate for Cs-137 was observed for the flow test.

\subsubsection{Vinyl Ester-Styrene/15\% Na, $\mathrm{SO}_{4} / \mathrm{H}, 0$ Emulsion. Plots of} incremental fractional release rates (Rate $(\mathrm{f} / \mathrm{s})$ ) of $\mathrm{Cs}-137$ from vinyl esterstyrene water emulsion polymer waste forms containing $15 \mathrm{wt} \% \mathrm{Na}_{2} \mathrm{SO}_{4}$ are shown in Figure 7.19. Leach rates were calculated using the modified flow test rate equation (Eq. 7.3). The $\mathrm{Cs}-137$ rate results after 10 days of leaching are only slightly lower than those observed for the modified ANS 16.1 leach test. No acceleration in the leach rate was observed. 


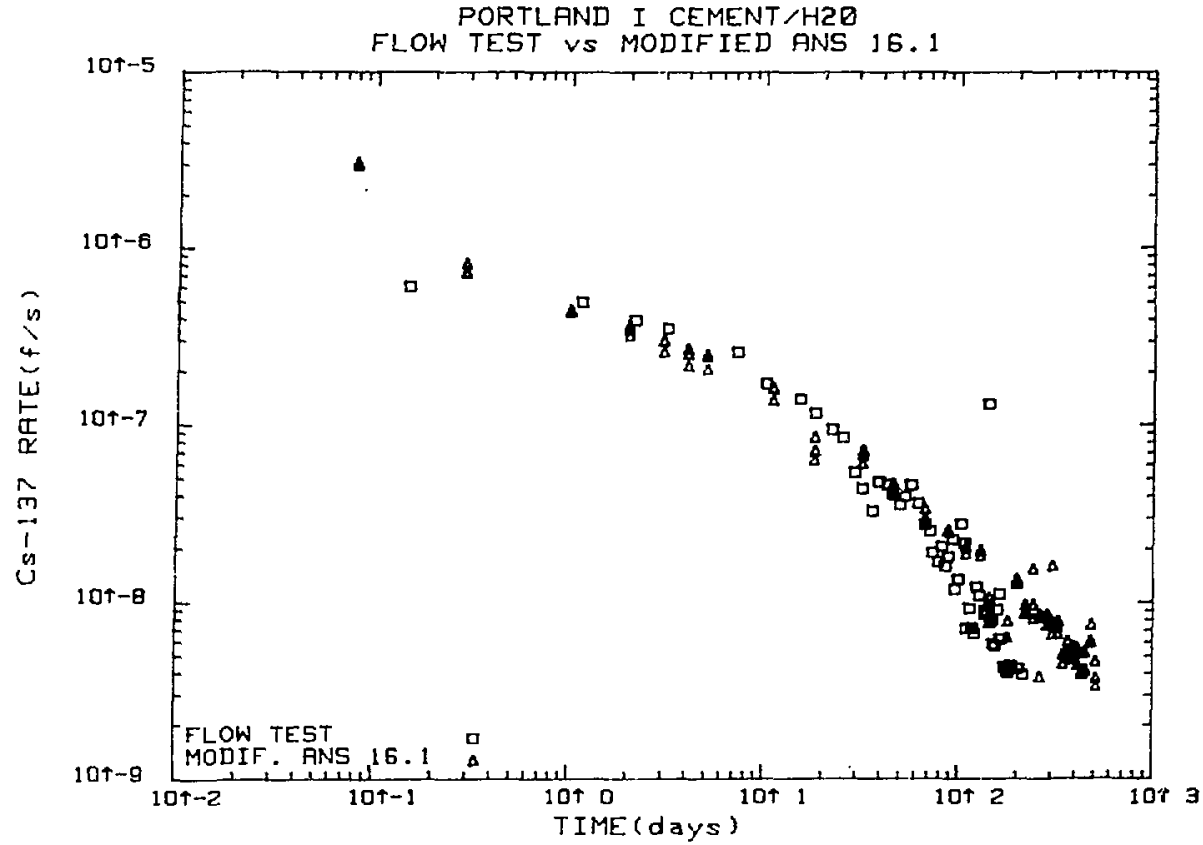

Figure $7.15 a$ Incremental fractional release rate (Rate (f/s)) for Cs-137 from portland type I cement waste forms comparing the MCC-4S flow test, using a modified rate equation to the modified ANS 16.1 semidynamic leach test.

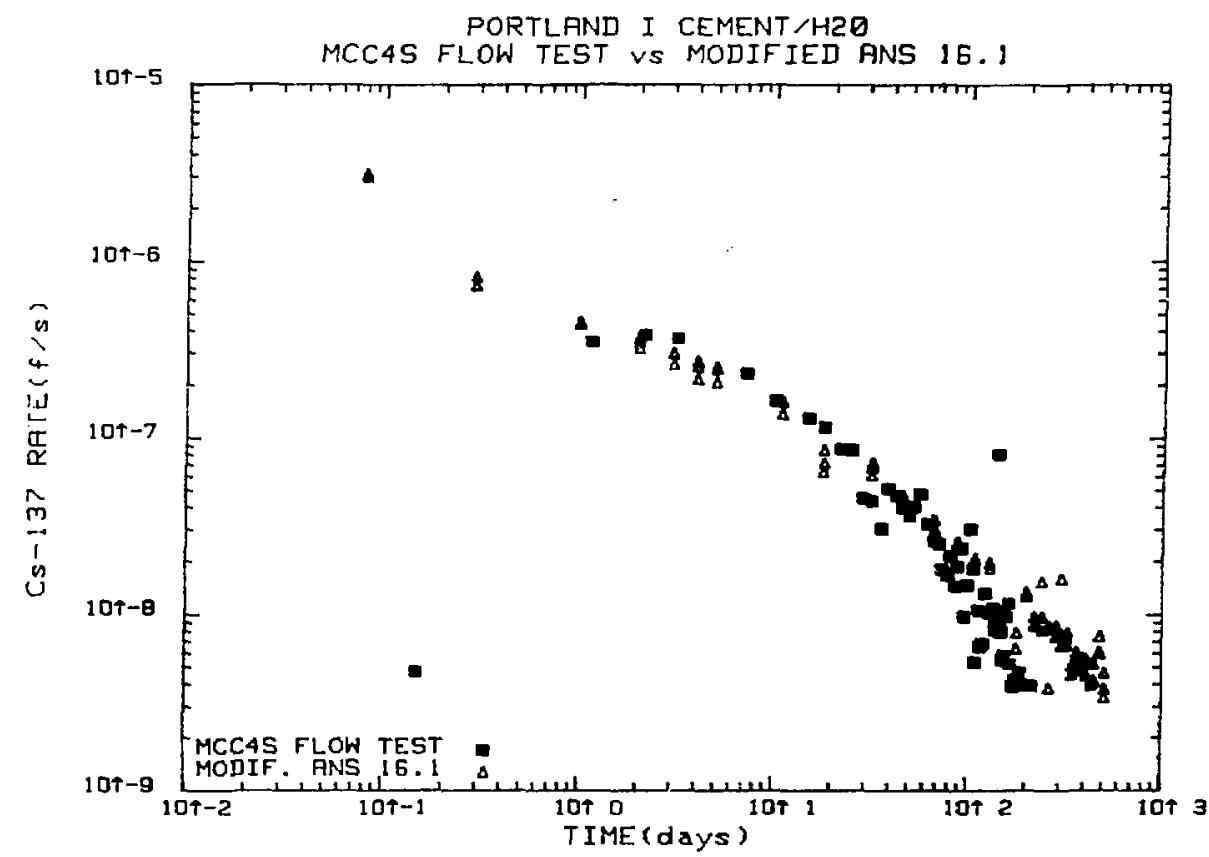

Figure $7.15 \mathrm{~b}$ Incremental fractional release rates (Rate (f/s)) for $\mathrm{Cs}-137$ versus time from portland type I cement waste forms comparing results for the MCC-4S flow test to the modified ANS 16.1 semidynamic leach test. 


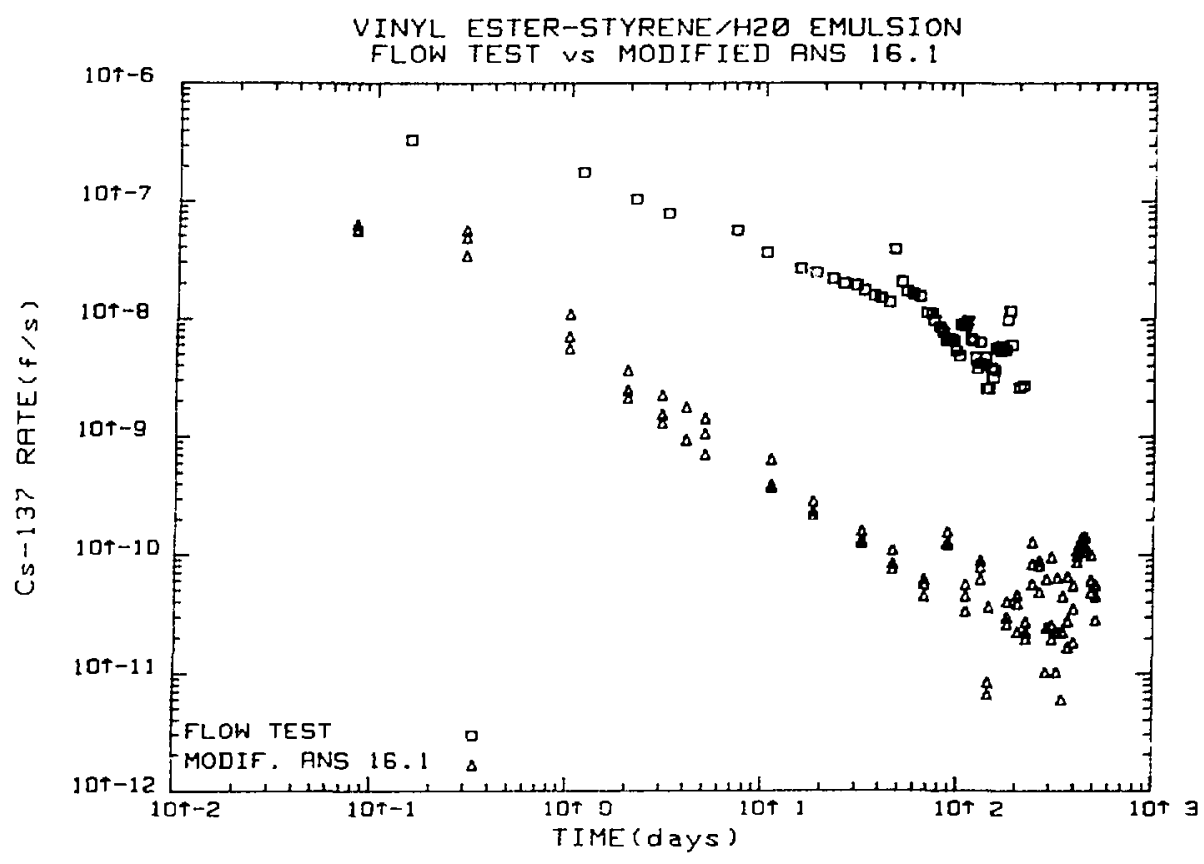

Figure 7.16a Incremental fractional release rates (Rate (f/s)) for Cs-137 versus time from vinyl ester-styrene water emulsion waste forms comparing results for the $M C C-4 S$ flow test, using a modified rate equation, to the modified ANS 16.1 semidynamic leach test.

VINYL ESTER-STYPENE/HZO EMULSION MCC4S FLOW TEST VS MODIFIED ANS 16.1

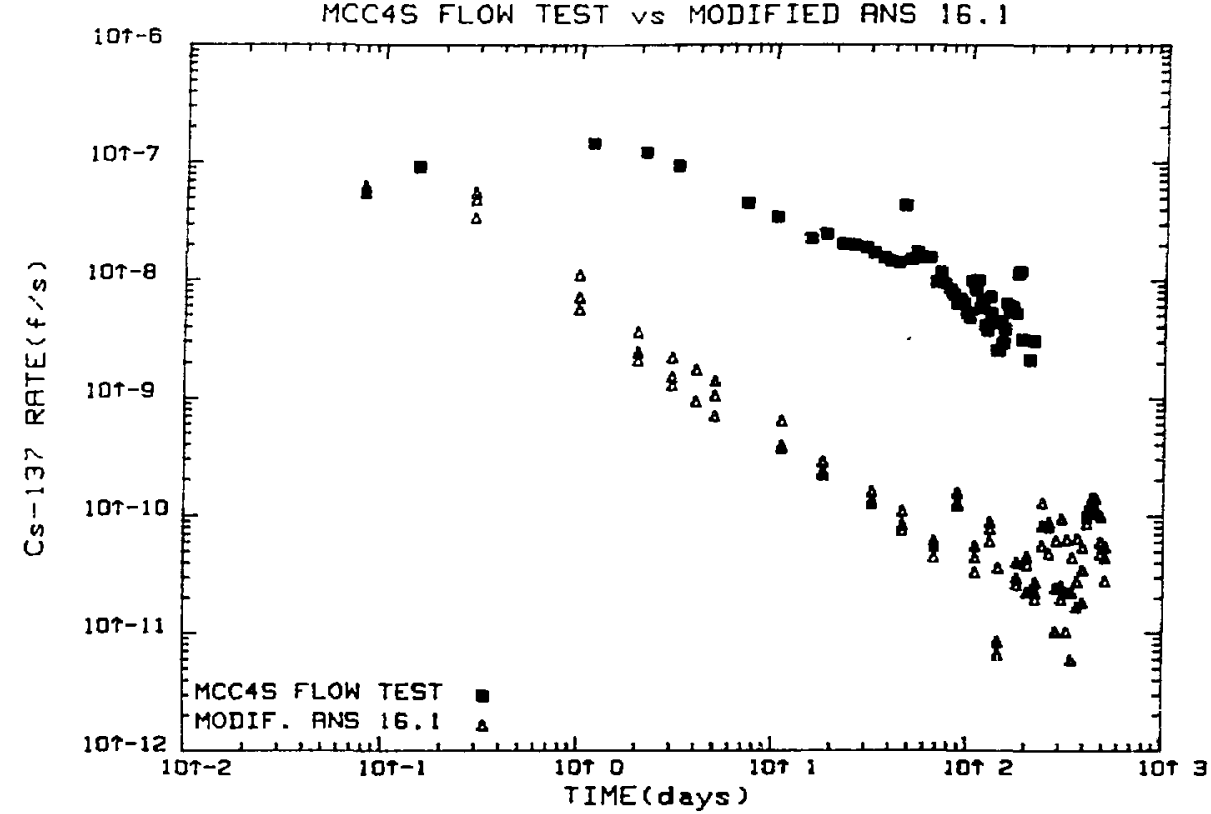

Figure 7.16b Incremental fractional release rates (Rate (f/s)) for Cs-137 versus time from vinyl ester-styrene water emulsion waste forms comparing results for the MCC -45 flow test to the modified AMS 16.1 semidynamic leach test. 


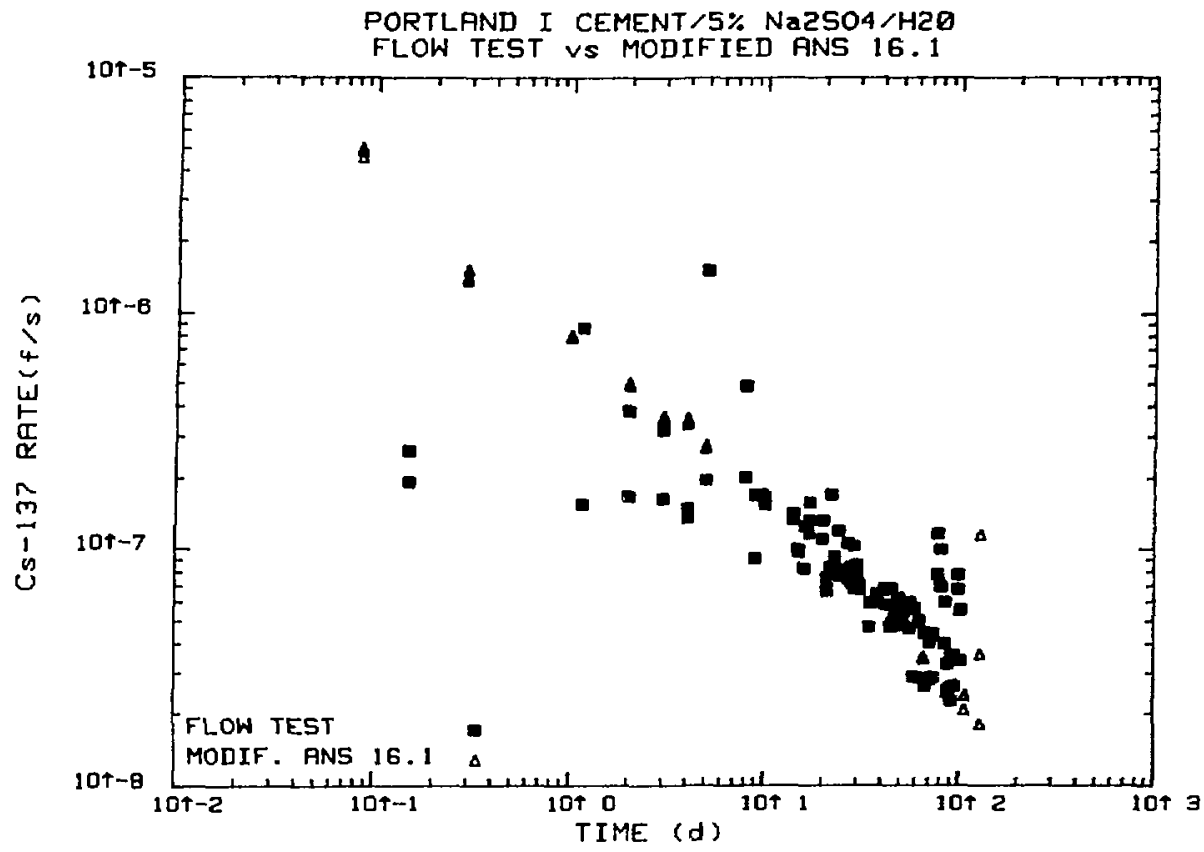

Figure 7.17 Incremental fractional release rates (Rate (f/s)) for $\mathrm{Cs}-137$ versus time from portland type I cement containing $5 \%$ by weight $\mathrm{Na}_{2} \mathrm{SO}_{4}$. Results for the MCC-4S flow test, using a modified rate equation, were compared to the modified ANS 16.1 semidynamic leach test.

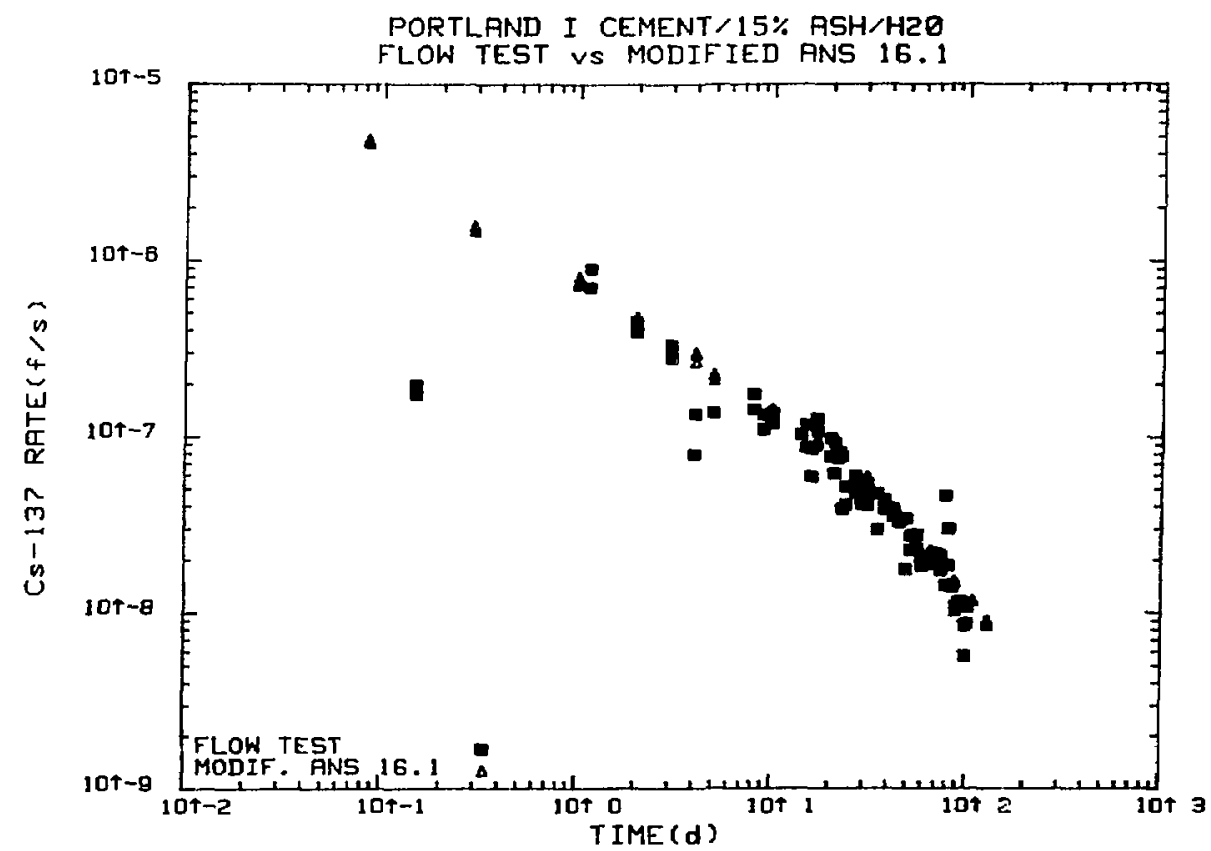

Figure 7.18 Incremental fractional release rates (Rate $(f / s)$ ) for $\mathrm{Cs}-137$ versus time from portland type I cement waste forms containing $15 \%$ by weight incinerator ash. Results for the MCC-4S flow test, using a modified rate equation, were compared to the modified ANS 16.1 semidynamic leach test. 
VINYL ESTER-STYRENE $15 \%$ NaZSO4/HZG EMLLSION FLOW TEST $\checkmark S$ MODIFIED ANS 16.1

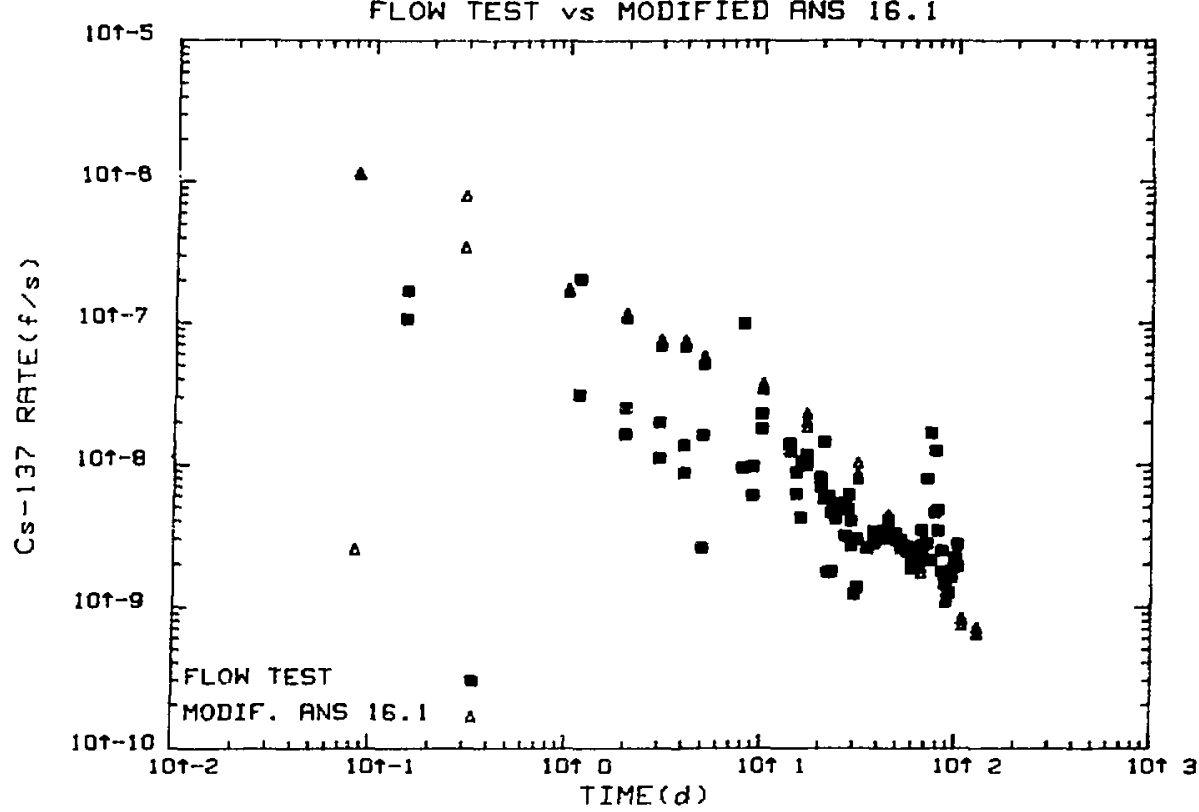

Figure 7.19 Incremental fractional release rates (Rate $(f / s)$ ) for $\mathrm{Cs}-137$ versus time from vinyl ester-styrene water emulsion waste forms containing $15 \% \mathrm{Na}_{2} \mathrm{SO}_{4}$. Results for the $\mathrm{MCC}-4 \mathrm{~S}$ flow test, using a modified rate equation, were compared to the modified ANS 16.1 semidynamic leach test.

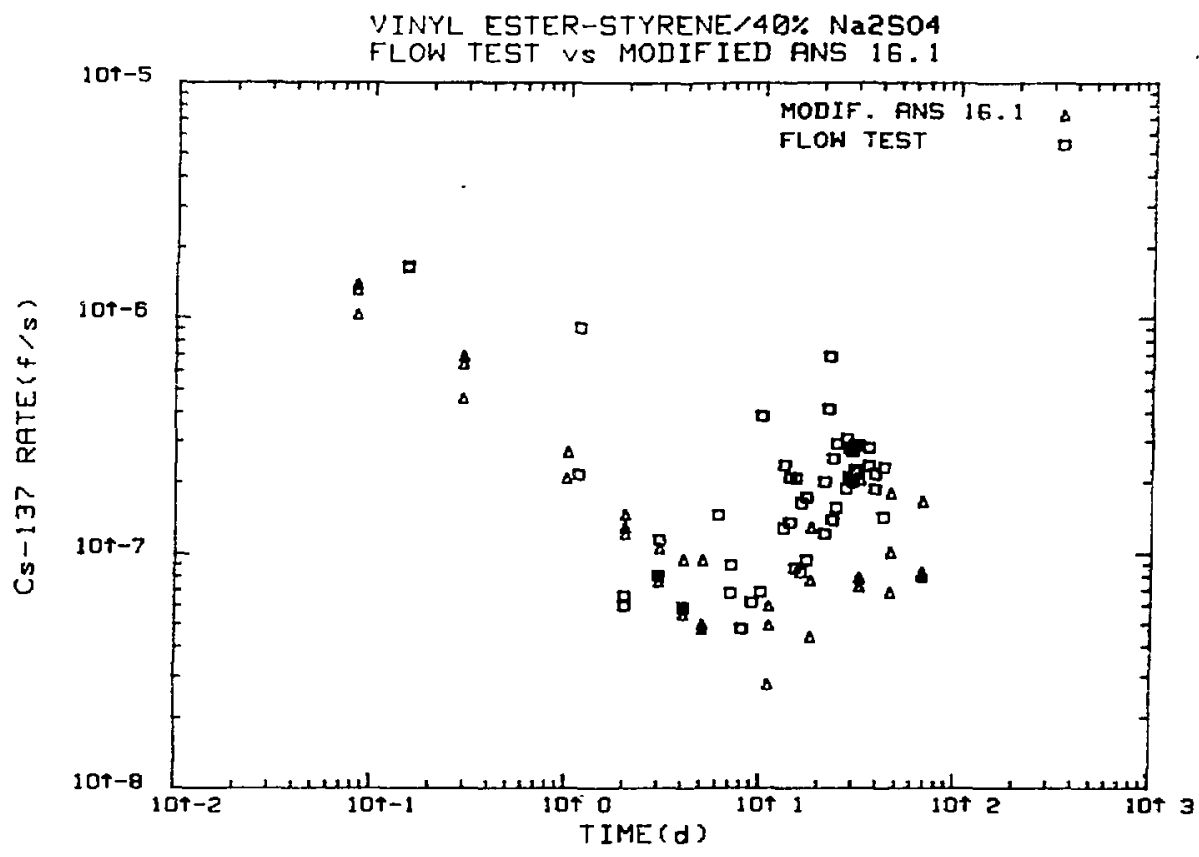

Figure 7.20 Incremental fractional release rates (Rate (f/s)) for $\mathrm{Cs-137}$ versus time from vinyl ester-styrene waste forms containing $40 \%$ $\mathrm{Na}_{2} \mathrm{SO}_{4}$. Results for the MCC-4S flow test, using a modified rate equation, were compared to the modified ANS 16.1 semidynamic leach test. 
7.4.2.6 Vinyl Ester-Styrene $/ 40 \% \mathrm{Na}_{2} \mathrm{SO}_{4}$. Plots of incremental fraction release rates (Rate (f/s)) of Cs-137 from vinyl ester-styrene waste forms containing $40 \mathrm{wt} \% \mathrm{Na}_{2} \mathrm{SO}_{4}$ are shown in Figure 7.20 . Leach rates were calculated using the modified flow test rate equation (Eq. 7.3) The Cs-137 rate results were somewhat accelerated after 10 days of leaching compared to the results for the modified ANS 16.1 leach test. Statistical evaluation of the significance of the results remains to be performed.

7.4.2.7 Bitumen $/ 20 \% \quad \mathrm{Na}_{2} \mathrm{~B}_{4} / \mathrm{O}_{7}$. Incremental fraction release rates (Rate $(\mathrm{f} / \mathrm{s})$ ) for $\mathrm{Cs}-137$ from bitumen waste forms containing $20 \mathrm{wt} \%$ sodium tetraborate $\left(\mathrm{Na}_{2} \mathrm{~B}_{4} \mathrm{O}_{7}\right)$ are shown in Figure 7.21. Leach rates were calculated using the modified flow test rate equation. No acceleration in the Cs-137 release rate for flow was observed relative to the modified ANS 16.1 Leach Test.

7.4.2.8 Bitumen $/ 40 \% \mathrm{Na}_{2} \mathrm{~B}_{4} \mathrm{O}_{7}$. Plots of incremental fraction release rates (Rate $(\mathrm{f} / \mathrm{s})$ ) for $\mathrm{Cs}-137$ from bitumen waste forms containing $40 \mathrm{wt} \%$ sodium tetraborate $\left(\mathrm{Na}_{2} \mathrm{~B}_{4} \mathrm{O}_{7}\right)$ are shown in Figure 7.22 . Leach rates were calculated using the modified flow test rate equation (Eq. 7.3). The Cs-137 release rate was essentially in agreement with the results observed for the modified ANS 16.1 leach test. No acceleration in the rate of release was observed.

\subsection{Waste Form Configuration}

As discussed in an earlier literature survey [2], small scale test specimen may provide an accelerating factor to estimate long-term radionuclide releases. Small test samples of large surface area to volume ratio can be used to predict leaching of larger waste forms under certain conditions. Powdered samples of homogeneous specimens would be ideal. However, most LLW forms are heterogeneous and the practical limitations of sample size must be considered to minimize the effects of inhomogeneity and particle size. Experiments were conducted with samples of increasing surface to volume ratio while keeping the leachate volume to sample surface area constant.

7.5.1 Experiment Description. Leaching test were conducted using the ANS 16.1 leaching procedure using a modified sampling schedule. The test was performed using deionized water at $20^{\circ} \mathrm{C}$ and a leachant volume 10 times the surface area of the sample. Three sample sizes were employed: a small cylinder (approximately $2.5 \mathrm{~cm}$ diameter by $2.5 \mathrm{~cm}$ height), a cylinder (approximately $5.1 \mathrm{~cm}$ diameter by $6.4 \mathrm{~cm}$ height) and a disc (approximately $15.2 \mathrm{~cm}$ diameter by $1.3 \mathrm{~cm}$ height). The larger cylinder $(5.1 \mathrm{~cm} \times 6.4 \mathrm{~cm})$ was used as a standard of comparison as most other tests in this report were conducted with samples of this size.

\subsubsection{Waste Form Volume to Surface Area Effects on Leaching}

7.5.2.1 Portland Type I Cement and $5 \% \mathrm{Na}_{2} \mathrm{SO}_{4}$. Cumulative fraction releases for $\mathrm{Cs}-137$ versus time from a small cylinder $(\mathrm{V} / \mathrm{S}=0.42)$ compared to a larger cylinder $(\mathrm{V} / \mathrm{S}=0.91)$ for portland type I cement waste forms containing $5 \%$ by weight $\mathrm{Na}_{2} \mathrm{SO}_{4}$ are shown in Figure 7.23. The results for the small cylinder showed a clear accelerating effect on leaching. The precision in the leaching data appears to be quite good, but statistical analysis needs to be performed. 


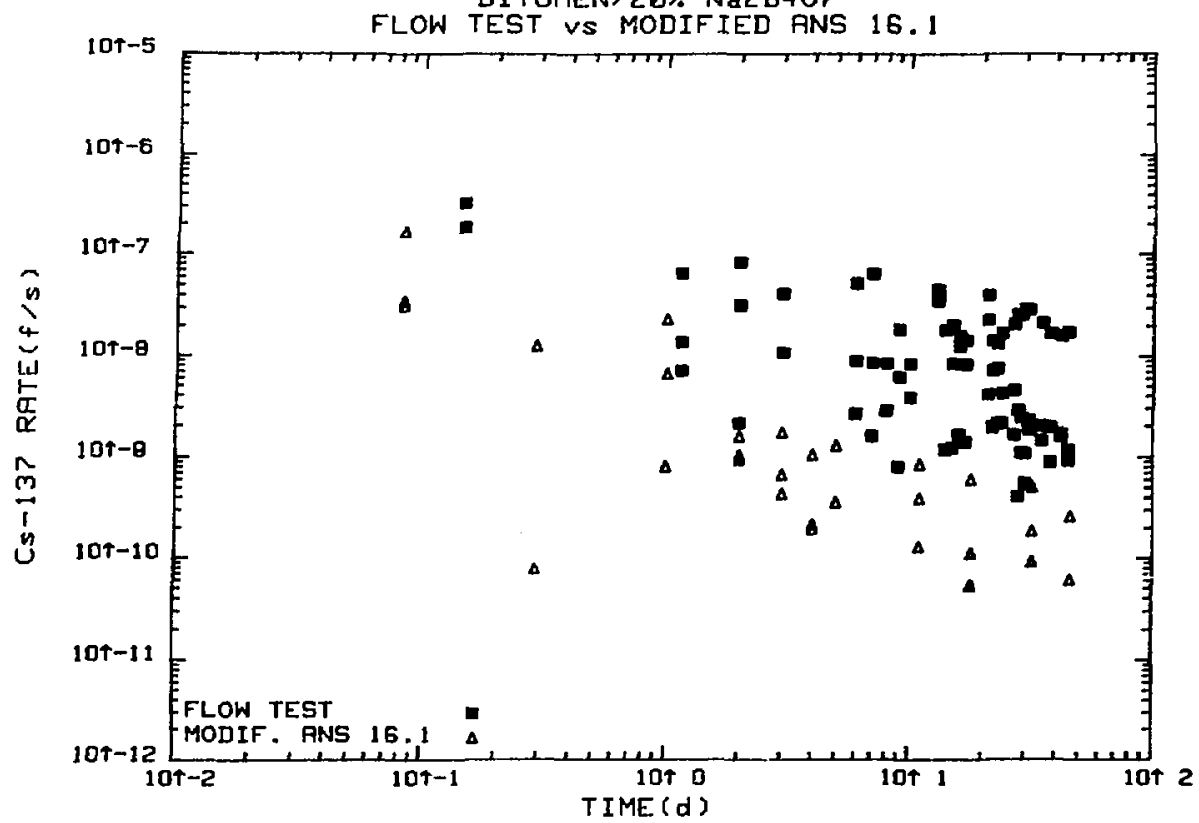

Figure 7.21 Incremental fractional release rates (Rate $(f / s)$ ) for $C s-137$ versus time from bitumen waste forms containing $20 \%$ by weight sodium tetraborate $\left(\mathrm{Na}_{2} \mathrm{~B}_{4} \mathrm{O}_{7}\right)$. Results for the MCC-4S flow test, using a modified rate equation, were compared to the modified ANS 16.1 semidynamic leach test.

BITUMEN/40\% Na2B4OP

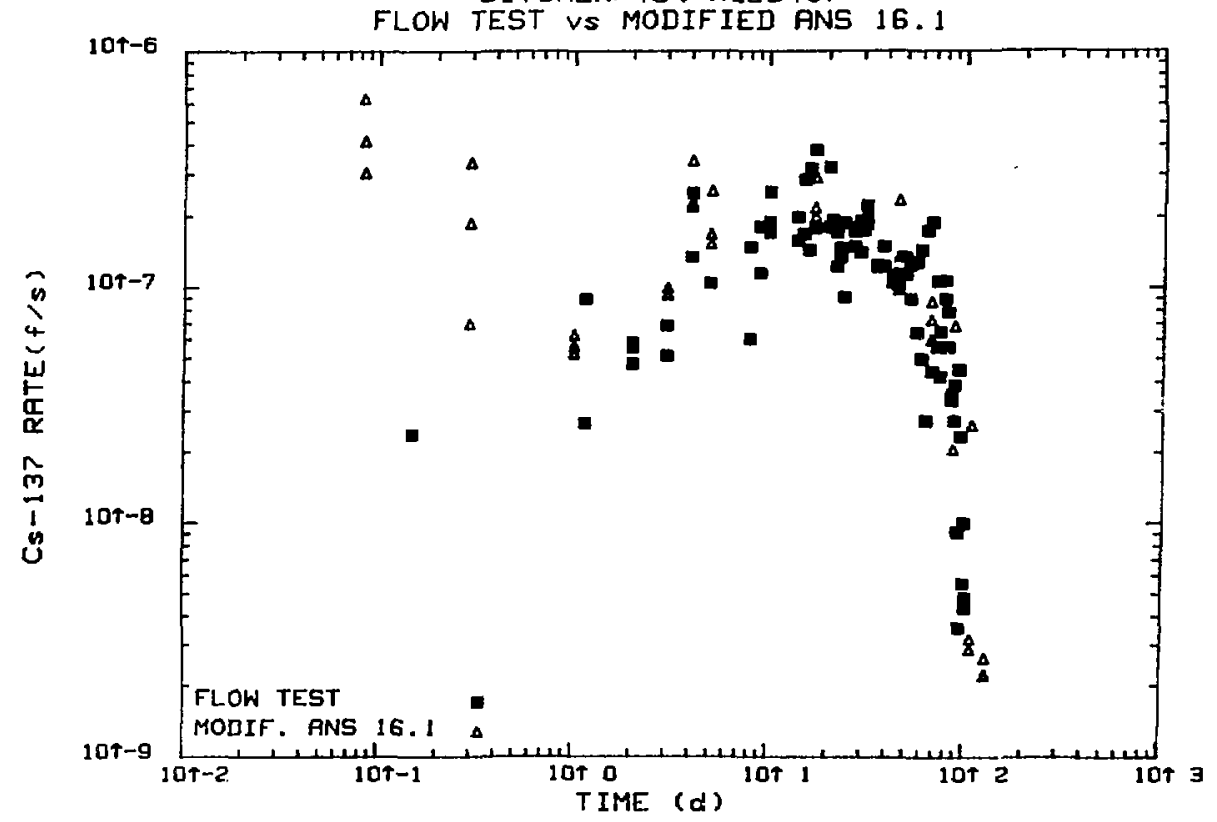

Figure 7.22 Incremental fractional release rates (Rate $(f / s)$ ) for $C s-13 i$ versus time from bitumen waste forms containing $40 \%$ by weight sodium tetraborate $\left(\mathrm{Na}_{2} \mathrm{~B}_{4} \mathrm{O}_{7}\right)$. Results for the MCC-4S flow test, using a modified rate equation, were compared to the modified ANS 16.1 semidynamic leach test. 


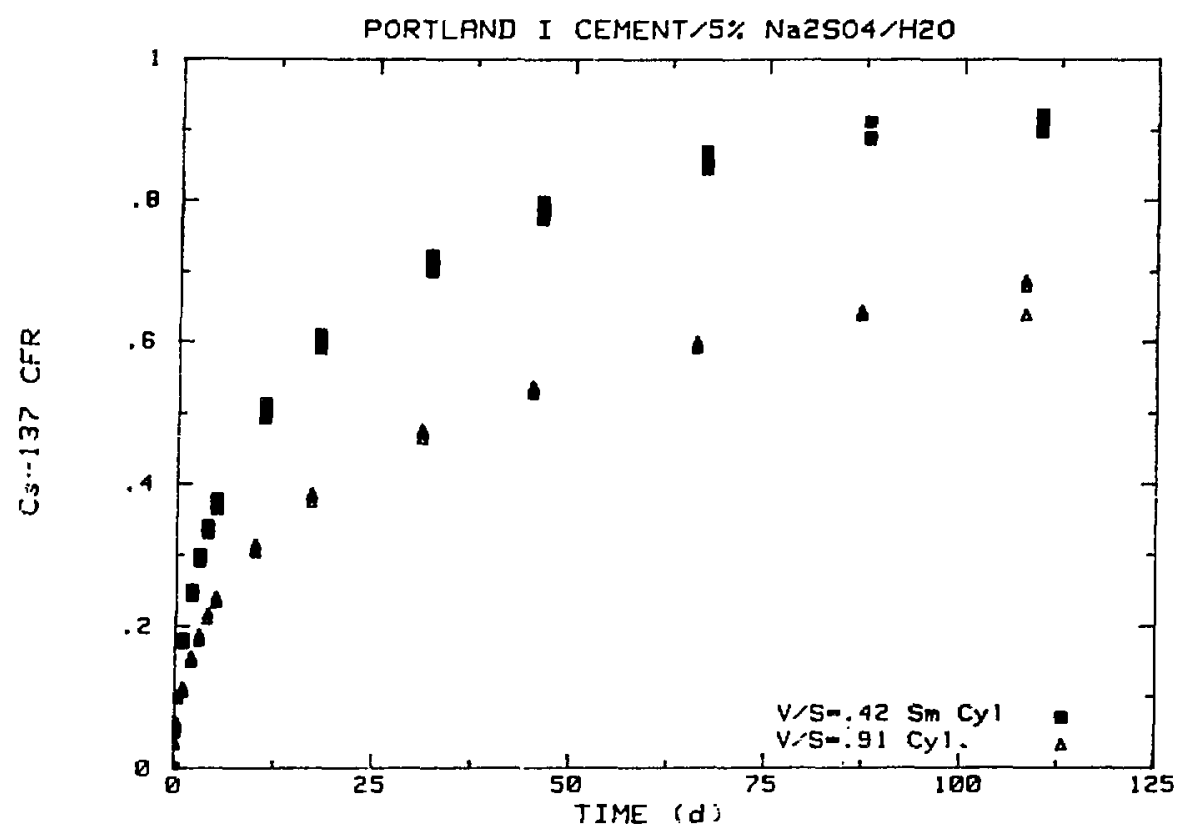

Figure 7.23 Cumulative fraction release (CFR) of $\mathrm{Cs}-137$ versus time from triplicate small cylinders ( $V / S=0.42)$ compared to triplicate larger cylinders $(V / S=0.91)$ from portland type I cement waste forms containing $5 \%$ by weight $\mathrm{Na}_{2} \mathrm{SO}_{4}$.

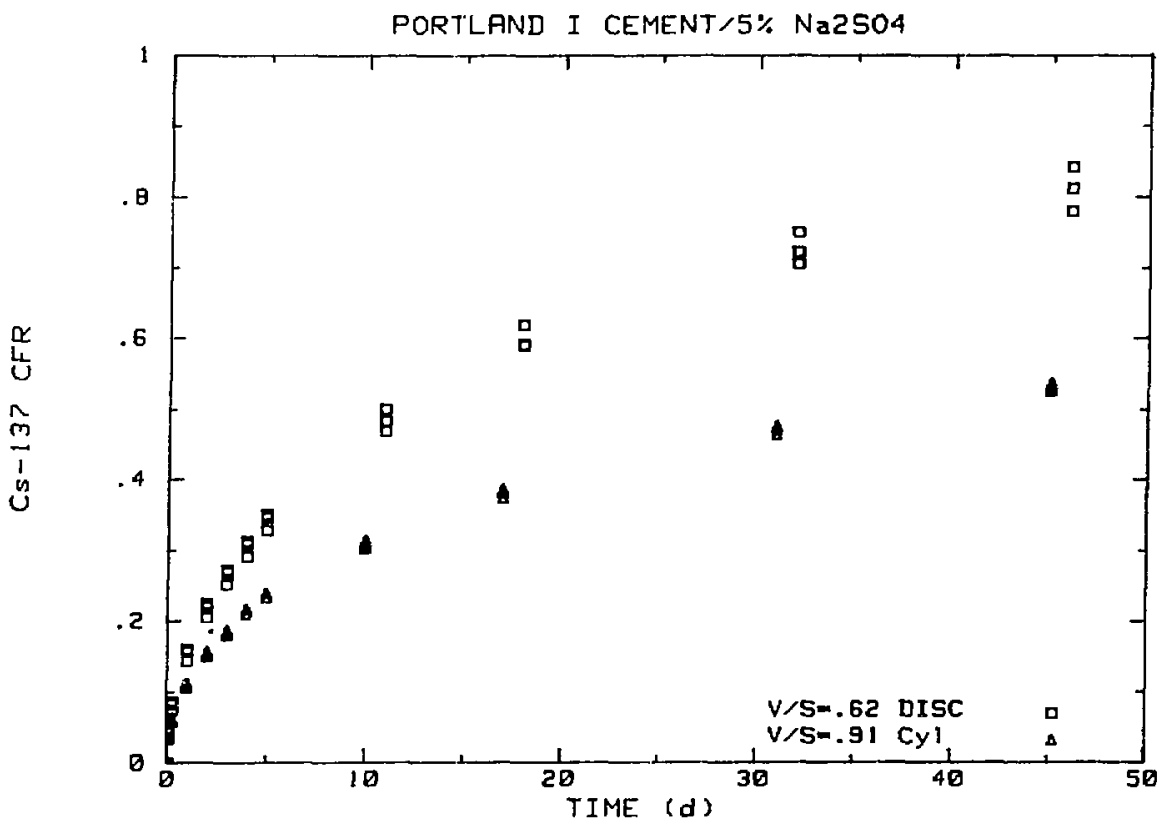

Figure 7.24 Cumulative fraction release (CFR) of Cs-137 versus time from triplicate disc $(V / S=0.62)$ compared to triplicate larger cylinders ( $V / S=0.91)$ from portland type I cement waste forms containing $5 \%$ by weight $\mathrm{Na}_{2} \mathrm{SO}_{4}$. 
Figure 7.24 shows the Cs -137 cumulative fraction releases versus time for a disc $(V / S=0.62)$ compared to a cylinder ( $/ S=0.91)$ of portland type I cement containing $5 \%$ by weight $\mathrm{Na}_{2} \mathrm{SO}_{4}$. The disc results also showed a definite acceleration in the release of $\mathrm{Cs}-137$ with relatively good precision in the data.

Figure 7.25 shows the Cs-137 for all the waste forms. The release of Cs-137 increased consistently with decreasing sample volume to surface area as expected.

7.5.2.2 Portland I Cement/15\% Incinerator Ash. Cumulative fraction

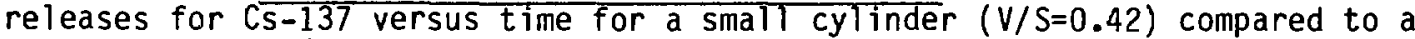
larger cylinder $(V / S=0.91)$ for portland type I cement forms containing $15 \%$ by weight incinerator ash are shown in Figure 7.26. Similar results are shown for the disc shape $(V / S=0.62)$ versus the cylinder $(V / S=0.91)$ in Figure 7.27. In both cases, some acceleration in the Cs-137 released was observed. A statistical analyses of the data will be performed in the future to determine if the results are significantly different.

7.5.2.3 Vinyl Ester $/ 15 \% \mathrm{Na}_{2} \mathrm{SO}_{4} / \mathrm{H}_{2} \mathrm{O}$ Emulsion. The cumulative fraction releases for $\mathrm{Cs}-137$ versus time for a small cylinder ( $/ \mathrm{S}=0.42$ ) compared to a larger cylinder $(V / S=0.91$ ) for vinyl ester-styrene water emulsion waste forms containing $15 \%$ sodium sulfate are shown in Figure 7.28. In addition, similar results for the same type of waste form, but the disc shape (V/S=0.62) versus the cylinder $(V / S=0.91)$ are shown in Figure 7.29. The degree of acceleration with decreasing waste form volume to surface area ( $V / S$ ) appears to be significantly less for the smaller cyclinder, but greater for the disc. The reason for the inconsistency in the results are not understood at this time.

7.5.2.4 Vinyl Ester-Styrene/40\% $\mathrm{Na}_{2} \mathrm{SO}_{4}$. The cumulative fraction releases for $\mathrm{Cs}-137$ versus time for small cylinder ( $/ \mathrm{S}=0.42)$ compared to a larger cylinder ( $V / S=0.91)$ are shown in Figure 7.30 for vinyl ester-styrene waste forms containing $40 \% \mathrm{Na}_{2} \mathrm{SO}_{4}$. Similar results for the same waste form type, but disc shape $(\mathrm{V} / \mathrm{S}=0.62)$ versus the cylinder $(\mathrm{V} / \mathrm{S}=0.91)$ are shown in Figure 7.31. The small cylinder appears to accelerate the release of Cs-137. However, all the waste forms could be expected to approach depletion of Cs-137 as 100 days of leaching is approached. The release of $\mathrm{Cs}-137$ is probably dominated by mechanistic factors that are of greater significance than sample shape.

7.5.2.5 Bitumen $/ 20 \% \mathrm{NaB}_{4} \mathrm{O}_{7}$. The release of $\mathrm{Cs}-137$ from bitumen waste forms containing $20 \%$ by weight sodium tetraborate were determined for three sample configurations. The results for Cs-137 CFR versus time for a small cylinder $(\mathrm{V} / \mathrm{S}=0.42)$ are shown in Figure 7.32 and results for a disc $(V / S=0.60)$ compared to the cylinder $(V / S=0.91)$ are shown in Figure 7.33 . Release rates for Cs-137 at this waste loading are very low. The observed differences in CS-137 CFR are probably not statistically significant. Encapsulation of the waste and radionuclide salt particles by bitumen, which is only slightly permeable to water is probably responsible for the observed very low release rates and overshadow any effects of sample configuration. 


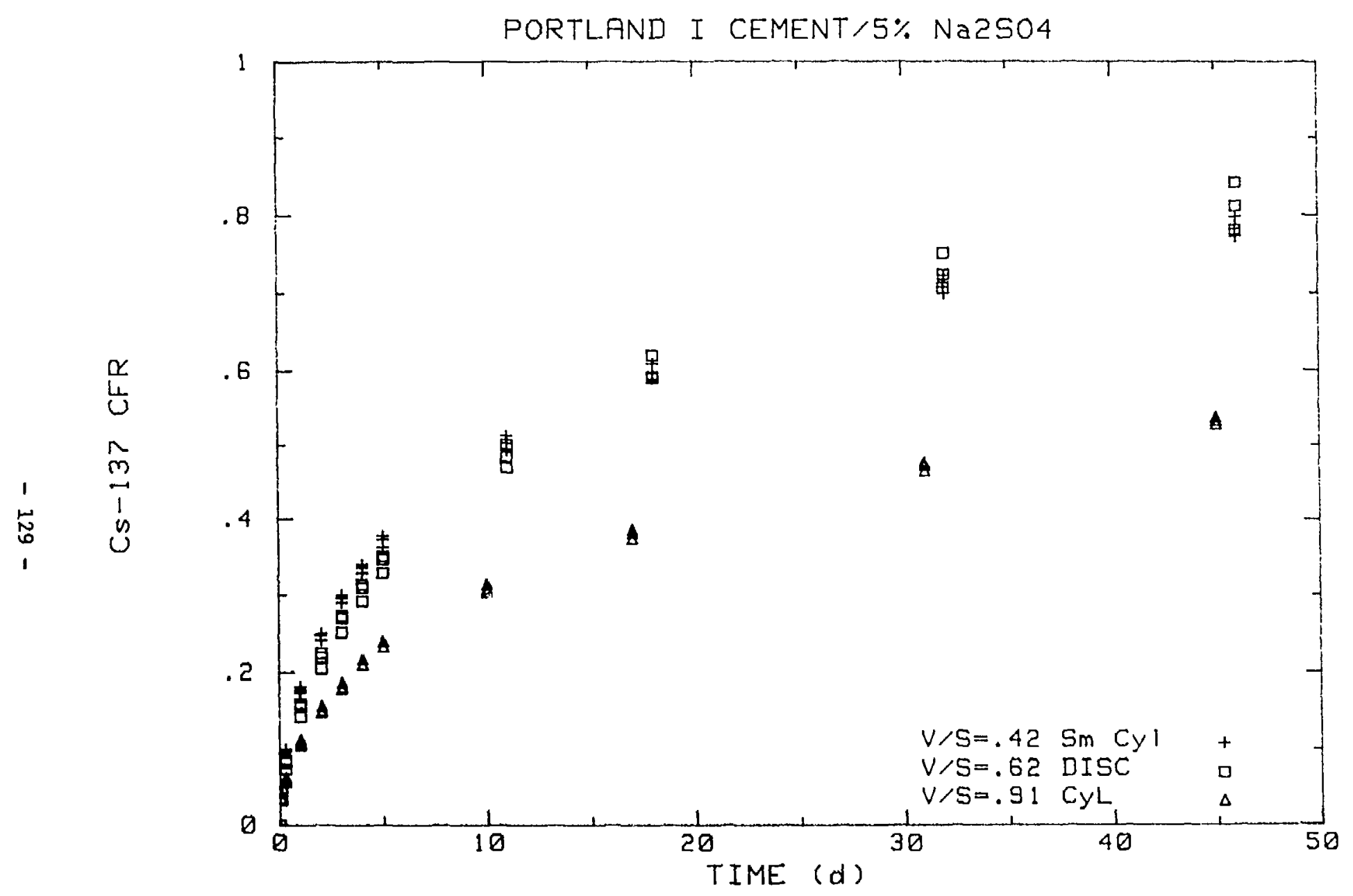

Figure 7.25 Cumulative fraction release (CFR) of Cs-137 versus time from portland type I cement waste forms containing $5 \%$ by weight $\mathrm{Na}_{2} \mathrm{SO}_{4}$. Results for triplicate replicates of small cylinders $(V / S=0.42)$, a disc $(V / S=0.62)$ and a larger cylinder $(V / S=0.91)$ were compared. 


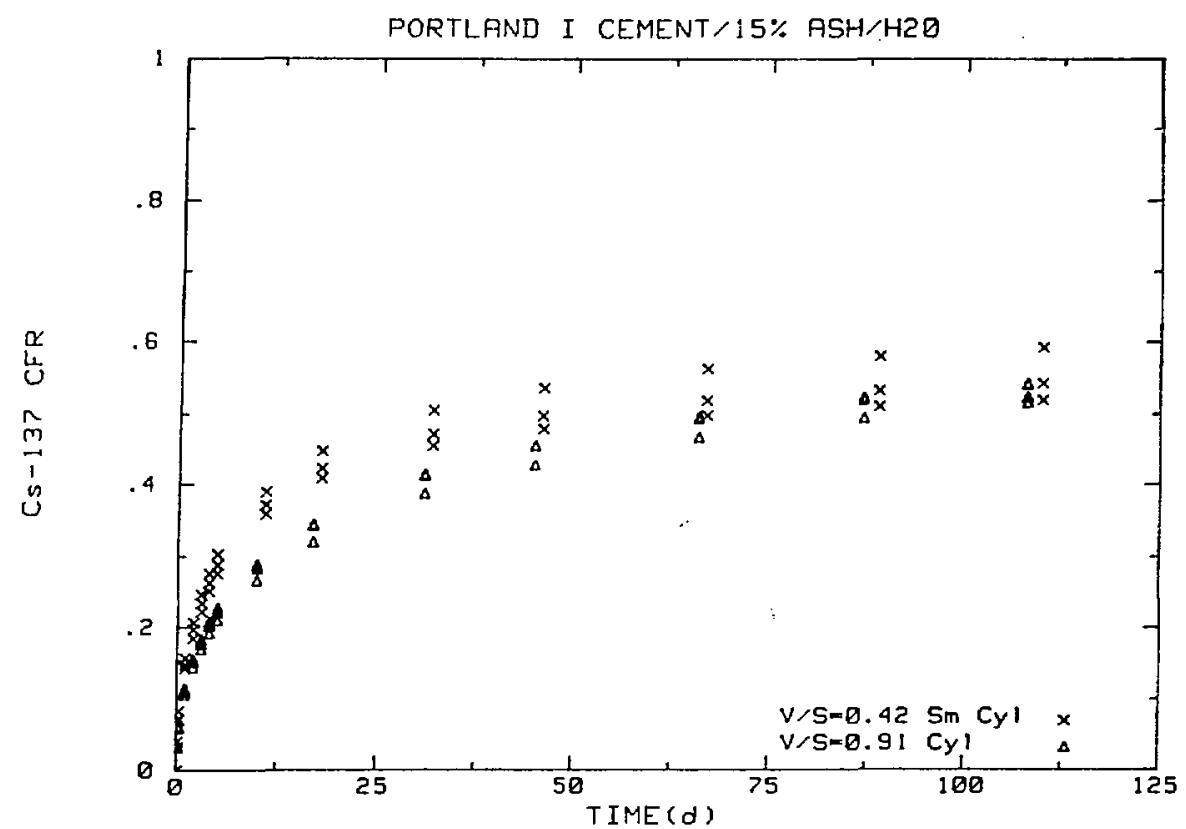

Figure 7.26 Cumulative fraction release (CFR) of Cs-137 versus time for a triplicates of a small cylinder $(V / S=0.42)$ compared to triplicate large cylinders $(V / S=0.91)$ from portland type $I$ cement waste forms containing $15 \%$ by weight incinerator ash.

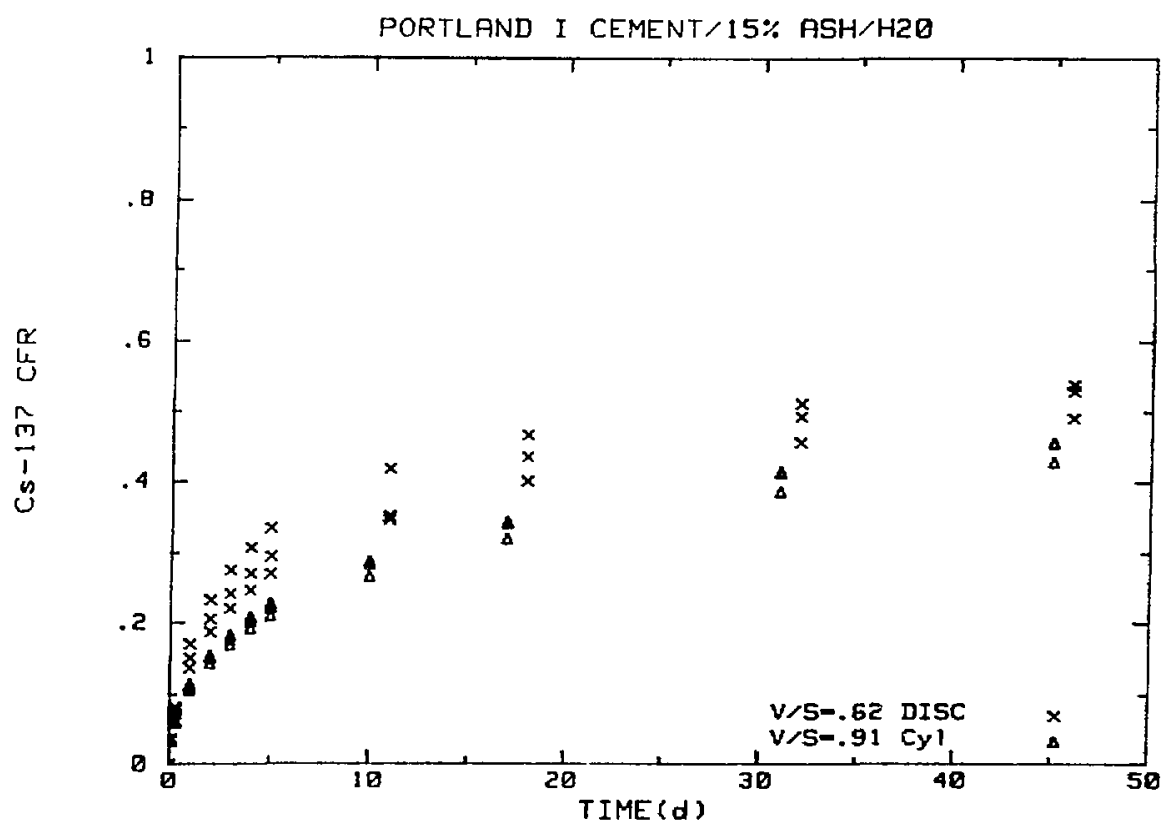

Figure 7.27 Cumulative fraction release (CFR) of Cs-137 versus time for triplicates of a disc $(V / S=0.62)$ compared to triplicates large cylinders $(V / S=0.91)$ from portland type I cement waste forms containing $15 \%$ by weight incinerator ash. 


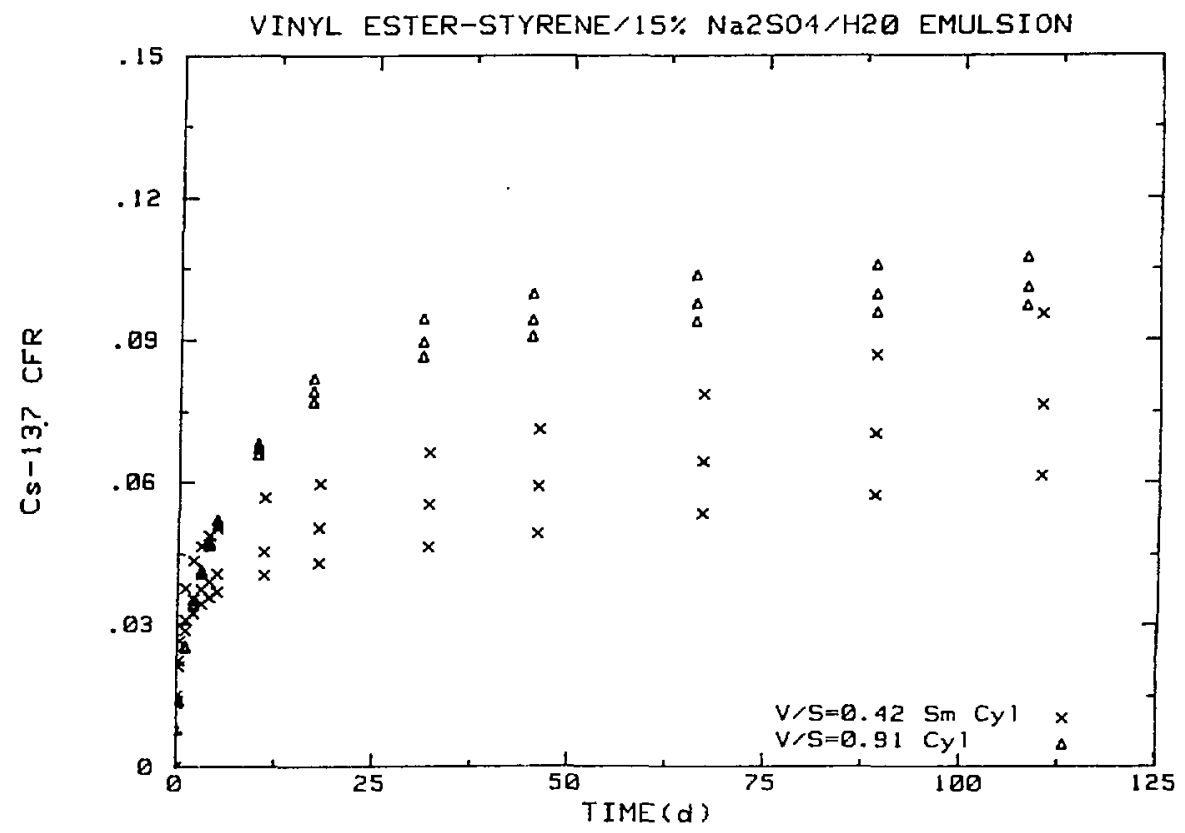

Figure 7.28 Cumulative fraction release (CFR) of $\mathrm{CS}_{5}-137$ versus time from triplicate small cylinders ( $/ S=0.42)$ compared to triplicate larger cylinders $(V / S=0.91)$ from vinyl ester-styrene water emulsion waste forms containing $15 \%$ by weight $\mathrm{Na}_{2} \mathrm{SO}_{4}$.

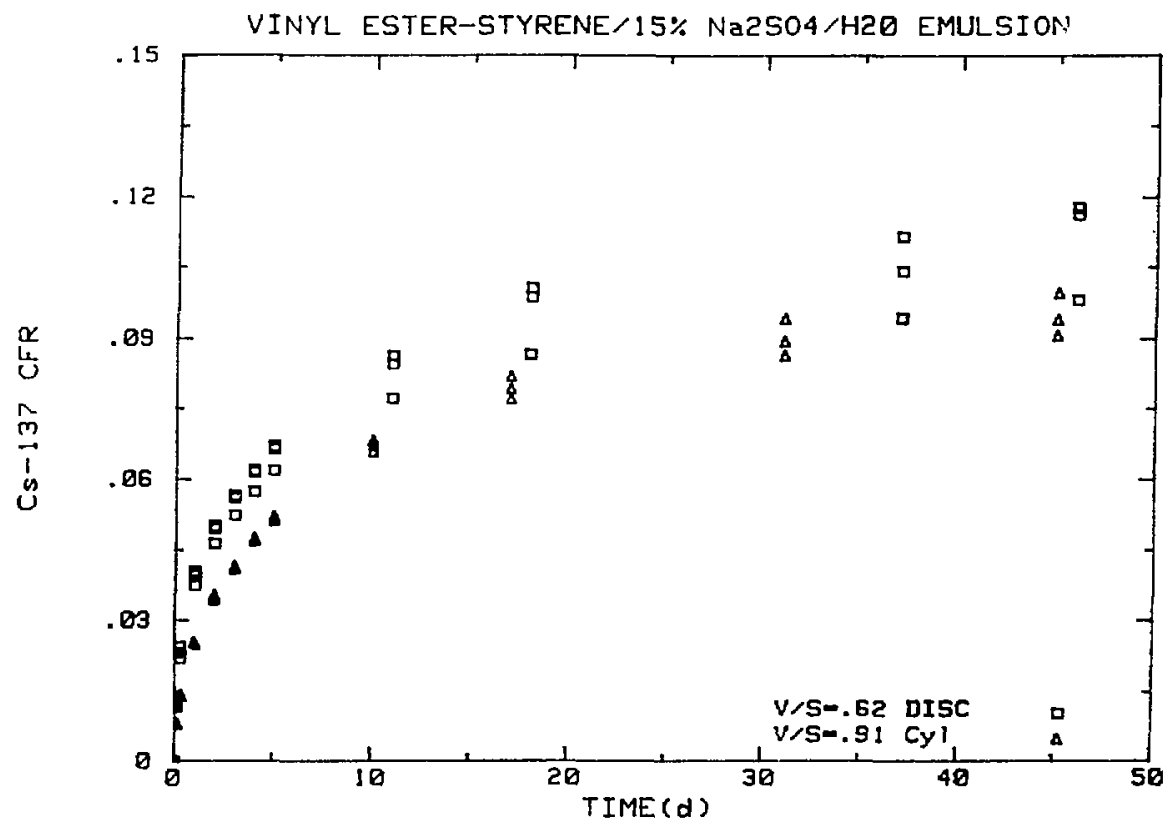

Figure 7.29 Cumulative fraction release (CFR) of Cs-137 versus time from triplicate discs (V/S=0.62) compared to triplicate larger cylinders $(V / S=0.91)$ from vinyl ester-styrene water emulsion waste forms containing $15 \%$ by weight $\mathrm{Na}_{2} \mathrm{SO}_{4}$.

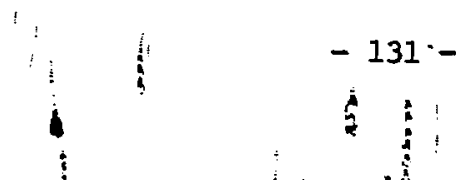


$\because$ INYL ESTER-STYRENE/4B\% NazSO4

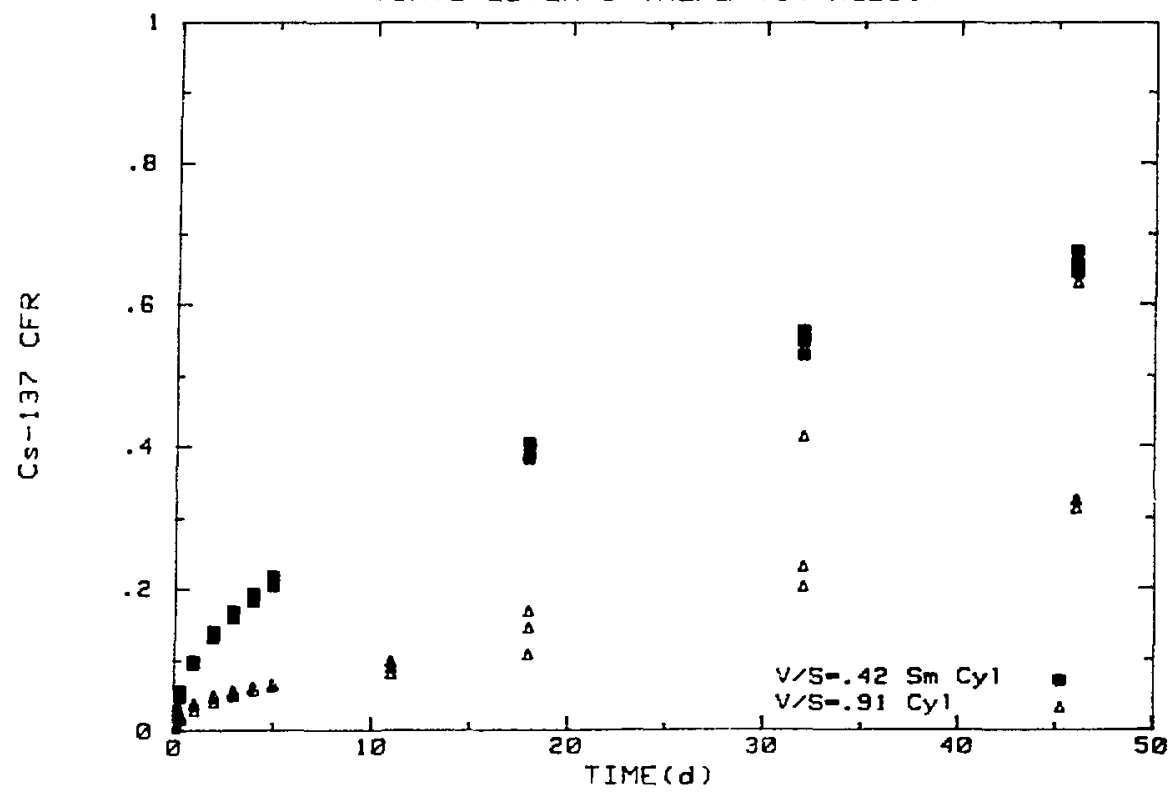

Figure 7.30 Cumulative fraction release (CFR) of Cs-137 from triplicate snall cylinders $(V / S=0.42)$ compared to triplicate larger cylinders ( $V / S=0.91$ ) from vinyl ester-styrene waste forms containing $40 \%$ by weight $\mathrm{Na}_{2} \mathrm{SO}_{4}$.

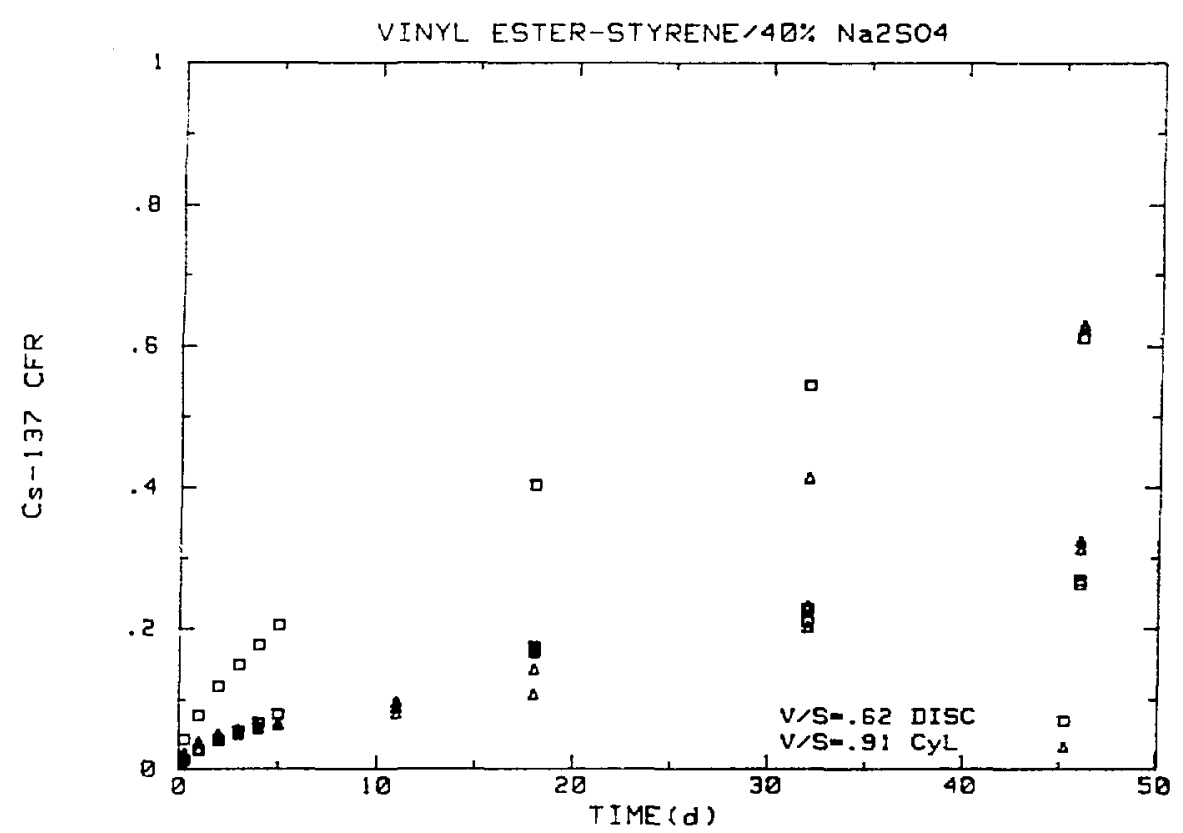

Figure 7.31 Cumulative fraction release (CFR) of Cs-137 from triplicate discs (V/S=0.62) compared to triplicate larger cylinders ( $V / S=0.91$ ) from vinyl ester-styrene waste forms containing $40 \%$ by weight $\mathrm{Na}_{2} \mathrm{SO}_{4}$. 


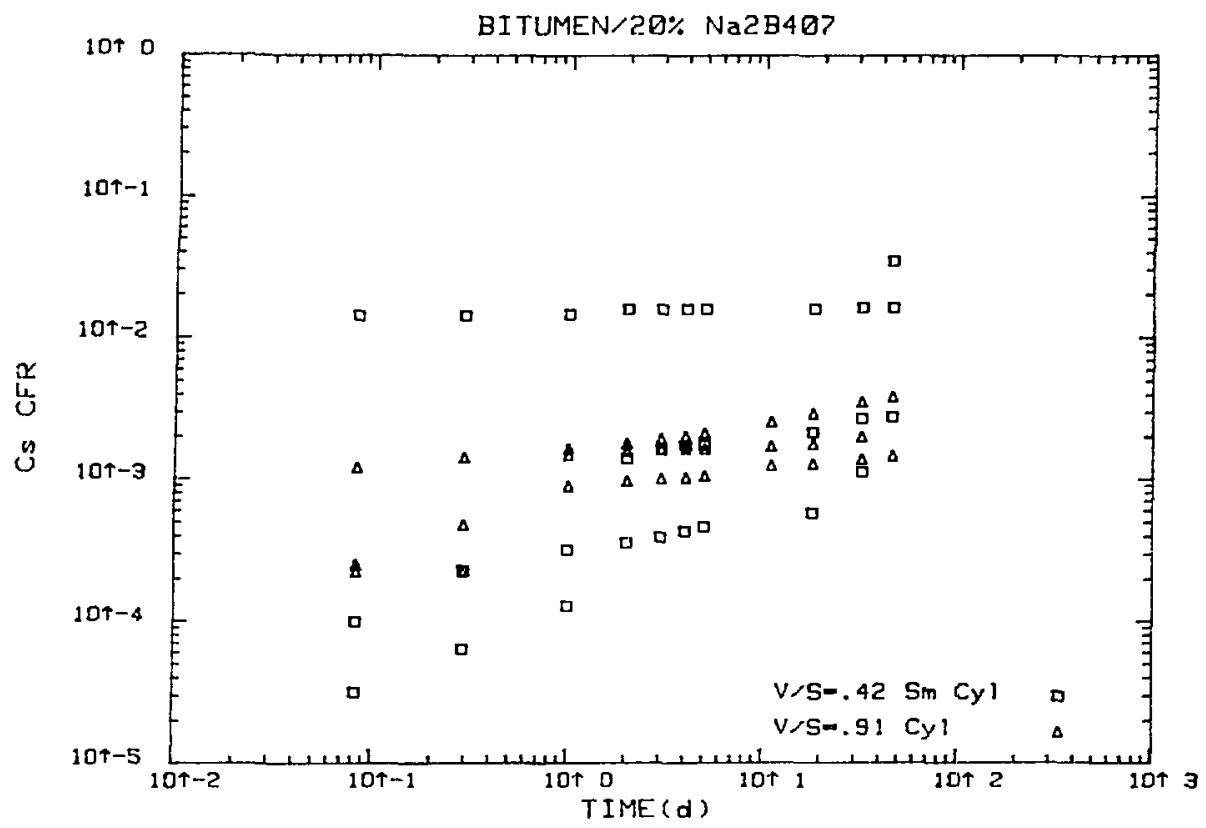

Figure 7.32 Cumulative fraction release (CFR) of Cs -137 versus time for triplicate small cylinders ( $V / S=0.42$ ) compared to triplicate larger cylinders $(V / S=0.91)$ from bitumen waste forms containing $20 \%$ by weight sodium tetraborate $\left(\mathrm{Na}_{2} \mathrm{~B}_{4} \mathrm{O}, 7\right)$.

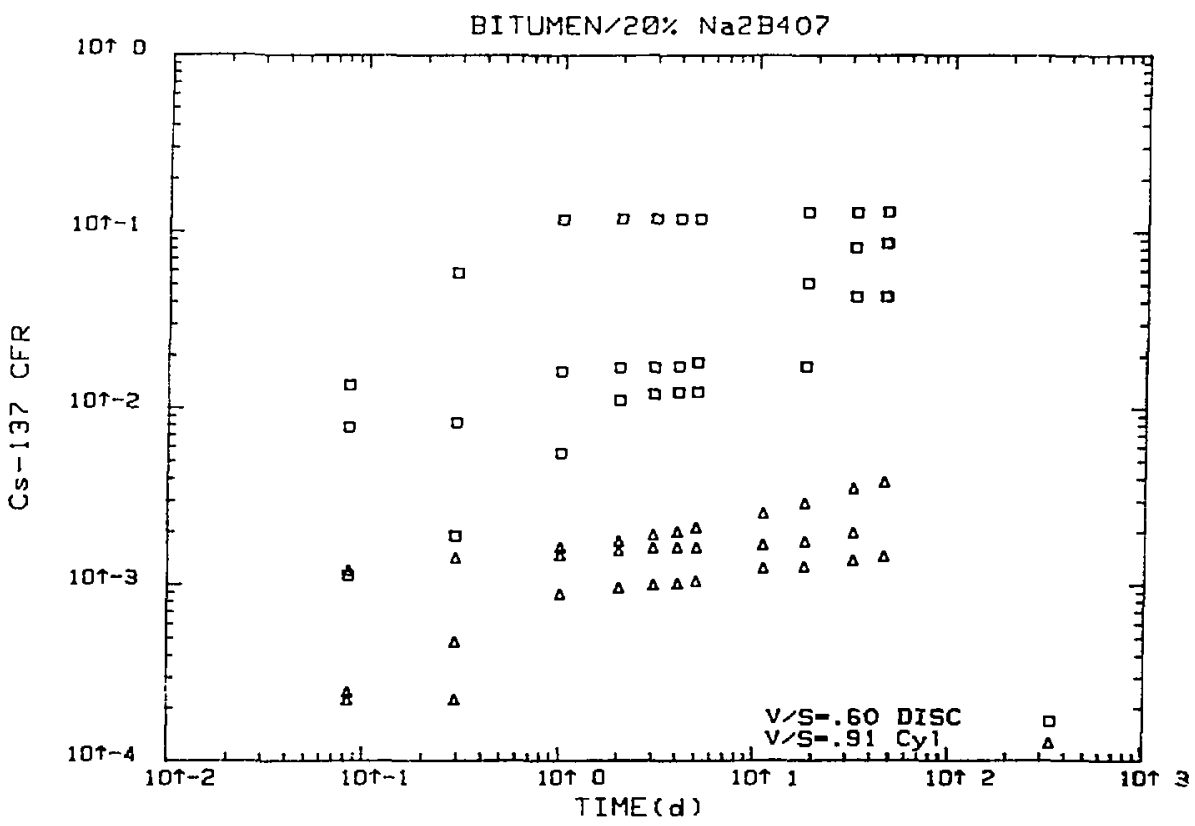

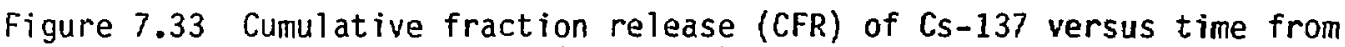
triplicate discs $(V / S=0.60)$ compared to triplicate larger cylinders ( $V / S=0.91$ ) from bitumen waste forms containing $20 \%$ by weight sodium tetraborate $\left(\mathrm{Na}_{2} \mathrm{~B}_{4} \mathrm{O}_{7}\right)$. 
7.5.2.6 Bitumen $/ 40 \% \mathrm{Na}_{2} \mathrm{~B}_{4} \mathrm{O}_{4}$ The release of $\mathrm{Cs}-137$ from bitumen waste forms containing $40 \%$ by weight sodium tetraborate were determined for three sample configurations. The results for Cs-137 CFR versus time for a small cylinder ( $V / S=0.42)$ compared to a large cylinder $(V / S=0.91)$ are shown in Figure 7.34 , and results for a disc ( $V / S=0.60)$ compared to cylinder ( $V / S=0.91)$ are shown in Figure 7.35. Significant amounts of Cs-137 were observed in the leachates so that the observations should be statistically accurate. Results for the three sample configurations do not appear to be significantly different. Sample inhomogenities and the nature of the release mechanism may account for the scatter in replicate sample precision. In all cases the release of Cs-137 appears to be completed by approximately 100 days of leaching. The dominant release process apparently overwhelms any differences from the effects of sample shape. 


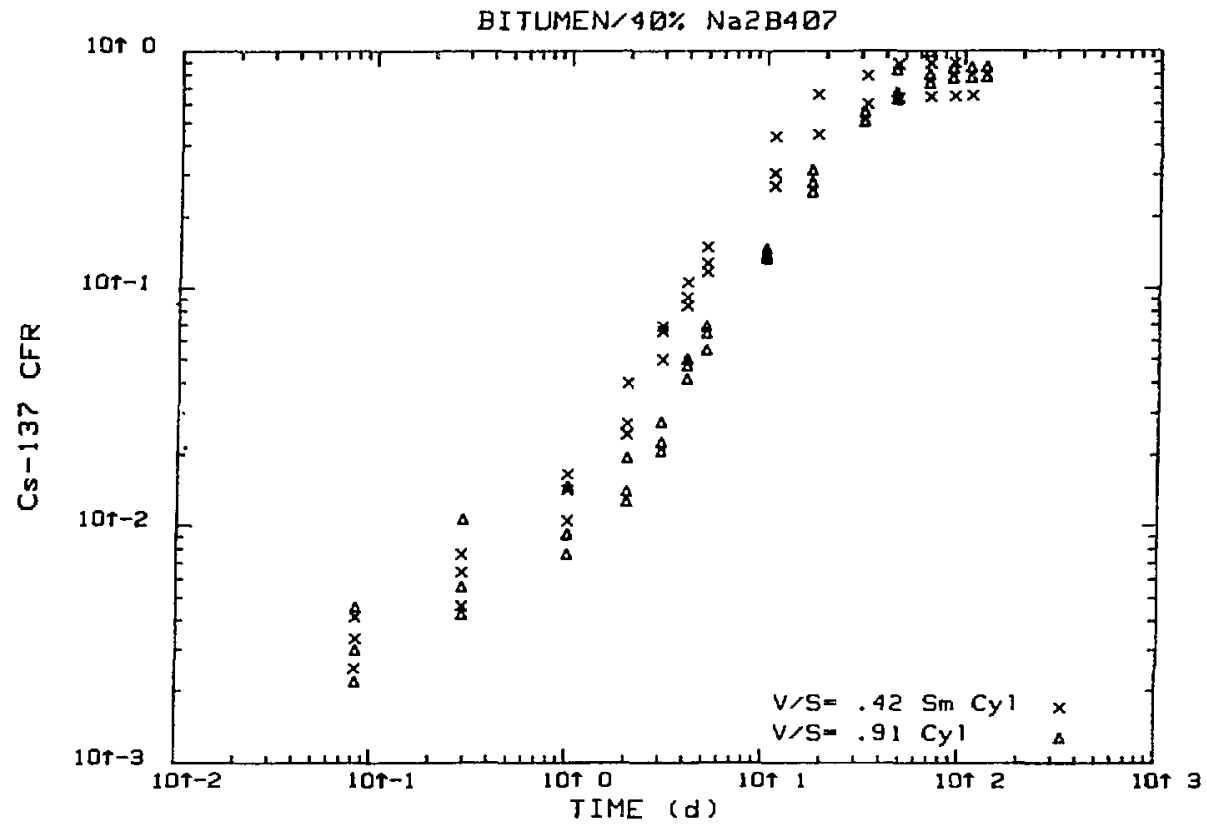

Figure 7.34 Cumulative fraction release (CFR) of Cs-137 versus time for triplicate small cylinders ( $V / S=0.42)$ compared to triplicate larger cylinders ( $V / S=0.91$ ) from bitumen waste forms containing $40 \%$ by weight sodium tetraborate $\left(\mathrm{Na}_{2} \mathrm{~B}_{4} \mathrm{O}_{7}\right)$.

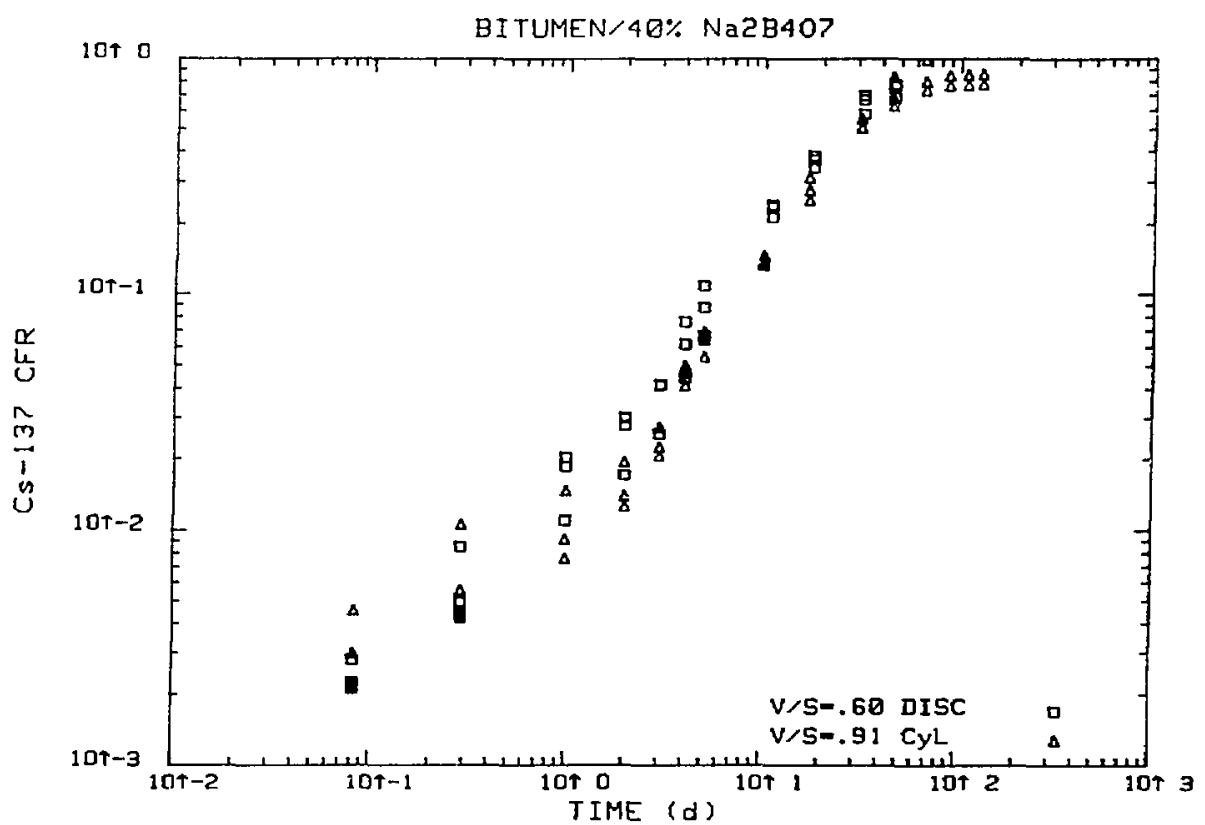

Figure 7.35 Cumulative fraction release (CFR) of Cs-137 versus time for triplicate discs $(V / S=0.60)$ compared to triplicate larger cylinders ( $V / S=0.91$ ) from bitumen waste forms containing $40 \%$ by weight sodium tetraborate $\left(\mathrm{Na}_{2} \mathrm{~B}_{4} \mathrm{O}_{7}\right)$. 


\title{
8. MODEL VALIDATION
}

The purpose of the model validation effort is to determine the validity of models of leaching behavior, since validated models will provide the technical basis for development of the accelerated leach test(s). The models consist of both physicochemical and mathematical models of both waste forms and leaching behavior. The validation procedure involves comparing leaching data and other data from the experimental part of this program and selected data from the literature to both types of models. Validated physicochemical models must account for all of the physical and chemical factors known to conirol leaching behavior. Validated mathematical models must contain mechanistic terms which account for these physicochemical processes. Specifically, understanding the physical and chemical factors that affect leaching behavior and that determine leaching mechanisms is necessary before meaningful validation of mathematical models is possible. The model validation effort this fiscal year has focused on physicochemical models of leaching behavior.

As part of the model validation effort in this program, physicochemical models of leaching behavior are needed for specific waste form/leachant/ radionuclide systems to evaluate the validity of mathematical leaching models independently of curve-fitting efforts. Mathematical curve fits are restricted to available data, which limit their generality to the leaching conditions and time frame over which the data have been obtained. Only by understanding the physicochemical aging processes which the waste form undergoes in specific leaching environments can there be reasonable confidence in the reliability of mathematical models over time periods longer than the data covers. For LLW, the time span of concern of the radioactivity hazard is on the order of hundreds of years, which is generally at least a hundred times longer than the duration of even "long-term" laboratory leach tests.

Since the goal of this work is development of accelerated leach testing procedures, the use of model validation efforts in accomplishing this goal must be specified. The procedures we are following to do this are outlined in the following description.

Consider physicochemical ageing of the solidification agent matrix and the incorporated waste separately. As a first approximation, assume that the leaching environment acts independently on matrix and waste. Thus, in the first approximation, only physical changes in the waste form affect leachability since no change in the chemical interaction between waste and matrix is allowed to occur. Then, correct the first order approximation to include changes in interaction between waste and matrix to arrive at the expected long-term leaching behavior of the waste form (under the specified conditions). Physicochemical changes which have been considered important in affecting leaching behavior include:

\author{
Waste Form Porosity \\ Sorption \\ Complexation and/or Chelation \\ Precipitation and/or Mineral Formation
}


The goal is to determine, from validated physicochemical models, whether there are long-term mechanistic changes which affect leaching behavior or whether the short-term mechanisms determined from standard, short-term leach tests control leachability over both the short and long term.

The approach is:

First, to compile and validate low-level waste leaching models. Mathematical models can be compared to data by curve-fitting. These curve fits must be considered to be empirical or semi-empirical unless and until the mechanistic parameters contained in the models are validated by correlation with physicochemical processes occurring in the waste form during leaching.

Predict leaching behavior based on the short-term behavior from validated mathematical models. This provides a "baseline" of leachability from which long-term leachability may be predicted to vary, if at all, from knowledge of leaching mechanisms and factors that affect leaching in the long term.

Finally, include long-term effects due to changes in the conditions/processes listed above. Each applicable condition/process will affect long-term leaching behavior by increasing, decreasing or having no effect on leachability. Presumably, the long-term effects occur in only one direction for each applicable condition/process. Quantify the effect, if possible.

\subsection{Physicochemical Models of Leaching Behavior of Low-Level Waste Forms}

The solidification agents chosen for investigation in this program portland cement, bitumen, vinyl ester-styrene - are either in use or being considered for use in solidifying low-level radwaste. This selection of solidification agents also provides a broad cross-section of materials properties.

8.1.1 Cement Waste Forms. Hydrated portland cement is a complex material consisting primarily of hydrated calcium silicate (CSH) along with portlandite (calcium hydroxide) and small amounts of calcium aluminum silicates, calcium iron silicates, sodium and potassium hydroxides, some sulfates and trace amounts of numerous other elements as impurities. Pure portland cement hardens to a microporous structure with a characteristic porosity of approximately $30 \%-40 \%$ [46-48] and a large surface area, typically $30-60 \mathrm{~m}^{2} / \mathrm{g}$ or more [49], depending upon how the measurement is performed. Several physical models of hydrated portland cement are reviewed in reference [20]. The inherent porosity of cement is a major factor affecting the leachability of cement waste forms. Additionally, since this porosity is increased both by increasing the water-to-cement ratio and by increased cure temperature, the conditions under which cement waste forms are fabricated influence leachability. Changes in porosity due to water-to-cement ratio variations and cure temperature affect leachability but do not change leaching mechanisms. Various treatments and processes for incorporating organic polymers into cement forms have been advanced to reduce their porosity and leachability [50-55] although none are used operationally in radwaste management to our knowledge. 
Physicochemical factors that affect the leaching behavior of waste forms solidified with portland cement may be summarized as follows:

- Hydrated portland cement has an inherent, connected porosity of approximately $30 \%$ and is readily permeable to water.

- For cement waste forms incorporating soluble wastes, this initial porosity may be expected to increase as the soluble material is leached.

- With insoluble wastes, especially silica-containing wastes or additives, the porosity may decrease due to continued, slow hydration of the cement and/or reaction of cement components with silica [56]. However, this continued, slow reaction, while beneficial due to the reduction in porosity, may adversely affect sorbent additives sometimes added to cement waste forms.

- As reviewed in reference [2], the apparent diffusion coefficient in a porous medium is related to the physical structure of the porous medium. Changes in porosity, which are known to affect diffusibility, would thus be expected to result not only in changes in leachability, but also to invalidate (if the change in porosity is significant) the use of a constant diffusion coefficient in mathematical modeling.

- Hydrated portland cement evidences a very limited, almost negligible sorption for cesium. Strontium sorption, though greater than that for cesium, is also limited. The sorption behavior of cobalt is generally considered irrelevant since the very low solubility of cobalt at $\mathrm{pH} 12$, which is typical of cement, effectively immobilizes cobalt in cement.

- The apparent diffusion coefficient of a substance in a sorbent system is affected by the distribution coefficient, Kd. As Kd increases the apparent diffusion coefficient decreases, all else being equal. The mathematics for both the semi-infinite medium and for cylinders for a system in which diffusion is the mass transport mechanism and in which sorption of the form,

$$
F=K C
$$

$F=$ concentration of diffusant which is fixed (immobile).

$C=$ concentration of diffusant which is mobile

$K=$ proportionality constant

is present was derived by Moore, et al [57]. The applicability of this to sorbent systems is clear upon recalling the definition of $\mathrm{Kd}$,

$$
C(\text { solid })=K d * C(1 \text { iquid })
$$



$\begin{aligned} & C(\text { solid })= \text { concentration of sorbed substance on the solid } \\ & \text { sorbent (quant ity/g) }\end{aligned}$

$C(1$ iquid) $=$ concentration in the liquid (quantity/ml)

Kd = distribution coefficient $(\mathrm{ml} / \mathrm{g})$

- Surption on a solid phase depends on its chemical composition, physical structure and on the composition of the liquid phase. Thus, changes in the chemical composition and/or physical structure and/or leachant composition during leaching may be expected to change the sorbtion behavior and, hence, the diffusion coefficient of the waste form. Such changes, if significant, would invalidate the use of a constant diffusion coefficient in mathematical modeling.

- Evidence from solid phase analyses of cement waste forms in Section 4 of this report and from other observations, as listed in Section 8.1.1.1 below, indicates that changes in both the chemical composition and physical structure occur during leaching.

8.1.1.1 Changes in Cemented Waste Forms Upon Leaching. Physical and chemical changes occur in cemented waste forms due to leaching $[3,58,59]$. Changes in the elemental composition of hardened portland cement due to leaching have been measured $[3,58]$. Such changes include depletion of soluble components, e.g., $\mathrm{Ca}$, $\mathrm{Na}$ and $\mathrm{K}$, which result in the relative enrichment of the leached solid in less soluble species. The implications of changes in the calcium silicate hydrate (CSH) gel and the pore water compositions have been discussed by Glasser, et. al., using Ca0-SiO-H2O phase diagrams for cement [59].

From SEM/EDS spectral analys is of leached versus unleached portland cement samples the following observations were reported in [1]. Changes in the leached sample compared to the unleached sample included:

* The elemental composition of the leached sample in the depletion zone was noticably enriched in magnesium and silicon relative to the calcium content compared to the unleached sample.

* The potassium peak in the leached sample had disappeared.

* Small, but definitely identifiable peaks corresponding to sulfur and chlorine appeared in the depletion zone of the leached sample.

These observations indicate that leaching depletes more soluble species such as potassium and calcium from cement leaving the relatively less soluble magnesium and silicon compounds in relatively greater concentration in the depletion zone. Additionally, it appears that sulfur and chlorine (probably as sulfate and chloride) accumulate in the depleted zone as leaching proceeds. 
These changes in chemical composition - depletion of potassium and calcium, enrichment in magnesium and silicon plus sorption of sulfate and chloride may lead to solubility and/or sorptive ability changes in the depleted zone which could significantly affect the leachability of radionuclides or ether species of, interest during leaching.

In reference [58], comparison of SEM micrographs of leached and unleached cement surfaces resulted in the following comments: "The striking difference between the before- and after-leaching micrographs is vividly evident. Judging by the after-leaching micrographs, an unspecified amount of materiai has dissolved into solution from the surface of the cement waste forms. Secondary phases appear to have formed on the surface of the leached pellets."

As discussed above, physicochemical factors that affect the leaching of cesium from portland cement include changes in chemical composition and porosity due to leaching. When cement is leached the depleted (leached) zone has been shown to become relatively depleted in calcium and enriched in silicon and aluminum. Other studies have shown that cesium sorption is greater on both alumina cement and on silica and additives rich in silica than on portland cement. Since cesium sorption on portland cement itself (i.e., CSH) has been shown to be almost negligibly small by many researchers, it seems reasonable to attribute the minimal degree of sorption that has been observed to the small amount of aluminum compound which is naturally present in portland cement. Thus, mechanisticaliy it might be expected that sorption in the leached zone of a cemented waste form would increase as the relative aluminum content increased. The relative increase in silicon content of the leached zone might also contribute to increased sorption. If this does, in fact, occur, then leaching would form a sorptive barrier which could progressively retard cesium release. The implication of such sorptive changes to modeling would be that the simple diffusion model with constant diffusion coefficient, $D$, would be inadequate and would not accurately reflect the long-term behavior of the waste form. Additionally, the diffusion coefficient is known to vary with porosity in porous media. Again, if leaching results in significant changes in waste form porosity, (e.g., due to the dissolution of soluble wastes from the waste form) then models incorporating a constant $D$ could be inadequate for long-term prediction of leaching behavior.

In sum, numerous differences have been observed between leached and unleached cement samples which indicate that changes in physicochemical properties occur during leaching which may affect leachability. The implication for mathematical modeling of the long-term leaching behavior of cement waste forms is that use of a constant diffusion coefficient may not be valid.

8.1.2 Bitumen Waste Forms. Bitumen is a relatively complex material that is composed mainly of hydrocarbons. Although generally considered to be hydrophobic, bitumen has a small, but definite, permeability to water. It is a viscoelastic material which has little mechanical strength at ordinary temperatures and creeps readily under loads that are typical of shallow land burial. Because it forms an adhesive coating and is only slowly permeable to water, bitumen waste forms typically have low short-term leachabilities. However, bitumen waste forms incorporating soluble wastes often swell at longer times during leaching and the leach rate increases substantially once swelling 
occurs. The onset of sweliting is also a furction of waste loading as is clear from Figures 5.22 and 5.23 in this report. Waste loading effects on leaching behavior are also discussed in Section 8.2.3.

The leach testing results shown in section 5 of this report for bitumen waste forms plus those referenced in the literature survey [2] have led us to conclude that the leaching behavior of bitumen waste forms incorporating soluble wastes generally follows the pattern shown in Figure 8.1. Specifically, there are two regions, $A$ and $B$, in the CFR versus Time plot. In region $A$ the low leach rate normaliy associated with short-term leach tests on bitumen Waste forms is evident. Water uptake within the waste form is not sufficient in region $A$ to cause swelling. In rejion $B$ water uptake has become sufficient to initiate swelling and, as swelling progresses, the leach rate increases substantially. The swelling is typically so severe in bitumen waste forms incorporating sodium sulfate salt that the waste form cracks open and falls apart as the cracking progresses [60]. With sodium sulfate this can occur in days for salt loadings greater than approximately $17 \mathrm{wt} \%$. With other salts and ion exchange resins the process is typically slower and region $B$ behavior is generally not observed in leach tests of relatively short duration (weeks or months). Bitumen waste forms incorporating insolubie wastes and wastes that do not swell should remain in Region $A$.

8.1.3 Vinyl Ester-Styrene (VES) Waste Forms. The vinyl cster-styrene copolymer system can be used to solidify both aqueous and dry waste streams. Aqueous wastes are solidified as an emulsion with comonomers. The emulsion is formed under high-shear mixing of the comonomers with the aqueous waste which then polymerized to form the solid waste form. Dry wastes are simply mixed with the comonomers, which then polymerize to form the solid waste form. Polymerization is normally accomplished using a catalyst and promoter system which is added to the comonomer solution along with the waste to be solidified.

8.1.3.1 VES Emulsion With Aqueous Wastes. No defensible physicochemical model of the leaching behavior of vinyl ester-styrene/aqueous waste emulsion waste forms is yet available, even in the preliminary state of those for portland cement and bitumen presented above. The solid phase analysis in Section 4.4 .2 is part of the effort to determine leaching mechanisms and factors that affect leaching from physical anaiysis of emulsion structure.

8.1.3.2 VES Incorporating Dry Wastes. The waste forms resuiting from the solidification of dry wastes in VES are two phase systems (i.e., counting the waste as one phase no matter what its actual composition) consisting of individual particles of waste in a polymer matrix. The polymer matrix is structurally rigid and of very limited permeability to water. The structural rigidity means that the pore structure of the polymer matrix remains intact even though the waste may dissolve out of or otherwise be removed from the waste form. The impermeability of the polymer matrix to water means that mass transport of waste substances out of the waste form occurs through, and is constrained by, the pore structure of the polymer matrix. The only other interaction that the polymer matrix may have with the waste that may affect leaching is sorption or ion exchange capacity. The effects of both waste form porosity and sorption can be included as multiplicative parameters to the diffusion coefficient, as was discussed in reference [2] and references therein. 


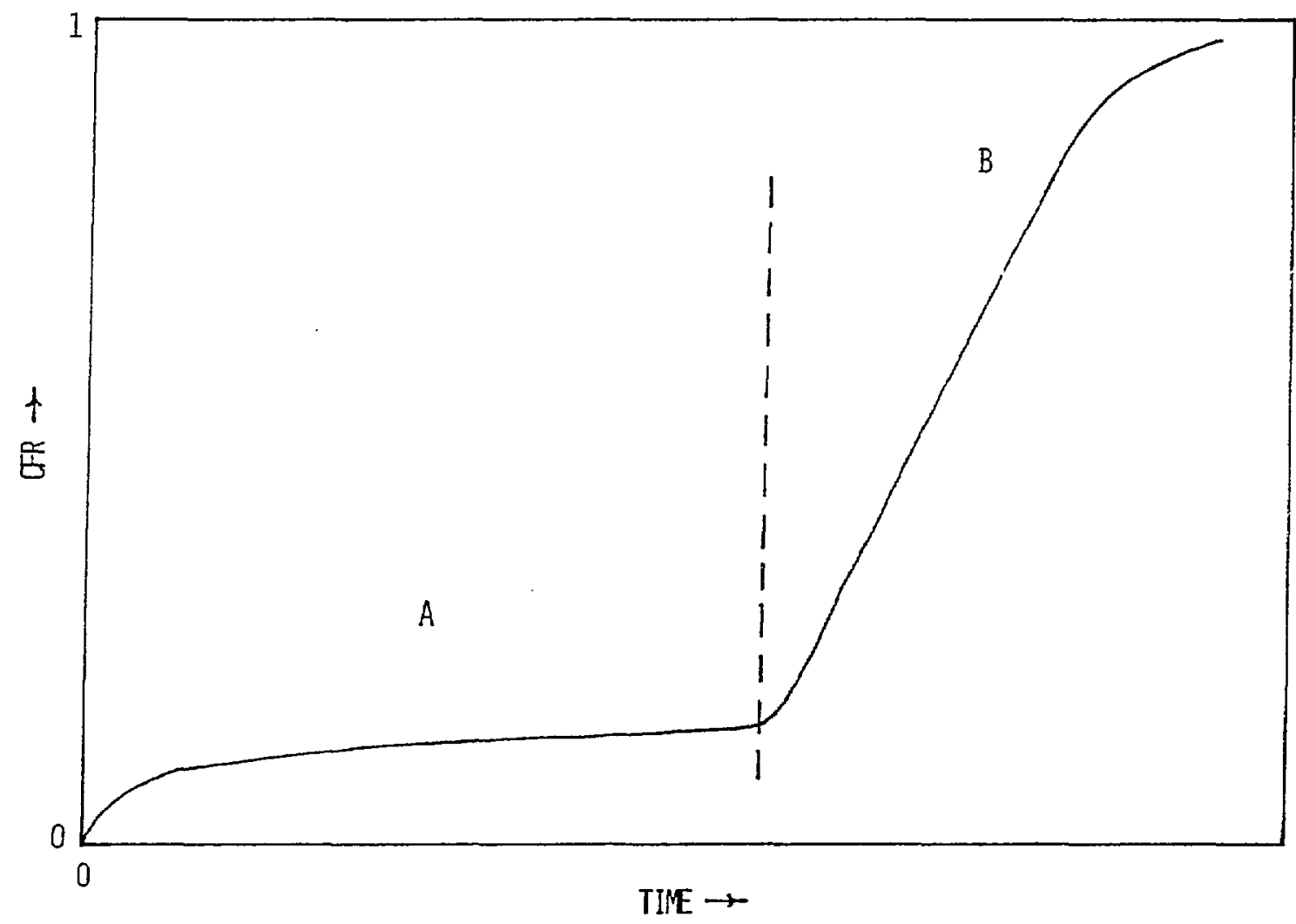

Figure 8.1 Schematic model of expected leaching behavior of bitumen waste forms incorporating soluble waste and/or waste which swells upon hydration. The dashed vertical line separates Region $A$, in which no swelling has occurred, and Region $B$, in which there has been enough water uptake to cause swelling. The leach rate increases markedly with swelling. 
However, both dissolution of waste in the waste form and dissolution of the waste form require a separate parameter, the dissolution rate constant, which was also reviewed in reference [2].

Waste loading is a major determinant of leaching behavior in VES waste forms incorporating soluble salts. This is evident from the scoping results on the effects of waste loading on the leaching behavior of sodium sulfate salt in VES as shown in Section 3, Figure 3.3. Such behavior is not explainable using the assumption that the waste form approximates a homogeneous medium. Instead, the two-phase nature of the waste form must be explicitly recognized as being a major factor that determines leaching behavior in this and similar systems. This is discussed in detail in Section 8.2.3, Waste Loading Effects On Leaching Behavior.

\subsection{Factors That Affect Model Validation}

Model validation is affected by everything that influences the interpretation of data for modeling purposes. Thus, any qualifications to data interpretation are especially important in model validation efforts. In this section several factors that need to be considered or be aware of before model validation efforts begin in earnest are listed and discussed. These include:

- The initial surface wash in leach testing

- The relationship between solid phase anaiysis and validation of leaching models

- Waste loading effects on leaching behavior

- Solubility effects on leaching behavior

- Ion exchange effects on leaching behavior

- Wet/dry cycling of leaching conditions

- Container effects on waste form leachability

The effect of leachant flow, which could also have been included here, is presented in Section 7.4 with the data generated from the experimental investigations of the effects of leachant flow.

Each of these topics is considered in the subsections following this introduction. The 1 ist above is not comprehensive but includes those factors that we feel to be most important based on current experience. The last two factors in the list, wet/dry cycling and container effects, are noted for completeness although no experimental work to investigate them is planned in this program. 
8.2.1 Initial Surface Wash in Leach Testing. The initial leach rate upon sample immersion is typicaliy larger than can be accounted for by back calculating from longer times and assuming a diffusion mechanism. This larger than expected initial release, or "surface wash", has been reported to last for periods of up to a week in laboratory leaching tests. As a result, this initial period is often discarded from analyses of long-term and/or bulk leachabilities using the argument that it occurs by a different mechanism than that which occurs in leaching the bulk waste form. However, since the surface wash contributions to the initial leach rate are often reported to extend several days into the leaching experiment, it would seem to require a more complete explanation than a simple surface wash, which would occur rapidly. The specific question of importance to model validation is whether discarding up to a weeks worth of data from a laboratory-size waste form significantly affects the interpretation of data from a mechanistic point of view.

Empirically, the surface wash has been accounted for by including a constant in the leaching release equation which represents an instantaneous release [61-65]. The form of the equation referenced in [61-65] is shown in equation 8.2 .

$$
\begin{aligned}
f & =A(0)+A(1) t t^{1 / 2} \\
f & =\text { cumulative fraction released at } t \text { ime, } t \\
A(0) & =\text { constant representing surface wash } \\
A(1) & =\text { constant coefficient } \\
t & =\text { cumulative leaching time }
\end{aligned}
$$

In general, mechanistic modelling which does not include a surface wash does not result in an expression which includes a constant. In reference [66] a mechanistic model is developed which includes an instantaneous surface wash release in a bulk diffusion plus surface dissolution model. The pnysical interpretation of the instantaneous surface wash was that it resulted from washing small particles from the surface and an instantaneous leaching of microscopic surface irregularities. The microscopic surface irregularities made the actual surface area larger than the geometric surface area unti] the leaching process depleted the irregularities. Since the surface irregularities were assumed to be microscopic, depletion occurred virtually instantaneously. Although this argument may be valid for polished glass samples, it is not clear that this physical mechanism is valid for low-level waste forms.

A possible explanation for an increased leach rate early on in a leaching experiment, but not requiring the instantaneous release of a surface wash mechanism, has been described. Crawford, et. al., [56] noted that evaporation from a cemented waste form can concentrate Cs and soluble material on the waste form surface, which can result in an increased initial leach rate. Transport of soluble material to the surface during curing of cement waste forms, if water evaporation occurs, could explain the initial high leach rate from cement waste forms, but could not explain it for bitumen waste forms or any waste form incorporating dry wastes in a non-water containing matrix. This efflorescence phenomenon may also be the reason for increased leaching observed from cement following wet-dry cycling $[6,67]$. 
8.2.2 Solid Phase Analysis. Specific examples of solid phase analysis have been reported in Section 4 of this report for cement and vinyl esterstyrene samples. These investigations are important because they show directly the physical structure of waste forms both before and after leaching and point to changes which may be important in determining the long-term behavior of waste forms. Additionally, studies using SEM/EDS can indicate changes in the elemental compusition of cement samples which may indicate changes in sorption behavici. A significant change in sorption behavior could change the dominant leaching mechanism, which clearly would affect long-term leaching behavior aris response to factors that affect leaching.

Solid phase analysis is required to investigate waste form porosity, surface conditions which may be different from bulk characteristics. It also provides information on changes in the elemental composition of cement samples due to leaching.

8.2.3 Waste Loading Effects On Leaching Behavior. The effect of waste loading ( $i . e_{.}$, waste to binder ratio) is one of the most important factors affecting the leaching behavior of low-level waste forms. The specific effects of waste loading depend on the physical and chemical characteristics of both the solidification agent and the waste. Waste loading effects dominate the leaching behavior of waste forms solidified using rigid, inert (to the waste), impermeable binders in that there are two distinct regions of leaching behavior in such systems which are determined by waste loading, as evidenced by the data shown in Figure 3.3, Section 3. Specifically, at waste loadings below a threshold value the leachability is little affected by waste loading while above it the leachability increases rapidly with waste loading. This kind of mass transport behavior (percolation behavior) is typical of two phase systems in which the diffusion coefficient in one phase (the conduction phase) is much greater than that in the other phase. The waste loading value at which the behavior changes is called the "percolation threshold" and the formalism that describes such behavior is percolation theory. The leaching behavior shown in Figure 3.3 cannot be explained using diffusion theory applied to homogeneous media, as has been common practice [2].

An analysis of the effect of waste loading on the leaching behavior of sodium sulfate salt solidified with low-density polyethylene is presented in the following paragraphs. Although polyethylene waste forms are not being specifically investigated in this program, polyethylene is, like vES, a rigid, impermeable material. As such, the leachability vs. waste loading of polyethylene-solidified waste forms is similar to that of the VES waste forms investigated in Figure 3.3.

Table 1 lists some of the data reported [79] for $\mathrm{Cs}-137, \mathrm{Sr}-85$ and $\mathrm{Co}-60$ leached from polyethylene waste forms containing sodium sulfate salt at loadings of $10 \mathrm{wt} \%, 30 \mathrm{wt} \%$ and $50 \mathrm{wt} \%$. The radionuclide tracers were incorporated into the salt by dissolution/evaporation to dryness before solidification. Leach testing was performed using the ANS 16.1 methodology. Table 8.1 1jsts the cumulative fraction released (CFR) after five days leaching time. These particular data were chosen because the leachant replacement intervals become much longer following the fifth day. Although the following analysis uses the five-day data, the same general results obtain over the whole range of data so that the use of only the five-day data does not limit the generaljty of the 
Table 8.1

Cumulative Fraction Released After Five Days Leaching Time From Leaching Polyethylene Waste Forms Containing $10 \mathrm{wt} \%, 30 \mathrm{wt} \%$ and $50 \mathrm{wt} \%$ Sodium Sulfate Salt [79].

\begin{tabular}{|c|c|c|c|}
\hline & 10 wt\% & 30 wt $\%$ & $50 \mathrm{wt} \%$ \\
\hline Cs -137 & .0013 & .0034 & .0120 \\
\hline Sr-85 & .0015 & .0039 & .0090 \\
\hline Co-60 & .0026 & .0041 & .0100 \\
\hline
\end{tabular}

Figure 8.2 shows the data from Table 8.1 plotted as CFR versus waste loading (wt\%). Since on ly one sample was leached at each laading, no estimates of the variability of the leaching process for these data are available. Three features of the plot in Figure 8.2 seem noteworthy.

(i) The CFR for each radionuclide increases as waste loading increases.

(ii) The relative increase in CFR from 30 wt\% to $50 \mathrm{wt} \%$ is much greater than that from $10 \mathrm{wt} \%$ to $30 \mathrm{wt} \%$.

(iii) The spread in CFR values at $50 \mathrm{wt} \%$ is much greater than at the lower loadings and the relative ordering has shanged with Cs-137 having the largest CFR at $50 \mathrm{wt} \%$ whereas it has the lowest CFR at the lesser waste loadings.

The observations in item ( $i j i$ ) may indicate that solubility limitations may be limiting the leaching of $\mathrm{Sr}$ and $\mathrm{Co}$ at the $50 w, \%$ loading whereas no such effect occurs for Cs.

The observation in item ( $i i)$ is not easily explained using diffusion theory as it has generally been applied to LLW leaching. Specifically, since waste forms are considered to be homogeneous, each waste loading may represent a qualitatively, as well as quantitatively, different "material". In this case there is no formal way to extrapolate the leaching behavior at one waste loading to another. Alternatively, a change in waste loading may be assumed to change only the concentration of the substance of interest without affecting the mass transport properties. In this case, for diffusion with constant diffusion coefficient as the leaching mechanism, an increase in waste loading results in a proportional increase in the amount leached at any specified time. However, the CFR would remain constant as long as the boundary conditions in the preceeding two sentences are met. This is clear from Equation 8.3, which specifies the amount leached per unit area, $m$, from a semi-infinite medium of uniform initial concentration, $C$ [80].

$$
m=2 C(D t / p i)^{1 / 2}
$$




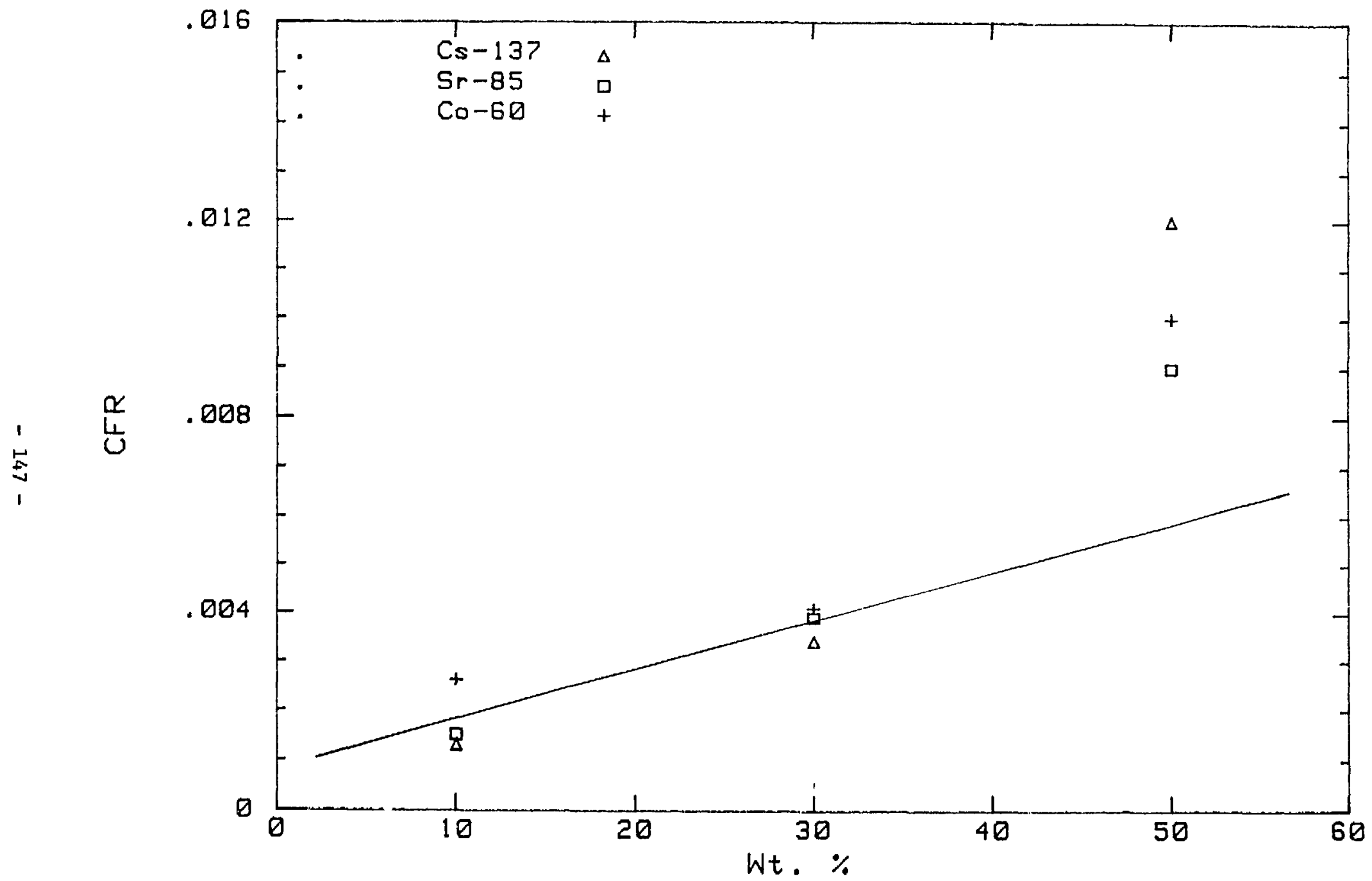

Figure 8.2 Linear plot of the data in Table 8.1. The line is the leastsquares fit to the $10 \mathrm{wt} \%$ and $30 \mathrm{wt} \%$ data. 


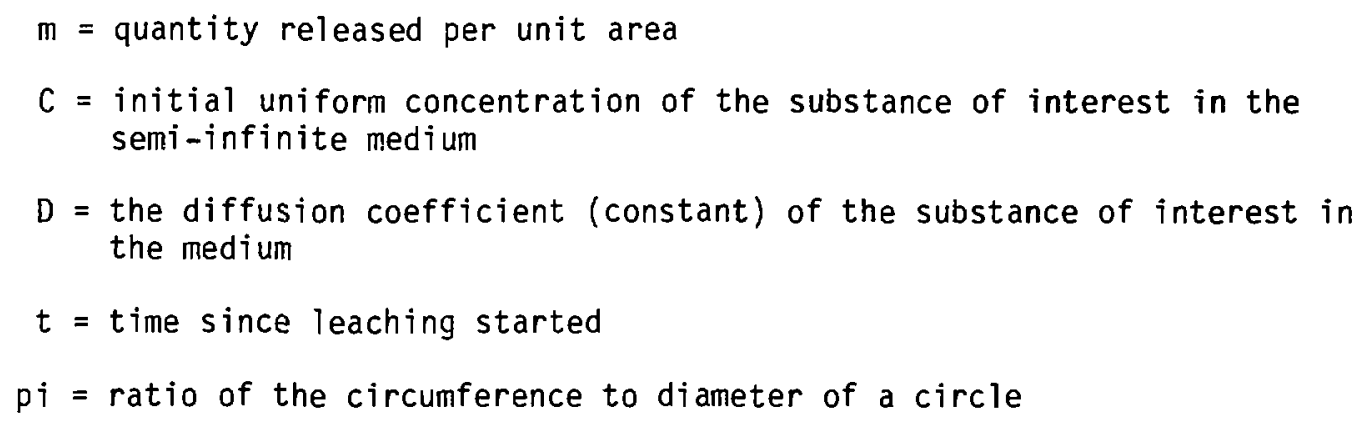

The transformation of Equation 8.3 to the more useful units of CFR versus time is shown in Equation 8.4 .

$$
\begin{aligned}
& \text { CFR }=2(S / V)\left(D t / D^{i}\right)^{1 / 2} \\
& S / V=\text { surface area to volume ratio of the (finite) waste form }
\end{aligned}
$$

Equation 8.4 shows that the CFR at any specified time should be constant for all waste loadings as long as the initial and boundary conditions specified above hold.

Returning to Figure 8.2 , it appears that an analysis based on Equation 8.3 which predicts a linear increase in the quantity leached, $m$, with increasing waste loading, may fit the data up to $30 \mathrm{wt} \%$ loading. Since the $50 \mathrm{wt} \%$ data lie well above the (least-squares fitted) line extrapolated from the 10 wt\%

$$
\begin{array}{rlrl}
\text { CFR } & =.0001(w t \%)+.0008 \\
r & =.91 & \text { correlation coefficient and } \\
\text { sigma } & =.0012 & \text { standard deviation of the curve fit }
\end{array}
$$

Although the CFR increases somewhat as waste loading increases, as shown in Equation 8.5, it is approximately constant up to 30 wt\% loading, which may imply that analysis based on Equation 8.4 ( $i$.e., the initial and boundary conditions under which Equation 8.4 is valid) accurately models leaching behavior as a function of waste loading in this systen up to approximately 30 wt\% loading.

Alternatively one could note that simple diffusion theory as expressed in Equations 8.3 and 8.4 does not fit all of the data in Table 8.1 and try to find other explanations which do fit the data. Figure 8.3 plots the data from Table 8.1 on a semi-log scale and Equation 8.6 shows the least-squares fit to the data (solid line).

$$
\begin{aligned}
& \text { CFR }=.00106 \exp [.0447(w t \%)] \\
& r=.97 \text {, correlation coefficient }
\end{aligned}
$$




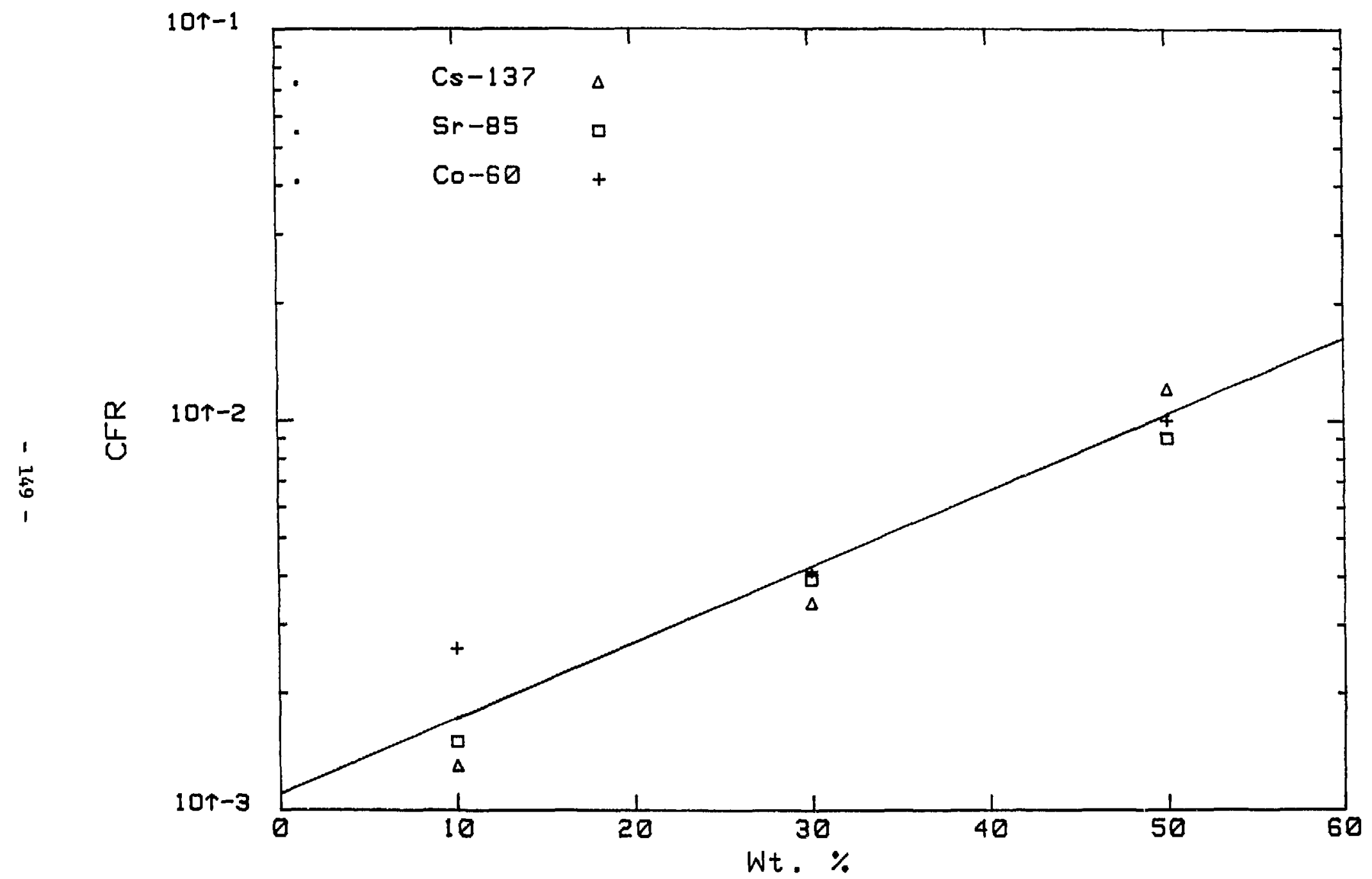

Figure 8.3 Semi-long plot of the data in Table 8.1. The line is the leastsquares fit to all of the data. 
The empirical curve fit of Equation 8.6 provides a better correlation for all the data than does Equation 8.5. However, the fact that the diffusional analysis of Equation 8.5 fit only part of the data should not be taken as proof that a diffusion mechanism is not important in this case. On the contrary, diffusion has traditionally been reported as a principal leaching mechanism for low-level waste forms. Rather, it may be that leaching behavior as a function of waste loading is better explained another way. In the remainder of this section an alternative analysis based on percolation theory [81,82] is applied to the problem of leachability as a function of waste loading using the data in Table 8.1.

Percolation theory $[81,82]$ is useful for describing diffusion in porous solids and other composite media which have the following property: The matrix is subdivided into regions with significantly different diffusivities e.g., a porous solid containing randomly distributed pores or cavities. Qualitatively, diffusion in such a matrix is characterized by two regions of behavior separated by the "percolation threshold" porosity. At porosities less than the percolation threshold, the diffusivity of the matrix is essentially that of the solid region. At porosities greater than the percolation threshold the diffusivity increases rapidly with increasing porosity. Physically, below the percolation threshold the porosity tends to be isolated or connected in only small clusters while above the percolation threshold the porosity is connected, which creates pathways in the high-diffusivity region throughout the medium.

Theoretically the threshold porosity is approximately 0.25 to 0.33 void fraction. However, experimentally observed values for all cases studied have been lower, in the range from approximately 0.1 to 0.15 [82]. These lower values of the threshold porosity compared to theoretical expectation have been attributed to the fact that, in real systems, factors such as the lack of uniform particle (void) size and shape lead to networks which have some degree of correlation as opposed to truely random porosity.

In sum, percolation theory is generally applicable to diffusional mass transport in porous media, porous implying a two (or more) phase system in which the diffusivity in one phase is much greater than that in the other(s). The leaching behavior of such a system is expected to approximate that of the pure solidification agent matrix up to a waste loading of $10 \%$ - 15\% by volume (the percolation threshold), beyond which the leachability would rapidly increase with increased waste loading.

Returning to Figure 8.2, it appears that the data from Table 8.1 may exhibit percolation behavior as waste loading increases. Table 8.2 transforms the waste loading values from wt\% to volume\% (v\%) using the following parameters and Equation 8.7 .

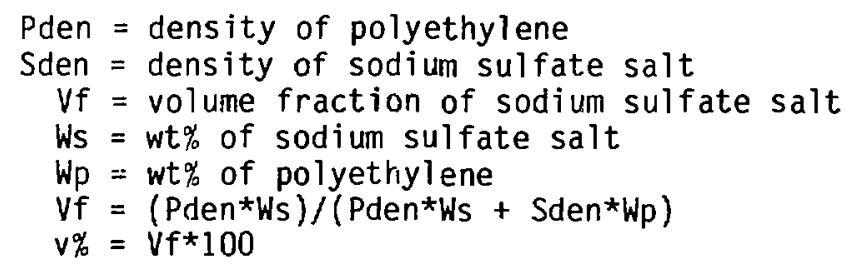


Equivalent Volume\% Values for the Weight\% Data Listed in Table 8.1

\begin{tabular}{c} 
Weight $\%$ \\
Sodium Sulfate \\
\hline
\end{tabular}

10

30

50
Volume\%

Sodium Sulfate

4

13.7

27

Since low-level waste forms typically consist of a matrix in which the solidification agent and incorporated waste are physically and chemically distinct, percolation theory may provide a better mechanistic description of the effect on leachability of increasing the waste loading than does simple diffusion theory.

8.2.4 Solubility Effects on Leaching Behavior. The rate at which a substance dissolves is influenced by the nature of the substance and its inherent solubility in the solvent, by the relative degree of saturation of the solvent relative to the dissolving substance and by the presence of solid matter which may act as a sorbent for the substance in solution $[68,69]$. Thus, for any substance undergoing leaching, the leachability may be influenced by its solubility and rate of dissolution in the leachant and by the distribution coefficient, Kd, of the dissolved substance with respect to the solid matrix.

In dynamic leaching systems the kinetics of approach to steady-state may be more important than the limiting concentration in solution. In an ideal dynamic system the concentration in the leachant remains effectively zero so that saturation effects are insignificant and the maximum leach rate under the specific conditions is observed.

Under static leaching conditions the kinetics of approach to saturation can be determined along with the concentration at saturation, or steadystate, for the system. If sorption is important, then the measured steadystate concentration would reflect the $\mathrm{Kd}$ value. If the solid phase is inert, then solubility considerations would control the steady-state concentration.

The properties of real systems generally change during leaching due to physical and/or chemical changes (aging) caused by the leaching process itself. If the system changes significantly during leaching, then the solubility and sorbtion properties may also change substantially as the system ages. For example, it has been shown that leaching changed the elemental composition of the depletion zone (i.e., surface and near surface) of a cement specimen compared to regions of the specimen nearer the center [1]. There is evidence that such changes in elemental composition affect the leachability of cesium from cemented waste forms $[58,59]$. 
Clearly, modeling efforts directed toward systems which age significantly due to leaching must either account for such aging or show that it is not significant for the long-term leaching behavior of the waste form.

8.2.5 Ion Exchange Effects on Leaching Behavior. If ion exchange is a potential mechanism for LLW leaching, then the nature of the ion exchange or adsorption, including factors which may affect the ion exchange mechanism in the long term, should be determined. Adsorption of radionuclides onto portland cement has been the subject of numerous investigations from which it has been well documented that cesium neither reacts with nor sorbs onto hydrated portland cement to any appreciable degree [70-77]. The situation for strontium is, however, less well defined. Although strontium sorbs onto hydrated portland cement to a greater degree than does cesium, the sorbtion is still not very large $[75,76]$. However, in the long term, sorbtion of strontium may be moot since there is some speculation that strontium reacts with cement, albeit slowly [68]. Thus, in the long term, strontium fixation in a cemented waste form may have little to do with sorption parameters measured from short-term testing.

To reduce the leachability of cesium from cemented waste forms, sorbent additives have been included in cement-based solidification agent formulations. Additives which have been evaluated for use include amorphous silica, powdered fly ashes, powdered blast furnace slags, clays and natural zeolites $[75,76]$.

Adsorbtion isotherms have been fit to some sorption data for cesium and strontium on cement and cement plus various additives. Since little sorption occurs on the cement itself, the nature of the sorption would seem to depend on the nature of the additive. Since silica-containing additives are known to react slowly with cement, thus losing their sorbent capacity, the long-term ability of such additives (e.g., zeolites, fumed silica and blast furnace slag) to reduce leachability from cement waste forms is questionable.

8.2.6 Wet-Dry Cycling of Leaching Conditions. Changing leaching conditions from continuously saturated to alternately saturated then unsaturated has been shown to lead to substantially different leaching behavior for the release of cesium from cement waste forms [6]. The important considerations in wet-dry cycling appear to include the durations of both the saturated and unsaturated conditions and the nature of the waste form. Specifically, wetdry cyciing has been shown to be important for leaching cesium from cement. This and other observations from reference [6] suggest that the conditions necessary for wet-dry cycling to substantially affect leachability include the following:

(i) The wet cycle is long enough for the (cement) waste form to imbibe a significant amount of water,

(ii) The dry cycle leads to much, if not all, of the water imbibed into the waste form in the wet cycle being released from the waste form during the dry cycle and, 
(iii) Soluble substances from within the waste form are carried to the surface by the water evaporating from the surface, which concentrates these substances at the surface where they are then readily leached by dissolution during the next wet cycle.

The effect of wet-dry cycling on insoluble, otherwise fixed and/or only slightly soluble substances should be minimal. However, other factors, such as the possibility that chelating or complexing agents may be imbibed in the leachant during the wet cycle and may mobilize otherwise immobile substances and lead to their enhanced leaching, may need to be considered in actual disposal environments compared to laboratory tests using deionized water as leachant.

8.2.7 Container Effects on Waste Form Leachability. The implication in leach tests incorporating bare waste forms is that such leaching shows the leaching behavior of the waste form itself and is the worst case. The function of the container has generally been considered to be limited to delaying the onset of leaching until the container is breeched and/or corrodes away. However, there is some evidence that interactions between waste form and container during leaching can occur which result in increased leachability [7].

In a study of the leaching of nitrate salts solidified in cement using the IAEA Standard Leach Test it was reported that the container cracked after approximately sixty days leaching time. Following this, the leach rate increased dramatically and far more than could be explained by a simple increase in the exposed surface area. The same effect was also observed upon removal of the container from another samplo after approximately the same duration of leaching [7]. These results were dramatically different from those typically seen from samples which are removed from their containers prior to leaching.

In general, leaching experiments on complete waste packages, which include waste forms in the containers in which they are to be disposed of, are not performed. Rather, the waste form is normally "decanned" prior to leaching so that the leaching behavior of the waste form itself can be measured in isolation. All of the standard leach tests used for low-level waste forms specify that the waste form shall be removed from its container prior to leach testing $[8,9,78]$. 


\section{SUMMARY AND CONCLUSIONS}

Although much of the work in this program is ongoing at this point in time, results obtained to data allow us to make several preliminary conclusions.

- Formulation development, Section 3, indicated that waste loading effects are of great significance in determining waste form stability toward immersion. Leaching studies on waste forms incorporating simulated wastes, Section 5, indicated that waste loading significantly affects the leaching behavior for all systems tested. Model validation analysis, Section 8, indicated that, in both bitumen and VES incorporating soluble salts, leaching behavior is controlled by waste loading effects.

- Baseline leaching studies on waste forms composed of the pure solidification agents, portland cement, bitumen and vinyl ester-styrene, doped with radiotracers of $\mathrm{Cs}, \mathrm{Sr}$ and $\mathrm{Co}$ have been completed. Reproducibility of replicate samples as measured by the total release of each radionuclide was excellent for portland cement when the cumulative faction released (CFR) was large, but less so for the other materials, where the CFR was small. This reflects the relatively large counting errors that result from low count rates for samples containing small amounts of activity.

- Correlation matrix analysis of leaching releases of $\mathrm{Cs}-137$ and $\mathrm{Sr}-85$ radiotracers and elemental releases of cement components including $\mathrm{Na}$, $\mathrm{K}, \mathrm{Ca}, \mathrm{Sr}, \mathrm{Al}$ and $\mathrm{Si}$ indicate no correlation between the radiotracer leaching and the cement component leaching. This does not mean that the leaching mechanisms of the chemically similar elements ( $\mathrm{Na}, \mathrm{K}$ and $\mathrm{Cs}-137)$ and the chemically identical elements ( $\mathrm{Sr}$ and $\mathrm{Sr}-85$ ) are different. However, it does suggest that factors which control radiotracer leaching and the cement matrix leaching are different under the conditions of these tests.

- Solid phase analysis, Section 4, of cement before and after leaching indicates that both the physical structure and elemental chemical composition of the cement has changed due to leaching. Physical changes include changes in waste form porosity while chemical changes include development of an altered surface layer due to leaching. These changes may indicate that the dominant leaching mechanism may change during leaching.

- Solid phase analysis of VES/aqueous waste emulsion waste forms show that the waste is contained in a polymer structure which is spongelike in appearance. The connectedness of the porosity in the polymer 'sponge' could not be definitely determined from the work to date. There was no obvious difference in morphology between the surface and the interior either as fabricated or after leaching at room temperature for 471 days. 
- Leaching of cement waste forms incorporating sodium sulfate resulted in reactions between the waste and cement. Crystals of reaction products filled voids in the cement and formed a surface coating on the waste form that had a different morphology and chemical composition when compared to an unleached waste form. This surface coating was also different from the surface of a leached cement sample that contained no waste.

- There appear to be two regimes of leachant (trench water) characteristics following trench closure. Immediately following trench clcsure, conditions in the trench should become anaerobic due to biodegradation and chemical decomposition of organic matter in the waste. Trench water would be anoxic under anaerobic conditions and its chemical composition would reflect the low Eh, reducing nature of the trench. However, in the long term, after biodegradation and chemical decomposition have depleted the organic matter in the trench, trench water composition would return to that characteristic of the area surrourding the trench. These long-term conditions are likely to result in trench water that is relatively oxic and whose chemistry reflects the higher Eh condition.

\subsection{Acceleration Factors}

Factors that affect leaching and that have the potential to accelerate leaching have been determiried to be strongly influenced by waste effects, which are due to waste loading (i.e., waste to binder ratio) and/or to interactions between solidification agent and waste. The potential accelerating factors investigated to date are briefly reviewed in the following paragraphs and schematically summarized in Table 9.1

- Temperature - The leaching of Cs-137 tended to increase with increased temperature. Some ambiguity in the results occurred where matrix effects (e.g., temperature-induced curing of vinyl ester-styrene waste forms) or waste effects (e.g., very rapid release of material) masked or interferred with the direct effect of increased temperature on leaching behavior.

- Leachant volume to Waste Form Surface Area - For the leaching of Cs-137 from cement with $5 \% \quad \mathrm{Na}_{2} \mathrm{SO}_{4}$, leachability decreased as the ratio of leachant volume to waste form surface area increased. For VES incorporating 40 wt $\% \mathrm{Na}_{2} \mathrm{SO}_{4}$ salt no effect due to increased leachant volume to waste form surface area was observed.

- $p H$ - In general, the highest leachabilities were observed in

deionized water, $\mathrm{pH}=6$. (The $\mathrm{pH}$ of pure water is 7 at room temperature, but dissolved carbon dioxide from the air reduces this to approximately 6.) only for bitumen containing $20 \mathrm{wt} \%$ sodium tetraborate did the leaching of $\mathrm{Cs}-137$ increase in more acidic solution. 
Table 9.1

Summary of Relative Change for Potential Acceleration Factors for Leaching of Cs-137 From Low-Level Waste Forms Relative Changea

\begin{tabular}{|c|c|c|c|c|c|c|c|c|c|}
\hline $\begin{array}{l}\text { Acceleration } \\
\text { Factor }\end{array}$ & Cement & $\begin{array}{c}\text { VESa } \\
\text { Emulsion }\end{array}$ & Bitumen & $\begin{array}{c}\text { Cement } \\
+ \\
\mathrm{Na}_{2} \mathrm{SO}_{4}\end{array}$ & $\begin{array}{c}\text { Cement } \\
+ \\
\text { Ash }\end{array}$ & $\begin{array}{c}\text { VES } \\
\mathrm{Na}_{2} \mathrm{SO}_{4} \\
\text { Emulsion }\end{array}$ & $\begin{array}{c}\text { VES } \\
\mathrm{Na}_{2} \mathrm{SO}_{4}\end{array}$ & $\begin{array}{l}\text { Bitumen } \\
20 \text { wt\% } \\
\mathrm{Na}_{2} \mathrm{~B}_{4} \mathrm{O}_{7}\end{array}$ & $\begin{array}{r}\text { Bitumen } \\
40 \text { wt\% } \\
\mathrm{Na}_{2} \mathrm{~B}_{4} \mathrm{O}_{7}\end{array}$ \\
\hline Groundwater & $\mathrm{NPb}$ & NP & NP & - & - & - & - & mixed & - \\
\hline Temperature & + & 0 & 0 & + & 0 & mixed & + & mixed & mixed \\
\hline $\begin{array}{l}\text { Leachant } \\
\text { Volume }\end{array}$ & NP & NP & NP & - & NP & NP & mixed & NP & NP \\
\hline $\mathrm{pH}$ & $\mathrm{NP}$ & $N P$ & NP & - & - & - & - & $\mathrm{pH} 4+$ & 0 \\
\hline Flow & 0 & + & 0 & 0 & 0 & 0 & 0 & 0 & 0 \\
\hline $\begin{array}{l}\text { Size } \\
\text { small cylinder } \\
\text { disc }\end{array}$ & $\begin{array}{l}\mathrm{NP} \\
\mathrm{NP}\end{array}$ & $\begin{array}{l}N P \\
N P\end{array}$ & $\begin{array}{l}\text { NP } \\
\text { NP }\end{array}$ & $\begin{array}{l}+ \\
+\end{array}$ & $\begin{array}{l}+ \\
+\end{array}$ & $\begin{array}{l}+ \\
+\end{array}$ & $\stackrel{+}{\operatorname{mixed}}$ & $\begin{array}{l}\text { mixed } \\
\text { mixed }\end{array}$ & $\begin{array}{l}\text { mixed } \\
\text { mixed }\end{array}$ \\
\hline
\end{tabular}

a. A qualitative comparison of Cs-137 CFR results for experiments compared to results obtained by the modified ANS 16.1 test using

$5 \mathrm{~cm}$ diameter $\times 6.4 \mathrm{~cm}$ high cylindrical waste forms and DIW at $20^{\circ} \mathrm{C}$.

+ - implies an increase in the leaching of $\mathrm{Cs}-137$

- implies a decrease in the leaching of $\mathrm{C}_{5-137}$

0 - implies statistically identical results.

mixed - implies no apparent trends, but irregulaties or significant statistical variations in the results.

NP - experiment not performed.

b. VES - Vinyl Ester-Styrene. 
- Leachant flow - Leach rates for Cs-137 from a flow test with DIW at 1 liter/day, were very similar to, but less reproducible than the results from the modified ANS 16.1 test. The flow test was substantially more difficult to perform than the ANS 16.1 test. The equation employed by the MCC4S flow test is formally valid only for a constant leach rate, which is seldom or ever the case for LLW waste forms.

In sum, the MCC4S flow test does not appear to be useful for LLW form leach testing because it is more difficult to perform, the results generally show a greater degree of irreproducibility than leachant replacement type tests and the data analysis procedure provided in the flow test is formally valid only when the leach rate is constant.

- Size - The release of Cs-137 generally increased for waste forms with increasing waste form surface area to volume ratios (S/V). Exceptions occurred where very substantial release of CS-137 occurred which overwhelmed the leaching effects of size.

Some of the ambiguity in results may be related to acceleration being limited by the leachant change frequency. This was necessarily kept the same for all experiments (to change only one variable at a time). Future work combining accelerating factors will clarify this point and is expected to show more distinct accelerations. 


\section{REFERENCES}

1. Dougherty, D.R., M. Fuhrmann and P. Colombo, "Leaching Mechanisms Program Annual Report," Brookhaven National Laboratory, BNL-51862, September, 1984.

2. Dougherty, D.R. and P. Colombo, "Leaching Mechanisms of Solidified LowLevel Wastes: The Literature Survey," Brookhaven National Laboratory, BNL-51899, June, 1985.

3. Dougherty, D.R., M. Fuhrmann and P. Colombo, "Accelerated Leach Test(s) Program Annual Report," Brookhaven National Laboratory, BNL-51955, September 1985.

4. Dougherty, D.R. and P. Colombo, "Development of a Computerized Data Base for Low-Level Radioactive Waste Leaching Data, Topical Report," Brookhaven National Laboratory, BNL-52020, September, 1986.

5. Armstrong, K.M. and L.M. Klingler, "Evaluation of a Processing Technique for Immobilization of Low-Level Radioactive Waste," Mound Laboratory, MLM-3149, July 13, 1984.

6. Dayal, R., H. Arora, J.C. Clinton and L. Milian, "Leaching Studies of Low-Level Radioactive Waste Forms," Brookhaven National Laboratory, BNLNUREG-37071, presented at the Seventh Annual Participants' Information Meeting, DOE Low-Level Waste Management Program, Las Vegas, Nevada, September, 1985 .

7. Sambell, R.A.J., R. De Batist, P. Van Iseghem, W. Timmermans and K. Brodersen, "Characterization of Low- and Medium-Level Radioactive Waste Forms," Commission of the European Communities, PB84-212976, EUR 8663 EN, 60-61, 1983.

8. American Nuclear Society, "Measurement of the Leachability of Solidified Low-Level Radioactive Wastes," ANS Standards Committee, ANS 16.1, June 20 1984.

S. Hespe, E.D., editor, "Leach Testing of Immobilized Radioactive Waste Solids, A Proposal for a Standard Method," Atomic Energy Review, 9, 195-207, 1971.

10. Colombo, P. and R.M. Neilson, Jr., "Properties of Radioactive Wastes and Waste Containers," NUREG/CR-1168, BNL-NUREG 51114, 1979.

11. Neilson, R.M. and P. Colombo, "Waste Form Development Program Annual Progress Report," BNL-51614, 1982.

12. R.L. Buschbom, et al., "Characterization of Cement and Bitumen Waste Forms Containing Simulated Low-Level Waste Incinerator Ash," NUREG/CR-3798, PNL-5153, 1984. 


\section{REFERENCES}

13. U.S. Energy Research and Development Administrations (USERDA), "Alternatives for Managing Wastes from Reactors and Post-Fission Operation in the LWR Fuel Cycle," Vol. 2, Alternatives for Waste Treatment, ERDA-76-43, 1976.

14. Mckercher, B.B., C.C. Miller and M.D. Naughton, "Operation Experience of the Palisade Station Volume Reduction System - The First Two Months," from Post (editor) Management 84, Volume 2, Tucson, AZ Symposium, 1984.

15. Materials Characterization Center, Agitated Powder Leach Test Method, MCC3s, 1981.

16. Materials Characterization Center, Low-FLow-Rate Leach Test Method, MCC4s, 1981.

17. American Society for Testing and Materials, "Standard Practices for the Measurements of Radioactivity," ASTM Standard D-3648 in 1982 Annual Book of ASTM Standards, Part 31, Water.

18. American Society for Testing and Materials, "Standard Practices for Gamma-Ray Spectrometry," ASTM Standard D-3649, in 1982 Annual Book of ASTM Standards, Part 31, Water.

19. American Society for Testing and Materials, "Standard Practice for Flame Atomic Absorption Analysis," Standard E663, in 1982 Annual Book of ASTM Standards, Part 42, Analytical Methods-Spectroscopy; Chromatography; Computerized Systems.

20. Perkin-Elmer, Analytical Methods for Atomic Absorption Spectroscopy, Perkin-Elmer Corporation, 1982.

21. Greenberg, A.E., J.J. Connors and D. Jenkins, editors, "Alkalinity," Method 403, in Standard Methods for the Examination of Water and Waste Water, 15th edition, American Public Health Association, Washington, $D C$ $\overline{1981 .}$

22. American Society for Testing and Materials, "Standard Test Methods for $\mathrm{pH}$ of Water," Standard D-1293 in 1982 Annual Book of ASTM Standards, Part 3, Water.

23. American Society for Testing and Materials, "Standard Test Methods for Electrical Conductivity and Resistivity of Water," Standard D-1125 in 1982 Annual Book of ASTM Standards, Part 31, Water.

24. Goldstein, J.I. and H. Yakowinz, (editors), Practical Scanning Electron Microscopy, Electron and Ion Microprobe Analysis, Plenum Press, 1975.

25. Lea, F.J. "The Chemistry of Cement and Concrete," Third Edition, F. Arnold (Publishers), Ltd., London, 1970. 


\section{REFERENCES (cont.)}

26. Zhou, Huan and P. Colombo, "Solidifisation of Radioactive Waste in Masonry Cement," presented at the Fall Convention of the American Concrete Institute, October 28-November 2, 1984, New York, NY.

27. Brownstein, M. and R.G. Levesque, "Experience with Cement Usage as the Binding Agent for Radwaste," ASME Publication \#78-NE-15, June, 1978, American Society of Mechanical Engineers, NY, NY.

28. Wedepoh1, K.L., "Geochemistry," Holt, Reirihartand Winston, Inc., New York, 1967.

29. Strumm, W.,m and J.J. Morgan, Aquatic Chemistry, John Wiley and Sons, New York, 1981.

30. Daya1, R., R.F. Pietrzak, and J. Clinton, "Geochemical Investigations at Maxey Flats Radioactive Waste Disposal Site - Topical Report," NUREG/CR-3993, Sept. 1984.

31. Dayal, R., R.F. Pietrzak, and J. Clinton, "Geochemical Studies of Commercial Low-Level Radioactive Waste Disposal Sites, a Topical Report," NUREG/CR-4644, BNL/NUREG-52004, June 1986.

32. Davis, E.C. and P.M. Craig, "Summary of Rainfall, Runoff, water Table, and Water Quality Data From ORNL's Solid Waste Storage Area Six Engineered Test Facility: 1980-1984 Data Base," ORNL/NFW-84/41 (August, 1984).

33. Hass, R., M.A. Anderson, R. Stegmann and R. Stanforth, "Background Study on the Development of a Standard Leaching Test," EPA-600/2-79-109, 197?.

34. Carver, R.E., Procedures in Sedimentary Petrology, Wily-Interscience, New Yor'k, 1971.

35. Langmuir, D., 1968, "Stability of Calcite Based on Aqueous Solubility ileasurement," Geochimica et Cosmochimica Acta, 32, No. 8, 835-851.

36. Gabrels, R.M., Mineral Equilibria at Low Temperature and Pressure: Harper and Brothers, 1960.

37. Boggs, S. Jr., D.L. Livermore and M.G. Seitz, "Humic Substances in Natural Water and Their Complexation with Trace Metals and Radionuclides. A Review," ANL-84-78, July 1985.

38. Reuter, J.H., E.M. Perdue, "Importance of Heavy Metal-Organic Matter Interactions in Natural Waters," Geochim. Cosmochim. Acta, 41:325-334, 1977. 
39. Christman, R.F. and E.T. Gjessing, Aquatic and Terrestrial Humic Materials, Ann Arbor Science Publishers, Ann Arbor, pp. 538, 1983.

40. Schnitzer, M. and S.U. Khan, Soil Organic Matter, Developments in Soil Science 8, Elsevier Sci. Publ. Co., New York, p. 319, 1978.

41. Boggs, S. Jr., and M.G. Seitz, "The Influence of Dissolved Organic Substances in Groundwater on Sorption Behavior of Americium and Neptunium," in Argonne National Laboratory, ANL-83-84, 1984.

42. Chebotina, M.Y., "Influence of Plant Extracts on the Mobility of Iron 59 and Cobalt 60 in Soil Under Conditions of Dynamic Laboratory Experiments," Sov. Radiochem., 13:756, 1971 .

43. Sheppard, J.C., M.J. Campbel7, T. Chang and J.A. Kittrick, "Retention of Radionuclides by Mobile Humic Compounds in Soil Particles," Environ. Sci. Technol., 14:1349-1353, 1980 .

44. Schnitzer, M. and S.U. Khan, Humic Substances in the Environment, Marcel Dekker, Inc., 327 pp., 1972.

45. Seefeldt, W.B., "VIII. Review of Simulated-Flow and True-Flow Leach Tests," Fuel Cycle Programs Quarterly Progress Report, April-June 1982, ANL-82-58-98-132, December 1982 .

46. Soroka, I., "Portland Cement Paste and Concrete," Chemical Publishing Co., Inc., New York, 49, 1980.

47. Powers, T.C., "Physical Properties of Cement Paste," Proceedings of the Washington Symposium on the Chemistry of Cement, 2, 577-613, 1960.

48. Crawford, R.W., F.P. Glasser, A.A. Rahman, M.J. Angus and C.E. McCulloch, "Diffusion Mechanisms and Factors Affecting Leaching of Cesium-134 from Cement-Based Waste Matrices," Radioactive Waste Management and the Nuclear Fuel Cycle, 6(2), Harwood Academic Publishers, 177-196, 1985 .

49. Feldman, R.F., "Density and Porosity Studies of Hydrated Portland Cement," Cement Technology, 3(1), 5-14, 1972.

50. Burnay, S.G. and J.R. Dyson, "A Preliminary Assessment of PolymerModified Cements for use in Immobilization of Intermediate Level Radioactive Waste," AERE Harwel1, United Kingdom, AERE-R10599, D0E/RW/82.104, November 1982.

51. M. Steinberg, L. Kukacka, P. Colombo, J. Kelsch, B. Manowitz, J. Kikeous, J. Backstrom and S. Rubenstein, "Concrete-Polymer Materials, First Topical Report," BNL-50134, Brookhaven National Laboratory, Upton, NY 11973, and the Bureau of Reclamation, Denver, Coloradio, 1968. 
52. B. Manowitz, M. Steinberg and P. Colombo, "Development of Durable LongTerm Radioactive Waste Composite Materials," Progress Report No. 1, Brookhaven National Laboratory, Upton, NY 11973, 1972.

53. Kukacka, L. A. Auskern, P. Colombo, J. Fontana and M. Steinberg, "Introductory Course on Concrete-Polymer Materials," BNL-19525, Brookhaven National Laboratory, Upton, NY, 1974.

54. Donato, A, "Incorporation of Radioactive Wastes in Polymer Impregnated Cement," I: Management of Radioactive Wastes From the Nuclear Fuel Cycle, Volume II, International Atomic Energy Agency, Vienna, Austria, 1976.

55. Colombo, P., and R.M. Neilson, Jr., "Some Techniques for Solidification of Radioactive Wastes in Concrete," In: Nuclear Technology, Vol. 32, 1977.

56. Crawford, R.W., F.P. Glasser, A.A. Rahman, M.J. Angus and C.E. McCuTloch, "Diffusion Mechanisms and Factors Affecting Leaching of Cesium-134 From Cement-Based Waste Matrices", Radioactive Waste Management and the Nuclear Fuel Cycle, 6(2), 187-192, June 1985.

57. Moore, J.G., H.W. Godbee, A.H. Kibbey and D.S. Joy, "Development of Cementatious Grouts for the Incorporation of Radioactive Wastes, Part I: Leach Studies," ORNL-4962, p. 28, April 1975.

58. Grutzeck, M.W., D. Brown and S. Hoyle, "Physical Chemistry of Portland Cement Hydrate, Radioactive Waste Hosts," Progress Report, June 15, 1984 - January 15, 1985, The Pennsylvania State University, DOE/ER/45145--1, DE85 006791, pp. 13-18, January 15, 1985.

59. Glasser, F.P., A.A. Rahman, D. Macphee, C.E.C. McCulloch and M.J. Angus, "Immobilization of Radioactive Waste in Cement-Based Matrices," Department of the Environment, Commission of the European Communities, DOE/RW/84.1 59, CEC Contract No.: 300.83.13, 31 October 1984.

60. Colombo, P. and R.M. Neilson, Jr., "Properties of Radioactive Wastes and Waste Containers," October-December 1977, Brookhaven National Laboratory, BNL-NUREG-50837, May 1978.

61. Anders, 0.U., J.F. Bartel and S.J. Altschuler, "Determination of the Leachability of Solids", Analytical Chemistry, 50, 564-569, 1978.

62. Matsuzuru, H. and A. Ito, "Effect Of Dimension of Specimen on Amounts of Cesium-137, Strontium-90 and Cobalt-60 Leached From Matrix of Hardened Cement Grout", Journal of Nuclear Science and Technology, 15, 296-301, 1978. 


\section{REFERENCES (cont.)}

63. Godbee, H.W., E.L. Compere, D.S. Joy, A.H. Kibbey, J.G. Moore, C.W. Nestor, 0.U. Anders and R.M. Neilson, Jr., "Application of Mass Transport Theory to the Leaching of Radionuclides From Waste Solids", Nuclear and Chemical Waste Management, 1, 29-35, 1980.

64. Christensen, H., "Leaching of Cesium From Cement-Solidified BWR and PWR Bead Resins," Nuclear and Chemical Waste Management, 3, 105-110, 1982.

65. Dayal, R., H. Arora and N. Morcos, "Estimation of Cesium-137 Release From Waste/Cement Composites Using Data From Small-Scale Specimens," Brookhaven National Laboratory, NUREG/CR-3382, BNL-NUREG-51690, July 1983.

66. Pescatore, C., "Mechanistic Modeling of Nuclear Waste Form Leaching by Aqueous Solution," Ph.D. Thesis, Nuclear Engineering Department, University of Illinois, Urbana, IL, 1983.

67. Dayal, R., D.G. Schweitzer and R.E. Davis, "Wet and Dry Cycle Leaching: Aspects of Releases in the Unsaturated Zone," Proceedings of the U.S. Nuclear Regulatory Commission NRC, Nuclear Waste Geochemistry '83, NUREG/CP-0052, 440-453, 1983.

68. Berner, R.A., "Rate Control of Mineral Dissolution Under Earzh Surface Conditions," American Journal of Science, Volume 278, 1235-1252, November 1978.

69. Strachan, D.M., "Effect of Flow Rate on the Leaching of Nuclear Waste Glass," Proceedings of the Second International Symposium on Ceramics in Nuclear Waste Management, G.G. Wicks and W.A. Ross, editors, American Ceramic Society, 12-18, 1984.

70. Anderson, K., B. Torstenfeld and B. Allard, "Sorption and Diffusion Studies of CS and I in Concrete," Chalmers University of Technology, Goteborg, Sweden, 1981.

71. Glasser, F.P., A.A. Rahman, R.W. Crawford, C.E. McCul loch and M.J. Angus, "Immobilization and Leaching Mechanisms of Radwaste in Cement-Based Matrices," First Half-Yearly Progress Report, DOE/RW 82.050, 61, March 1982.

72. Glasser, F.P., A.A. Rahman, R.W. Crawford, C.E. McCulloch and M.J. Angus, "Immobilization and Leaching Mechanisms of Radwaste in Cement-Based Matrices," Second Half-Yearly Progress Report, DOE/RW 82.108, 106, March 1982.

73. Komarnerni, S. and D.M. Roy, "Mechanisms of Immobilization of Nuclear Waste Elements by Cement Minerals, Cement and Mortar," Cement and Concrete Research, 11, 789-794, 1981 . 
74. Matsuzura, H., N. Moriyama, Y. Wadachi and A. Ito, "Leaching Behavior of Cesium-137 in Cement-Waste Composites," Health Physics, 32, 529-534, 1977.

75. Neilson, R.M., Jr. and P. Colombo, "Waste Form Development Program Annual Progress Report," October 1980 - September 1981, Brookhaven National Laboratory, BNL-51517, 80-85, January 1982.

76. Atkinson, A., A.K. Nickerson and T.M. Valentine, "The Mechanisms of Leaching From Some Cement-Based Nuclear Wasteforms," United Kingdom Atomic Energy Authority, Harwell, AERE-R10809, June 1983.

77. Rudolph, G. and R. Koster, "Immobilization of Strontium and Cesium in Intermediate-Level Liquid Wastes by Solidification in Cements," Scientific Basis for Nuclear Waste Management, Volume 1, Plenum Press, New York, G.J. McCarthy, editor, 467-470, 1979.

78. International Standards Organization, $5 / \mathrm{N} 38$, "Long-Term Leach Testing of Radioactive Waste Solidification Products," ISO/TC $85 /$ SC 5/WG 5/N 38, Berlin, West Germany.

79. Kalb, P.D. and P. Colombo, "Polyethylene Solidification of Low-Level Wastes," Brookhaven National Laboratory, BNL-51867, 47-49, October 1984.

80. Crank, J., "The Mathematics of Diffusion," Oxford iniversity Press, London, 30-31, 1970.

81. Broadbent, S.R. and J.M. Hammersley, "Percolation Processes I. Crystals and Mazes," Proceedings of the Cambridge Philosophical Society, 53, $629-641,1953$.

82. Davis, H.T., L.R. Valencourt and C.E. Johnson, "Transport Processes in Composite Media," Journal of the American Ceramic Society, 58(9-10), 446-452, Sept.-Oct. 1975. 